\title{
Physikalische Kartierung der RT1-C/M-Region des
}

\section{Haupthistokompatibilitätskomplexes der Ratte}

\author{
Dissertation \\ zur Erlangung des Doktorgrades \\ der Mathematisch-Naturwissenschaftlichen Fakultäten \\ der Georg-August-Universität zu Göttingen
}

\author{
vorgelegt von \\ Sofia Ioannidu \\ aus Vergina/Griechenland
}

Göttingen 2000 
D7

Referent: $\quad$ Prof. Dr. H.-J. Fritz

Korreferent: $\quad$ Prof. Dr. W. Engel

Tag der mündlichen Prüfung: 
I. Inhaltsverzeichnis I

II. Abkürzungsverzeichnis IV

1 Einleitung 1

1.1 Der Haupthistokompatibilitätskomplex des Menschen (HLAKomplex) 1

1.2 Der Haupthistokompatibilitätskomplex der Maus (H2-Komplex) 4

1.3 Vergleich des Haupthistokompatibilitätskomplexes zwischen Mensch und Maus; Vorstellung der framework Hypothese 5

1.4 Der Haupthistokompatibilitätskomplex der Ratte (RT1-Komplex) 6

1.5 Struktur und Funktion von MHC-Klasse-I Molekülen 7

1.6 Ziel dieser Arbeit 9

2 Verwendete Materialien 10

2.1 Escherichia coli-Stämme 10

2.2 Verwendete Vektoren $\quad 10$

2.3 Oligonukleotide 13

2.3.1 Oligonukleotide zur Generierung von Hybridisierungsproben 13

$\begin{array}{ll}\text { 2.3.2 Oligonukleotide für PAC-Endsequenzierung } & 16\end{array}$

$\begin{array}{lll}2.3 .3 & \text { Sonstige Primer } & 16\end{array}$

$\begin{array}{lll}2.4 & \text { Chemikalien } & 16\end{array}$

$\begin{array}{lll}2.5 & \text { Radiochemikalien } & 18\end{array}$

2.6 Enzyme 18

$\begin{array}{lll}2.7 & \text { Versuchstiere } & 19\end{array}$

2.8 Lösungen und Puffer 19

2.9 Zusammensetzung von Nährmedien 22

2.9.1 Nährmedien $\quad 22$

2.9.2 Zusätze für prokaryotische Nährmedien 22

2.10 Einwegartikel 23

2.11 Verwendete Kits 23

2.12 Geräte $\quad 24$

2.13 Herstelleradressen 26

2.14 Verwendete Hybridisierungsproben $\quad 27$

2.15 Verwendete Ressourcen $\quad 30$

2.16 Verwendete Computerprogramme 31

3 Methoden 32

3.1 Allgemeine Richtlinien zur Arbeit mit DNA

3.2 Isolierung von DNA 32

3.2.1 Präparation von genomischer DNA aus kleiner Menge Lebergewebe 32

3.2.2 Isolierung und Verarbeitung von Lymphozyten-DNA 32

3.2.3 Gewinnung von Plasmid-DNA mittels Säulenelution 33

3.2.4 Präparation von low-copy Plasmid-DNA (PAC) im größeren
Maßstab mittels Nucleobond ${ }^{\circledR}$ AX-Säulen 
3.2.5 Kleinansatz zur Präparation von PAC-DNA 34

3.2.6 Kleinansatz zur Plasmidisolierung (lange Methode) 35

$\begin{array}{lll}\text { 3.2.7 Minipräparation von Plasmid-DNA } & 35\end{array}$

3.3 Konzentrations- und Reinheitsbestimmung von DNA 36

3.4 Spaltung von DNA mit Restriktionsenzymen 36

3.4.1 Partieller Verdau genomischer DNA für Bank-Konstruktion 36

3.5 Gelelektrophorese von Nukleinsäuren 37

3.6 Transfer von DNA aus Agarosegelen (Southernblot) 38

3.7 Radioaktive DNA-Markierung mittels random-priming Reaktion 39

3.8 Radioaktive Endmarkierung synthetischer Oligonukleotide durch $\gamma-\left[{ }^{32} \mathrm{P}\right]$-dATP $\quad 39$

3.9 Hybridisierung der Southernblots 40

3.10 Autoradiographie $\quad 40$

3.11 Bakterien-Kolonie-Screening erstellter Subbanken 41

3.12 Erstellung von DNA dot blots 42

3.13 Isolierung von DNA-Fragmenten aus Gelen 42

3.13.1 Isolierung von DNA-Fragmenten aus Agarosegelen mittels JETQUICK

3.13.2 Isolierung von DNA-Fragmenten aus Agarosegelen durch Elektroelution 43

3.14 Dephosphorylierung freier 5'-Enden 43

3.15 Ligation von DNA-Enden 43

3.16 Nukleotidsequenzanalyse doppelsträngiger DNA 44

3.17 Endsequenzierung der PAC-Klone durch inverse PCR 45

3.18 Reverse Transkription $\quad 47$

3.19 Polymerasekettenreaktion (PCR) 47

3.20 3'RACE (rapid amplification of cDNA ends) 48

3.21 Long range PCR 49

3.22 Klonierung von PCR-Produkten 49

3.23 Screening einer PAC-Bank 50

3.24 Herstellung elektrokompetenter Bakterienzellen 51

3.25 Elektroporation 53

4 Ergebnisse 54

4.1 Konstruktion einer genomischen Bank aus der LEW.1W-Ratte (RT1 ${ }^{\text {u-Haplotyp) }} 54$

4.2 Etablierung von Hybridisierungsproben $\quad 59$

4.2.1 Sonden aus klassischen MHC-Klasse-I-Genen 59

4.2.2 Herstellung von Hybridisierungsproben aus MHC-Klasse-Ib-Genen 60

4.2.3 Herstellung von Hybridisierungssonden aus verschiedenen „Ankergenen“ 61

4.2.4 Herstellung von STS-Markern bei der Ratte und Maus 65

4.3 Klonierung und physikalische Kartierung der RT1-C/M Region

4.3.1 Contig $1 \quad 68$

4.3.1.1 Sequenzierung der Enden einiger PAC-Klone aus dem Contig 1 77

4.3.1.2 11/3R-homologe Gene im Contig 1 
4.3.1.3 Subklonierung und Teil-Sequenzierung einiger Klasse-I-Gene aus dem Contig 1

4.3.2 Beschreibung von Contig 2

4.3.2.1 Contig 2, erster Abschnitt

4.3.2.1.1 Die grc-Region

4.3.2.1.2 RT.BMI-Gene

89

4.3.2.1.3 „Ankergene“ des Contig 2 im ersten Abschnitt 90

4.3.2.2 Contig 2, zweiter Abschnitt 91

4.3.2.3 Contig 2, dritter Abschnitt 102

4.3.2.4 Endsequenzierung einiger Klone aus dem Contig $2 \quad 107$

4.3.3 Contig 3 und Contig 4 (RT1-M3-, RT1-M2-positive Klone) 108

5 Diskussion $\quad 115$

5.1 Contig $1 \quad 116$

$\begin{array}{lll}5.2 & \text { Contig } 2 & 119\end{array}$

5.3 Contig 3 und $4 \quad 122$

5.4 Vergleich zwischen der Klasse-I- Regionen des RT1-, H2- und HLA-Komplex $\quad 125$

$\begin{array}{lll}5.5 & \text { Ausblick } & 127\end{array}$

$6 \quad$ Zusammenfassung $\quad 128$

$7 \quad$ Literaturverzeichnis 130

8 Anhang I 145

8.1 Zusammmenstellung der insgesamt erhaltenen PAC-Klone aus
mehreren Sreeningansätzen der Ratten-Bank

8.2 Sequenzierungsdaten aus PAC-Endsequenzierung 156

$9 \quad$ Anhang II (Physikalische Karte der RT1-C/M-Region des Haupthistokompatibilitätskomplexes der Ratte) 


\section{Abkürzungsverzeichnis}

\begin{tabular}{|c|c|}
\hline $\mathrm{Abb}$ & Abbildung \\
\hline $\mathrm{AC}$ & Accession Number \\
\hline $\mathrm{BAC}$ & bacterial artificial chromosome \\
\hline bp & Basenpaar \\
\hline BSA & Bovines Serumalbumin \\
\hline ddNTP & Didesoxynukleotid-5'-triphosphat \\
\hline DNA & Desoxyribonukleinsäure \\
\hline dNTP & Desoxynukleotid-5'-triphosphat \\
\hline dsDNA & doppelsträngige DNA \\
\hline E.coli & Escherichia coli \\
\hline EDTA & Ethylendiamintetraessigsäure \\
\hline ER & Endoplasmatisches Retikulum \\
\hline ES & EDTA-Sarcosyl-Puffer \\
\hline Etbr & Ethidiumbromid \\
\hline $\mathrm{g}$ & Erdbeschleunigung $\left(9,81 \mathrm{~m} / \mathrm{s}^{2}\right)$ \\
\hline grc & growth and reproduction complex \\
\hline $\mathrm{h}$ & Stunde \\
\hline HLA & human leukocyte antigen \\
\hline Hsp & Hitzeschockprotein \\
\hline IDDM & Insulin dependent diabetes mellitus \\
\hline IPTG & Isopropyl- $\beta$-D-Thiogalactopyranosid \\
\hline $\mathrm{kb}$ & Kilobase \\
\hline LB & Luria-Bertani \\
\hline M & Molarität \\
\hline$\mu \mathrm{Ci}$ & Mikrocurie \\
\hline $\mathrm{MHC}$ & major histocompatibility complex \\
\hline $\min$ & Minute \\
\hline MMLV reverse Transkriptase & Moloney Mouse Leukemia Virus \\
\hline & Transkriptase \\
\hline RNA & messenger RNA \\
\hline & non-coding \\
\hline
\end{tabular}


OD

PAC

PFGE

PCR

RNA

RNAse

rpm

RT

SDS

SHR

SOB

SOC

ssDNA

$\mathrm{SSC}$

STS

Tab

TBE

TE

TNF

Tris

$\mathrm{U}$

utr

V

X-Gal

YAC optische Dichte

P1 artificial chromosome

Pulsfeldgelelektrophorese

Polymerase-Ketten-Reaktion

Ribonukleinsäure

Ribonuklease

Umdrehungen pro Minute

Raumtemperatur

Natriumdodecylsulfat

spontaneously hypertensive rat

Hefe-Peptone-Salz-Medium

glukosehaltiges SOB-Medium

einzelsträngige DNA

Natriumchlorid-Natriumcitrat-Puffer

sequence-tagged sites

Tabelle

Tris-Borat-EDTA-Puffer

Tris-EDTA-Puffer

Tumornekrosefaktor

Tris(hydroxymethyl)aminomethan

Enzymeinheit

untranslatierter Bereich

Volt

5-Brom-4-chlor-3-indolyl- $\beta$-D-Galactosid

yeast artificial chromosome 


\section{Einleitung}

\subsection{Der Haupthistokompatibilitätskomplex des Menschen (HLA, human leukocyte antigen)}

Der Haupthistokompatibilitätskomplex (major histocompatibility complex, MHC) ist eine besonders gut untersuchte Region des menschlichen Genoms. Die in dieser Region kodierten Klasse-I- und Klasse-II-Proteine kontrollieren die Immunreaktionen des Organismus. Die Klasse-I- und Klasse-II-Gene sind die polymorphsten humanen Gene; einige sind mit über 250 Allelen repräsentiert. Die Bezeichnung Haupthistokompatibilitätskomplex beruht auf der Erkennung polymorpher Klasse-I- bzw. Klasse-II-Moleküle bei der Transplantat-Abstoßung. Die meisten autoimmmunen Krankheiten, wie z.B. Rheumatoide Arthritis, Insulin-abhängiger Diabetes Mellitus und Multiple Sklerose (Thomson, 1995), aber auch andere Erkrankungen wie Narkolepsie (Gruen et al., 1997) und Dyslexie (Fisher et al., 1998) sind MHC-assoziiert.

Aus diesen Gründen ist der MHC eine der am intensivsten untersuchten Regionen des menschlichen Genoms. Der MHC wurde vor über 60 Jahren entdeckt als eine einer Gruppe von Histokompatibilitätsgenen. Die physiologische Funktion und Natur der Genprodukte des MHC wurde jedoch erst in den letzten zwei Dekaden bekannt. Der HLA ist auf dem Chromosom 6p21.31 lokalisiert, umfaßt 3,6 Mb und ist inzwischen komplett sequenziert (The MHC sequencing consortium, 1999). Die MHC-Region hat, unter den bis jetzt sequenzierten Regionen des humanen Genoms die größte Dichte an Genen. Von den 224 identifizierten Genen könnten 128 exprimierbar sein. Es wurde geschätzt, daß 40\% der exprimierten Gene eine Funktion im Immunsystem haben. Mehrere Gene, u.a. aus der Klasse-II- und Klasse-IIIRegion (Abbildung 1), können aufgrund der Sequenzähnlichkeit und Syntenie bis zu 700 Millionen Jahre zurückverfolgt werden.

Der Haupthistokompatibilitätskomplex des Menschen wird HLA (human leukocyte antigen) genannt. Ein Schema der genomischen Organisation ist der Abbildung $1 \mathrm{zu}$ entnehmen. Die unterhalb der Linie grau gezeichneten Gene sind in der Immunantwort involviert, oberhalb der Linie sind schwarz Gene gezeichnet, die keine Funktion im Immunsystem haben (Forbes und Trowsdale, 1999). Der HLA-Komplex ist in drei Regionen unterteilt, Klasse-I-, Klasse-II- 
und Klasse-III-Region. Die Klasse-II-Region hat eine Länge von ca.800 kb und kodiert für Gene, die für die Antigen-Prozessierung (LMP2, LMP7, TAP1, TAP und TAPBP) und -Präsentation (DP, DQ, DR, DM, DO) fungieren. Die auf der Oberfläche antigenpräsentirender Zellen Klasse-II-Moleküle präsentieren aus exogen aufgenommenen Proteine gewonnene Peptide den T-Helferzellen. Es werden aber auch Peptide aus intrazellulären Krankheitserregern wie Leishmanien und Mykobakterien, welche Lepra und Tuberkulose verursachen und sich in intrazellulären Vesikeln von Makrophagen vermehren, den THelferzellen präsentiert.

In der Klasse-III-Region, deren Länge ca. $800 \mathrm{~kb}$ beträgt, sind u.a. Gene lokalisiert, die für Komplement-Faktoren (C2, C4, Bf), Hitzeschockproteine (HSP70-Familie) sowie Zytokine $(\mathrm{TNF} \alpha)$ kodieren.

Die Klasse-I-Region erstreckt sich über eine Länge von 1800 kb. Die Gene HLA-A, HLA-B und HLA-C kodieren für klassische Klasse-I-Moleküle , während es sich bei HLA-E, HLA-F und HLA-G um nicht-klassische Klasse-I-Gene handelt. Es finden sich in dieser Region ferner zwei Klasse-I-verwandte Gene, MICA und MICB. Weiterhin enthält die Klasse-IRegion auch eine Reihe von Klasse-I-Pseudogenen und Genfragmenten (HLA-17, -X, -30, L/92, -80, -21, -K/70, -16, -H/54, -90 und -75), sowie vier MIC-Pseudogene (MICC, MICD, MICE, MICF) (Shiina et al., 1999). Die Funktion der Klasse-I-Moleküle auf der Zelloberfläche besteht darin, Peptide den zytotoxischen T-Lymphozyten zu präsentieren. Dazu werden zytoplasmatische Proteine im Proteasom unter Beteiligung der MHC-kodierten Proteasomuntereinheiten LMP2 und LMP7 zu Peptiden abgebaut, die über den MHCkodierten Transporter (TAP1 und TAP2) in das Lumen des Endoplasmatischen Retikulums (ER) transportiert werden. Im ER erfolgt mit Hilfe des ebenfalls im MHC kodierten Moleküls Tapasin (TAPBP) eine Beladung des MHC-Klasse-I-Moleküls mit 8-10 Aminosäuren langen Peptiden. Unter einer Infektion mit Viren oder interzellulären Bakterien werden dann auch Peptide dieser Infektionserregern prozessiert und den zytotoxischen T-Zelln präsentiert.

Von medizinischer Bedeutung ist, daß einige Krankheiten, z. B. Morbus Beh $\chi$ et, ankylosierende Spondylitis, Psoriasis vulgaris sowie einige infektiöse Krankheiten jeweils mit bestimmten Klasse-I-Allelen assoziiert sind. Aus diesem Grund ist die Suche nach polymorphen Markern wie z.B. Mikrosatelliten von großer Wichtigkeit für die Kartierung von Regionen, die für die Suszeptibilität gegenüber bestimmten Krankheiten verantwortlich sind und zur Identifizierung von entsprechenden Kandidaten-Genen führen können. 

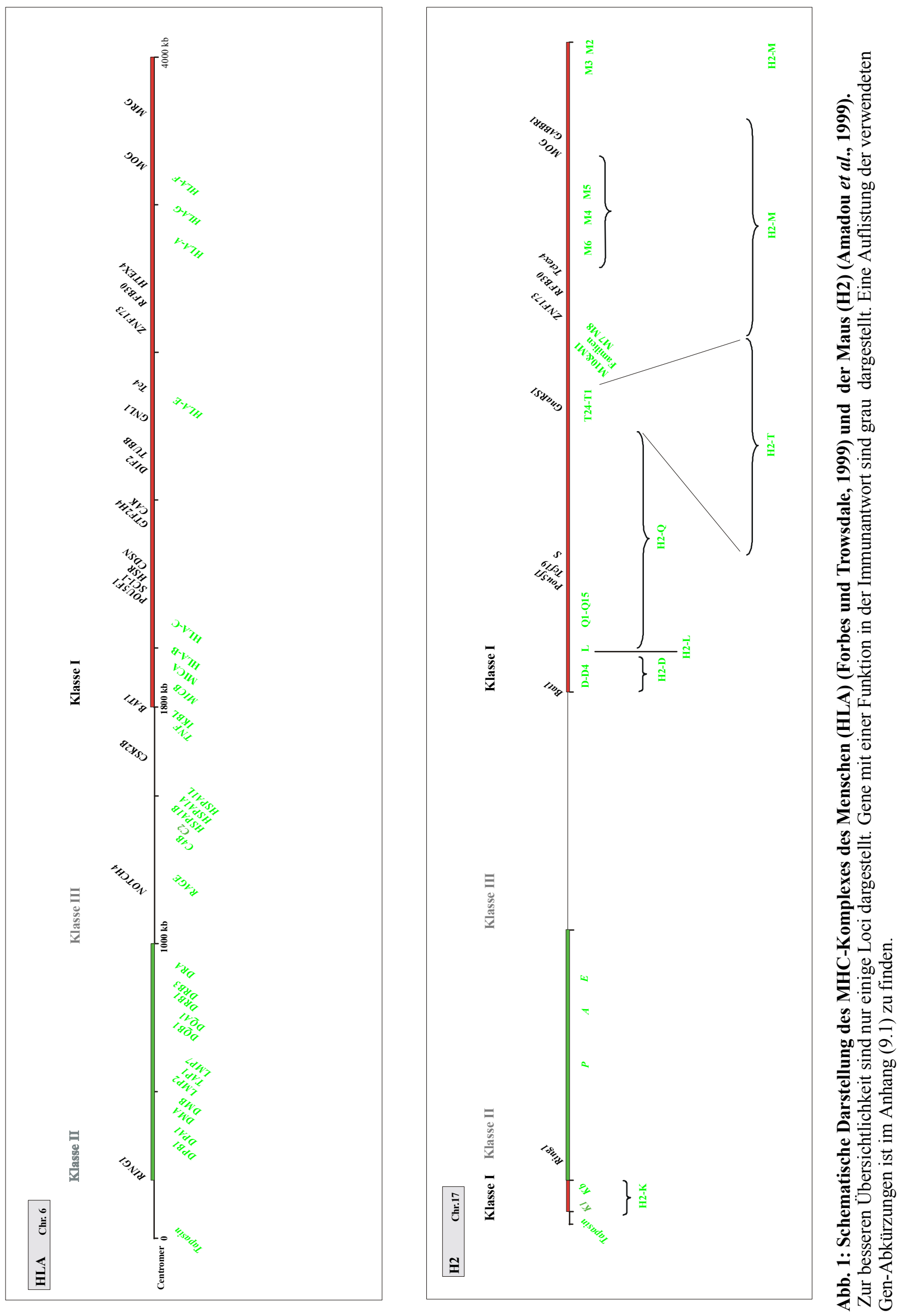


\subsection{MHC der Maus (H2-Komplex)}

Schon die ersten Versuche zur Gewebsunverträglichkeit (Jensen, 1903) wurden an Mäusen durchgeführt. Sie bieten ein optimales experimentelles Tiermodell für Transplantationsversuche sowie für MHC-assoziierte Krankheiten. Es ist in relativ kurzer Zeit möglich, Inzuchtsstämme zu züchten und so genetisch identische Individuen zu erzeugen, eine für Transplantations-Versuche wichtige Voraussetzung. Durch Anwendung congener Stämme (es handelt sich um Tiere, die im genetischen Hintergrund identisch sind und sich nur in einer bestimmten Region unterscheiden, hier den MHC) konnte Snell (1948) für die Transplantatabstossung verantwortliche Gene identifizieren. Durch die weitere Analyse solcher MHC-congener Stämme konnte ermittelt werden, daß ein Komplex enggekoppelter Gene in besonderem Maße für die Gewebsunverträglichkeit verantwortlich ist, welcher dann als „major histocompatibility complex“ bezeichnet wurde.

Aufgrund der von Gorer bereits 1936 beschriebenen Antigene, die mit der Transplantatabstoßung und Tumorsuszeptibilität korreliert sind, und Antigen II hiessen, erhielt der MHC der Maus die Bezeichnung H2-Komplex (Snell, 1948).

Aufgrund der Anwendbarkeit der Maus als experimentelles Tiermodel ist der H2-Komplex neben dem HLA-System sehr gut untersucht. Der H2-Komplex ist auf dem Chromosom 17 lokalisiert und umfasst ebenfalls ca. $4 \mathrm{Mb}$ (Klein, 1986).

Die genomische Organisation des H2-Komplexes ist in der Abbildung 1 dargestellt. Gegenüber der genomischen Organisation des HLA-Komplexes besteht die Besonderheit, daß centromerwärts der Klasse-II-Region eine weitere Klasse-I-Region zu finden ist. In dieser Klasse-I-Region werden zwei Klasse-I-Gene codiert (Steinmetz et al., 1982a; Weiss et al., 1984). Es handelt sich um das klassische Klasse-I-Gen H2-K und das Pseudogen H2-K2. Die strukturelle Organisation des H2-Komplexes, speziell in den telomeren Klasse-I-Regionen D, Q, T und M, kann von Haplotyp zu Haplotyp variiren. In den $\mathrm{H} 2^{\mathrm{b}}$ - und $\mathrm{H} 2^{\mathrm{k}}$-Haplotypen und vermutlich auch bei anderen beinhaltet die D-Region nur ein Klasse-I-Gen, nämlich H2-D (Weiss et al., 1984; Stephan et al., 1986). Im Gegensatz dazu enthalten die Haplotypen $\mathrm{H} 2^{\mathrm{d}}$, $\mathrm{H} 2^{\mathrm{q}}$ und vermutlich $\mathrm{H} 2^{\mathrm{v}}$ in der D-Region fünf Klasse-I-Gene, die als H2-D, -D2, -D3, -D4 und H2-L bezeichnet werden (Stephan et al., 1986; Duran et al., 1987; Rubocki et al., 1990). Das am Ende der Klasse-III-Region lokalisierte Tnf-Gen und das Bat1-Gen (Wroblewski et al., 1990) werden durch ein Interval von $40 \mathrm{~kb}$ getrennt. Eine ähnliche Distanz findet man auch beim Menschen. Im Gegensatz dazu ist der Abstand zwischen dem Bat1-Gen und dem nächsten Klasse-I-Gen im H2 ${ }^{\mathrm{b}}$-Haplotyp $10 \mathrm{~kb}$, während beim Menschen dieses Interval 170 kb beträgt. Bei den Haplotypen $\mathrm{H} 2^{\mathrm{d}}$ (Müller et al., 1987) und $\mathrm{H} 2^{\mathrm{b}}$ ( Wroblewski et al., 1990) 
der Maus sind Längen-Unterschiede im Interval zwischen Bat1 und dem nächsten Klasse-IGen zu beobachten. Es zeigt sich also eine gewisse Variabilität. Im $\mathrm{H} 2{ }^{\mathrm{d}}$-Haplotyp wurde gezeigt, daß eine weitere Kopie des Batl-Gens zwischen dem D4 ${ }^{\mathrm{d}}$-Gen und dem L ${ }^{\mathrm{d}}$-Gen ( Wroblewski et al., 1994) existiert. So könnten die fünf H2-D-Gene in der H2-D -Region durch ein ungleiches crossing over-Ereignis (Stephan et al., 1986; Rubocki et al., 1990) und die H2-D- und H2-L-Gene durch Duplikation entstanden sein (Wroblewski et al., 1994).

Die H2-Q-Gene und die H2-T-Gene (Abbildung 1) sind durch Sequenzvergleiche in Familien gruppiert worden. Die Expansion von Klasse-I-Genen in dieser Region ist wahrscheinlich durch Tandem-Duplikation und ungleiches crossing over entstanden. Differenzen in der Zahl enggekoppelter homologer Gene zwischen unterschiedlichen Stämmen führen die Rekombinationsereignissen zu Duplikationen, Deletionen oder Genfusionen, wie die Q8/Q9Fusion in der BALB/c Maus zeigt (Fischer Lindahl et al., 1997). Auf ähnliche Weise sind wahrscheinlich die H2-M1- und H2-M10-Familien entstanden, welche im proximalen Teil der H2-M-Region lokalisiert sind. Bis heute sind keine anderen Gene als Klasse-I-Gene innerhalb der H2-Q- und H2-T-Region identifiziert worden. Durch Arbeiten mit bestimmten Stämmen, die teilweise eine Deletion dieser Klasse-I-Gene aufweisen, konnte gezeigt werden, daß diese Gene, auch wenn sie exprimierbar sind, nicht essentiell für das Überleben des Organismus sind (Klein und Figueroa, 1986). Am telomeren Ende des H2-Komplexes befinden sich die H2-M2, -M3, -M4, -M5 und -M6 Klasse-I-Gene (Amadou et al., 1999; Brorson et al., 1989; Jones et al., 1998)

\subsection{Vergleich des Haupthistokompatibilitätskomplexes zwischen Mensch und Maus; Vorstellung der framework Hypothese (Amadou 1999)}

Beim Vergleich des HLA- und des H2-Komplexes sind sowohl Konserviertheit als auch Variabilität zu beobachten. Die Klasse-II- und Klasse-III-Regionen tragen in beiden Spezies die gleichen Gene in der selben Anordnung, die Gene sind ortholog (Beck et al., 1996; Trowsdale, 1995). Wahrscheinlich existierten die Bereiche in ähnlicher Organisation in einem gemeinsamen Vorfahren von Mensch und Maus. Orthologe Gene sind per Definition der Comparative Genome Organisation 1996, homologe Gene in unterschiedlichen Spezies, welche aus demselben Gen des nächsten Vorfahren abstammen.

Im Gegensatz zu den Klasse-II- und Klasse-III-Genen sind die Klasse-I-Gene von Mensch und Maus paralog und waren mehrfachen Reorganisationen unterworfen. Paraloge Gene sind 
Gene innerhalb derselben Spezies, welche aus einem Vorläufer-Gen durch Duplikation und weitere Entwicklung im Laufe der Evolution entstanden sind.

Wenn in den Klasse-I-Regionen zwischen Mensch und Maus nur die Klasse-I-Gene betrachtet werden, ist es schwierig, einen direkten Vergleich durchzuführen. Werden jedoch die NichtKlasse-I-Gene (Ankergene) in einer komparativen Karte betrachtet, ist ersichtlich, daß nicht nur die Ankergene zwischen Mensch und Maus ortholog sind, sondern daß sich auch die verschiedenen Klasse-I-Subregionen an orthologer Position befinden

Die im Laufe der Evolution konservierten Ankergene des MHC bilden einen Rahmen (framework). Zwischen Ankergen Bereiche der Klasse-I-Region kam es an bestimmten Positionen zu Expansion oder Deletion von Klasse-I-Genen. Dieses Konzept wird auch als framework Hypothese bezeichnet (Amadou 1999; Amadou et al., 1999).

\subsection{Der MHC der Ratte (RT1-Komplex)}

Der Haupthistokompatibilitätskomplex der Ratte ist auf dem Chromosom 20p12 lokalisiert (Helou et al., 1996) und wird als RT1-System bezeichnet. Die Ratte wird, wie die Maus, als Versuchstier eingesetzt. Eine Reihe MHC-assoziierter-Krankheiten sind in der Ratte untersucht, wie der im BB-Rattenstamm spontan auftretende Insulinabhängige Diabetes mellitus (IDDM) (Cole et al.,1986; Günther et al., 1991), sowie verschiedene experimentell induzierbare Autoimmunkrankheiten, wie experimentelle Encephalomyelitis, experimentelle Arthritis und experimentelle Nephritis (Günther, 1990). Auch für Organtransplantation (Günther, 1985) findet die Ratte als experimentelles Tiermodell breite Anwendung.

Die allgemeine Organisation des RT1-Komplexes ist der des MHC der Maus ähnlich (Günther, 1996; Gill et al., 1997). Sowohl in der Maus als auch in der Ratte existiert eine Klasse-I-Region centromerwärts der Klasse-II-Region. Diese $R T 1-A$ genannte Region kodiert für klassische Klasse-I-Moleküle, die an der Oberfläche fast aller Zellen exprimiert und polymorph sind.

Telomerwärts der RT1-A-Region schließt sich die RT1-B/D genannte Klasse-II-Region an. Anhand von intra-MHC-rekombinanten Ratten-Stämmen (Stark et al, 1977; Butcher and Howard, 1997) sowie Cosmid Klonen der Klasse-II-Region (Diamond et al., 1989) konnte gezeigt werden, daß die Gene der Klasse-II-Region der Ratte ortholog zu denen der Klasse-IIRegionen von Maus und Mensch sind. 
Der Klasse-II-Region schließt sich wie bei Maus und Mensch die Klasse-III-Region an. Die meisten Klasse-III-Gene, die bei Maus und Mensch identifiziert sind, wurden auch bei der Ratte beschrieben. Auch hier finden sich die Komplement-Gene C2, C4, Bf (Wurst et al., 1988; Cortese Hassett et al., 1989), die Gene der Hitzeschockprotein-Familie Hsp70 (Walter et al., 1994a) die Tumor-Nekrose-Faktor-Gene (Tnfa, Tnfb) (Kirisitis et al., 1994a; Kwon et al. 1993) und das Gen für eine nukleäre RNA Helikase (Batl) (Nair et al., 1992).

Die sich telomerwärts anschließende Klasse-I-Region wird in der Ratte als RT1-C(Kohoutova et al., 1980) bzw. neuerdings RT1-C-M-Region bezeichnet und entspricht der H2$D / Q / T / M$-Region der Maus. Für diese Region existieren auch weitere Bezeichnungen wie E/C-grc oder grc-G/C. In diesem Abschnitt des Ratten-MHC sind ca. 60 Klasse-I-Gene oder Genfragmente zu erwarten (Jameson et al., 1992). Die bislang analysierten Klasse-I-Gene dieser Region sind nicht-klassische Klasse-I-Gene, deren Genprodukte durch geringe Expression auf der Zelloberfläche, Gewebsspezifische Expression und niedrigen Polymorphismus charakterisiert sind.

Es gibt bis jetzt nur vereinzelte Kartierungsdaten des Ratten-MHC. Es existieren kleine Cosmid-Contigs aus vereinzelten Abschnitten des MHC: RT1-A (Walter et al., 1996), RT1B/D (Diamond et al., 1989; Arimura et al., 1995a,b) und RT1-C/M (Jameson et al., 1992; Yuan et al., 1996; Salgar et al., 1998). Ein YAC-Contig aus der RT1-M-Region wurde ebenfalls publiziert (Lambracht-Washington et al., 1999).

Eine physikalische Karte und die detaillierte genomische Analyse des RT1-Komplexes würde von großer Wichtigkeit für die Verwendung der Ratte als Tiermodell bei der Erforschung von MHC-assoziierten Krankheiten sein und zum Verständniss der MHC-Evolution beitragen.

\subsection{Struktur und Funktion von MHC-Klasse-I-Molekülen}

Die MHC-Klasse-I-Genprodukte sind Glykoproteine, die auf der Zelloberfläche fast aller kernhaltiger Körperzellen vorkommen. Die tertiäre Struktur der MHC-Klasse-I-Moleküle wurde durch Röntgenstrukturanalyse (Bjorkman et al., 1987a) aufgeklärt. Die Moleküle bestehen aus zwei Polypeptidketten: einer $\alpha$ - oder schweren Kette, die im MHC codiert ist, und einer kleineren, nicht kovalent gebundenen Kette, dem $\beta_{2}$-Mikroglobulin, die nicht im MHC codiert ist. Die $\alpha$-Kette enthält drei extrazelluläre Domänen, eine transmembranöse und eine cytoplasmatische Region. Die Faltung der extrazellulären Domänen ( $\alpha 1, \alpha 2$ und $\alpha 3)$ der $\alpha$-Kette und des $\beta_{2}$-Mikroglobulin ist in der Abbildung 2 dargestellt. Die $\alpha 3$ Domäne und das 
$\beta_{2}$-Mikroglobulin zeigen jeweils eine $\beta$-Faltblatt-Struktur, die einer Immunglobulin-Domäne ähnelt. Die $\alpha 1$ - und $\alpha 2$-Domänen bilden eine grubenähnliche Struktur aus $\beta$-Faltblatt und $\alpha$ Helix. In der Grube befindet sich die Bindungsstelle für Peptide, die aus dem Cytosol der Zelle kommen und nach einer Infektion auch von Viren oder intrazellulären Bakterien stammen. Der Peptid-Klasse-I-Komplex wird auf die Zelloberfläche gebracht und den cytotoxischen T-Zellen präsentiert, die nach Erkennung dieses Komplexes die infizierte Zelle abtöten können.

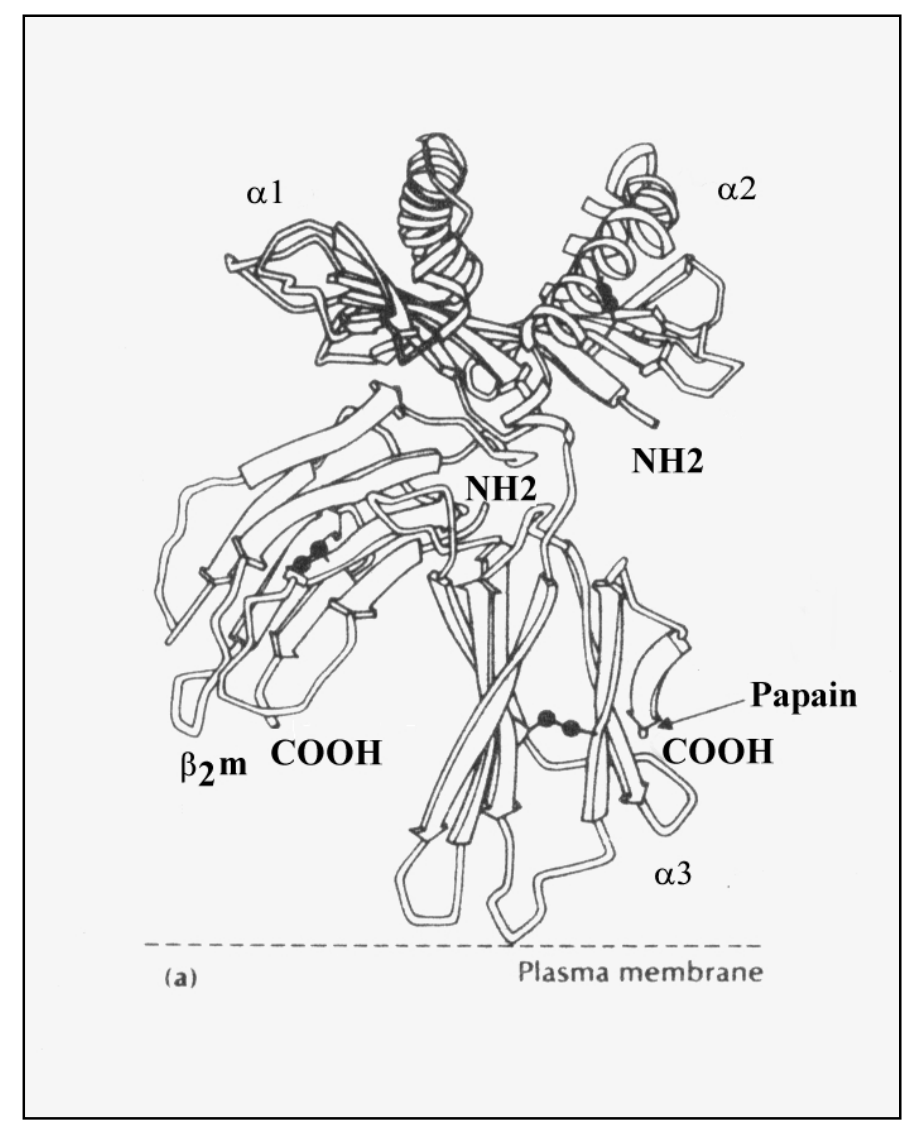

Abb. 2: Schematische Darstellung der Struktur eines Klasse-I-Moleküls. Die Transmembranöse und intrazelluläre Domäne wurden durch Papain abgespalten. Gezeigt ist der extrazelluläre Abschnitt des Moleküls ( $\alpha 1-, \alpha 2-$,und $\alpha 3$-Domäne), assoziiert mit dem $\beta 2$-Mikroglobulin. Aus: Klein 1990. 


\subsection{Ziel dieser Arbeit}

Ziel dieser Arbeit ist die Klonierung und strukturelle Analyse der RT1.C/M Region des Ratten-MHC. Im Rahmen dieses Projekts sollte zunächst im Rahmen dieses Projekts eine genomische Bank in künstlichen Bakterienchromosom (BAC) hergestellt werden. Bei den bis jetzt einsetzbaren genomischen Banken der Ratte, handelt es sich um YAC-Banken, die trotz erwünschten langen Inserts schwer handzuhaben sind und häufigen Chimerismus aufweisen. Für die strukturelle Analyse dieser Region, deren Länge ca. 2 Mb beträgt, ist die Verwendung einer genomischen Bank mit langen Inserts notwendig. Der Umfang der zu konstruierenden BAC-Bank sollte ca. zehn Genomäquivalente betragen, und eine Insert Länge von $>100 \mathrm{~kb}$ aufweisen.

In einem weiteren Schritt sollen durch das Screening der Bank mit MHC-Proben, Contigs etabliert werden, welche die RT1.C/M-Region umfassen. Die Klasse-I-tragenden Bereiche dieser Region sollten im Vordergrund stehen und je nach Möglichkeit kontinuerliches Contig der gesamten Region von ca. 2 Mb erstellt werden. 


\section{Verwendete Materialien}

\subsection{Escherichia coli Stämme}

\section{DH10B}

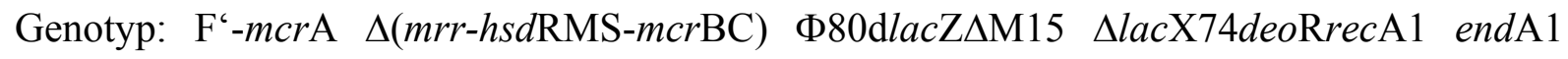
araD139 $\Delta($ ara, leu $) 7697$ galU galK 1-rpsL nup G

\section{Top10F 6}

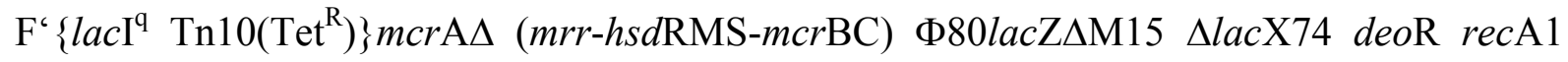
araD139 $\Delta($ ara-leu $) 7697$ galU galK rpsL end $\mathrm{A} 1$ nup $\mathrm{G}$

\subsection{Verwendete Vektoren}

Für die Subklonierungen wurden die Vektoren pUC19, pBR322, pBluescript KS+ und pBeloBAC11 verwendet.

Der Vektor pBeloBAC11 wurde zusätzlich für die Konstruktion einer genomischen Bank aus dem Inzuchtstamm LEW.1W/Gun (RT1 ${ }^{\mathrm{u}}$-Haplotyp) verwendet. Die BamHI-Schnittstelle wurde als Klonierungsstelle der mit dem Restriktionsenzym MboI gespaltenen genomischen DNA benutzt.

Die Abbildungen 3 und 4 zeigen die physikalische Karte des Vektors pBeloBAC11 bzw. des Vektors pPAC4. 


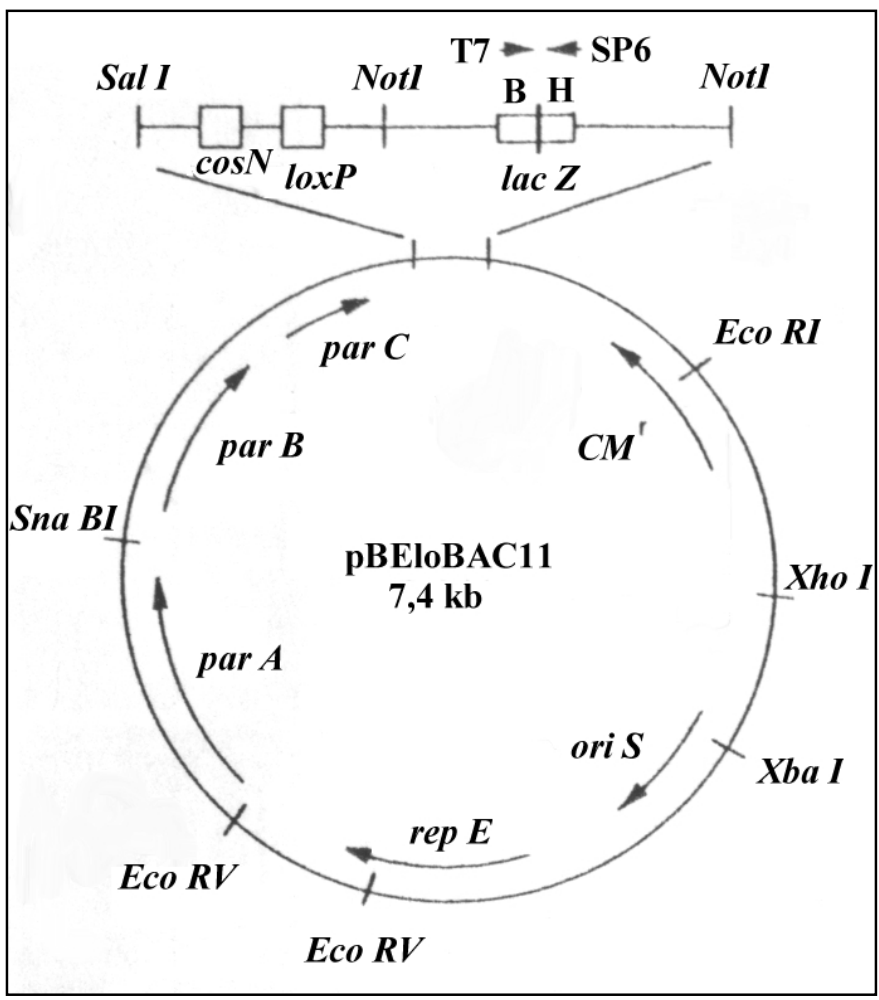

Abb. 3: pBELOBAC11 (Bacterial Artificial Chromosome) Vektor. Dieser Vektor wurde für die Konstruktion einer Bank aus dem Genom der LEW.1W-Ratte verwendet. Ausführiche Beschreibung des Vektors im Text. Aus: http//www.rzpd.de/general/htlm/glossary/vectors/pbelobac_pic.shtml.

Für die Konstruktion einer genomischen Bank ist die strukturelle Stabilität der inserierten langen Fragmente von großer Wichtigkeit. Viele der verwendeten bakteriellen Vektoren, die in hoher oder mittlerer Zahl repliziert werden, zeigen Instabilität, indem es zu partiellen Deletionen oder Rearragements der klonierten DNA kommt, speziell bei Inserts aus eukaryotischen Organismen, die repetitive Sequenzen enthalten. Ein geeigneter Vektor, um solche Vorgänge zu vermeiden, ist der BAC-Vektor (Shizuya et al., 1992). Dieser kodiert nicht nur für Gene, die essentiell für die Regulation der eigenen Replikation sind, sondern trägt auch Gene, die die Anzahl der Replicons kontrollieren. $\mathrm{Zu}$ den regulatorischen Genen auf dem BAC-Vektor gehören oriS, repE, parA und parB. Die oriS und repE Gene vermitteln unidirektionale Replikation des F-Faktors, während parA und parB die Kopienzahl auf ein bis zwei Kopien pro E.coli Zelle regulieren. Weiterhin enthält der BAC-Vektor einen Chloramphenicol-Resistenz-Marker sowie ein Klonierungssegment. Das Klonierungssegment enthält die Bakteriophagen-Stellen $\lambda \cos N$ und $P 1 \operatorname{lox} P . \operatorname{Cos} N$ ist für die spezifische Spaltung durch die $\lambda$-Terminase notwendig. LoxP ist eine spezifische Spaltungsstelle für das P1 CreProtein. 
Das Klonierungssegment enthält zwei Klonierungsstellen, BamHI und HindIII, sowie mehrere C+G-reiche Restriktionsstellen (NotI, EagI, XmaI, BglI, SfiI) für die potentielle Excision des Inserts. Die Klonierungsstelle ist durch die T7- und SP6- Promotoren flankiert. Dies ist nützlich für das Ansequenzieren des Inserts vom Vektor aus und für das Generieren von RNA Proben für chromosomal walking.

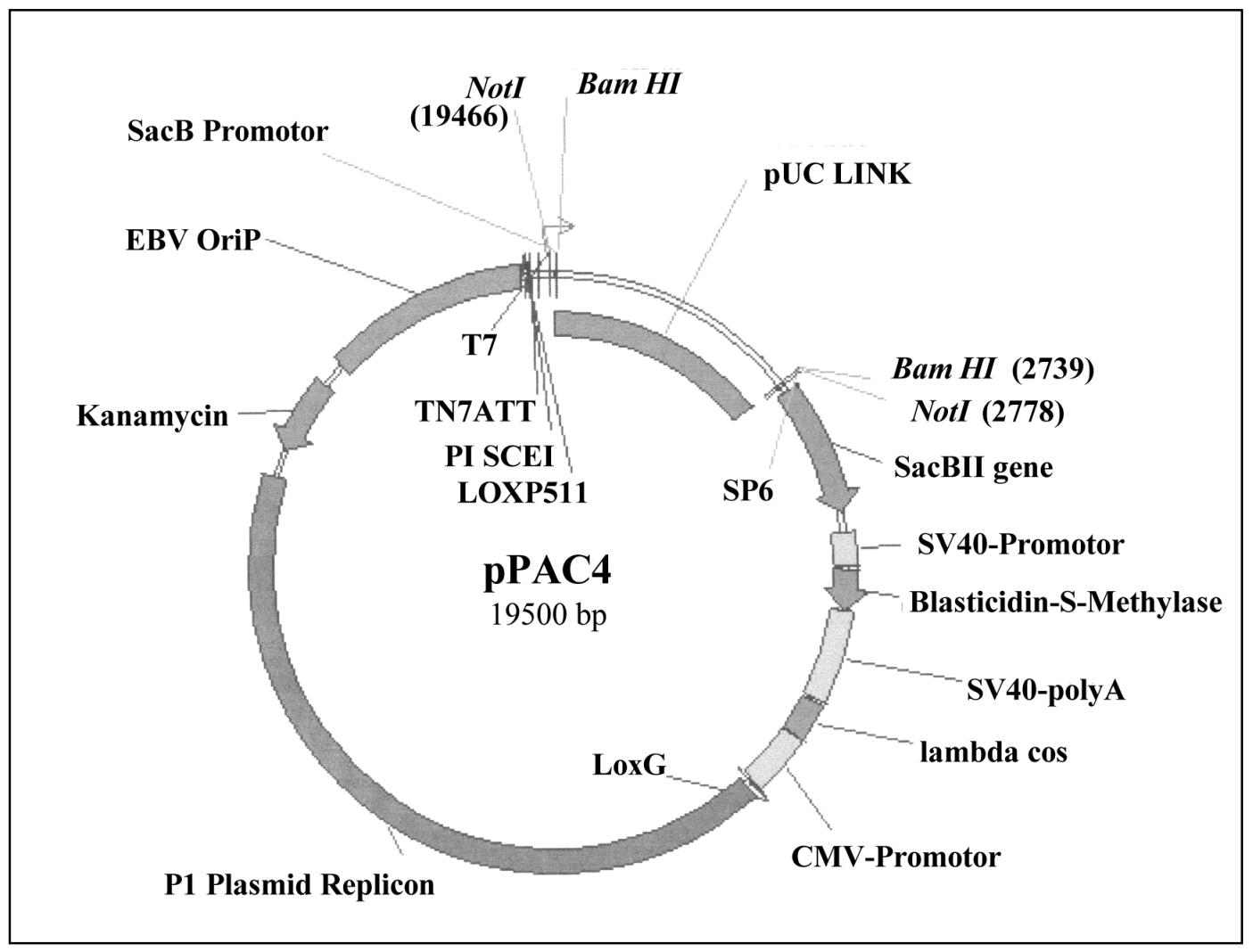

Abb. 4: Physikalische Karte des Vektors pPAC4. Dieser Vektor wurde zur Konstruktion der genomischen Bank der BN-Ratte (Woon et al., 1998) verwendet, die zur Analyse der RT1-C/MRegion eingesetzt wurde.

Der PAC-Vektor (Fregen et al., 1996; http://128.205.166.214/cgi-bin/vectorquery? Vector $=\mathrm{pPAC} 4 \&$ Choice $=\mathrm{G}$ ) ist wie der oben erwähnte BAC-Vektor ein low copyPlasmid, basiert aber auf dem Bakteriophagen P1 und kann ebenfalls stabil fremde klonierte DNA in E.coli vermehren. Die BamHI-Klonierungsstelle ist flankiert von den T7- und SP6Promotor-Sequenzen. Bei der Klonierung wird das 2,7 kb umfassende BamHI-Fragment durch das neue Insert ersetzt. Eine NotI-Restriktions-Schnittstelle flankiert direkt das T7BamHI-SP6-Segment. Der Vektor trägt ein Kanamycin-Resistenz-Gen. Eine aus dem HefeIntron kodierte Nuklease-Erkennungs-Stelle (PI-SceI) erlaubt das Linearisieren aller 
rekombinanten Klone unabhängig von der Länge und dem Inhalt. Dieses ist nützlich für optimale Kartierungs-Prozeduren.

Ein weiteres Element diesen Vektors ist das Epstein-Barr-Virus-Replikon (EBV oriP) für die Replikation in humanen Zellen.

Die 43 bp große spezifische Rekombinations-Stelle loxG rekombiniert in vivo mit komplementären lox-Stellen des Säuger-Genoms und erlaubt die Aktivierung der G418Resistenz unter der Kontrolle des CMV-Promoters und des ATG-Startcodon.

Das Blasticidin-S-Methylase-Gen unter der Kontrolle des SV40-Promoters verleiht Blasticidin-Resistenz in Säugerzell-Kulturen.

\subsection{Oligonukleotide}

\subsubsection{Oligonukleotide zur Generierung von Hybridisierungsproben}

Die folgenden Oligonukleotide wurden eingesetzt, um Proben aus verschiedenen frameworkGenen zu erstellen. Weiterhin dienten sie zur Etablierung von STS-Markern, die für die Hybridisierung der PACs verwendet worden sind, aber auch für Sequenzierungen.

Die Oligonukleotide wurden von der Firma NAPS in Göttingen synthetisiert.

\begin{tabular}{|c|c|c|}
\hline RT1.A36 & 5`-CTC ACA CTC GCT GCG GTA TT-3‘ & (20mer) \\
\hline RT1.A7 & 5`ACC GYC CTC GCT CTG GTT GTA GTA G-3‘ & $(25 \mathrm{mer})$ \\
\hline alpha 3 & 5'-AGC CAC TTT CCC AGA GAT GG-3‘ & (20mer) \\
\hline TM-1 & 5'-TGT CCT TTC CTA CCT GTG TTT C-3‘ & (22mer) \\
\hline $5 / 1-56$ & 5'-CTG AGA TAA GAC CTA ACA GAG-3‘ & (21mer) \\
\hline $5 / 1-3^{6}$ & 5'-AGA CTT CAG GGA GTT AAC TCC-3‘ & (21mer) \\
\hline Pou-1 (mouse) & 5'-CAA CGA GAA GAG TAT GAG GCT-3’ & $(21 \mathrm{mer})$ \\
\hline Pou-2 (mouse) & 5'-GTT TGA ATG CAT GGG AGA GCC-3‘ & (21mer) \\
\hline S-1 (human) & 5‘-AGC AAT GGT GGC CTT CCA GGC AA-3‘ & (23mer) \\
\hline S-2 (human) & $5^{\circ}$-GAA TGC AAT GGC CGA GGA AGC TG-3' & (23mer) \\
\hline
\end{tabular}




\begin{tabular}{|c|c|c|}
\hline TCF19-5 & $5^{\circ}$-GAC TTT GCT GCC ATT ACC ATC-3‘ & (21mer) \\
\hline TCF19-36 & $5^{\circ}$-GCT CAC TCT CAT CAT CCA GT-3“ & (20mer) \\
\hline RFB30-5 $^{6}$ & $5^{\circ}$-GCT CAG TTC TCC TCA AAA TGG-3‘ & (21mer) \\
\hline RFB30-36 & $5^{`}$-GCC CAA AGA AGG GAA TGA CC-3‘ & (20mer) \\
\hline Mog-5 6 & 5`-GGA CAG TTC AGA GTG ATA GG-3‘ & (20mer) \\
\hline Mog-36 & 5`-GAA CCT CAC GTT CTG GAT CCT-3‘ & (21mer) \\
\hline grc-56 & $5^{\circ}$-GCT GCA TCT AAT CAG TCT GTG-3‘ & (21mer) \\
\hline grc-36 & 5'-GCA GAA TGC AGT AGT GGG CAT-3‘ & (21mer) \\
\hline 255D16-5' (mouse) & 5`-GTG CAG TGT GCT TTC AAA TTC-3‘ & (21mer) \\
\hline 255D16-3‘ (mouse) & $5^{`}$-CCA AGT TCT TCC CTG CTG CT-3‘ & (20 mer) \\
\hline $261 \mathrm{A5}^{-5} 5^{6}$ (mouse) & 5`-GTT GAC CTA GAA TTG CCA CC-3‘ & (20mer) \\
\hline 261A5-3' (mouse) & $5^{\circ}$-CAT ATT ACT CTG GGT GGA CC-3‘ & (20mer) \\
\hline ZNF173-5' (human) & $5^{\prime}$-CAC GGA AGA AGT TCT GGG TT-3‘ & (20mer) \\
\hline ZNF173-3' (human) & $5^{\circ}$-ACT TCC ACT TCC CAG TAG AC-3‘ & (20mer) \\
\hline BM1-56 & 5`-GCA AGG CTT TCC AGA TCT CT-3‘ & (20mer) \\
\hline BM1-36 & 5'-GAC CAT AAG AGG AAT GGT GGA-3‘ & (21mer) \\
\hline M4-56 & 5‘-GCT GTG ATT ACC CTC ACT GG-3‘ & (20mer) \\
\hline M4-36 & $5^{\circ}$-AGC TCC CGT ACT AGA GTG TG-3‘ & (20mer) \\
\hline $5^{6}$-repeat & 5`-GCG ATG TGA GGA AGT CGT TA-3‘ & (20mer) \\
\hline $3^{6}$-repeat & 5`-CTT ATC TAT TTC CTG GTC CTG-3‘ & (21mer) \\
\hline H12587ano-5 & 5`-TGT CCC TCT GAC AAA GCA GA-3‘ & (20mer) \\
\hline H12587ano-36 & $5^{\circ}-\mathrm{CCA}$ AAG AAG TCT CAG CCT GA-3‘ & (20mer) \\
\hline H12587ORF2-56 & 5'-ATG GAA AAC CAT CAA TGT GAT-3‘ & (21mer) \\
\hline H12587ORF2-36 & 5`-GGC ATT TGC TGT GTT TAG GTA-3‘ & (21mer) \\
\hline $\mathrm{I16223R}^{1-5^{6}}$ & 5`-GTA CAG GAG ACA ACT GTG AC-3‘ & (20mer) \\
\hline I16223R1-36 & $5^{\circ}$-GGC TTG CAA CAG TCC ACA AC-3‘ & (20mer) \\
\hline A22434TCF-5 $^{6}$ & $5^{5}$-GGA CCT ATT CAA AGT CCT GGA-3‘ & (21mer) \\
\hline A22434TCF-36 & $5^{\circ}$-GTC ATG AGA GCA GGA GAA CT-3‘ & (20mer) \\
\hline PRG1-5' & $5^{\circ}$-GCT CTA CCC TCG AGT GGT GA-3‘ & (20mer) \\
\hline PRG1-36 & 5`-GTA ATG GGC GCA GAG ATG GG-3‘ & (20mer) \\
\hline RT1.M3-5 & $5^{`}$-GTT CTC ACA TCC TGC AGT GG-3‘ & (20mer) \\
\hline RT1.M3-36 & $5^{5}$-GCA GGA ATC TAT GGA GCA GC-3‘ & (20mer) \\
\hline H2-M2-56-3 & 5`-GAT CCC ACT CCT TGC GGT AC-3‘ & (20mer) \\
\hline
\end{tabular}




\begin{tabular}{|c|c|c|}
\hline H2-M2-3 & 5`-GTT CTG GCT CTG GTT GTA GT-3‘ & (20mer) \\
\hline $86 \mathrm{E} 23-5^{6}$ & 5‘-GGC TGT ACT TGA ATT TCC CTC-3‘ & (21mer) \\
\hline $86 \mathrm{E} 23-3^{6}$ & 5`-GTC TGT GCC ACC ATC CAA AC-3‘ & (20mer) \\
\hline 261A5S-56 & 5'-GTC AAT ATC CTA GTC CTG TCT-3‘ & (21mer) \\
\hline 261A5S-36 & 5‘-GGT CTG ATA TCC TGT AGA TCC-3‘ & (21mer) \\
\hline 573K1S-5 6 & 5‘-GCT TCT GTT CTG TGT GTG CC-3‘ & (20mer) \\
\hline $573 K 1 S-36$ & 5'-GAC TGT ATC GGT TGC TGG AA-3‘ & (20mer) \\
\hline P08462-5' & $5^{\prime}$-GGA TCA AGG ACT AAG TAC CAC-3' & (21mer) \\
\hline P08264-36 & $5^{\prime}-$ GGA ACA CGT GGA GCT CAG AC-3‘ & (20mer) \\
\hline rBAT1-56 & 5'-TCT CAC CTG CTC TGG GAC TC-3‘ & (20mer) \\
\hline rBAT1-36 & 5‘-TGC CCA GTA ACT GGC TCC AG-3‘ & (20mer) \\
\hline rBAT1.3 & 5‘-TGG ACT GTG GCA GTC TGT GTA GAA-3‘ & (24mer) \\
\hline rBAT1.3-neu & 5`-GTC ACC ACC ACT CCT AAA CC-3“ & (20mer) \\
\hline PNUTS-5 6 & 5'-GCA GCA TCG CCT GGA GCA-3‘ & (18mer) \\
\hline PNUTS-3 6 & $5^{5}-$ GCC TGT GAA GAA GAA CTC CA-3‘ & (20mer) \\
\hline H10232-5 & 5'-GCT GGT CTG ACA ATA ACC CA-3‘ & (20mer) \\
\hline H10232-36 & 5`-CAT GCA AAT TTT ATG GTG GAA C-3‘ & (22mer) \\
\hline F05479-5 & $5^{\prime}$-GAG ATA TGG GAA GTA TAC TTC A-3 & (22mer) \\
\hline F05479-36 & $5^{\circ}-\mathrm{CTG}$ TAG TCC ATT GAT CAC CAT-3' & (21mer) \\
\hline TC4-56 & 5`-GTC CAG TTC AAA CTT GTA TTG G-3‘ & (22mer) \\
\hline TC4-36 & $5^{`}-\mathrm{CAC}$ AGG TCA TCA TCC TCA TC-3‘ & (20mer) \\
\hline $\mathrm{CAK}^{-5}{ }^{6}$ & $5^{\prime}$-GCA GGA TGA CCC TCT CTG C-3‘ & (19mer) \\
\hline CAK-36 & 5'-GAT ACA CTC CCA GGC CAT C-3’ & (19mer) \\
\hline GTF2H-5 & 5'-GAA ATG TCC CGA TGT GTA AAC-3‘ & (21mer) \\
\hline GTF2H-36 & 5`-GTG GAC TTT GAA TTG CTG CTG-3‘ & (21mer) \\
\hline alpha1-56 & 5'-GCT CAC ACT CGC TGC GGT A-3‘ & (19mer) \\
\hline \multicolumn{3}{|c|}{ (Anfang Exon 2) } \\
\hline alpha1-36 & 5'-GCC CTC GCT CTG GTT GTA G-3‘ & (19mer) \\
\hline
\end{tabular}

(Ende Exon 2) 


\begin{tabular}{|c|c|c|}
\hline D20Wox5-1 & 5'-GAA AAA TAC TTC CAC ACA CTA ATG-3‘ & $(24 \mathrm{mer})$ \\
\hline D20Wox5-2 & 5'-AAA GTC AAG CCC TGG AGT G-3‘ & (19mer) \\
\hline D20Arb2-1 & 5'-CAG GAG GAT TAA GAG AGG TGC C-3“ & (22mer) \\
\hline D20Arb2-2 & $5^{\prime}$-CTG GCT TCA GAG ATT CAA CTG C-3‘ & (22mer) \\
\hline D20Mgh3-1 & $5^{\prime}$-AAC TTC CTG GTC CAG CCT G-3‘ & (19mer) \\
\hline D20Mgh3-2 & $5^{\circ}$-CTC AGT GTG GAA GTG AGG AGC-3‘ & (21mer) \\
\hline Bat-si242 & 5`-GTG GCT GTG GGT GGT GAA-3‘ & $(18 \mathrm{mer})$ \\
\hline Bat-cod. & $5^{\circ}$-GTG TCA GAC GAG AAC GAT G-3‘ & (19mer) \\
\hline
\end{tabular}

\subsubsection{Oligonukleotide für PAC-Endsequenzierung}

$\begin{array}{lll}\text { pPAC4-3 } & 5^{`} \text {-GTT TCG ATC CTC CCG AAT TG-3‘ } & \text { (20mer) } \\ \text { pPAC4-4 } & 5^{`} \text {-CAT ACA GAA GGA GAC ATG AAC-3‘ } \\ \text { pPAC4-5 } & 5^{`} \text {-CGC TAA TAC GAC TCA CTA TA-3` } \\ \text { pPAC4-6 } & 5^{`} \text {-CAA TAT AGT CCT ACA ATG TC-3‘ }\end{array}$

\subsubsection{Sonstige Primer}

Adaptor-Primer 5'-GAC TCG AGT CGA CAT CG-3`

(18mer)

ID-rat

5`-CCA CTG AGC TAA ATC CCC AAC CCC-3‘

(24mer)

\subsection{Chemikalien}

Agar

Agarose, genetic technology grade

Agarose, low melting point

AmpTabs ${ }^{\mathrm{TM}}$

Bacto-Hefe-Extrakt

Bacto-Pepton

Biophenol, trisstabilisiert, $\mathrm{pH} 7,8-8,0$

Borsäure, p.A.

Bromphenolblau
GIBCO BRL GmbH

ICN Biomedicals

ICN Biomedicals

Stratagene GmbH

GIBCO BRL GmbH

GIBCO BRL GmbH

Biomol Feinchemikalien GmbH

Merck KGaA

Merck KGaA 
5-Brom-4-chlor-3-indolyl- $\beta$-D-Galaktosid

Biomol Feinbiochemikalien $\mathrm{GmbH}$

(X-Gal)

1-Butanol, p.A.

Merck KGaA

Calciumchlorid-2-hydrat, p.A.

Merck KGaA

Chloroform, p.A.

Merck KGaA

Dextransulfat

Pharmacia Biosystems GmbH

Dinatriumethylendinitrilotetraessigsäure Dihydrat

Merck KGaA

(EDTA), p.A.

Dinatriumhydrogenphosphat, wasserfrei, p.A.

Merck KGaA

Entwickler LX 24

Kodak

Essigsäure $100 \%$, p.A.

Merck KGaA

Ethanol 99,9\%, vergällt

Zentralapotheke, Klinikum

Göttingen

Ethidiumbromid, kristallin

Merck KGaA

Ficoll 400

Pharmacia Biosystems GmbH

Fixierer AL 4

Kodak

Formamid

PE Applied biosystems

Glucose, p.A.

Merck KGaA

Glycerin

Merck KgaA

Roth $\mathrm{GmbH}$

Heringsspermien-DNA

Boehringer Mannheim GmbH

Isoamylalkohol, p.A.

Merck KGaA

Isopropanol, p.A.

Merck KGaA

Isopropyl- $\beta$-D-thiogalaktopyranosid (IPTG)

Biomol Feinbiochemikalien GmbH

Kaliumacetat, p.A

Merck KGaA

Kaliumchlorid, p.A.

Merck KGaA

Kanamycin Monosulfat

Sigma-Aldrich GmbH

Lambda-DNA ( $\lambda$-DNA)

MBI Fermentas GmbH

Magnesiumchlorid-Hexahydrat, p.A.

Merck KGaA

Magnesiumsulfat-Heptahydrat, p.A.

Merck KGaA

N-Lauroylsarcosin

Merck KGaA

Natriumacetat-Trihydrat, p.A.

Merck KGaA

Natriumbicarbonat

Sigma-Aldrich GmbH

Natriumchlorid, p.A.

Sigma-Aldrich GmbH 
Natriumdihydrogenphosphat Monohydrat, p.A

Natriumdodecylsulfat, p.A.

Tri-Natriumcitrat (Dihydrat), p.A.

Natriumhydrogencarbonat, p.A.

Natriumhydroxid, p.A.

Nucleotide (dATP, dCTP, dGTP, dTTP)

ortho-Phosphorsäure, $85 \%$, p.A.

Paraffin

Phenol, p.A.

PMSF (Phenylmethansulfonyl-Fluorid)

Polyvinylpyrrolidon

RNase-Inhibitor (RNasin)

Salzsäure, rauchend, p.A.

Spermidin

Spermin

Template Supression Reagent

Xylencyanol FF
Merck KGaA

Merck KGaA

Merck KGaA

Merck KGaA

Merck KGaA

Boehringer Mannheim GmbH

Merck KGaA

Merck KGaA

Merck KGaA

Fluka Feinchemikalien GmbH

Merck KGaA

Amersham Buchler GmbH

Merck KGaA

Merck KGaA

Merck KGaA

PE Applied Biosystems

Bio-Rad Laboratories GmbH

\subsection{Radiochemikalien}

$\alpha-\left[{ }^{32} \mathrm{P}\right]-\mathrm{dCTP}$

$\gamma-\left[{ }^{32} \mathrm{P}\right]-\mathrm{dATP}$

\subsection{Enzyme}

Alkalische Phosphatase

Lysozym

MMLV reverse Transkriptase

Proteinase K

Restriktionsenzyme

Rinderserumalbumin (BSA), Fraktion V
Amersham Buchler GmbH

Amersham Buchler GmbH
Boehringer Mannheim GmbH

Sigma-Aldrich GmbH

Amersham Buchler GmbH

Merck KGaA

Amersham Buchler GmbH

Boehringer Mannheim GmbH

Biomol Feinbiochemikalien $\mathrm{GmbH}$ 
RNase A

Boehringer Mannheim GmbH

T4-DNA-Ligase

Boehringer Mannheim GmbH

Taq-DNA-Polymerase

Boehringer Mannheim GmbH

\subsection{Versuchstiere}

Zur Konstruktion einer genomischen Bank wurde die Spezies Rattus norvegicus, Stamm LEW.1W/Gun, der als Inzuchtstamm in der Abteilung Immungenetik gehalten wird, benutzt. Dem Tier wurden zur Isolierung der DNA (Methode 3.2.2) die Milz und die Lymphknoten entnommen.

\subsection{Lösungen und Puffer}

Alle Lösungen und Puffer wurden mit Milli-Q-Wasser (Milli-Q-Water-System, Millipore)angesetzt. Je nach Verwendungszweck wurde anschließend 30 Minuten bei $121^{\circ} \mathrm{C}$ und 1,1 bar im Dampfautoklaven autoklaviert oder bei hitzeempfindlichen Lösungen sterilfiltriert (Porengröße 0,2 $\mu \mathrm{m}$ ).

$\begin{array}{ll}\text { Auftrags-Puffer (DNA) } & 0,25 \% \text { Bromphenolblau } \\ & 0,25 \% \text {, Xylencyanol } \\ & 25 \% \text { Ficoll } 400 \\ & 50 \text { mM EDTA pH } 8,0\end{array}$

Denaturierungslösung

$1,5 \mathrm{M} \mathrm{NaCl}$

(Alkalizer)

$0,5 \mathrm{M} \mathrm{NaOH}$

Denhardt-Lösung (50x)

$1 \%$ Ficoll 400

$1 \%$ Polyvinylpyrrolidon

$1 \%$ BSA (Fraktion V)

ESP-Lösung

0,5 M EDTA

$1 \% \mathrm{~N}$-Lauroylsarcosin

0,05\% Proteinase K 


\begin{tabular}{|c|c|}
\hline Hybridisierungslösung & $6 \times \mathrm{SSC}$ \\
\hline & $5 \times$ Denhardt-Lösung \\
\hline & $10 \%$ Dextransulfat \\
\hline & $0,5 \% \mathrm{SDS}$ \\
\hline
\end{tabular}

Hybridisierungslösung für PAC- 0,5 M Natriumphosphat $\mathrm{pH}$ 7,2

Klone

1 mM EDTA

$7 \%$ SDS

Lysis-Lösung I

$50 \mathrm{mM}$ Glucose

25 mM Tris- $\mathrm{HCl} \mathrm{pH} 8,0$

10 mM EDTA pH 8,0

Lysis-Lösung II

$0,2 \mathrm{~N} \mathrm{NaOH}$

$1 \%$ SDS

Neutralisierungslösung

3 M Natriumacetat $\mathrm{pH} 5,5$

P1-Lösung

$50 \mathrm{mM}$ Tris $\mathrm{pH} 8,0$

10 mM EDTA pH 8,0

$100 \mu \mathrm{g} / \mathrm{ml}$ RNAse A

P2-Lösung

$200 \mathrm{mM} \mathrm{NaOH}$

$1 \%$ SDS

P3-Lösung

2,55 M Kaliumacetat pH 4,8

$100 \times$ PA Stocklösung

Spermidin $75 \mathrm{mM}(0,109 \mathrm{~g} / 10 \mathrm{ml})$

Spermin $30 \mathrm{mM}(0,06 \mathrm{~g} / 10 \mathrm{ml})$

PBS

$$
\begin{aligned}
& 1 \% \mathrm{NaCl} \\
& 0,025 \% \mathrm{KCl} \\
& 0,0143 \% \mathrm{Na}_{2} \mathrm{HPO}_{4} \\
& 0,0025 \% \mathrm{KH}_{2} \mathrm{PO}_{4}
\end{aligned}
$$


Puffer S1

Puffer S2

Puffer S3

$\operatorname{SSC}(20 x)$

TE-Puffer (10x)

Tris-Phosphat-Puffer(20x)

TOP-Agar

\author{
$50 \mathrm{mM}$ Tris/ $\mathrm{HCl}$ \\ 10 mM EDTA \\ $100 \mu \mathrm{g} / \mathrm{ml}$ RNase A \\ $\mathrm{pH} \mathrm{8,0} \mathrm{mit} \mathrm{HCl}$
}

$200 \mathrm{mM} \mathrm{NaOH}$

$1 \%$ SDS

2,80 M Kaliumacetat pH 5,1

$3 \mathrm{M} \mathrm{NaCl}$

0,3 M Natriumcitrat

$\mathrm{pH}$ 7,0 mit $\mathrm{HCl}$ eingestellt

0,5 M Tris-Borat $\mathrm{pH} \mathrm{8,0}$

10 mM EDTA pH 8,0

$100 \mathrm{mM}$ Tris-HCl pH 8,0

10 mM EDTA pH 8,0

1,75 M Tris

$40 \mathrm{mM}$ EDTA

pH 7,8 mit Phosphorsäure eingestellt

1\% Bacto-Pepton

0,5\%Bacto-Hefe-Extrakt

$1 \% \mathrm{NaCl}$

0,75\% Agar

\subsection{Zusammensetzung von Nährmedien}

\subsubsection{Nährmedien}

LB (Luria-Bertani)-Medium $\quad 10 \% \mathrm{NaCl}$ 
$10 \%$ Bacto-Pepton

5\% Bacto-Hefe-Extrakt

(15\% Agar für Platten)

SOB-Medium

2\% Bacto-Pepton

0,5\% Bacto-Hefe-Extrakt

$10 \mathrm{mM} \mathrm{NaCl}$

$2,5 \mathrm{mM} \mathrm{KCl}$

$10 \mathrm{mM} \mathrm{MgCl}_{2}$

$10 \mathrm{mM} \mathrm{MgSO}_{4}$

SOC-Medium

SOB-Medium

$20 \mathrm{mM}$ Glucose

\subsubsection{Zusätze für prokaryotische Nährmedien}

Ampicillin-Tabs (25 mg/Tab) 2 Tabletten pro Liter Medium bzw. Agar

Kanamycin-Stammlösung

$(50 \mathrm{mg} / \mathrm{ml})$

$2 \mathrm{M} \mathrm{MgSO}_{4}$

\subsection{Einwegartikel}

Dialyseschlauch, 6/32, $27 \mathrm{~mm}$

$50 \mathrm{mg}$ sterilfiltriertes Kanamycin pro Liter Medium bzw.Agar

$5 \mathrm{ml}$ sterilfiltriertes $\mathrm{MgSO}_{4}$ pro Liter LB-Medium (Endkonzentration $10 \mathrm{mM}$ )
Whatman Gel-Blotting-Papier GB003

Reagiergefäß $1,5 \mathrm{ml}$

Reagiergefäß 2,0 ml

Faltenfilter 595 1⁄2, Ø $185 \mathrm{~mm}$
Serva Feinbiochemika GmbH \& Co. KG

Schleicher \& Schuell

Sarstedt GmbH + Co.

Sarstedt GmbH + Co.

Schleicher \& Schuell 
Parafilm PM-992 Laboratoryfilm

Petrischalen, Ø $9 \mathrm{~cm}$

Pipettenspitzen

Polaroidfilme 667

Röntgenfilme, Hyperfilm MP

50 ml-Röhrchen

Sterilfilter, 0,2 $\mu \mathrm{m}$ Porengröße

Steril Filtertips über Schütt Labortechnik

Sarstedt GmbH + Co.

Sarstedt GmbH + Co.

(über die Klinikumsapotheke Göttingen)

Amersham Buchler GmbH

Sarstedt GmbH + Co.

Sarstedt GmbH + Co.

Sarstedt GmbH + Co.

\subsection{Verwendete Kits}

\begin{tabular}{|l|l|}
\hline ABI Prism & PE ${ }^{\mathrm{TM}}$ Bige $^{\mathrm{TM}}$ \\
Terminator Cycle Sequencing & \\
Ready Reaktion Kit & \\
\hline Expand TM Long Template PCR System & Boehringer Mannheim GmbH \\
\hline & \\
\hline Jetquick Gel Extraction Spin Kit & Genomed GmbH \\
\hline & \\
\hline Jetstar Plasmid Kit & Genomed GmbH \\
\hline & \\
\hline MegaprimeTM labelling systems & Amersham Buchler GmbH \\
\hline & \\
\hline Nucleobond AX & Macherey-Nagel \\
\hline & \\
\hline Original TA Cloning Kit & Invitrogen \\
\hline
\end{tabular}




\subsection{Geräte}

Autoklaven:

Hochdruck-Dampfsterilisator Typ C

und Typ A40 (Tischautoklav) Webeco

Autoradiographiekassetten,

Cronex-Cassetten

Du Pont de Nemours GmbH

Brutschränke, $\mathrm{CO}_{2}$-begast

Heraeus $\mathrm{GmbH}$

Digital pH-Meter 646

Knick Elektronische Meßgeräte GmbH \& Co

Elektrophoresekammern:

Agagel Mini

Biometra $\mathrm{GmbH}$

Modelle H1, H3 und S2

Gibco BRL GmbH

Modell V16

Gibco BRL GmbH

Elektroporations-Impulsgenerator EPI 2500

Dr. Fischer- Intergen

Handmonitor, Typ LB 1210 B

Laboratorium

Prof. Dr. Berthold

Heizblock, Liebisch, Typ S-12-140

Gebr. Liebisch Bielefeld über Schütt

Labortechnik GmbH

Hybridisierungsofen, Typ 430

Bachofer GmbH

Kryostat-Wasserbad, Multi-Temp II

Pharmacia Biosystems GmbH

Minishaker, Typ MS1 IKA

über Krannich GmbH \& Co. KG

Netzteile:

Fröbel Laborgeräte 
Consort Electrophoresis Power Supply

Pharmacia Biosystems GmbH

2197 Power Supply

Photometer, Ultrospec II

Pharmacia Biosystems GmbH

Polaroid-Kamera CU-5

Polaroid GmbH

Rundschüttler, IRC-1-U Clim-O-Shake

Adolf Kühner AG Apparatebau

Sequenziergerät ABI 310 Genetic Analyzer

PE Applied Biosystems

Thermocycler, Biometra Uno-Thermoblock

Biometra GmbH

Trilux 1450 MicroBeta, liquid scintillation and

Wallac

luminescence counter

UV-Durchleuchter, Fluo-link TYP CL1

Biometra $\mathrm{GmbH}$

UV-Handlampe

Vetter GmbH

Vakuumanlage:

Pumpe VP 200, SpeedVac SC 110

Kühlfalle RVT 100

Savant, über Schütt Labortechnik GmbH

Vakuumofen, Heraeus Typ VTR 5022

Heraeus GmbH

Waagen:

Typ 1574 MP 8

Sartorius GmbH

Typ 414/13

Sauter

Wasserbäder:

Schüttel-Wasserbad

Wasserbad Köttermann

über Schütt Labortechnik GmbH

Zentrifugen 
Hettich MikroliterTyp 2025 und 2042

Heraeus Christ Labofuge GL

Minifuge GL, Typ 4400

Sigma 3K30 Tischkühlzentrifuge

Sorvall RC-5B Refrigerated Superspeed

Centrifuge, Rotoren SS-34 und GSA

Varifuge 3.2 RS
Andreas Hettich

Heraeus Sepatech GmbH

Heraeus Sepatech GmbH

Sigma Laborzentrifugen $\mathrm{GmbH}$

DuPont de Nemours GmbH

Heraeus Sepatech GmbH

\subsection{Herstelleradressen}

PE Applied Biosystems

Amersham Buchler GmbH

Andreas Hettich

Biometra $\mathrm{GmbH}$

Biomol Feinchemikalien GmbH

Boehringer Mannheim GmbH

Dr. Fischer-Intergen

Du Pont de Nemours GmbH

Fluka

Fröbel Laborgeräte

Genomed GmbH

GIBCO BRL Life Technologies

Heraeus GmbH

Heraeus Sepatech GmbH

Intas

Invitrogen BV

Knick Elektronische Meßgeräte $\mathrm{GmbH}$ \& Co

Krannich $\mathrm{GmbH} \& \mathrm{Co} . \mathrm{KG}$

Laboratorium Prof. Dr. Berthold

Macherey-Nagel GmbH \& Co. KG

Merck KGaA
Brunnenweg 13, 64331 Weiterstadt

Gieselweg 1, 38110 Braunschweig

78532 Tuttlingen

Rudolf-Wissell-Str. 30, 37079 Göttingen

Waidmannstr.35, 22769 Hamburg

Sandhofer Str.116, 68305 Mannheim

Schneidmühlstr.9, 69115 Heidelberg

Opernplatz 2, Postfach 2607, 60313 Frankfurt

Dieselstr. 18, 61231 Bad Nauheim

Sigma-Aldrich-GmbH

Grünwalder Weg 30, 82041 Deisenhofen

Alwindstr. 4, 88131 Lindau

Wielandstr. 28 a, 32545 Bad Oeynhausen

Dieselstr.5, 76344 Eggenstein

Postfach 1553, 63457 Hanau

Postfach 1220, 37520 Osterode

Florenz-Sartorius-Str.14, 37079 Göttingen

De Schelp 12, 9351 NV Leek, Niederlande

Beuckestr. 22, 14163 Berlin

Elliehäuser Weg 17, 37079 Göttingen

Siemensstr. 4, 30173 Hannover

Postfach 101352, 52313 Düren

Postfach, 64271 Darmstadt 
NAPS Göttingen GmbH

Pharmacia Biotech AB

Polaroid $\mathrm{GmbH}$

Sarstedt GmbH + Co

Sartorius GmbH

Sauter

Schleicher \& Schuell

Schütt Labortechnik GmbH

Serva Feinbiochemica GmbH \& Co. KG

Sigma Laborzentrifugen $\mathrm{GmbH}$

Sigma-Aldrich Chemie GmbH

Wallac

Webeco
Rudolf-Wissel-Str. 28, 37079 Göttingen

Munzingerstr. 9, 79111 Freiburg

Sprendlinger Landstr. 109, 63069 Offenbach

51582 Nümbrecht

Weender Landstr. 94-108, 37079 Göttingen

Ringstr. 134, 70839 Gerlingen

Postfach 4, 37582 Dassel, über Krannich

GmbH \& Co. KG

Rudolf-Wissell-Str. 11, 37079 Göttingen

Carl-Benz-Straße 7, 69115 Heidelberg

An der unteren Söse 50, 37520 Osterode

Postfach, 82039 Deisenhofen

EG \& G Berthold, Laboratorium Prof. Dr.

Berthold GmbH \& Co. KG Postfach 100163, 75312 Bad Wildbad

Webecke \& Co., 23611 Bad Schwartau

\subsection{Verwendete Hybridisierungsproben}

\section{Bezeichnung}

a1-Probe*

a3-Probe*

Walter et al. (1995)

Bat1: Nukleäre RNA Nair et al. (1992)

Helikase

BM1: MHC-Klasse-I, Parker et al. (1990) 3‘utr (NC1-Region)

Cyto-Poly-A-Probe* Walter et al. (1995)
Probe

700 bp Not $\mathrm{I} /$ Pst $\mathrm{I} \quad$ R.norvegicus

289 bp Pst $\mathrm{I} /$ Pst $\mathrm{I}$

R.norvegicus

400 bp PCR

R.norvegicus

Produkt an cDNA

1 kb PCR-Produkt R.norvegicus

731 bp Pst $\mathrm{I} /$ Pst $\quad$ R.norvegicus 
(GAAA)n: repeat

PAC Endsequenzierung, Klon J2298

Gna-rs1(R1): GTP- Vernet et al. (1994)

binding protein

pGrc1.4: growth and Salgar et al. (1997)

reproduction complex

H12587

I162T: STS-Marker

M2: MHC-Klasse-Ib

Exon 2

M3: MHC-Klasse-Ib

Exon 3

M4: MHC-Klasse-Ib (polymorpher Mikro-

Lambracht-Washington et al. (1998)

satelliten- Marker)

Mog: Myelin/

oligodendrocyte

glycoprotein

PNUTS: Phosphatase

PAC-Endsequenzierung Klon E16374

Allen et al. (1998)

(kommt mehrfach in der

gesamten Region von Contig

$2 \mathrm{a}$ und $2 \mathrm{~b}$ vor)

PAC-Endsequenzierung

Pham-Dinh et al (1993) subunit

\section{1 nuclear targeting}

200 bp PCR-

R.norvegicus

Produkt

359 bp EcoRI-

M.musculus

Fragment

500 bp PCR-Prod. R.norvegicus

PAC-Endsequenzierung

R.norvegicus

230 bp PCR-

R.norvegicus

Produkt

270 bp PCR-

M.musculus

Produkt

250 bp PCR-

R.norvegicus

Produkt

129 bp PCR-

$R$. norvegicus

Produkt

Stamm BN

270 bp PCR-

R.norvegicus

Produkt

$100 \mathrm{bp}$

R.norvegicus 
Pou5f1: Oct-4

Rosner et al. (1990)

Transkriptionsfaktor

PRG1: early

response gene

Promotor -Probe

Walter et al. (1995)

aus einem Klasse-Ia-

Gen*

RFB30: Ring finger Henry et al. (1997)

protein

S: Skin expressed gene

TCF19:

Transkriptionsfaktor

Tctex5: t-complex Yeom et al. (1992)

Testis expressed

Tnf: Tumor Nekrose Kirisitis et al.(1994)

Faktor

Tu42: Olfaktorisches Erhalten von

Rezeptor Gen

Dr. P. Pontarotti, Marseille

ZNF173: Zinc finger Chu et al. (1995)

protein 173

255D1: STS-Marker Jones et al (1999).
$1,9 \mathrm{~kb}$

M.musculus

EcoRI/BamHI-

Fragment

170 bp PCR- M.musculus

Produkt

300 bp PCR-

R.norvegicus

Produkt

1300 bp PstI/NotI R.norvegicus

420 bp PCR-

H.sapiens

Produkt

288 bp PCR-

H.sapiens

Produkt

330 bp PCR-

H.sapiens

Produkt

500 bp EcoRI-

M.musculus

Fragment

PCR Produkt

M.musculus

320 bp PCR-

H.sapiens

Produkt

260 bp PCR-

M.musculus

Produkt. 
261A5: STS-Marker Jones et al (1999)

261 A5S: STS-Marker Jones et al. (1999)
360 bp PCR-

M.musculus

Produkt

330 bp PCR-

M.musculus

Produkt

\footnotetext{
*Eine Schematische Darstellung dieser Hybridisierungs-Proben ist in der Abbildung 5 zu sehen. Die Erläuterung folgt im Text.
}

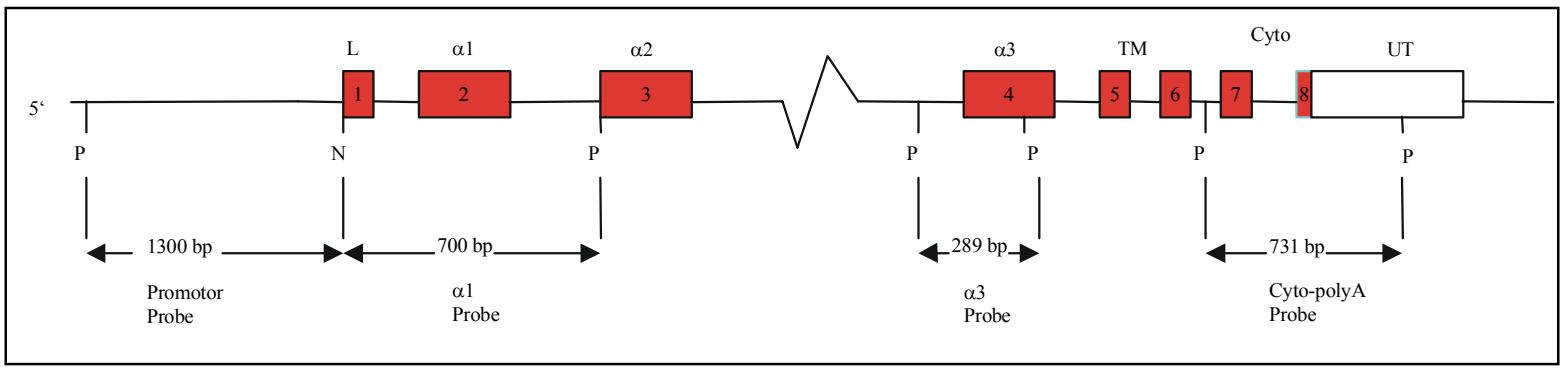

Abb. 5: Schematische Darstellung der Exon-Intron-Organisation eines Klasse-I-Gens und der davon abgeleiteten Hybridisierungssonden. Beschreibung sieheText.

Aus Subklonen des Klons 9b1 (Walter et al., 1995), der ein funktionelles MHC-Klasse-I-Gen mit der in Abb. 5 gezeigten, typischen Exon-Intron Organisation für MHC-Klasse-I-Gene trägt und in die $R T 1-A$-(RT1 ${ }^{\mathrm{u}}$-Haplotyp) Region kartiert, wurden vier Hybridisierungsproben erstellt. Diese wurden durch Restriktionsspaltung mit PstI und PstI/NotI erhalten. Die Promotor-Probe enthält noch einen Teil der Exon-1-Sequenz, während die alpha-1-Probe den anderen Teil des Exons 1, das Intron 1, die gesamte Exon 2-Sequenz sowie das Intron 2 in einer Länge von 700 bp umfasst. Die alpha 3-Probe besteht aus einem Teil des Introns 3 und aus einem Teil des Exons 4 mit einer Gesamtlänge von 289 bp. Die Cyto-polyA-Probe besteht aus dem Exon 7, Exon 8, einem Teil des Introns 6, Intron 7 und einem Teil der 36untranslatierten Region.

\subsection{Verwendete Ressourcen}

Eine PAC-Bank aus genomischer DNA des Inzuchtstammes BN (Woon et al., 1998) wurde als "gridded library" (library Nummer 712) vom Ressourcen-Zentrum im Deutschen Humangenomprojekt (RZPD) Heubnerweg 6, 14059 Berlin zur Verfügung gestellt. Die Bank 
repräsentiert 10,7 Genomäquivalente, wobei die durchschnittliche Insertlänge 147,3 kb beträgt. Die zur Konstruktion der Bank verwendete genomischer DNA entstammt dem Gehirn einer weiblichen Ratte des Inzuchtstammes BN/ssNHsd (Brown Norway). Nach partieller MboI-Spaltung wurden die Restriktionsfragmente in den Vektor pPAC4 ligiert und zur Transformation von E.coli-Zellen des Stammes DH10B eingesetzt.

Tab. 1: Übersicht der verwendeten PAC-Filter

Library-No

Bezeichnung

Filter \# 1

Library-No. 712, Part 1

$110-1-116$

Filter \# 2

Library-No. 712, Part 2

$110-2-127$

Filter \# 3

Library-No. 712, Part 3

110-3-110

Filter \# 4

Library-No. 712, Part 4

$110-4-122$

Filter \# 5

Library-No. 712, Part 5

110-5-134

Filter \# 6

Library-No. 712, Part 6

110-6-116

Filter \# 7

Library-No. 712, Part 7

110-7-161

Filter \# 8

Library-No. 712, Part 8

110-8-158

Filter \# 9

Library-No. 712, Part 9

110-9-122

\subsection{Verwendete Computerprogramme}

Die Auswertung der Sequenzierungen erfolgte mit dem Programm „Sequencing Analysis“ der Firma PE Applied Biosystems.

Die Suche nach homologen Sequenzen erfolgte im Internet mit den Programmen BCM Search Launcher (http://kiwi.imgen.bcm.tmc.edu) sowie BLAST (http://www.ncbi.nlm.nih.gov). DNA- und Aminosäuresequenzen wurden mit den Programmen ALIGN und LALIGN (http://dot.imgen.bcm.tmc.edu) verglichen. 


\section{Methoden}

\subsection{Allgemeine Angaben zur Arbeit mit DNA}

Die im Umgang mit Nukleinsäuren erforderliche Sterilität der Geräte und Lösungen wurde durch das Autoklavieren der Glasgeräte und Edelstahlbestecke bei $134^{\circ} \mathrm{C}$ und 2,1 bar für 10 Minuten bzw. der Plastikartikel bei $121^{\circ} \mathrm{C}$ und 1,1 bar für 20 min im Dampfdruckautoklaven erreicht. Die thermostabilen Lösungen wurden 20 Minuten bei $121^{\circ} \mathrm{C}$ und 1,1 bar autoklaviert, thermolabile Lösungen dagegen sterilfiltriert (Porengröße der Filter 0,2 $\mu \mathrm{m}$ ).

\subsection{Isolierung von DNA}

\subsubsection{Präparation von genomischer DNA aus kleiner Menge Lebergewebe}

Eins bis zwei kleine Organstücke (aus eingefrorenem Material) wurden über Nacht in $700 \mu 1$ Lysepuffer und $35 \mu 1$ Proteinase K-Lösung $(10 \mathrm{mg} / \mathrm{ml})$ bei $55^{\circ} \mathrm{C}$ im Wasserbad inkubiert. Anschließend wurden die Proteine durch Extraktion mit $700 \mu 1$ Phenol und Zentrifugation (Tischzentrifuge, $15000 \mathrm{rpm}, 3$ Minuten) entfernt. Der Überstand wurde mit $700 \mu 1$ Chloroform gewaschen und unter den gleichen Bedingungen zentrifugiert. Die DNA präzipitierte durch den Zusatz von $70 \mu 13 \mathrm{M}$ Natriumacetat pH 6,0 und $700 \mu 1$ eiskaltem absoluten Ethanol. Nach der 10-minütigen Zentrifugation bei $4^{\circ} \mathrm{C}$ und $15000 \mathrm{rpm}$ wurde das DNA-Pellet mit 70 \%igem Ethanol gewaschen, getrocknet und in $1 \mathrm{x}$ TE-Puffer gelöst.

\subsubsection{Die Isolierung und Verarbeitung von Lymphozyten-DNA}

Die Lymphknoten wurden aus der mit $\mathrm{CO}_{2}$ getöteten Ratte präpariert und direkt in kalten PBS-Puffer $\left(1 \% \mathrm{NaCl}, 0,025 \% \mathrm{KCl}, 0,0143 \% \mathrm{Na}_{2} \mathrm{HPO}_{4}, 0.0025 \% \mathrm{KH}_{2} \mathrm{PO}_{4}\right)$ gelegt. Die in einer Petrischale mit einem Skalpell zerkleinerten Lymphknoten wurden in einem FalconRöhrchen in $50 \mathrm{ml}$ PBS resuspendiert. Die Inkubation des Röhrchens für 5 min auf Eis bewirkte, daß grobe Gewebe Bestandteile sedimentierten. Der in ein neues Falcon-Röhrchen transferierte Überstand zentrifugierte für $10 \mathrm{~min}$ bei $600 \mathrm{x} \mathrm{g}$ und $4^{\circ} \mathrm{C}$. Das Pellet wurde in 
weiteren $50 \mathrm{ml}$ PBS resuspendiert und die Zellzahl mikroskopisch bestimmt. Die Endkonzentration von $4 \times 10^{7}$ Zellen/ml wurde durch erneute Zentrifugation und Aufnahme in einer berechneten Menge PBS eingestellt. Diese Zellsuspension wurde mit einem äquivalenten Volumen 1,5\% low-melting-point-Agarose (gekocht in PBS, abgekühlt auf $37^{\circ} \mathrm{C}$ ) gemischt, so daß eine $0,75 \%$ ige Agarose-Lösung resultierte. Durch das Gießen der noch warmen Agarose/Zell-Lösung in entsprechende autoklavierte Einsätze erhielt man Blöckchen, die nach Abkühlen, in ESP-Lösung äquilibriert und für $48 \mathrm{~h}$ bei $50^{\circ} \mathrm{C}$ unter schnellem Schütteln inkubiert wurden. Anschließend erfolgte ein 30-minütiger Waschschritt der Blöckchen mit 1xTE-Puffer, $\mathrm{pH} 8$ bei $50^{\circ} \mathrm{C}$ und die Überführung in 1xTE-Puffer, welcher $1 \mathrm{mM}$ PMSF enthielt sowie die erneute Inkubation bei $50^{\circ} \mathrm{C}$ für $30 \mathrm{~min}$. Zuletzt wurden die Blöckchen in 1xTE bei Raumtemperatur gewaschen. Aufbewahrt wurden die Blöckchen in 0,5 $\mathrm{M}$ EDTA bei $4^{\circ} \mathrm{C}$ und vor der weiteren Verwendung in 1xTE äquilibriert.

\subsubsection{Gewinnung von Plasmid-DNA mittels Säulenelution}

Für die Plasmidisolierung im präparativen Maßstab wurden Anionenaustauschersäulen der Firma Genomed verwendet. $100 \mathrm{ml}$ einer frischen Übernachtkultur der Plasmid-tragenden $E$. coli-Transfektante wurden abzentrifugiert (Hettich Rotanta, 4000 rpm, 10 min), der Überstand vollständig verworfen und das Pellet in $10 \mathrm{ml}$ E1-Puffer resuspendiert. Anschließend erfolgte die Zugabe von $10 \mathrm{ml}$ des alkalischen Lysepuffers E2. Während der Inkubationszeit von 5 min bei RT denaturierten die zellulären Proteine unter dem Einfluß des enthaltenen SDS und die alkalischen Bedingungen bewirkten die Denaturierung der chromosomalen- und PlasmidDNA. Die Zugabe von $10 \mathrm{ml}$ E3- Puffer bewirkte die gemeinsame Präzipitation von chromosomaler DNA, denaturierten Proteinen und Zelltrümmern. Die kleinere Plasmid-DNA liegt nach der sich anschließenden Zentrifugation (15000 g, $10 \mathrm{~min}$, RT) renaturiert im Überstand vor, welcher, filtriert durch eine doppelte Zellstoff-Lage, auf eine mit $30 \mathrm{ml}$ E4Puffer äquilibrierte Maxi-Jetstarsäule aufgetragen wurde. Nach dem Waschen mit $60 \mathrm{ml}$ E5Puffer wurde die Säulenmatrix-gebundene DNA mit $15 \mathrm{ml}$ des Hochsalzpuffers E6 eluiert und durch den Zusatz von 0,7 Vol\% Isopropanol gefällt. Nach einer 20minütigen Inkubation bei RT folgte eine 30minütige Zentrifugation $\left(15000 \mathrm{~g}, 4^{\circ} \mathrm{C}\right)$. Das DNA-Pellet wurde sodann

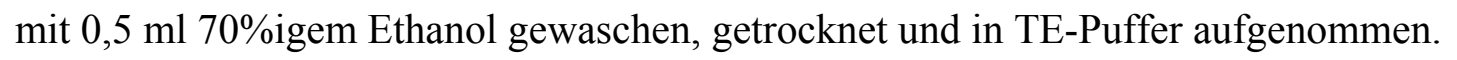




\subsubsection{Präparation von low-copy Plasmid-DNA (PAC) im größeren Maßstab mittels Nucleobond $^{\circledR}$ AX Säulen}

Nucleobond $^{\circledR}$ AX ist ein Anionenaustauscher auf Silikat-Basis. Die Aufreinigungen wurden in wässrigen Puffern, welche teilweise Ethanol enthielten, durchgeführt. Die Bindung der Nukleinsäuren an den großporigen Anionenaustauscher erfolgte bei niedrigen Salzkonzentrationen. In den nachfolgenden Waschschritten stieg der Salzgehalt kontinuierlich an; die Elution der dsDNA fand bei Salzkonzentrationen zwischen 1,35 $\mathrm{M}$ bis 1,5 $\mathrm{M} \mathrm{KCl}$ in $100 \mathrm{mM}$ Tris-Phosphat statt.

Es wurden $100 \mathrm{ml}$ Antibiotika-haltiges LB-Medium mit einer einzelnen Bakterienkolonie angeimpft und über Nacht inkubiert $\left(160 \mathrm{rpm}, 37^{\circ} \mathrm{C}\right)$. Die Ernte der Bakterien erfolgte durch eine 10minütige Zentrifugation (4000 rpm, Raumtemperatur). Das erhaltene Zellpellet wurde nach der Resuspension in $8 \mathrm{ml} \mathrm{S1-Puffer} \mathrm{mit} 8 \mathrm{ml}$ Puffer S2 versetzt und durch vorsichtiges inverses Schwenken der Röhre gemischt. Nach 5minütiger Inkubation bei Raumtemperatur folgte der behutsame Zusatz $8 \mathrm{ml}$ Puffer S3. Das erhaltene Lysat inkubierte vor der Zentrifugation $\left(15000 \mathrm{x}\right.$ g, 25 Minuten, $\left.4^{\circ} \mathrm{C}\right) 5$ Minuten auf Eis. Während der Zentrifugation wurde die Säule mit $2 \mathrm{ml}$ Puffer N2 äquilibriert. Der klare Überstand wurde auf die Säule gegeben und diese nach dem Durchlauf dreimal mit 4 ml Puffer N3 gewaschen. Die PlasmidDNA wurde mit zweimal 2 ml Puffer N5 von der Säule eluiert. Die DNA präzipitierte durch den Zusatz von 1,4 ml Isopropanol während der anschließenden 45minütigen Inkubation bei Raumtemperatur. Nach der Zentrifugation bei 15000 x g für 10 min und $4^{\circ} \mathrm{C}$ wurde das Pellet getrocknet (RT) und in einer adäquaten Menge bidest. Wasser aufgenommen.

\subsubsection{Kleinansatz zur Präparation von PAC-DNA}

Der Überstand einer frischen 20 ml-Übernachtkultur wurde nach der Zentrifugation (4000 rpm, $4^{\circ} \mathrm{C}$ ) dekantiert und das erhaltene Zellpellet in $400 \mu$ R RaseA-haltiger P1-Lösung resuspendiert und für 5 min auf Eis gestellt. Nach dem Zusatz von $800 \mu$ P2-Lösung und der Inkubation für 5 min bei RT wurden $600 \mu \mathrm{l}$ P3-Lösung dazugegeben, durchmischt und der Ansatz zentrifugiert $\left(15000 \mathrm{x} \mathrm{g}, 4^{\circ} \mathrm{C}, 15 \mathrm{~min}\right)$. Der Überstand zuerst mit $0,5 \mathrm{Vol}$ Phenol/Chloroform und dann mit 1 Vol Chloroform extrahiert. Die DNA wurde aus dem Überstand durch den Zusatz von 2,5 Vol Ethanol p.a und 1/10 Vol 7 M Ammoniumacetatlsg. während der Inkubation bei $4^{\circ} \mathrm{C}(1 \mathrm{~h})$ gefällt. Nach der Zentrifugation $(15000$ x g, 15 min, 
$4^{\circ} \mathrm{C}$ ) wurde das Pellet mit $200 \mu 170 \%$ igem Ethanol gewaschen und nach dem Trocknen in 30 $\mu 1$ TE-Puffer aufgenommen.

\subsubsection{Kleinansatz zur Plasmidisolierung (lange Methode)}

Zwanzig ml selektives LB-Medium wurde mit einer einzelnen Bakterienkolonie angeimpft und über Nacht inkubiert $\left(37^{\circ} \mathrm{C}, 160 \mathrm{rpm}\right)$. Nach der Ernte der Bakterien durch Zentrifugation bei 4000 x g für 10 Minuten wurde das Zellpellet in $320 \mu$ Lysis-Lösung I resuspendiert und für 5 Minuten bei Raumtemperatur inkubiert. Im Anschluß wurden $480 \mu 1$ Lysis-Lösung II zugegeben und für 5 Minuten auf Eis inkubiert. Nach dem Zusatz von $360 \mu 13 \mathrm{M}$ Natriumacetat und erneuter Inkubation (5 Minuten, auf Eis), wurden Proteine während einer 10 minütigen Zentrifugation $\left(15000 \mathrm{x} \mathrm{g}, 4^{\circ} \mathrm{C}\right)$ pelletiert. Die Nukleinsäuren präzipitierten durch den Zusatz von $600 \mu$ I Isopropanol zu $900 \mu 1$ des Überstand und der sich anschließenden 15 minütigen Inkubation bei Raumtemperatur. Das Nukleinsäurepellet wurde durch Zentrifugation (15000 x g, 20 Minuten) erhalten, getrocknet, in $200 \mu 1$ TE-Puffer gelöst, mit $6 \mu 15 \mathrm{M} \mathrm{NaCl}$ und $10 \mu \mathrm{RNase}$ A $(20 \mathrm{mg} / \mathrm{ml})$ versetzt und für 30 Minuten bei $37^{\circ} \mathrm{C}$ inkubiert. Die restlichen Proteine wurden durch Extraktion mit $400 \mu 1$ Phenol/Chloroform/Isoamylalkohol (25:24:1) sowie mit $400 \mu$ l Chloroform/Isoamylalkohol (24:1) entfernt. Die DNA präzipitierte durch den Zusatz von 2,5 Vol Ethanol p.a. und 1/10 Vol $3 \mathrm{M}$ Natriumacetat, Inkubation bei $-80^{\circ} \mathrm{C}$ für 10 Minuten und anschließender Zentrifugation (15000 x g, 20 Minuten). Nach dem Trocknen wurde das Pellet in $30 \mu 11 \mathrm{x}$ TE-Puffer aufgenommen.

\subsubsection{Mini-Präparation von Plasmid-DNA}

Nach dem Animpfen von drei ml LB-Medium, welche ein entsprechendes Antibiotikum enthielten, mit einer einzelnen Bakterienkolonie und Inkubation über Nacht ( $\left.37{ }^{\circ} \mathrm{C}, 160 \mathrm{rpm}\right)$ wurden die Bakterien bei 15000 x g geerntet. Die Resuspension des Zellpellets erfolgte in 150 $\mu 1$ P1-Lösung. Anschließend wurden $150 \mu$ P2-Lösung zugegeben und 5 Minuten bei Raumtempertatur inkubiert. Nach dem Zusatz von $150 \mu \mathrm{l}$ P3-Lösung wurde für 20 Minuten zentrifugiert (15000 x g, RT). $400 \mu \mathrm{l}$ des Überstandes wurden abgenommen und die enthaltene Plasmid-DNA durch den Zusatz von 2,5 Vol Ethanol und 1/10 Vol 7M Ammoniumacetat präzipitiert. Nach 30 minutige Inkubation bei $-20^{\circ} \mathrm{C}$, oder 5 min bei $-80{ }^{\circ} \mathrm{C}$ wurde die DNA durch Zentrifugation pelletiert (15000 x g, 20 Minuten). Der Niederschlag 
wurde mit $70 \%$ Ethanol gewaschen, getrocknet und in $1 \times$ TE oder bidestilliertem Wasser aufgenommen.

\subsection{Konzentrations- und Reinheitsbestimmung von DNA}

Fünf $\mu \mathrm{l}$ der $\mathrm{zu}$ messenden DNA-Lösung wurden in $1 \mathrm{ml} \mathrm{H}_{2} \mathrm{O}$ aufgenommen und die Konzentration durch Messung der $\mathrm{OD}_{260}$ im Spektralphotometer (Quarzküvette, Schichtdicke $1 \mathrm{~cm}$ ) bestimmt. Eine $\mathrm{OD}_{260}$ von 1 entspricht bei doppelsträngiger DNA einer Konzentration von $50 \mu \mathrm{g} / \mathrm{ml}$ und bei einzelsträngiger DNA $40 \mu \mathrm{g} / \mu \mathrm{l}$. Aus dieser Beziehung ergibt sich folgende Formel zur Berechnung der Konzentration:

$$
C=E \times(50 \mu \mathrm{g} / \mathrm{ml}) \div F
$$

$\mathrm{C}=$ Konzentration $(\mu \mathrm{g} / \mu \mathrm{l})$

$E=$ Extinktion (gemessene $O_{260}$ nach Referenzabgleich)

$\mathrm{F}=$ eingesetzte DNA-Lösung $(5 \mu \mathrm{l} / \mathrm{ml})$

Ein Maß für die Reinheit der DNA ist der Quotient aus $\mathrm{OD}_{260}$ und $\mathrm{OD}_{280}$, welcher bei allen Proben zusätzlich bestimmt wurde. Für proteinfreie DNA-Lösungen liegt der Wert zwischen 1,8 und 2,0; ein geringerer Wert deutet auf Verunreinigungen hin.

Geringe DNA-Mengen, z.B. PCR-Produkte wurden nach der elektrophoretischen Auftrennung im Agarosegel über ihre Fluoreszenz-Intensität unter UV-Licht durch Vergleich mit einem DNA-Standard (z.B. $\lambda /$ HindIII) bekannter Konzentration quantifiziert (densitometrische Konzentrationsbestimmung 


\subsection{Spaltung von DNA mit Restriktionsenzymen}

Doppelsträngige DNA wird von Restriktionsendonukleasen an sequenzspezifischen Erkennungsstellen geschnitten. Die Restriktion erfolgte unter den vom jeweiligen Lieferanten empfohlenen Temperatur- und Pufferbedingungen. pro $\mu \mathrm{g}$ DNA wurde im allgemeinen mit 1,5 Einheiten des Enzymes für $3 \mathrm{~h}$ inkubiert.

\subsubsection{Partieller Verdau genomischer DNA für Bank-Konstruktion}

Wie im Abschnitt 3.2.2 beschrieben, wurde die isolierte genomische DNA in AgaroseBlöckchen verarbeitet, die dann in 0,5 M EDTA-Lösung bei $4^{\circ} \mathrm{C}$ aufbewahrt wurden. Vor dem partiellen Verdau der genomischen DNA wurde diese in einem Vorlauf durch Pulsfeldgelelektrophorese $5 \mathrm{sec}, 120^{\circ}$ Rotationswinkel, $80 \mathrm{~V}$ bei $11^{\circ} \mathrm{C}$, für $10 \mathrm{~h}$ aufgetrennt wobei die kurzen, durch Scherkräfte entstandenen DNA-Moleküle aus den Blöckchen entfernt werden sollten.

Nach diesem Vorlauf wurden die DNA-Blöckchen wieder aus den Geltaschen herausgelöst und erneut bis zur anschließenden Anwendung in 0,5 M EDTA-Lösung aufbewahrt.

Am Tag der Anwendung wurden die DNA-Blöckchen $3 \mathrm{x}$ in $1 \mathrm{xTE}-\mathrm{Puffer}$ bei $4^{\circ} \mathrm{C}$ je $30 \mathrm{~min}$ und anschließend $1 \mathrm{x}$ in destilliertem Wasser für $10 \mathrm{~min}$ gewaschen, um das enthaltene EDTA, welches die anschließende Restriktionsspaltung hemmen würde, zu entfernen. Für den partiellen Verdau durch die Restriktionsenzyme BamHI oder MboI wurden zunächst die Blöckchen in dem Restriktionspuffer für $1 \mathrm{~h}$ auf Eis inkubiert. Danach erfolgte der Zusatz unterschiedlicher Mengen Enzym: 0,56, 0,5, 0,4, 0,3, 0,1, 0 (Units/ $\mu$ g DNA). Nach einer Inkubation auf Eis für 45 min wurde die Spaltungsreaktion für 30 min bei $37^{\circ} \mathrm{C}$ durchgeführt. Das Abstoppen der Reaktion erfolgte durch Zugabe von 200 mM EDTA.

Die auf diese Art behandelte genomische DNA wurde unter geeigneten Bedingungen mittels Pulsfeldelektrophorese in einem Agarose-Gel aufgetrennt, der Bereich der gewünschten Länge aus dem Gel ausgeschnitten und die gespaltene DNA durch Elektroelution (Methode 3.14.2) aus dem Gel isoliert. Die erhaltene DNA-Lösung diente zur Ligation in den BACVektor. 


\subsection{Gelelektrophorese von Nukleinsäuren}

Nukleinsäuren unterschiedlicher Länge sind aufgrund ihrer Größenunterschiede mittels Elektrophorese trennbar. Dies beruht auf der Tatsache, daß sich gelöste Moleküle in einem elektrischen Feld mit einer Geschwindigkeit bewegen, die vom Ladungs/Masse-Verhältnis der Moleküle abhängig ist.

Die Porengröße der Gele bestimmt die Lauf-Geschwindigkeit der aufzutrennenden Moleküle. Nukleinsäuren mit einem identischen Ladungs/Masse-Quotienten werden in Abhängigkeit von ihrer Kettenlänge getrennt, wobei kürzere Moleküle schneller durch die Gelporen wandern.

Die aufgetrennten Banden wurden mit Ethidiumbromid, welches zwischen den Basen der Nukleinsäuren interkaliert, angefärbt: sie erschienen im UV-Licht weiß fluoreszierend. Bei Agarosegelen wurde das Ethidiumbromid zumeist vor dem Gießen zugefügt $(0,1 \mu \mathrm{g} / \mathrm{ml})$, es war auch möglich, das Gel nach der Elektrophorese in einem Ethidiumbromidbad (500 $\mu \mathrm{g} / 500 \mathrm{ml}$ bidest. Wasser) zu färben.

Die Dokumentation der gefärbten Gele erfolgte auf den UV-Transilluminator mit einer Polaroidkamera.

\subsection{Agarose Gelelektrophorese}

\subsubsection{Auftrennung von DNA}

Die Auftrennung von DNA erfolgte in unterschiedlichen horizontalen Systemen, welche sich in der Gelgröße und somit in der Auftrennlänge unterschieden. Zur Auftrennung von PACDNA und genomische DNA dienten Gele der Größe 20 × 25 cm inTris-Phosphat-Puffer. PCR-Produkte, Plasmid-Restriktionsspaltungen und für präparative Zwecke wurden Gele der Größe 10 × $10 \mathrm{~cm}$ und 7 x $10 \mathrm{~cm}$ sowie TBE-Puffer eingesetzt. Die angelegte Spannung betrug je nach Bedarf 30 bis 120 Volt, Elektrophoresen genomischer Spaltungen liefen bei 30 bis 40 Volt über Nacht. Vor dem Gelauftrag wurden die Proben mit 1/6 des Volumens Auftrag-Puffer versetzt. 
Als Längenstandard dienten drei verschiedene Marker: 1 kb Leiter (MBI Fermentas), 100 bp Leiter (MBI Fermentas) und HindIII-geschnittene $\lambda$-DNA.

\subsection{Transfer von DNA aus Agarosegelen (Southernblot)}

Die Übertragung der mit Restriktionsenzymen gespaltenen und auf einem Agarosegel aufgetrennten DNA, auf einen Nitrocellulosefilter geschieht in einem Kapillarblot: mittels kapillarer Saugspannung wird aus einem unter dem Gel befindlichen Vorratsgefäß 20 x SSC nach oben durch das Gel und die darauf liegende Membran in die Blottingpapiere, auf denen zusätzlich noch ein Papierhandtuchstapel ruht, gezogen. Bei diesem Vorgang bleiben die Nukleinsäuren auf der Nitrocellulose-Membran hängen und können dort fixiert werden (Southern, 1975).

Konkret wurden die Gele nach der Elektrophorese passend geschnitten, die Längenstandards markiert und das Gel photographiert. Die DNA wurde depuriniert während das Gel für 20 Minuten in $250 \mathrm{mM} \mathrm{HCl}$ inkubierte. Diesem Schritt folgte die Denaturierung in Alkalisierungslösung (25 Minuten) und abschließend die Neutralisierung in Neutralisierungslösung ( 30 Minuten und länger). Über das Transferpuffergefäß wurde eine Glasplatte so gelegt, das ein darauf ruhendes, mit 20 x SSC befeuchtetes Blottingpapier beiderseits einheitlich in das Reservoir eintauchte und so eine Brücke bildete. Das Gel wurde aus dem Neutralisierungspuffer luftblasenfrei auf das Papier gelegt und die nicht abgedeckten Bereiche der Brücke mit Haushaltsfolie isoliert, so daß der Kapillarsog nur durch das Gel erfolgen konnte, welches nacheinander mit einer in bidest. Wasser getränkten NitrocelluloseMembran und drei feuchten Blottingpapieren luftblasenfrei bedeckt wurde. Zur Erhöhung der Kapillarkraft wurden zwei Stapel Papierhandtücher zuoberst gelegt und mit $500 \mathrm{~g}$ beschwert. Die Dauer des Transfers betrug mindestens 12 Stunden. Nach dem Transfer wurden der Längenstandard sowie die Lage der Geltaschen markiert. Verbleibende Agarosereste entfernte eine kurze Spülung der Nitrocellulose-Membran in 2 x SSC, die im Anschluß luftgetrocknet sodann bei $80^{\circ} \mathrm{C}$ im Vakuumofen gebacken wurde. 


\subsection{Radioaktive DNA-Markierung mittels Random-priming Reaktion}

In dieser Methode finden Nonamernukleotid-Zufallssequenzen Anwendung, welche an verschiedenen Stellen der denaturierten template-DNA anlagern und somit die DNA-Synthese initiieren können. Der entstandene Primer-template-Komplex bildet das Substrat des KlenowFragmentes der DNA-Polymerase I. Die Markierung der neusynthetisierten DNA geschieht durch den Einbau eines radioaktiv markierten Nukleotid-Äquivalentes, welches sich zu einem bestimmten Prozentsatz im Ansatz befindet (Feinberg und Vogelstein, 1983).

Der verwendete Kit enthielt die benötigten Puffer und Lösungen. Für die Reaktions werden 25-50 ng template-DNA in $30 \mu 1$ bidest. Wasser und $5 \mu 1$ Primer-Lösung angesetzt. Nach der Denaturierung $\left(95^{\circ} \mathrm{C}, 5\right.$ Minuten), kurzem Anzentrifugieren und Abkühlen auf Eis wurden 10 $\mu 1$ Labelling-Puffer, $3 \mu \mathrm{l}$ (entspricht $30 \mu \mathrm{Ci}$ ) $\left[\gamma^{32} \mathrm{P}\right]$-dCTP und $2 \mu \mathrm{l}$ Klenow-Polymerase zugegeben. Die DNA-Synthese erfolgte durch Inkubation bei $37^{\circ} \mathrm{C}$ für 15 bis 30 Minuten. Durch den Zusatz von $5 \mu$ 1 0,2 M EDTA pH 8,0 wurde die Reaktion abgebrochen. Die radioaktiv markierte Sonde wurde vor dem Gebrauch denaturiert (5 Minuten, $100^{\circ} \mathrm{C}$ ).

\subsection{Radioaktive Endmarkierung synthetischer Oligonukleotiden durch $\left[\gamma^{32} \mathbf{P}\right] \mathbf{d A T P}$}

Die Endmarkierung eines synthetischen Oligonukleotids am 5'-Ende erfolgte durch das Enzym T4-Polynukleotid-Kinase. Das 5'-Ende des Oligonukleotids wurde mit der radioaktiv markierte Phosphatgruppe des $\left[\gamma^{32} \mathrm{P}\right] \mathrm{dATP}$ phosphoryliert.

Reaktionsansatz:

Oligonukleotid

10x Polynukleotid-Kinase-Puffer:

$\left[\gamma^{32} \mathrm{P}\right] \mathrm{dATP}$

T4-Polynukleotid-Kinase

Bidestiliertes Wasser:
$25-50 \mathrm{ng}$

1/10 Volumen

$50 \mu \mathrm{Ci}$

$10 \mathrm{U}$

ad $20 \mu \mathrm{l}$ 
Der Ansatz wurde für $1 \mathrm{~h}$ bei $37{ }^{\circ} \mathrm{C}$ inkubiert. Vor dem Gebrauch wurde das radoaktiv markierte Oligonukleotid für 5 min bei $100^{\circ} \mathrm{C}$ denaturiert.

\subsection{Hybridisierung der Southernblots}

Die unter dem Punkt 3.7 erstellten Filter inkubierten vor der Hybridisierung in 2 x SSC. Die feuchte Membran wurde, mit der Nukleinsäureseite nach innen orientiert, luftblasenfrei in einen Hybridisierungsroller überführt und dort mit $10 \mathrm{ml} 65^{\circ} \mathrm{C}$ warmer Hybridisierungslösung und $500 \mu \mathrm{l}$ denaturierter Heringsspermien-DNA versetzt. Die Prähybridisierungzeit im Rollerschrank betrug mindestens drei Stunden bei $55-65^{\circ} \mathrm{C}$ und $10 \mathrm{rpm}$. Die unter 3.8 vorbereitete, radioaktiv markierte Probe wurde nach der Denaturierung zugesetzt. Die Hybridisierung vollzog sich über Nacht (mindestens 10 Stunden) unter den selben Bedingungen wie die Prähybridisierung. Nach der Hybridisierung wurde der radioaktive Hybridisierungspuffer ausgegossen, die Membran in $2 \times$ SSC mit $0,1 \%$ SDS bei Hybridisierungstemperatur im Schüttelbad gewaschen. Dieser Waschschritt wurde zwei bis dreimal wiederholt bis im Waschpuffer keine Aktivität nachweisbar war. Eine Erhöhung der Stringenz war durch abnehmende Salzkonzentration im Waschpuffer bis auf 0,1 x SSC oder Erhöhung der Waschtemperatur möglich. Die feuchte Membran wurde in Haushaltsfolie eingeschlagen und autoradiographiert.

Dehybridisierung der Southernblots erfolgte in 0,1\%ige SDS-Lösung, welche aufgekocht und auf die Blots gegeben wurde. Inkubation wurde im Schüttelbad bei 60 bis $70{ }^{\circ} \mathrm{C}$ und der Vorgang wurde wiederholt bis keine Radioaktivität mehr auf dem Blot mit dem Handmonitor zu messen war.

\subsection{Autoradiographie}

Die im vorhergehenden Schritt in Haushaltsfolie eingeschlagenen Membrane wurden, in der Dunkelkammer unter Rotlicht in eine Autoradiographiekassette mit zwei Verstärkerfolien gelegt und mit einem Röntgenfilm bedeckt. In Abhängigkeit von der Strahlungsintensität exponierte die Probe für einige Stunden bis zu zwei Wochen bei $-70^{\circ} \mathrm{C}$. Die Filme wurden zur Entwicklung bis zur erkennbaren Schwärzung des Röntgenfilmes in Entwickler getaucht und 
sodann fixiert. Im Anschluß wurde der Film im fließenden Leitungswasser gespült und getrocknet.

\subsection{Bakterien-Kolonie-Screening erstellter Subbanken}

Von einigen PAC-Klonen, an denen besonderes Interesse bestand, wurden durch Subklonierung der BamHI-Restriktionsfragmente kleine Subbanken erstellt. Die Suche nach bestimmten Subklonen wurde auf der Basis des Bakterien-Kolonie-screenings durchgeführt. Die Bakterien-Suspension wurde auf mehrere Platten (welche das benötigte Antibiotikum enthielten) ausplattiert. wobei der Titer so gewählt wurde, das ca. 2000 Kolonien pro Platte wachsen sollten. Die Kolonie-tragenden Platten wurden erst für mindestens $1 \mathrm{~h}$ bei $4{ }^{\circ} \mathrm{C}$ abgekühlt, anschließend luftblasenfrei für $1 \mathrm{~min}$ mit einem sterilen runden Nitrocellulosefilter von ca. $8 \mathrm{~cm}$ Durchmesser bedeckt und Filter sowie Platte asymmetrisch markiert. Ein zweiter Filter (Replica-Filter), der zur Überprüfung der positiven Signale eingesetzt wurde, inkubierte für 2 min auf der Bakterienplatte. Die Filter wurden vorsichtig abgenommen und mit der Abdruck-Seite nach oben luftgetrocknet. Die Platten wurden sodann für $5-7 \mathrm{~h}$ bei $37{ }^{\circ} \mathrm{C}$ inkubiert um das Nachwachsen der Bakterien-Kolonien zu beschleunigen.

Die erhaltenen Filter wurden zunächst, mit der Bakterienseite nach oben, für 3 min auf 10\% SDS-getränktem Whatman-Papier inkubiert. Diese Behandlung reduzierte die Diffussion der Plasmid-DNA während der folgenden Denaturierung und Neutralisierung und resultierte in einem schärferen Hybridisierungs-Signal. Anschließend wurden die Filter für $5 \mathrm{~min}$ auf denaturierungslösungsgetränktes Whatman-Papier und dann nochmals 5 min auf neutralisierungslösungsgetränktes Whatman-Papier gelegt Zuletzt wurden die Nitrocellulosefilter 5 min in 2 x SSC gewaschen, wobei noch vorhandene Bakterien-Reste mit weichem Papier von dem Filter abgewischtwurden, da diese bei der Hybridisierung einen starken Hintergrund ergeben könnten. Die Hybridisierung der Filter zur Identifizierung der gesuchten positiven Klone wurde wie unter 3.10 und 3.11 beschrieben durchgeführt. Die Signale auf dem Röntgenfilm, die sich während der Hybridisierung ergaben, wurden anhand der asymetrischen Markierung der Platte und des Filters der positiven Kolonie zugeordnet. Derart als positiv identifizierte Klone wurden von der Platte gepickt und zur Gewinnung weiteren Materials in LB-Medium mit dem entsprechendem Antibiotikum hochgezogen. 


\subsection{Erstellung von DNA dot blots}

Durch das Screening der genomischen Bank mit einer bestimmten Hybridisierungsprobe wurden positive Klone erhalten. Um ein schnelles Vorscreening dieser Klone zu ermöglichen, vor der Durchführung der aufwendigeren Southern-Blotanalyse wurden DNA dot blots erstellt.

Dazu wurden Nitrocellulosestreifen ausgeschnitten und entsprechend beschriftet und im Anschluß in separat markierten Kästchen 1-2 $\mu$ l (ca. 30-50 ng) DNA aus einer low copyPlasmid-Präparation aufgetropft. Nach dem Trocknen der Nitrocellulose wurden die Filter wie unter 3.12 beschrieben behandelt.

\subsection{Isolierung von DNA-Fragmenten aus Gelen}

\subsubsection{Isolierung von DNA-Fragmenten aus Agarosegelen mittels JETQUICK spin columns}

Im UV-Durchlicht wurde die zu isolierende Bande mit einem sauberen Skalpell möglichst knapp ausgeschnitten und in einem E-cup ausgewogen. Die Isolierung der DNA aus dem Agarose-Stück wurde nach dem empfohlenen Protokoll durchgeführt. Hierzu wurde die Agarose durch den Zusatz von $3 \mathrm{Vol}$ (w/v) L1-Puffer und Inkubation bei $50{ }^{\circ} \mathrm{C}$ (ca. $15 \mathrm{~min}$ ) aufgelöst und auf eine Extraktionssäule gegeben. Nach der Abzentrifugation des Durchlaufs (1 min, $14000 \mathrm{~g}$ ) wurde die Säule mit 0,7 ml L2-Puffer gefüllt, 5 Minuten bei Raumtemperatur inkubiert und zentrifugiert (1 min, 14000 g). Nach dem Verwerfen des Durchflaufes folgte eine erneute Zentrifugation (1 min, $14000 \mathrm{~g})$ um den ethanolhaltigen Waschpuffer vollständig zu entfernen. Die DNA eluierte durch den Auftrag von $30 \mu 1$ BidestWasser, das vor der abschließenden Zentrifugation (2 min, $14000 \mathrm{~g}$ ) eine Minute auf der Säule stand. Die Ausbeute konnte durch die Verwendung von bidest. Wasser, welches auf 65$70^{\circ} \mathrm{C}$ erhitzt war, gesteigert werden. 


\subsubsection{Isolierung von DNA-Fragmenten aus Agarosegelen durch Elektroelution}

Die gewünschte DNA Bande wurde aus dem Gel mit einem Skalpell ausgeschnitten und in einen, an einem Ende mit einer Klammer abgedichteten Dialyseschlauch eingeführt und darin mit 1 bis $2 \mathrm{ml}$ TE-Puffer versetzt, worauf der Schlauch mit einer zweiten Klammer vorsichtig luftblasenfrei verschlossen wurde. Er wurde in eine mit TBE-Puffer gefüllte ElektrophoreseKammer gelegt; durch die angelegte Spannung wurden die DANN-Moleküle aus dem Agarosestück eluiert. Nach ca. 2stündigem Lauf wurde der TBE-Puffer, welcher nun die DNA enthielt, vorsichtig dem Schlauch entommen.

\subsection{Dephosphorylierung freier 5'-Enden}

Die Phosphatgruppe an dem 5'-Ende linearisierter dsDNA kann durch das Enzym alkalische Phosphatase entfernt werden. Linearisierte Plasmide werden so zur Erhöhung der Effizienz anschließender Ligationen dephosphoryliert, da dadurch das Religieren des Vektors ohne Aufnahme des zu inserierenden DNA-Fragmentes vermieden werden kann.

Der linearisierte Vektor wurde mit 2,5 Volumen 99\% Ethanol gefällt, mit 70\% Ethanol gewaschen, und das getrocknete Pellet wurde in $1 \mathrm{x}$ TE aufgenommen. $2 \mathrm{U}$ alkalische Phosphatase und 1/10 Volumen Reaktionspuffer wurden dazu pipettiert und der Ansatz bei $37^{\circ} \mathrm{C}$ für 30 min inkubiert. Nach der Dephosphorylierungsreaktion wurde der Ansatz in ein präparatives Agarosegel geladen, nach dem Lauf die DNA-Bande, die der Länge des linearisierten Vektors entsprach, ausgeschnitten und nach einer der erwähnten Gelextraktionsmethoden aus dem Gel eluiert.

\subsection{Ligation von DNA Enden}

Die aus dem Agarosegel eluierten DNA-Fragmente wurden in den BAC-Vektor ligiert. Die zu klonierenden Fragmente wurden in einem drei- bis fünffachen molaren Überschuß zum Vektorfragment gegeben. Zur Ligationsreaktion wurden 1 U T4-DNA Ligase und 
Reaktionspuffer hinzugefügt. Die Reaktion wurde in einem Gesamtvolumen von $20 \mu 1$ bei $14^{\circ} \mathrm{C}$ über Nacht durchgeführt.

Bei dem Ligationsansatz zur Bank-Konstruktion wurden Vektor und Insert in einem molaren Verhältis von 10:1 eingesetzt. Es wurden generell Ansätze mit verschiedenen Mengen an eingesetzter DNA hergestellt, um die benötigte Konzentration Insert-DNA für optimale Ligationsergebnisse zu bestimmen. Zusätzlich wurde dem Ligationsansatz 1/60 Volumen $10 \mathrm{x}$ PA-Lösung (Mischung aus Spermin und Spermidin) zugegeben. Das Gesamtvolumen variierte zwischen 50 und $120 \mu$. Die Ligationsreaktion wurde bei $16^{\circ} \mathrm{C}$ über Nacht durchgeführt. Es folgte eine Mikrodialyse des Ligationsansatzes in 0,5 x TE, 1 x PA für $2 \mathrm{~h}$ bei Zimmertemperatur. Anschließend folgte eine Elektroporation des dialysierten Ligationsansatztes in den E.coli-Stamm DH10B.

\subsection{Nukleotidsequenzanalyse doppelsträngiger DNA}

Nukleotidsequenzanalysen wurden nach der Kettenabbruchmethode (Sanger et al., 1977) durchgeführt. Die hier verwendete Methode war die Cycle-Sequenzierung, eine Variante der enzymatischen Sanger-Sequenzierung, bei der eine hitzestabile Polymerase verwendet wurde, um das eingesetzte DNA-Template in wiederholten Zyklen von Denaturierung, Primerannealing und Elongation mehrfach zu nutzen.

Die Sequenzierung doppelsträngiger DNA wurde mit dem BigDye ${ }^{\mathrm{TM}}$ Terminator Cycle Sequenzing Ready Reaction Kit durchgeführt und zur Analyse der Genetic Analyser der Firma PE Applied Biosystems, Modell 310 eingesetzt. Das Sequenzierungs-Kit enthielt außer den mit verschiedenartigen Fluoreszenzfarbstoffen markierten ddNTPs auch dNTPs, $\mathrm{MgCl}_{2}$ sowie ein AmpliTaq DNA Polymerase/thermostabile Pyrophosphatase-Gemisch. Die am Ende der Reaktion vorliegenden DNA-Stränge waren am 3‘-Ende basenspezifisch Farbstoffmarkiert und wurden im genetic Analyser in einer Glaskapillare aufgetrennt. Die durch Laserstrahlung angeregten Fluoreszenzfarbstoffe emittierten Licht einer für jeden Farbstoff spezifischen Wellenlänge welche vom Gerät detektiert und ausgewertet wurde.

Für eine Sequenzierung wurden 0,5 bis 1,0 $\mu \mathrm{g}$ DNA, 5 pmol Primer, 4 bis $8 \mu 1$ TerminationsMix mit bidest. Wasser auf ein Gesamtvolumen von $20 \mu 1$ aufgefüllt und in eienm PCR-Gefäß pipettiert mit Paraffinöl überschichtet. Die Reaktion fand nach dem im folgenden aufgeführten Programm statt: Denaturierung bei $96^{\circ} \mathrm{C}$ für $30 \mathrm{sec}$, Annealing bei $50{ }^{\circ} \mathrm{C}$ für 15 
Sekunden, Elongation bei $60{ }^{\circ} \mathrm{C}$ für vier Minuten bei einer Zyklenzahl von 24. Bei Sequenzierung von Plasmid DNA wurde der erste Denaturierungsschritt auf 3 bis 5 min verlängert. Die DNA wurde aus der fertigen Reaktion mit 1/10 Volumen 3 M Natriumacetat $\mathrm{pH} 4,8$ und 2,5 Volumen 100\% Ethanol gewaschen, getrocknet und in $25 \mu 1$ Template Suppression Reagent (TSR) oder $13 \mu$ l Formamid aufgenommen. Nach einer Denaturierung (5 Minuten, $95{ }^{\circ} \mathrm{C}$ ) und schnellen Abkühlung auf Eis konnten die Proben in speziellen Gefäßen überführt und auf den ABI 310 Genetic Analyser geladen werden.

\subsection{End-Sequenzierung der PAC-Klone durch inverse PCR}

Die Bestimmung der End-Sequenz des inserierten Fragments eines PAC-Klones wurde zur Erstellung von walking-Proben benötigt, welche die vollständigen Kartierung lückenhafter Regionen ermöglichten. Ca. 150 ng einer Mini-DNA-Präparation des PAC-Klones wurden mit dem Enzym PstI gespalten. Der Klonierungs-Vektor enthielt 5 Pst I Schnittstellen, deren genaue Position der Abbildung $6 \mathrm{zu}$ entnehmen ist. Da die PstI-Schnittstelle im eukaryotischen Genom häufig vorkommt wird auch die inserierte DNA mehrfach gespalten. Durch diese Restriktionsspaltung entsteht also eine große Zahl an PstI-Fragmenten. Diese sind entweder nur Vektor-Fragmente oder Fragmente, die aus der Insert-DNA hervorgegangen sind oder gemischte Fragmente, die einen kleinen Teil des Vektors mit den jeweiligen Ende der inserierten DNA. An den flankierenden PstI-Fragmenten des Vektors (Abb. 6) wurden folgende Primer-Paare definiert: Das Primer-Paar pPAC4-3, pPAC4-4 (auf der Abbildung mit 3,4 abgekürzt) sowie das Primer-Paar pPAC4-5, pPAC4-6 (mit 5,6 abgekürzt). Für die Religation über Nacht die in einem Gesamtvolumen von $40 \mu 1$ stattfand, wurde der gesamte Spaltungsansatz $(10 \mu \mathrm{l})$ verwendet. Nach Ablauf dieser Reaktion wurde mit jeweils $5 \mu 1$ des Religationsansatzes eine PCR durchgeführt, in welcher entweder das Primer-Paar 3, 4 oder das Primer-Paar 5, 6 eingesetzt wurde. Die Elongationszeit betrug 4 min. Die Ansätze wurden auf ein Gel aufgetragen und ein evtl. enstandenes PCR-Produkt aus diesem extrahiert und zur Sequenzierung eingesetzt. 

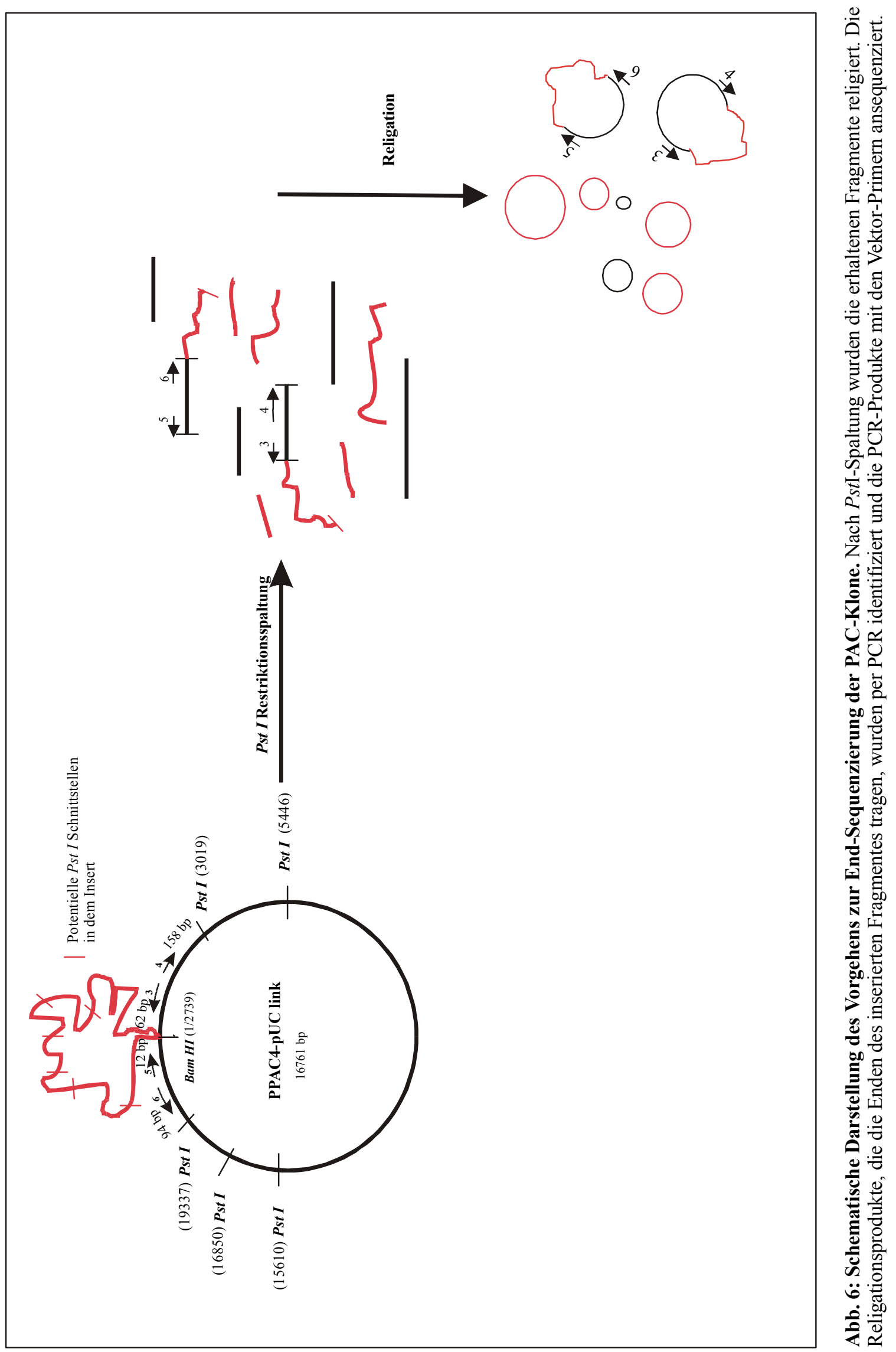


\subsection{Reverse Transkription (RT)}

Als reverse Transkription wird die enzymatische Synthese von cDNA mit RNA als template bezeichnet. Angewandt wurde die „oligo (dT)-primed“ reverse Transkription mit einem Oligo(dT)-Primer, welcher sich Poly $(\mathrm{A})^{+-}$mRNA anlagert und deren reversen Transkribtion ermöglicht.

Für einen Reaktionsansatz der „oligo(dT)-primed“ reversen Transkription wurden $5 \mu \mathrm{g}$ totale RNA, $10 \mu 15$ x Erststrangpuffer (im Kit enthalten), 25 pmol Oligo(dT)-Primer, $1 \mu 110 \mathrm{mM}$ dNTP, 10 U RNasin (inhibiert RNasen) mit bidest. Wasser auf ein Gesamtvolumen von $50 \mu 1$ aufgefüllt und vor der Zugabe von 200 U MMLV Reverser Transkriptase zur Denaturierung der RNA-Sekundärstrukturen und zur Ausbildung des Primer/template-Komplexes fünf Minuten im Wasserbad bei $65^{\circ} \mathrm{C}$ inkubiert und im Eisbad abgekühlt. Die reverse Transkription erfolgte bei $37^{\circ} \mathrm{C}$ im Verlauf von 2 Stunden. Anschließend wurde die reverse Transkriptase durch 5minütige Inkubation bei $70^{\circ} \mathrm{C}$ hitzeinaktiviert. $2 \mu 1$ dieses Reaktionsansatzes wurden nachfolgend in einer PCR (Vol $50 \mu \mathrm{l})$ eingesetzt.

\subsection{Polymerasekettenreaktion (PCR)}

Die Polymerase-Kettenreaktion ermöglicht die in vitro-Amplifikation von DNA-Sequenzen. Die Amplifikation der DNA vollzieht sich in mehreren Reaktionszyklen, welche aus drei Schritten bestehen. Im ersten werden die DNA-Doppelstränge durch Erhitzen voneinander getrennt (Denaturierung). Anschließend erfolgt die Abkühlung auf eine Temperatur von $50{ }^{\circ} \mathrm{C}$ bis $65^{\circ} \mathrm{C}$, bei der sich die den $5^{\prime}$ - und 3'- Enden der cDNA komplementären Oligonukleotide spezifisch ihrer Zielsequenz anlagern (Annealing). Im dritten Schritt erfolgt die Verlängerung der hybridisierten Primer durch eine thermostabile DNA-Polymerase bei $72^{\circ} \mathrm{C}$ (Elongation).

Die Annealing-Temperatur von Primern, deren Länge $17-25$ bp beträgt, ergibt sich aus der Schmeztemperatur, die anhand folgender Formel berechnet wird:

$$
\mathrm{T}_{\mathrm{m}}=(\mathrm{C}+\mathrm{G}) \times 4+(\mathrm{A}+\mathrm{T}) \times 2
$$


Die Elongationszeit ist von der Länge der zu amplifizierenden DNA abhängig und beträgt zumeist eine Minute pro $1000 \mathrm{bp}$.

Die Reaktion wurde im allgemeinen mit 50 - 500 ng der zu amplifizierenden DNA und jeweils 25 pmol an PCR-Primern, $1 \mu 1$ dNTP-Mix (10 mM), $5 \mu 1$ Taq-Polymerasepuffer, und $1 \mathrm{U}$ Taq-DNA-Polymerase in einem Volumen von $50 \mu 1$ durchgeführt. Der Ansatz wurde mit Paraffinöl überschichtet, um Verdunstung zu vermeiden. Die PCR-Produkte wurden zur Reinigung einer Gelelektrophorese mit sich anschließender DNA-Präparation unterzogen.

\subsection{3'RACE (rapid amplification of cDNA ends)}

Die 3'RACE dient der Generierung von cDNA mittels reverser Transkription, die Amplifikation spezifischer Bereiche erfolgt in den sich anschließenden PCR-Reaktionen. Es können Sektionen amplifiziert werden, die sich zwischen einem bekannten Abschnitt einer mRNA und derem 3'Ende befinden. Die Transkription durch die reverse Transkriptase erfolgt nach dem Annealing eines Oligo(dT)-Adaptor-Primers. In der darauf folgenden PCR verwendet wird ein Adaptor-Primer und ein spezifischer Primer (seminested PCR) verwendet. Zur Erhöhung der Spezifität wird in einer zweiten Amplifikation ein dem 3'-Ende näher gelegener (nested), spezifischer Primer und ebenfalls der Adaptor-Primer verwendet (Frohman et al., 1988).

Die reverse Transkription wurde wie unter 3.19 beschrieben durchgeführt. Dieser cDNA wurden $2 \mu 1$ entommen und in die erste PCR der 3'RACE eingesetzt, die außerdem $5 \mu 110 \mathrm{x}$ PCR-Puffer inclusiv $\mathrm{MgCl}_{2}, 1 \mu 10 \mathrm{mM}$ dNTP, 25 pmol Adaptor-Primer, 25 pmol des spezifischen Primers, 1 U Taq-DNA-Polymerase in einem Gesamtvolumen von $50 \mu 1$ enthielt. Der Reaktionsansatz wurde auf Eis angesetzt, mit Paraffinöl überschichtet und im Thermocycler unter spezifischen Bedingungen inkubiert. $2 \mu 1$ des ersten PCR-Produkt dienten als template in einer zweiten PCR, die sich nur in der Verwendung des nested gelegenen Primer von der ersten unterschied. 


\subsection{Long range-PCR}

Das „Expand ${ }^{\mathrm{TM}}$ Long Template“-PCR-System, das einen Enzym-Mix enthält, der sich aus den thermostabilern DNA-Polymerasen Taq und Pwo zusammensetzt, wird zur Herstellung sehr langer Amplifikate eingesetzt. Das System ist mit drei verschiedenen Puffersystemen erhältlich, die in Abhängigkeit von der zu amplifizierenden Länge angewandt werden. Zur Amplifikation genomischer Sequenzen an PAC-Klonen, der Größenordnung nicht abschätzbar war, wurde das Puffersystem 3, mit dem die Generierung von $15 \mathrm{~kb}$ messenden PCR-Produkten gelingt, verwendet.

Der PCR-Ansatz wurde zunächst als Pool $1+2$ in getrennten PCR-Gefäßen auf Eis angesetzt. Poo 1 enthielt 2,5 $\mu 110$ mM dNTP, 25 pmol 3'-Primer, 25 pmol 5'-Primer sowie 10 ng PACDNA in einem Gesamtvolumen von $25 \mu 1$. Pool 2 bestand aus $5 \mu 1$ Puffer 3 und $0,75 \mu 1$ Enzym-Mix und in einem Gesamtvolumen von $25 \mu 1$. Die vereinigten und gut durchmischten Pools wurden mit Paraffinöl überschichtet und sofort dem folgenden PCR-Protokoll unterworfen:

$\begin{array}{llll}\text { Anzahl } & \text { Zeit } & \text { Temperatur } & \text { Schritt } \\ 1 \mathrm{x} & 2 \mathrm{~min} & 94^{\circ} \mathrm{C} & \text { Denaturierung } \\ 10 \mathrm{x} & 10 \mathrm{sec} & 94^{\circ} \mathrm{C} & \text { Denaturierung } \\ & 30 \mathrm{sec} & 65^{\circ} \mathrm{C} & \text { Annealing } \\ & 8 \mathrm{~min} & 68^{\circ} \mathrm{C} & \text { Elongation } \\ & 10 \mathrm{sec} & 94^{\circ} \mathrm{C} & \text { Denaturierung } \\ & 30 \mathrm{sec} & 65^{\circ} \mathrm{C} & \text { Annealing } \\ & 8 \mathrm{~min} & 68^{\circ} \mathrm{C} & \text { Elongation } \\ & +20 \mathrm{sec} \text { Verlängerung pro Zyklus } & & \\ & 7 \mathrm{x} & 68^{\circ} \mathrm{C} & \text { Elongation }\end{array}$

\subsection{Klonierung von PCR-Produkten}

Der TA-Cloning® Kit erlaubt die schnelle 1-Schritt-Klonierung von PCR-Produkten in einen Plasmid-Vektor. Diese Methode nutzt den Effekt, daß die Taq-DNA-Polymerase einzelne 
Desoxyadenosine an die 3'-Enden der entstandenen PCR-Produkte anhängt. Der im Kit enthaltene linearisierte Vektor pCR2.1 weist an den 3'-Enden einzelne Desoxythymidin-Reste auf, welche eine effiziente Ligation des Inserts gestatten.

Der Ligationsansatz setzte sich aus $2 \mu$ frisch hergestelltem PCR-Produkt, $1 \mu 110 \mathrm{x}$ Ligationspuffer, $2 \mu 1$ pCR2.1 Vektor (50 ng), $1 \mu 1$ T4-DNA-Ligase (4 Weiss Units) und bidest. Wasser mit einem Gesamtvolumen von $10 \mu 1$ zusammen und wurde über Nacht bei $14^{\circ} \mathrm{C}$ im Wasserbad inkubiert Die im Kit enthaltenen kompetenten Zellen wurden zur Transformation genutzt, indem sie auf Eis aufgetaut, mit $2 \mu 1 \beta$-Mercaptoethanol und $2 \mu 1$ Ligationsansatz versetzt und für 30 Minuten auf Eis inkubiert wurden. Nach dem Hitzeschock $\left(42^{\circ} \mathrm{C}, 30\right.$ Sekunden). und 2minütiger Inkubation auf Eis wurden die Zellen mit $450 \mu 1$ SOCMedium versetzt. Die sich anschließende Inkubation für eine Stunde bei $37^{\circ} \mathrm{C}$ und $75 \mathrm{rpm}$ diente der Expression der Plasmid-kodierten Antibiotikaresistenz.. Es wurden jeweils pro Transformationsansatz 100 und $400 \mu$ lauf selektive Platten ausgestrichen. Die Insertion in die multi cloning site zerstört das Leseraster der $\beta$-Galaktosidase, die ein blau/weiß-assay ermöglichte. Dieses Enzym setzt das in den Platten enthaltene X-Gal, welches farblos ist, in einen blauen Farbstoff um: eine erfolgte Insertion gibt sich demnach durch eine farblose Kolonie zu erkennen.

\subsection{Screening einer PAC-Bank}

Die im Abschnitt 2.15 beschriebene, vom Ressourcen Zentrum des Deutschen Humangenomprojekt (RZPD) zur Verfüng gestellte Ratten-PAC-Bank wurde mit mehreren spezifischen Proben gescreent.

Die Nylon-Membranen wurden, wie in Kapitel 3.10 beschrieben, unter Verwendung eines speziellen Hybridisierungspuffer bei $65^{\circ} \mathrm{C}$ hybridisiert. Im Anschluß an die Hybridisierung wurde der Filter in $40 \mathrm{mM}$ Natriumphosphatpuffer $\mathrm{pH}$ 7,2, welcher 0,1\% SDS enthielt, zweimal bei $65^{\circ} \mathrm{C}$ für jeweils 30 Minuten gewaschen. Die Filter wurden in Haushaltsfolie eingewickelt und eine Autoradiographie (Kapitel 3.11) über 24 h durchgeführt. 
Die Klone waren als Duplikate auf dem Filter aufgetragen, so das die Auswertung der Filter folgendermasen geschah:. Zunächst wurden die $\mathrm{x}-\mathrm{y}$-Koordinaten jedes Blocks mit positiven Signalen lokalisiert, sodann wurde gemäß eines vom RZPD mitgelieferten Schemas die Position des positiven Signals innerhalb des Blocks bestimmt, wobei nur bestimmte Hybridisierungsmuster auftreten konnten. Die exakte Position der positiven Klone innerhalb des Blocks wurde nach der folgenden Formel berechnet:'

$$
\begin{aligned}
& x=5(X-1)+x^{\prime} \\
& y=5(Y-1)+y^{\prime}
\end{aligned}
$$

$5=5 \times 5$ Block

$\mathrm{X}, \mathrm{Y}=$ Koordinaten des Blocks auf dem Filter

$\mathrm{x}^{\prime}, \mathrm{y}^{\prime}=$ Koordinaten von jedem Klon innerhalb des Blocks

$\mathrm{x}, \mathrm{y}=$ Endkoordinaten des Klons

Die Koordinaten wurden dann dem RZPD übermittelt, das die positiven Klone zuschickte.

\subsection{Herstellung elektrokompetenter Bakterienzellen}

Elektrokompetente Zellen des Stammes DH10B wurden zum einem für die Generierung einer genomischen Bank der Ratte hergestellt, sie dienten aber auch für alle weiteren Transformationen. Sechs $500 \mathrm{ml}$ Flaschen sowie eine 11 Flasche wurden mit bidest. Wasser autoklaviert, wonach das Wasser vollständig ausgegossen wurde. Diese Vorbehandlung diente dem Entfernen von Ionen, welche möglicherweise an den Wänden der Glasgefäße hafteten. In die 500-ml-Flaschen wurden jeweils $100 \mathrm{ml}$ SOB-Medium ohne $\mathrm{Mg}^{2+}$ gegeben, in der 11 Flasche wurde 10\% Glycerin angesetzt und anschließend autoklaviert. In einem 50-mlFalconröhrchen, welches $5 \mathrm{ml}$ LB-Medium ohne Antibiotikumenthielt, wurde eine Vorkultur der DH10B-Bakterien angeimpft und über Nacht bei $37^{\circ} \mathrm{C}$ und $160 \mathrm{rpm}$ geschüttelt. Aus dieser Vorkultur wurden am nächsten Morgen die vorbereiteten Medien mit jeweils $100 \mu 1$ (1:1000 Verdünnung) angeimpft. Nach 3 bis $4 \mathrm{~h}$ Wachstum bei $37^{\circ} \mathrm{C}$ wurde die OD bei 550 $\mathrm{nm}$ bestimmt und das Wachstum überwacht, bis die optische Dichte in jeder einzelnen Kultur 
eine von $\mathrm{OD}_{550}$ von 0,7 bis 0,75 erreicht hatte. Auf keinen Fall durfte die $\mathrm{OD}_{550}>0,8$ sein. Nach dem Erreichen der gewünschten optischen Dichte wurden die Zellen auf Eis gestellt und im folgenden ausschließlich auf Eiswasser gearbeitet. Nach dem Verteilen der Kulturen auf 50-ml-Falcon Röhrchen folgte die Ernte der Zellen durch Zentrifugation bei $4000 \mathrm{rpm}, 4^{\circ} \mathrm{C}$ für 10 min. Nach dem Abgiessen des Überstandes wurde in jedes Röhrchen $1 \mathrm{ml}$ der 10\%Glycerinlösung gegeben, darin das Pellet resuspendiert und anschließend jeweils bis $30 \mathrm{ml}$ mit $10 \%$ Glycerin aufgefüllt. Nach dem Zentrifugieren $\left(4000 \mathrm{rpm}, 4^{\circ} \mathrm{C}, 10 \mathrm{~min}\right)$ wurde der

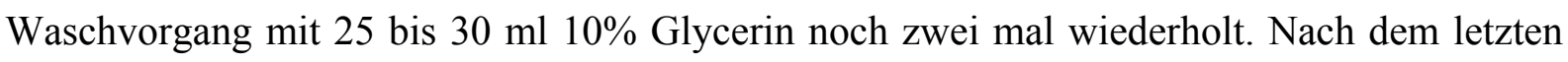
Waschen wurde der Überstand dekantiert, das Pellet in dem Rest Glycerin resuspendiert, und die gesamten Zellen in einem Falconröhrchen gesammelt. Die Zellen wurden erneut wie beschrieben abzentrifugiert, der Überstand vollständig abgenommen und das Zellpellet mit $10 \%$ Glycerin versetzt (195 $\mu 1 / 100 \mathrm{ml}$ Ausgangskultur). Die resuspendierten Zellen wurden in vorgekühlten Eppendorfcups $\mathrm{zu}$ je $25 \mu \mathrm{l}$ aliquotiert und in flüssigem Stickstoff schockgefroren. Sie konnten so über einen längeren Zeitraum bei $-70{ }^{\circ} \mathrm{C}$ aufbewahrt werden. Von großer Wichtigkeit bei der Erstellung von Banken ist die möglichst hohe Transformationseffizienz der elektrokompetenten Zellen, die aus diesem Grund vor Anwendung der Zellen überprüft wurde.

Dazu wurde eine 2-mm-Elektroporationsküvette auf Eis vorgekühlt und ein Reaktiongefäß mit elektrokompetenten Zellen auf Eis aufgetaut, mit $1 \mu 1$ einer pUC19-DANN-Stocklösung $(0,01 \mu \mathrm{g} / \mathrm{ml})$ versetzt und der Ansatz in die Elektroporationsküvette überführt. Die Transformation erfolgte in einem Elektroporationsgerät bei $1800 \mathrm{~V}$ für 7,5 msec. Zehn $\mu \mathrm{lder}$ elektroporierten Zellen wurden in $1 \mathrm{ml}$ SOC Medium, das Raumtemperatur hatte, überführt und für $1 \mathrm{~h}$ bei $37^{\circ} \mathrm{C}$ mit $160 \mathrm{rpm}$ geschüttelt. Danach wurden die transformierten Zellen 1:100 mit SOC-Medium verdünnt und $100 \mu$ dieser Verdünnung auf LB-Amp-Platten ausplattiert. Die über Nacht bei $37^{\circ} \mathrm{C}$ auf der Platte gewachsenen Kolonien wurden gezählt. Die Transformationseffizienz wurde nach der folgenden Formel berechnet:

Transforma-
tionseffizienz $=\frac{\text { CFU auf Kontrollplatte }}{\text { pUC (verwendet für }}$
dieTransformation)




\subsection{Elektroporation}

Für jeweils eine Elektroporation wurden 1 bis $3 \mu$ der dialysierten Ligationslösung verwendet. Aliquots (20 bis $25 \mu \mathrm{l}$ ) der elektrokompetenten Zellen wurden langam auf Eis aufgetaut und anschließend in eine sterile, bei $4^{\circ} \mathrm{C}$ vorgekühlte Elektroporationsküvette gegeben. Das Vorkühlen der Küvette kann eine 10fache Erhöhung der Transformationseffizienz bewirken (Miller et al., 1988). Anschließend erfolgte der Zusatz der Ligationslösung, welcher durch antippen der Küvette in der Zellsuspension verteilt wurde, wobei die Bildung von Luftblasen in dem Gemisch vermieden werden sollte. Unmittelbar danach wurde die Küvette in den Elektroporations-Impulsgenerator eingesetzt und die Elektroporation durchgeführt. Studien zur Elektroporation langer DNA in Bakterienzellen zeigten, daß bei Transformationen dieser Art eine gleiche Transformationseffizienz erreicht werden kann, wenn sie entweder bei hoher Feldstärke und kurzer Impulsdauer oder bei schwacher Feldstärke und langer Impulsdauer durchgeführt wurden. Die hier beschriebenen Experimente zur Bank-Konstruktion wurden bei starkem elektrischen Feld und kurzer Impulsdauer durchgeführt $(2500 \mathrm{~V}(12,5 \mathrm{kV} / \mathrm{cm})$ für 2,4 msec.) Nach der Elektroporation wurde der Ansatz sofort in $500 \mu$ l angewärmtes (RT) SOC-Medium transferiert und bei $37^{\circ} \mathrm{C}$ für 45 min inkubiert. Anschließend wurde der Inhalt auf LB-Platten aufgetragen, welche 12,5 $\mu \mathrm{g} / \mathrm{ml}$ Chloramphenicol, $50 \mu \mathrm{g} / \mathrm{ml}$ X-Gal und $25 \mu \mathrm{g} / \mathrm{ml}$ IPTG enthielten. Nach einer Inkubation über Nacht bei $37{ }^{\circ} \mathrm{C}$ wurden die weißen, Insert-enthaltenden und blauen, insertfreien Kolonien gezählt. Die positiven Kolonien wurden in LB-ChloramphenicolMedium aufgenommen. Diese Bakterien-Lösungen wurden als Glycerin-Kulturen bei $-70{ }^{\circ} \mathrm{C}$ aufbewahrt. 


\section{Ergebnisse}

\subsection{Konstruktion einer genomischen Bank aus der LEW.1W/Gun Ratte (RT1" Haplotyp)}

Zur Kartierung, positionellen Klonierung und für ausgedehnte Sequenzierungsarbeiten von komplexen Genomen ist die Verfügbarkeit von kompletten rekombinanten DNA-Banken erforderlich. YAC-Banken (yeast artificial chromosome), die lange Insert-Fragmente tragen, sind für die physikalische Kartierung großer Genombereiche geeignet. Die YAC-Klone sind jedoch oft instabil, und außerdem ist es schwierig, ausreichende Mengen an DNA aus YACKlonen für die Erstellung von Subbanken dieser Klone zu isolieren. Die in den letzten Jahren erstellten BAC- (bacterial artificial chromosome) (Shizuya et al., 1992) und PAC-Banken (P1-derived artificial chromosome) (Ioannou et al., 1994) bieten eine günstige Alternative zur Kartierung und Sequenzierung von Säugergenomen, denn diese bakteriellen Klone tragen zwar kürzere Insert-Fragmente als die YAC-Klone, sind aber relativ stabil und die rekombinante DNA kann einfacher isoliert werden.

Über die Konstruktion und Analyse mehrerer BAC- und PAC-Banken sind in den letzten Jahren publikationen erschienen, z.B. humane BAC-Banken (Shizuya et al., 1992; Kim et al., 1996; Wang et al., 1994), Sorgum bicolor- (Woo et al., 1994), Reis- (Wang et al., ) und bovine BAC-Bank (Li Cai et al., 1995) oder eine PAC-Bank der Maus (Pierce et al., 1992).

$\mathrm{Zu}$ Beginn der vorliegenden Arbeit wurde versucht, eine genomische BAC-Bank aus dem Genom des Inzuchtstammes LEW.1W/Gun (RT1 ${ }^{\mathrm{u}}$-Haplotyp) der Ratte zu konstruieren.

Genomische DNA wurde aus der Milz bzw. aus den Lymphozyten isoliert, in low-meltingpoint Agarose-Blöckchen verarbeitet (s. 3.2.2) und bis zur Verwendung in 0,5 M EDTA bei $4^{\circ} \mathrm{C}$ aufbewahrt.

Als Klonierungsvektor zur Bankkonstruktion wurde der pBeloBAC11-Vektor verwendet (s. 2.2), der in 1 bis 2 Kopien pro E.coli-Zelle vorkommt. Dadurch kommt es seltener zu Rearrangements der inserierten DNA, ein wichtiger Aspekt bei der Konstruktion einer Bank aus einem Eukaryonten-Genom, welches eine große Zahl an repetitiven Elementen enthält, die Rearrangements begünstigen. 
$\mathrm{Zu}$ beachten war ebenfalls die Qualität des präparierten Plasmids. In einer Bakterienzelle liegen eine bis zwei Kopien des Vektors vor; somit ist die Menge an isolierbarer PlasmidDNA gering, und es müssen größere Mengen an Bakterienkulturen verwendet werden, um für die Experimente ausreichend Vektor-DNA zu erhalten. Dieses hat zu Folge, daß es schwierig ist, DNA des isolierten Plasmids in hoher Reinheit zu erhalten, denn Kontaminationen mit E.coli-DNA waren nicht auszuschließen, da diese 99\% des totalen DNA-Gehaltes ausmacht. Aus $500 \mathrm{ml}$ Bakterienkultur konnten einige $\mu \mathrm{g}$ DNA des reinen Vektors erhalten werden. Grundsätzlich wurde die durch Restriktionsspaltung linearisierte Plasmid-DNA nach Dephosphorylierung und elektrophoretischer Trennung aus dem Agarose-Gel eluiert. Auf diese Weise wurden bei der Bank-Konstruktion Religationen des Vektors ohne aufgenommene Inserts, die Bildung von Concatameren des Vektors oder die Anwesenheit nicht linearisierter Moleküle auf das Minimum reduziert. Folglich betrug der Hintergrund an Kolonien ohne inserierte DNA nur 3\% bezogen auf die Gesamtanzahl der die Bank darstellenden Kolonien.

Als Klonierungsstelle wurde die BamHI Restriktionsstelle aus dem Klonierungssegment des Vektors verwendet.

Die isolierte genomische DNA wurde entweder mit dem Restriktionsenzym BamHI oder MboI partiell gespalten (s. 3.4.1) und zur Ligation in den Klonierungsvektor eingesetzt. Mittels Pulsfeld-Gelelektrophorese wurde ein Vorlauf durchgeführt, um kurze durch Scherkräfte entstandene DNA-Fragmente zu entfernen (Abb. 7).

Die Abbildung 8 zeigt repräsentativ einen Lauf partiell gespaltener genomischer DNA in einem PFGE-Gel nach Färbung mit EtBr. Aus dem Gel wurde vor der Färbung anhand des Markers ( $\lambda$-Leiter) die Region, die eine Länge zwischen 100 bis $150 \mathrm{~kb}$ aufwies, ausgeschnitten. Aus den ausgeschnittenen Gelstücken wurde die darin enthaltene DNA durch Elektroelution isoliert und für die Ligation in den Klonierungsvektor verwendet.

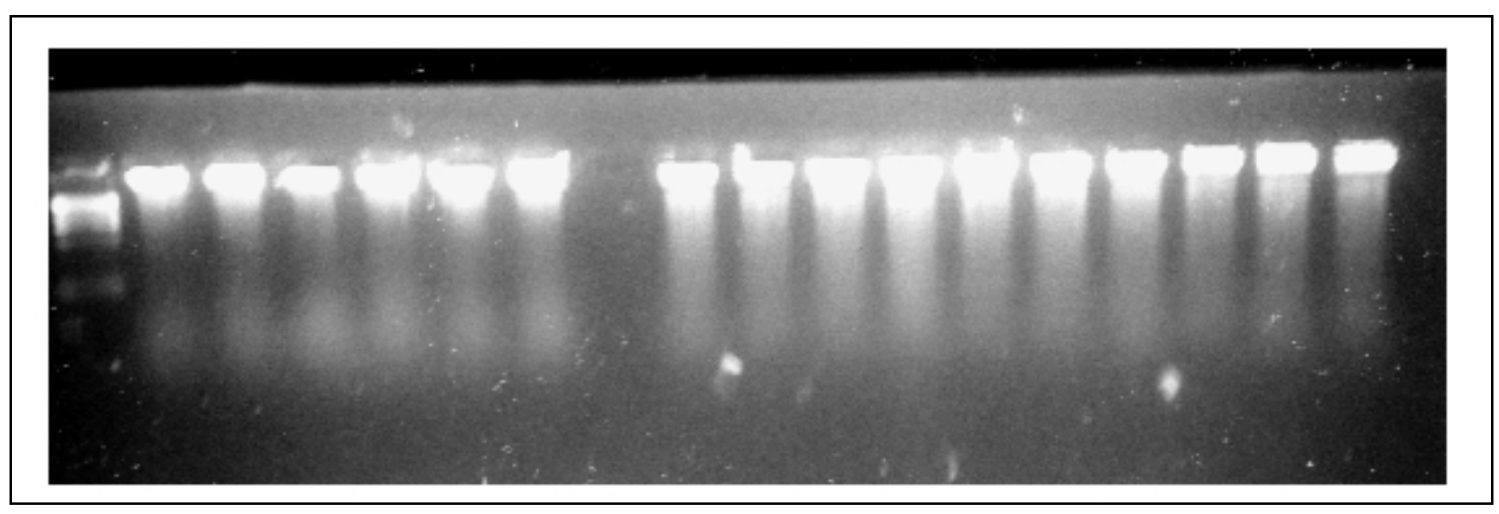

Abb. 7: Pulsfeldgelektrophorese des Vorlaufs der in Blöckchen verarbeiteten genomischen DNA.

Die Lauf-Bedingungen waren $80 \mathrm{~V}$, Rotationswinkel $120^{\circ}$, Pulsdauer $5 \mathrm{sec}$ und $11^{\circ} \mathrm{C}$ Temperatur. 


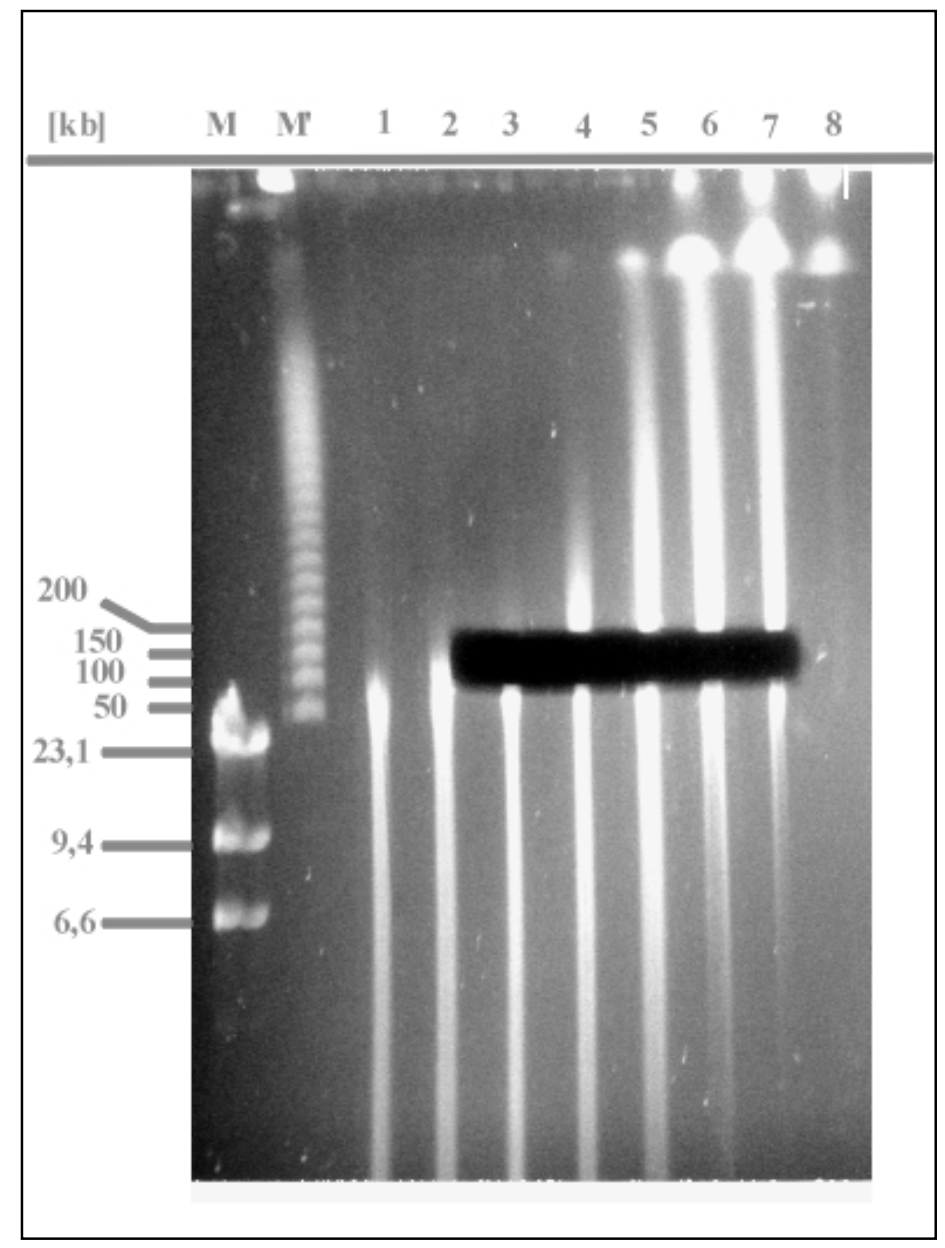

Abb. 8: Pulsfeldgelelektrophorese partiell gespaltener genomischer DNA. Eingesetzt wurden jeweils Blöckchen, die 4,5 $\mu \mathrm{g}$ DNA enthielten und mit abnehmender Enzymkonzentration inkubiert

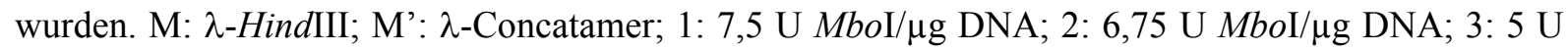

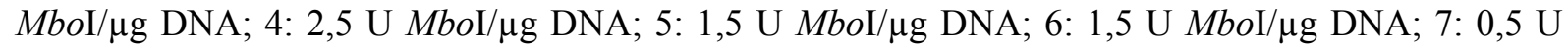

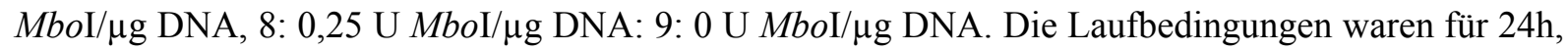
bei einer Temperatur von $11{ }^{\circ} \mathrm{C}$ : Zeitintervall in Sekunden, logarithmisch verändert von $100 \rightarrow 10$, Rotationswinkel in ${ }^{\circ}$, linear verändert von $120 \rightarrow 110$, und eine logarithmisch veränderten Spannung in $\mathrm{V}$ von $200 \rightarrow 150$

Die Ligation der partiell gespaltenen genomischen DNA der Ratte in den BAC-Vektor erfolgte nach der in 3.16 beschriebenen Methode. Der Ligationsansatz wurde nach Mikrodialyse in 0,5 x TE Spermin/Spermidin-Lösung in den E.coli-Stamm DH10B elektrotransformiert. Die elektrokompetenten- Zellen stammten aus eigener Herstellung und wiesen eine Transformationseffizienz von $1,5 \times 10^{10}$ Transformanten pro $\mu \mathrm{g}$ DNA auf.

Für jeweils eine Elektroporation wurden 1 bis $3 \mu 1$ der dialysierten Ligationslösung verwendet (s. 3.26). In einem ersten Ansatz von Ligationen und 120 anschließenden Transformationen 
wurden 33.600 Kolonien erhalten. Die Durchschnittslänge der Inserts der überprüften Kolonien betrug $30 \mathrm{~kb}$ (Abb. 9). Es handelt sich allerdings um einen der ersten Ansätze ohne Vorlauf der DNA.

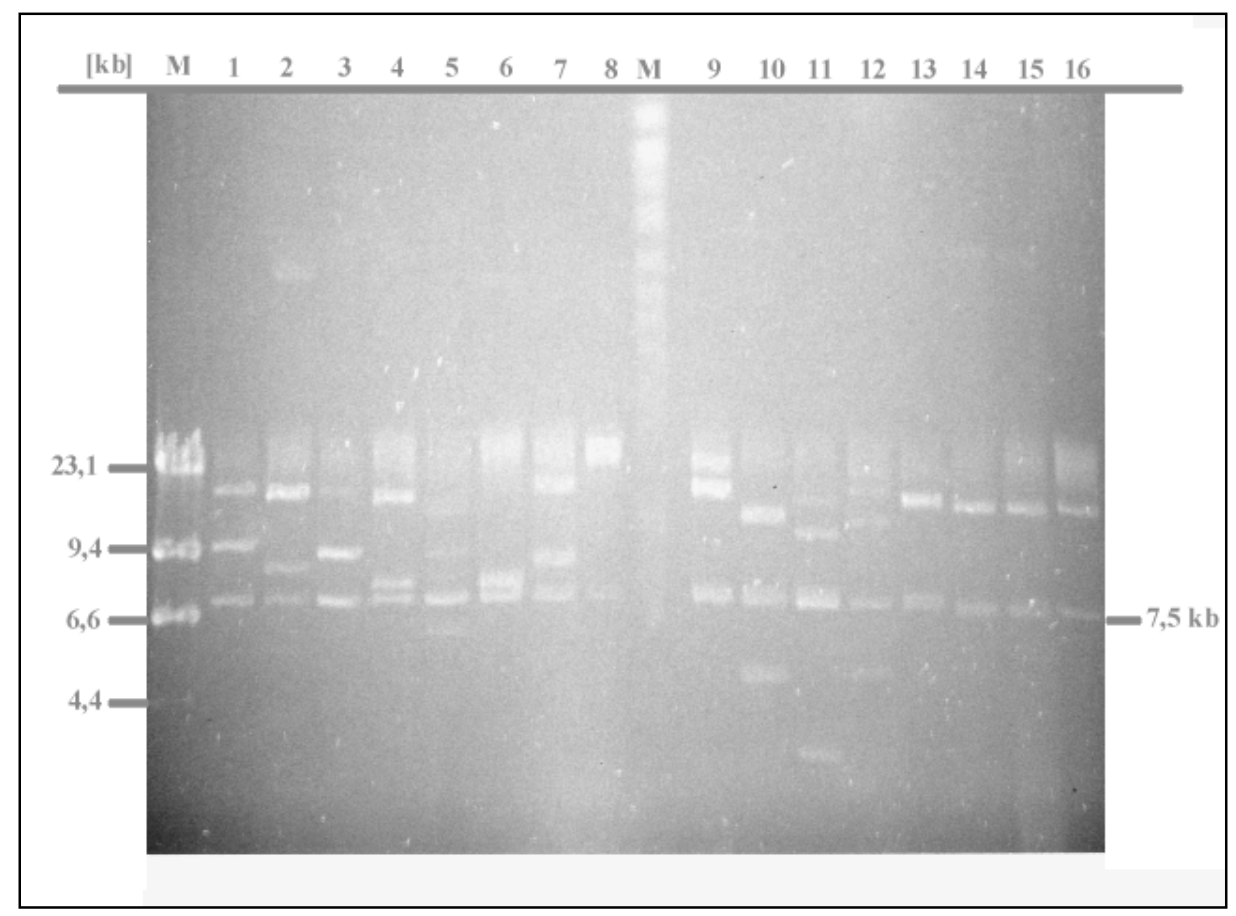

Abb. 9: Pulsfeldgelelektrophorese einiger mit NotI gespaltener BAC-Klone (1-16). Auf der Höhe von 7,5 kb ist der linearisierte pBeloBAC11-Vektor zu sehen. Die Laufbedingungen waren für 24h, bei einer Temperatur von $11^{\circ} \mathrm{C}$ : Zeitintervall in Sekunden, logarithmisch verändert von $100 \rightarrow 10$, Rotationswinkel in ${ }^{\circ}$, linear verändert von $120 \rightarrow 110$, und eine logarithmisch veränderten Spannung in $\mathrm{V}$ von $200 \longrightarrow 150$.

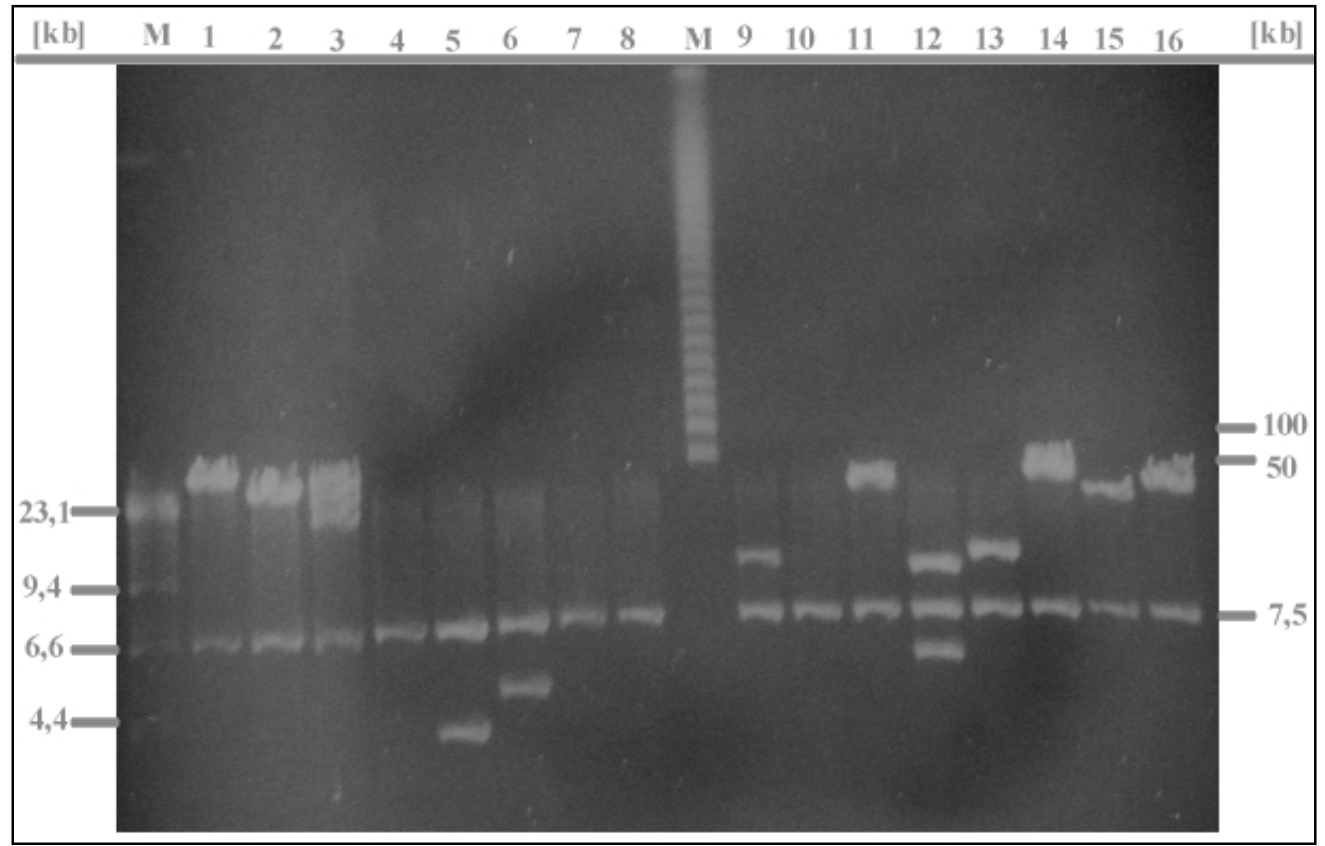


Abb. 10: Pulsfeldgelelektrophorese einiger mit NotI gespaltener BAC-Klone nach Optimierung der Bedingungen. Auf der Höhe von 7,5 kb befindet sich der linearisierte Vektor. Rechts ist die Länge der ersten zwei Banden aus den $\lambda$-Concatameren (50 und $100 \mathrm{~kb}$ ) gezeichnet. Die Laufbedingungen waren für $24 \mathrm{~h}$, bei einer Temperatur von $11{ }^{\circ} \mathrm{C}$ : Zeitintervall in Sekunden, logarithmisch verändert von $100 \rightarrow 10$, Rotationswinkel in ${ }^{\circ}$, linear verändert von $120 \rightarrow 110$, und eine logarithmisch veränderten Spannung in V von $200 \rightarrow 150$.

Es wurden weitere Versuche zur Optimierung der Insertlänge durchgeführt, diese bestanden darin, daß die in Blöckchen verarbeitete DNA vor dem partiellen Verdau einen Vorlauf unterzogen wurde und kleineren DNA-Mengen zum Restriktionsverdau eingesetzt wurden. Durch den Einsatzt geringerer DNA-Menge war eine bessere Auftrennung der langen DNAMoleküle im Pulsfeldgel ermöglicht. Außerdem wurde DNA aus einem höheren Bereich nach der Auftrennung isoliert von $100 \mathrm{~kb}$ bis 200 oder $250 \mathrm{~kb}$.

Es wurden 120 weitere Elektroporationen durchgeführt und 128.760 positive Klone erhalten. Der Anteil der Kolonien ohne ein Insert betrug 3\%. Die Analyse der Insert-Länge mehrerer Klone zeigte, daß etwa die Hälfte der analysierten Klone eine Insert-Länge von durchschnittlich $50 \mathrm{~kb}$ hatte, und die anderen Klone relativ kleine Fragmente mit durchschnittlich ca. $6 \mathrm{~kb}$ aufgenommen haben. In der Abb. 10 sind repräsentativ einige mit NotI gespaltene BAC-Klone aus diesen Ansätzen abgebildet.

Die Größe eines haploiden Säugergenoms beträgt $3 \times 10^{9} \mathrm{bp}$. Durch die folgende Beziehung kann der Umfang der erstellten genomischen Bank berechnet werden:

Anzahl der Kolonien x durchschnittliche Größe der inserierten Fragmente $[b p]=$ Größe der erhaltenen Bank [bp].

Insgesamt ergab sich eine Größe von 4,24 x $10^{9} \mathrm{bp}$. Dieser Wert, geteilt durch die haploide Genomgröße, ergibt die Anzahl der klonierten Genom-Äquivalente (GE) und entspricht hier 1,4 Genom-Äquivalenten.

Für folgende Analysen zur Untersuchung der RT1.C/M-Region des Ratten MHC wurde jedoch diese Bank nicht weiter verwendet, denn in der zwischen Zeit wurde eine PAC-Bank des Ratten Genoms eines Umfangs von 10 GE (Woon et al., 1998) über das RessourcenZentrum im Deutschen Humangenomprojekt verfügbar (s. 2.14). 


\subsection{Etablierung von Hybridisierungsproben}

Für die Isolierung von PAC-Klonen und die Erstellung von PAC-Contigs wurden spezifische Hybridisierungsproben an klonierten Genen oder anhand von spezifischen Primern mittels PCR für bekannte MHC-gekoppelte Genen etabliert. Weitere Hybridisierungsproben wurden aus STS-(sequence-tagged sites) Markern der Maus definiert. Außerdem wurden aus PACEndsequenzdaten (s. 3.18) eigene STS-Marker der Ratte etabliert.

Alle verwendeten Primer sind im Abschnitt 2.3 und eine Zusammenstellung der Hybridisierungsproben ist im Abschnitt $2.13 \mathrm{zu}$ finden.

Die verwendete DNA für Proben aus der Ratte stammte aus dem Ratteninzuchtsstamm BN/Gun. Für Maus-Proben wurde der Stamm C57BL/6 verwendet. Für die humanen Proben wurde DNA aus verschiedenen Individuen verwendet.

\subsubsection{Sonden aus klassischen MHC-Klasse-I-Genen}

Für die Klonierung und physikalische Kartierung der RT1-C-Region war es notwendig, die genomische PAC-Bank der Ratte (Woon et al., 1998) mehrfach mit unterschiedlichen Sonden zu screenen.

Zunächst wurden MHC-Klasse-I-Gen-spezifische Proben benutzt. Dazu wurden Subklone des Klasse-I-Gens RT1- $A^{u}$ verwendet (Walter et al., 1995), die von Herrn Dr. L.Walter, Abt. Immungenetik, zur Verfügung gestellt wurden. Eine Zusammenstellung der Subklone findet sich in Tab. 2.

Tab. 2: Subklone des RT1- $A^{u}$ Gens (Walter et al., 1995) und daraus generierte MHC-Klasse-Ispezifische Proben.

\begin{tabular}{|l|l|l|l|l|}
\hline Subklon & Spaltung durch: & $\begin{array}{l}\text { Länge des als Sonde } \\
\text { verwendeten } \\
\text { Fragments }\end{array}$ & $\begin{array}{l}\text { Bereich des Klasse-I-Gens, } \\
\text { aus dem die Sonde stammt }\end{array}$ & $\begin{array}{l}\text { Bezeichnung } \\
\text { der Probe }\end{array}$ \\
\hline P6 1.3 & Not $\mathrm{I} /$ Pst $\mathrm{I}$ & $1,3 \mathrm{~kb}$ & Promotor-Region & Promotor Probe \\
\hline
\end{tabular}




\begin{tabular}{|c|c|c|c|c|}
\hline P6 0.7 & $N o t \mathrm{I} / P s t \mathrm{I}$ & $678 \mathrm{bp}$ & $\begin{array}{l}\text { Exon } 1+\text { Intron } 1 \\
+ \text { Exon } 2(\alpha 1) \\
+ \text { Intron } 2\end{array}$ & $\alpha 1$-Probe \\
\hline P4 & Pst I & $289 \mathrm{bp}$ & $\begin{array}{l}130 \text { bp Intron } 3+ \\
159 \text { bp Exon } 4(\alpha 3)\end{array}$ & $\alpha 3$-Probe \\
\hline P7 & PstI/HindIII & $731 \mathrm{bp}$ & $\begin{array}{l}\text { Exon } 7+\text { Intron } 8+\text { Exon } 8 \\
+3^{\text {'}} \text {-untranslatierte Region } \\
\text { bis poly(A)-Signal }\end{array}$ & $\begin{array}{l}\text { Cyto-Poly-A- } \\
\text { Probe }\end{array}$ \\
\hline
\end{tabular}

Am Anfang des Exons 2 des $R T 1-A^{u}$ - Gens wurde der Primer alpha1-5` definiert und am Ende des Exons 2 der Primer alpha1-3‘. Eine PCR mit diesen Primern an dem $R T 1-A^{u}$-Gen lieferte das gesamte Exon 2 in einer Länge von 270 bp. In der Sequenz dieses Exons existiert eine $K s p$ I Schnittstelle. Diese wurde verwendet, um das Exon 2 in zwei Teile zu spalten. Das Fragment, das die 5'-Hälfte des Exons enthält, hat eine Länge von 141 bp und das Fragment der 3'-Hälfte des Exons umfasst 129 bp. Diese Restriktionsfragmente wurden auf einem 2,5\% igen Agarose-Gel aufgetrennt und als Hybridisierungssonden zur Überprüfung der Exon 2reichen Region im Übergang vom Contig 2-1 zum Contig 2-2 verwendet.

\subsubsection{Erstellung von Hybridisierungsproben aus MHC-Klasse-Ib-Genen}

\section{RT1-M3 (Rattus norvegicus)}

Das MHC-Klasse-Ib-Gen RT1-M3 ist ortholog zu H2-M3 der Maus (Wang et al., 1991b). Untersuchungen an der Maus zeigten, daß das H2-M3-Gen für ein Klasse-Ib-Molekül kodiert, welches N-formylierte Peptide mitochondrialen oder bakteriellen Ursprungs zytotoxischen TLymphozyten präsentieren kann. Dieses Molekül ist an der Immunantwort nach Infektion mit Listeria monocytogenes beteiligt. Das Gen wurde am telomeren Ende des MHC sowohl bei der Maus (Jones et al., 1995) als auch bei der Ratte (Lambracht et al., 1995) lokalisiert.

Zur Erstellung der spezifischen RT1-M3 Probe wurde ein Primer-Paar im Exon 3, das 60-70\% Homologie zu anderen Klasse-I-Genen in dieser Region zeigt, ausgewählt. Das PCR-Produkt 
besitzt eine Länge von 250 bp und wurde verwendet, um diejenigen Klone aus dem $\alpha 3$ Screening zu identifizieren, die das M3-Gen tragen.

\section{RT1-M4 (Rattus norvegicus)}

Das H2-M4-homologe Gen der Ratte konnte durch einen Mikrosatellitenmarker identifiziert werden (Lambracht et al., 1998). Es wurden den Mikrosatellit flankierende Primer definiert und ein PCR-Produkt von 129 bp erhalten, welches als Sonde zur Identifizierung des RT1M4-Gens in PAC-Klonen verwendet wurde.

\section{H2-M2 (Mus musculus)}

Das H2-M2-Gen (oder Thy19.4) der Maus (Brorson et. al., 1989) wurde wie H2-M3, am telomeren MHC-Ende lokalisiert. Um PAC-Klone identifizieren zu können, die das homologe Gen der Ratte tragen, wurde eine Probe aus dem Exon 2 von H2-M2 durch PCR generiert, welche eine Länge von 270 bp aufweist.

\section{RT.BM1 (Rattus norvegicus)}

Eine Hybridisierungsprobe wurde aus dem RT.BM1-Gen (Parker et al., 1990) generiert, das in der RT1-C/E-Region liegt und in der NC2-Region* ( $\mathrm{NC}=$ non-coding) ein Alu-ähnliches repeat-Element enthält. Zur Generierung der BMI-spezifischen Probe wurden Primer in der NC1-Region* definiert. Das erhaltene PCR-Produkt sollte auf cDNA-Ebene 300 bp betragen. Auf genomischer Ebene hat es eine Länge 1000 bp. Es beinhaltet das Exon 7, Intron 7, Exon 8, ein 619 bp langes Intron im 3'-utr (Salgar et al., 1998) und einen Teil der NC1-Region.

\subsubsection{Erstellung von Hybridisierungssonden aus verschiedenen „Ankergenen“6}

Die vollständige Kartierung und teilweise Sequenzierung des H2-Komplexes sowie die komplette Sequenzierung des HLA-Komplexes liefern bisher nicht bekannte Informationen über die Gene des Haupthistokompatibilitätskomplexes in diesen Spezies. Anhand dieser Daten war es möglich, für viele MHC-Gene Proben zu generieren um zu untersuchen, ob diese Gene an orthologer Position im RT1-Komplex vorkommen.

\section{Bat 1 (Rattus norvegicus)}

Das Gen codiert für eine nukleäre RNA Helikase. Für die Herstellung einer Bat1-Probe wurden die in der Abteilung Immungenetik vorhandenen Primer rBat1-5' und rBat1-3', 
welche der codierenden Region des Ratten-Bat1-Gens entstammen, verwendet, um an cDNA eine PCR durchzuführen. Die Sequenz, aus der die Primer stammen, ist unter M75168 in der EMBL/Genbank zu finden (Nair et al., 1992). Die Länge des PCR Produkts beträgt 400 bp.

*Der 3 '-untranslatierte Bereich der Maus-Klasse-I-Gene ist in zwei Regionen unterteilt worden, NC1 und NC2 (Lalanne et al., 1982). Eine ähnliche Aufteilung ist auch für die Klasse-I-Gene der Ratte vorgeschlagen worden, wobei die ersten 320 Nukleotide des 3'-utr die NC1-Region umfaßt und die NC2-Region den Rest von in der Regel ca. 130 bp (Mauxion et al., 1989)

\section{Pou5f1 (Mus musculus)}

Pou5f1 ist ein Gen, das für einen Transkriptionsfaktor (auch OTF-3, oct4 genannt) kodiert. Dieser Trankriptionsfaktor enthält eine POU-Domäne sowie eine Homeodomäne und ist in undifferenzierten pluripotenten Zellen des frühen Embryos und der Keimzellen exprimiert. Dementsprechend spielt dieses Gen in der frühen Entwicklung eine Rolle und reguliert die Transkription von Genen mit dem Octamer/DNA-Bindungs-Motiv (Rosner et al., 1990).

Die Primer wurden an cDNA der Maus-Sequenz S58426 (Rosner et al., 1990) in der codierenden Region, 3'-wärts von der Homeodomäne, und exakt vor dem Beginn des 3'-UT definiert. In dieser Region, der sogenannten spacer-Region zwischen der POU-spezifischen Domäne und der Homeodomäne, und an verschiedenen Aminosäure-Positionen in der POUspezifischen Domäne unterscheidet sich dieses Protein von anderen POU-Proteinen. Die PCR zur Erstellung der Sonde wurde an genomischer DNA durchgeführt, und das erhaltene Produkt wies eine Länge von 170 bp auf.

\section{Cak (Rattus norvegicus)}

Dieses Gen ist auch unter den Bezeichnungen DDR, EDDR1, NEP bekannt und codiert für eine Zell-Adhäsions-Kinase. Die Primer-Definition erfolgte an der cDNA der Ratten Sequenz AW144724 (Laval et al., 1994). Das RT-PCR Produkt sollte theoretisch 370 bp enthalten. Verglichen mit der genomischen Sequenz, die für das menschliche Gen bekannt ist, sollten diese Primer jedoch ein Intron überspannen. Die PCR an genomischer DNA der Ratte ergab ein Produkt von 1 kb Länge.

\section{Gtf2h4 (Rattus norvegicus)}

Dieses Gen codiert für p52, die fünfte Untereinheit des Kernenzyms des Transkription/DNAReparatur-Faktors IIH. Die Primer Definition erfolgte an cDNA der Ratte Y07595, Marinori 
et al., 1997. Das PCR-Produkt beträgt auf cDNA- und genomischer-Ebene $228 \mathrm{bp}$, es ist also kein Intron in dem Primer umfassenden Bereich vorhanden.

\section{Prg1 (Rattus norvegicus)}

Prgl ist ein „early response“-Gen (Schäfer et al., 1996), homolog dem gly96 (Charles et al., 1993) der Maus und ein potentieller Transkriptionsfaktor. Die Primer wurden an der 36' untranslatierten Region definiert. Das PCR Produkt umfaßt 300 bp. Die benutzte Sequenz ist unter X96437 zu finden. Durch Ansequenzieren des hier beschriebenen Klones I16223 wurde am telomeren Ende eine Sequenz aus dem Prgl-Gen identifiziert.

\section{Pnuts (Rattus norvegicus)}

Das Gen Pnuts (phosphatase I $\underline{\boldsymbol{n}}$ uclear targeting $\underline{\mathbf{s}}$ ubunit) ist auch unter der Bezeichnung FB19 zu finden (Totaro et al., 1998). Das FB19-Gen wurde 70 kb centromerwärts von HLAE lokalisiert.

\section{Gna-rs1 (Mus musculus)}

Bei Gna-rsl handelt es sich um ein putatives GTP-bindendes Protein. Das homologe MausGen wird auch als Mmr1, das homologe humane Gen auch als HSR1 oder GNL1 bezeichnet. Die verwendete Probe ist ein 359 bp EcoRI-Fragment und wurde von Dr. Pierre Pontarotti, Marseille, zur Verfügung gestellt.

\section{TC4 (Homo sapiens)}

Das TC4-Gen kodiert für ein Ras-ähnliches Protein. Die Primer entstammen aus der humanen cDNA Sequenz M31469 (Drivas et al., 1990). Das PCR Produkt besitzt eine Länge von 625 bp.

\section{ZNF173 (Homo sapiens)}

Das Zinkfinger-Protein ZNF173 (Chu et al., 1995) gehört einer Multigen-Familie an. Es enthält zwei Cystein- und Histidin-reiche Domänen, welche charakteristisch für Metallabhängige, DNA bindende Proteine sind. Zusätzlich ist eine coiled-coil-Domäne vorhanden, die eventuell zur Dimerisation beiträgt. Vor dem Carboxy-Terminus ist eine Polyglutaminsäure-Region zu finden.

Primer wurden an der humanen cDNA Sequenz aus NM_003449 im Bereich zwischen coiledcoil-Domäne Polyglutamin-Region definiert. Im Vergleich mit der genomischen Sequenz 
überspannen diese Primer eine Region von zwei Introns. Das PCR Produkt wurde an humaner cDNA generiert und beträgt 328 bp.

\section{RFB30 (Homo sapiens)}

Das Gen RFB30 gehört zur Multigen-Familie der B30-RING-Finger-Proteine. Diese enthalten eine konservierte Domäne, die als B30.2 bezeichnet wird. Die Proteine dieser Familie haben eine RING-B-Box- Domäne in Exon 1, sowie eine coiled-coil-Domäne im Exon 2 und binden sehr wahrscheinlich Nukleinsäuren oder Proteine. Die B30.2 ähnliche Domäne (Exon 7) wurde ursprünglich in einem transmembranen Protein, Butyrophylin, welches in der Milchdrüse während der Laktation exprimiert ist, nachgewiesen. In diesem Protein folgt auf ein transmembranes Segment eine cytoplasmatische B30.2 Domäne, der sich zwei extrazelluläre Immunglobulin-ähnliche Domänen anschliessen. Die distale Immunglobulin-

ähnliche Domäne entspricht der Immunglobulin-ähnlichen Domäne des Myelin/Oligodendrocyten-Glycoproteins (MOG).

Zur Erstellung der RFB30-Probe wurden Primer an Exon G (Exon 7) definiert (Y07829, Henry et al., 1997) und die PCR an humaner genomischer DNA durchgeführt. Die Länge des erhaltenen PCR-Produktes beträgt 420 bp.

\section{Tctex5 (Mus musculus)}

Tctex5 gehört zu den t-complex testis-expressed genes (Young et al., 1993). Die Maus-Probe umfaßt 500 bp (EcoRI Fragment) und wurde von Dr. Pierre Pontarotti, Marseille, zur Verfügung gestellt.

\section{Mog (Rattus norvegicus)}

Das Myelin/Oligodendrocyten-Glykoprotein (MOG) kommt im Myelin des zentralen Nervensystems vor. $M O G$ wird, im Vergleich zu anderen, gut charakterisierten MyelinProteinen, erst spät in der Entwicklung des Gehirns gebildet. Die externale Lokalisation des MOG an der Myelin-Scheide und an Oligodendrozyten sowie die späte Expression sprechen für eine spezifische Rolle des MOG in den letzten Stadien der Myelinisierung. Das MOGProtein hat sich als ein wichtiges Autoantigen bei autoimmunen Krankheiten des ZNS, wie der Autoimmunen Encephalomyelitis und der Multiplen Sklerose, erwiesen.

Die Mog-Primer wurden an der Sequenz des Exons 2 des Ratten Gens definiert (L21995; Pham-Dinh et al., 1993). Das generierte PCR Produkt umfaßt 270 bp. 


\section{Tu42 (Mus musculus)}

Das Tu42-Gen kodiert für einen olfaktorischen Rezeptor. Die Probe (1,9 bp EcoRI/BamHI) wurde von Dr. Pierre Pontarotti, Marseille, zur Verfügung gestellt.

\subsubsection{Erstellung von STS-Markern aus der Ratte und der Maus}

\section{I162T (Rattus norvegicus)}

Aus der Endsequenzierung des Klones I16223 wurde am telomeren Ende (4.4.2.1.4) eine Sequenz erhalten, die kein repeat darstellt, aber auch keine Homologie zu bereits bekannten Sequenzen aufweist. Auf der Basis dieser Sequenz wurden Primer definiert und ein PCRProdukt von 230 bp Länge generiert. Die Probe wurde als STS- Marker verwendet, um damit die im Contig benachbarten PAC-Klone zu überprüfen.

\section{Grc (Rattus norvegicus)}

Der Grc-Phänotyp ist durch Kleinwuchs, reduzierte Fertilität und erhöhte Suszeptibilität für chemisch induzierte Tumoren charakterisiert (Gill et al., 1997). Eine Probe von 500 bp, die die Grc-Region detektiert wurde aus der Sequenz des Klones pGRC1.4 (Cortese Hassett et al., 1989) generiert. Die genaue Beschreibung erfolgt unter 4.4.2.1.1

\section{Mikrosatellit D20Gun1 (Rattus norvegicus)}

Aus der Endsequenzierung des centromeren Endes des Klones J2298 wurde u.a. die Sequenz eines Mikrosatelliten erhalten. Es handelt sich um eine repetitive Sequenz, die mit der Insertion von Retrotransposons kombiniert ist. Dieses repeat besteht aus (GAA)n/(GAAA)n und hat eine Länge von 100 bp. Die flankierende Sequenz ist homolog der Sequenz eines intracisternalen A-Partikels, das sowohl in metastatischen Tumor-Zellinien der Ratte (Grassi, 1998 unpupliziert) als auch bei der sogenannten Eker-Ratte vorkommt. Die Eker-Mutation ist auf dem Chromosom 10 lokalisiert. Die Tiere erkranken an renalem Carcinom (Kobayashi et al., 1995).

Durch den Mikrosatelliten flankierende Primer wurde aus dem Klon J2298 ein PCR-Produkt generiert und als Marker verwendet.

\section{H12587 (Rattus norvegicus)}

Die Endsequenzierung des PAC-Klones H12587 am centromeren Ende ergab eine anonyme, d.h. nicht in der Datenbank (Genbank/EMBL) vorhandene Sequenz. Aus dieser Sequenz 
wurden Primer etabliert und das erhaltene 160 bp umfassende PCR-Produkt als STS Marker verwendet. Das Screening der genomischen Bank mit dieser Sonde ergab jedoch bekannnte Klone aus der Region des Contig 2-1. Aus diesem Ergebnis wurde der Schluß gezogen, daß es sich um einen Marker handelt, der mehrfach in dieser Region vorkommt.

\section{D16 (Mus musculus)}

Anhand von YAC- oder BAC-Klonen, die für den MHC der Maus etabliert worden sind (Amadou et al., 1999) wurde der STS-Marker 255D16 mittels PCR hergestellt und zur Kartierung bei der Ratte eingesetzt. Dazu wurden an der Sequenz B88392 Primer gewählt und an genomischer DNA der Maus die PCR durchgeführt. Die generierte Probe hat eine Länge von 260 bp. Dieser STS-Marker ist am centromeren Ende der H2-M Region lokalisiert.

\section{A5T und 261A5S (Mus musculus)}

Der STS-Marker 261A5T der Maus ist ca. $300 \mathrm{~kb}$ telomerwärts vom Marker 255D16 (s. oben) entfernt. Wiederum der Marker 261A5S ist ca. $100 \mathrm{~kb}$ telomerwärts von 261A5T entfernt. Beide Marker befinden sich in der H2-M Region. Die 261A5T-Probe wurde durch Primer aus der Sequenz B88394 erstellt, wobei sich ein PCR-Produkt von 360 bp ergab. Analog wurde die 261 A5S-Probe aus der Sequenz B88393 erstellt, und die per PCR erhaltene Hybridisierungssonde weist eine Länge von 330 bp auf.

\subsection{Klonierung und physikalische Kartierung der RT1-C/M-Region anhand einer genomischen Bank aus der BN-Ratte (RT1 ${ }^{\mathrm{n}}$-Haplotyp)}

Zur Klonierung der RT1-C-Region wurde eine genomische Bank des Inzuchtstammes BN (RT1 ${ }^{\mathrm{u}}$-Haplotyp) verwendet, die von Woon et al., (1998) konstruiert worden ist und über das Ressourcen-Zentrum des Humanen Genom-Projekts in Berlin verfügbar ist.

$\mathrm{Zu}$ Beginn der Versuche, die RT1-C/M-Region zu klonieren, wurde die oben genannte Bank mit der Bat1 Probe gescreent (s. 4.2). Dieses Gen ist am telomeren Ende der Klasse-IIIRegion lokalisiert. Aus diesem screening wurden drei Bat1-positive Klone erhalten. Diese Klone erwiesen sich auch positiv mit der Tnfa-Probe. Das Tnfa-Gen ist ca. $40 \mathrm{~kb}$ (Walter et al. 1997) centromerwärts vom Batl-Gen lokalisiert. Diese Klone zeigten nach Hybridisierung 
mit der $\alpha 1$ - und $\alpha 3$-Probe (s. 2.13. und Abb. 14) eine große Anzahl an positiven Fragmenten, deren Zuordnung eine dachziegelartige Anordnung (Überlappung) ergab und zu der Annahme berechtigte, daß eine dichte Abfolge von MHC-Klasse-I-Genen in dieser Region vorhanden ist.

Ein Screening der PAC-Bank mit der $\alpha 3$-Probe, deren Sequenz hochkonserviert in allen MHC-Klasse-I-Genen ist, sollte alle Klone, die solche Gene tragen, identifizieren. Da die genomische Bank einen Umfang von 10 Genom-Äquivalenten hat, mußte mit einer großen Anzahl solcher Klone gerechnet werden. Da aber im Bereich der $\alpha 1$-Domäne eine größere Variabilität innerhalb der Klasse-I-Gene besteht, mußte ein Screening mit einer $\alpha 1$-Probe unter stringenten Hybridisierungs-Bedingungen eine geringere Anzahl an solchen Klonen liefern, die untereinander eine höhere Homologie in der $\alpha 1$-Sequenz aufweisen.

Durch das Screening mit der $\alpha 1$-Probe (s. 4.2) wurden 43 positive Klone erhalten, davon wurden 7 Klone der RT1-A Region zugewiesen, da sie auch das Ring1-Gen tragen, das sich am centromeren Ende des RT1-Komplexes befindet (Walter et al., 1996). Die restlichen 37 Klone konnten anhand der $\alpha 1$ - bzw $\alpha 3$-Hybridisierungs-Banden in zwei Contigs angeordnet werden (Abb. 14, 23).

Durch das weitere Screening der Bank mit der $\alpha 3$-Probe konnten die meisten der $\alpha 1$-positiven Klone erhalten werden sowie weitere $61 \mathrm{Klone}$, die sich offensichtlich im $\alpha 1$-Bereich von den vorigen $\alpha 1$-positiven Klonen stark unterscheiden. Auch bei diesen Klonen war eine Zusammenstellung in 2 Contigs anhand des $\alpha 3$-Hybridisierungsmusters möglich (s. Abb. 32, $34)$.

Bei 22 Klonen, die entweder ein oder zwei $\alpha 3$-hybridisierende Fragmente vorweisen, fand sich eine Hybridisierung mit den RT1-M2- bzw. RT1-M3- Proben.

Zur Erstellung der Contigs wurde es nach folgendem Prinzip gearbeitet: aus den durch die Screenings der PAC-Bank (Wonn et al., 1998) positiv identifizierten Klonen wurde DNA isoliert (s. 3.2.5) und nach 3.4 mit dem Restriktionsenzym BamHI gespalten. Nach elektrophoretischer Trennung der gespaltenen DNA (s. 3.6.1) wurden Southernblots auf Naylon Membranen erstellt (s. 3.7), welche zur Hybridisierung (s. 3.8) mit gewünschten Sonden verwendet wurden. In diesem Fall wurden zunächst die Hybridisierungsproben $\alpha 1$ und $\alpha 3$ eingesetzt. Durch den Vergleich der mit diesen Proben hybridisierenden BamHIFragmenten konnte festgestellt werden, ob und welche der Fragmente aus den untersuchten Klonen überlappen. PAC-Klone, die überlappende $\alpha 1$ und/oder $\alpha 3$ hybridisierende BamHIFragmente trugen wurden zunächst in Contigs zusammengesetzt. Weiterhin wurden die auf 
dieser Weise in Contigs zusammengestellte PAC-Klone mit zusätzlichen Proben überprüft (durch Hybridisierung oder PCR-Durchführung), die entweder aus PAC-Endsequenzierung hergestellt wurden oder/und mit verschieden Genproben, wodurch auch das genaue Kartieren dieser Gene erfolgte.

Die in den Contigs aufgezeichnete Klasse-I hybridisierende Fragmente wurden nach der Länge der jeweils mit der $\alpha 1$ und/oder $\alpha 3$ Sonde hybridisierenden BamHI Restriktionsfragmente genannt, ein Prinzip das auch bei der Kartierung des MHC der Maus angewendet wurde (Amadou et al., 1999). Folgend werden im einzelnen die erstellten Contigs besprochen.

\subsubsection{Beschreibung von Contig 1}

In einem ersten Contig, das durch Hybridisierung mit der Tnfa- und Bat1-Probe in der KlasseIII-Region verankert ist, konnten insgesamt 24 PAC-Klone zusammengestellt werden (s. Tab. 3). Das Contig beginnt ca. $60 \mathrm{~kb}$ centromerwärts des Tnfa-Gens. Telomerwärts des Tnfa-Gens befindet sich das Bat1-Gen. Der Abstand zwischen diesen Genen beträgt im RT1 ${ }^{\mathrm{u}}$-Haplotyp ca. $40 \mathrm{~kb}$ (Walter et al., 1997). Dies entspricht der Länge, die auch bei Mensch und Maus bekannt ist. In dem hier untersuchen RT1 ${ }^{\mathrm{n}}$-Haplotyp wurde dieser Abstand nicht vermessen; auch die Abstände zwischen den einzelnen Klasse-I-Genen oder -Genfragmenten ist nicht bekannt. Zwischen dem Bat1-Gen und dem ersten Klasse-I-Gen konnte per long range PCR ein Abstand von $10 \mathrm{~kb}$ festgestellt werden. Durch die Definition der verwendeten Primer wurde es möglich, die Orientierung dieser Gene zu bestimmen (Abb. 11).

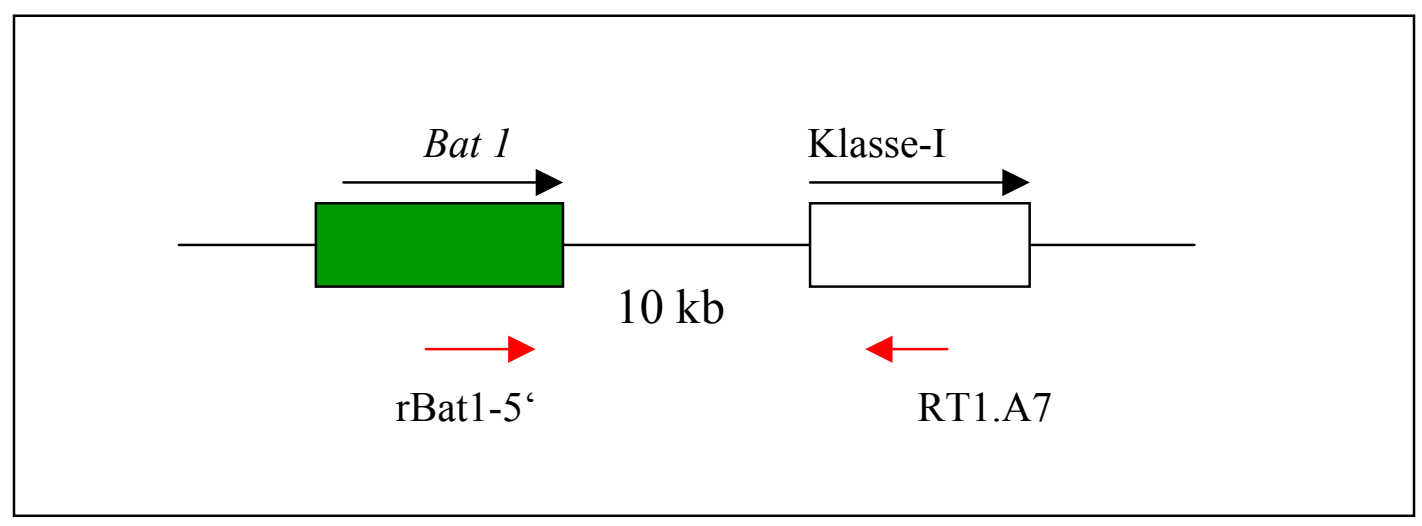

Abb. 11: Long-range PCR mit Primern aus dem Bat1-Gen und einem Klasse-I-Gen. Die schwarzen Pfeile zeigen die Orientierung des Bat1-Gens und des nachfolgenden Klasse-I-Gens. Die grauen Pfeile deuten die Orientierung der für die long range PCR verwendeten Primer an. 
An die fünf PAC-Klone, die mit der Tnfa- und Bat1-Probe hybridisiereten, konnten weitere 14 Klone angefügt werden, die eine dichte Abfolge an $\alpha 1 / \alpha 3$-hybridisierenden Fragmente zeigten. Die mit der $\alpha 1$ - bzw. $\alpha 3$-Probe hybridisierende Fragmente sind in den Abbildungen 12 bzw. 13 zu sehen. Insgesamt waren 20 solcher BamHI-Fragmente in dieser Region zu finden. Es wurden alle hybridisierenden Fragmente separat in der Abbildung 14 eingetragen, wobei, zumindest bei den $\alpha 1 / \alpha 3$-doppeltpositiven Fragmenten davon auszugehen ist, daß es sich um komplette Gene handelt. Bei den nebeneinander gezeichneten $\alpha 1 / \alpha 3$-positiven Fragmenten könnte es sich auch um Gene handeln, die eine interne BamHI-Schnittstelle enthalten. Das Hybridisierungsmuster mit der Promotor- und der Cyto-Probe (siehe 2.13. und Abb.15 bzw. 16) bestätigte diese Annahme. Demzufolge könnten sich in dieser Region 15 Klasse-I-Gene befinden. Bei dem 23 kb langen $\alpha 1$-positiven Fragment könnte es sich um ein unvollständiges Gen handeln, es ist aber auch nicht auszuschließen, daß sich das zu diesem Gen gehörende $\alpha 3$-Fragment auf einem der benachbarten langen Fragmente befindet.

An dem oben genannten long-range PCR-Produkt von $10 \mathrm{~kb}$ (Abb. 11) wurde von Bat1 telomerwärts eine Sequenzierung durchgeführt. Verwendet wurde der Primer rBAT1.3-neu, der im $3^{\text {'}}$-utr des Bat1-Gens definiert wurde. Es wurde eine Sequenz von 400 bp erhalten. Ein Vergleich dieser Sequenz mit der homologen Maus-Sequenz (Schäfer et al., 1999) ergab, daß nach dem Bat1-Polyadenylierungs-Signal die Sequenz für 45 bp völlig identisch sind, dann aber die Homologie abbricht. (Anhang 8.2)

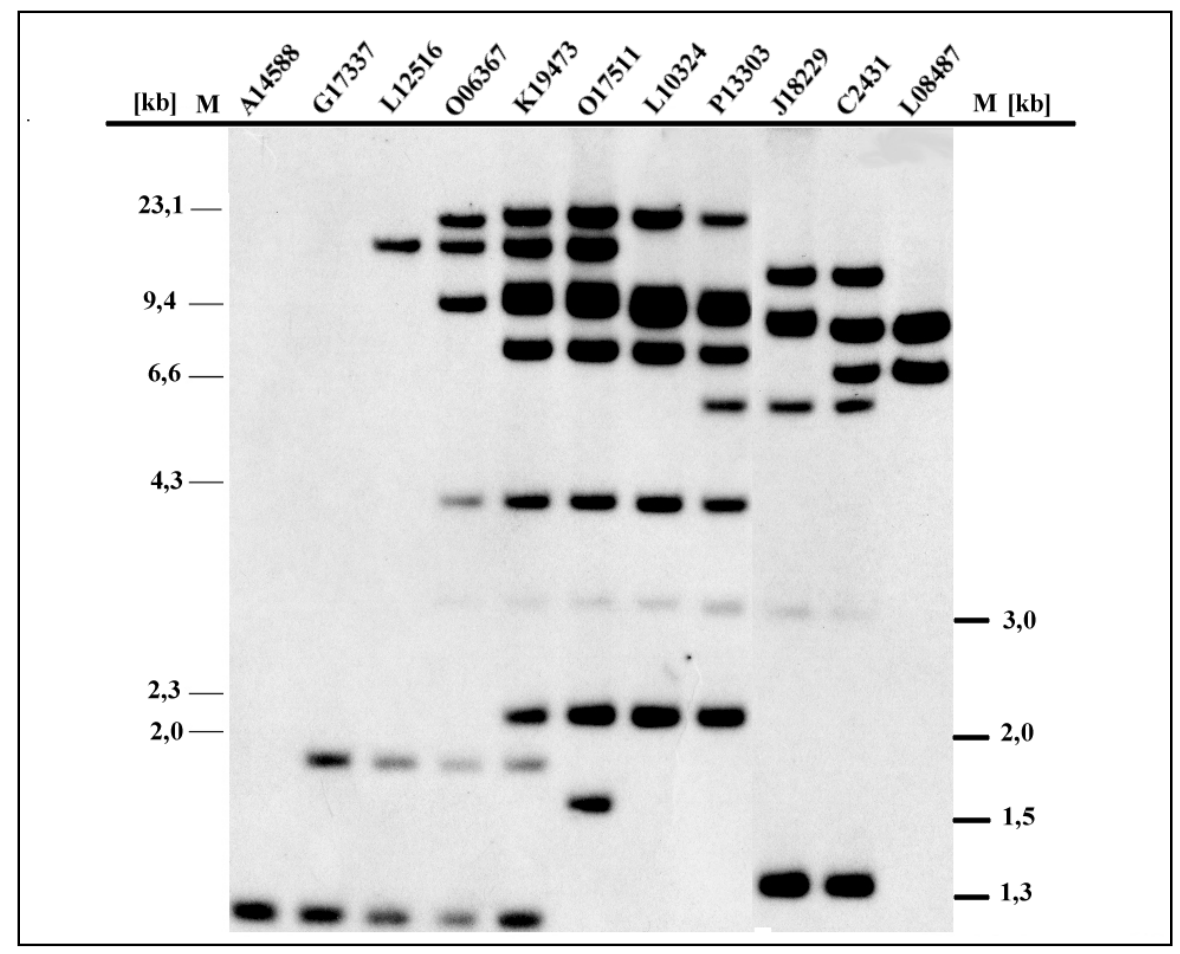


Abb. 12: Southernblotanalyse von BamHI verdaute DNA von PAC-Klonen des Contigs 1 mit der a1-Probe. Die Bezeichnungen der Klone finden sich über den Bahnen. Links und rechts ist der Längenstandard angegeben. Eine Zusammenstellung der Klone finden sich in Tab. 3, die Zuordnung zu Contig 1 ist in Abb. 14 gezeigt.

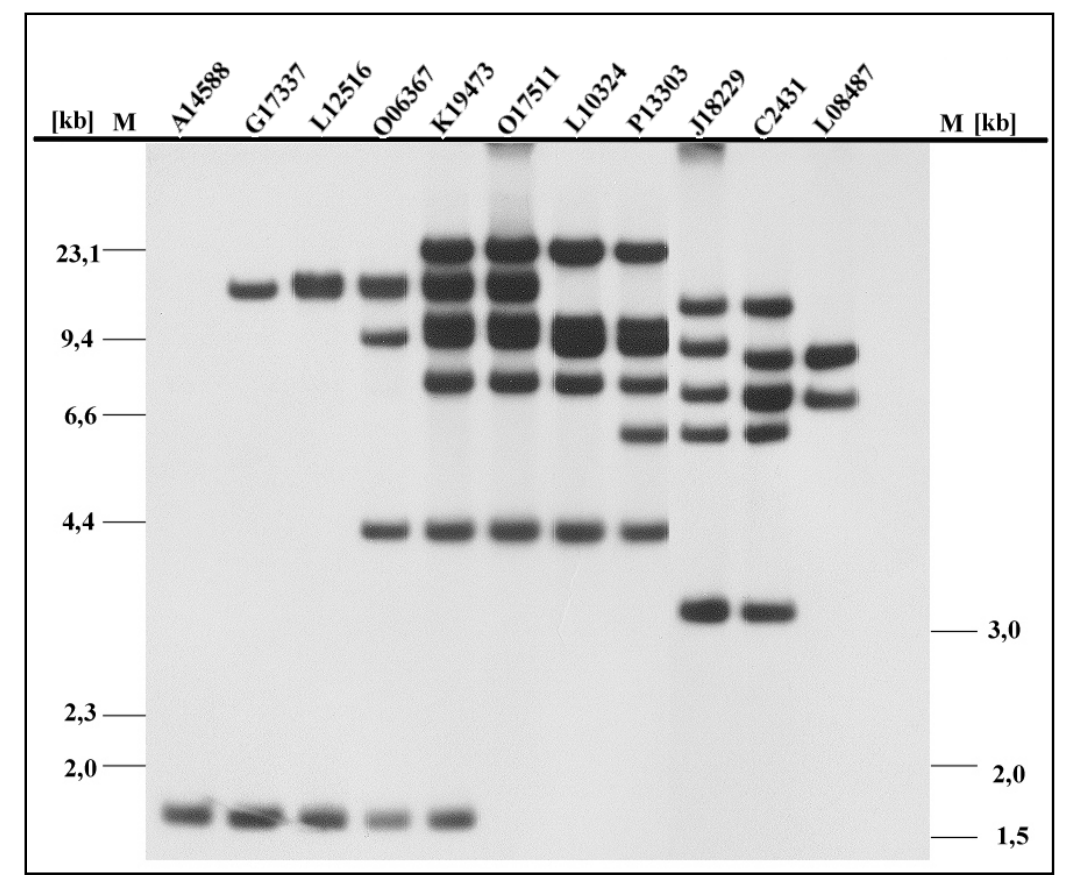

Abb. 13: Southernblotanalyse von BamHI verdaute DNA von PAC-Klonen des Contigs 1 mit der a3-Probe. Es sind repräsentativ die meisten PAC-Klone, die Klasse-I-Gene tragen gezeigt. Links und rechts ist der Längenstandard angegeben.Die Zusammenfassung der gesamten Klone dieses Contigs ist auf der Tab. 3 und Abb. 14 zu entnehmen.

Tab. 3: Zusammenfassung der PAC-Klone, die dem Contig 1 zugeordnet wurden. Aufgeführt sind die PAC-Bezeichnung, Filter-Nummer der Ratten-PAC-Bank sowie die Koordinaten der Klone. Weiterhin ist das Ergebnis der Hybridisierung der PAC-Klone mit verschiedenen Proben aus dieser Region angegeben.

\begin{tabular}{|l|l|l|l|l|l|l|}
\hline & PAC & Filter Nr. & Koordinaten & $\begin{array}{l}\text { Hybridisierungs- } \\
\text { Fragmente mit } \\
\text { der } \alpha 1 \text {-Probe }\end{array}$ & $\begin{array}{l}\text { Hybridisierungs- } \\
\text { Fragmente mit } \\
\text { der } \alpha 3 \text {-Probe }\end{array}$ & $\begin{array}{l}\text { Hybridisierung } \\
\text { mit weiteren } \\
\text { Proben }\end{array}$ \\
\hline 1 & $\mathbf{A 1 4 5 8 8}$ & $110-9-122$ & $\begin{array}{r}17178, \\
17380\end{array}$ & 1 & 1,8 & $\begin{array}{l}\text { Tnfa } \\
\text { Bat1 }\end{array}$ \\
\hline 2 & $\mathbf{H 0 4 4 7 3}$ & $110-6-161$ & $\begin{array}{l}104203, \\
101204\end{array}$ & $1 / 2$ & $1,8 / 18$ & Tnfa \\
Bat1
\end{tabular}




\begin{tabular}{|c|c|c|c|c|c|c|}
\hline 3 & G17337 & & $\begin{array}{l}36128 \\
38130\end{array}$ & $1 / 2$ & $1,8 / 18$ & $\begin{array}{l}\text { Tnfa } \\
\text { Bat1 }\end{array}$ \\
\hline 4 & L12516 & $110-7-158$ & $\begin{array}{l}184101 \\
181101\end{array}$ & $1 / 2 / 19$ & $1,8 / 18 / 19$ & $\begin{array}{l}\text { Tnfa } \\
\text { Bat1 }\end{array}$ \\
\hline 5 & 006367 & $110-6-116$ & $\begin{array}{l}9186, \\
9486\end{array}$ & $1 / 2 / 19 / 23 / 10 / 4$ & $1,8 / 18 / 19 / 10 / 4$ & $\begin{array}{l}\text { Tnfa } \\
\text { Bat1 }\end{array}$ \\
\hline 6 & K19473 & $110-6-161$ & $\begin{array}{l}29188, \\
26189\end{array}$ & $\begin{array}{l}1 / 2 / 19 / 23 / 10 / 4 / \\
2,3 / 12 / 8\end{array}$ & $\begin{array}{l}1,8 / 18 / 19 / 10 / 4 / \\
24 / 12 / 8\end{array}$ & Bat1 \\
\hline 7 & 017511 & $110-7-158$ & $\begin{array}{l}3986 \\
3686\end{array}$ & $\begin{array}{l}2 / 19 / 23 / 10 / 4 / \\
2,3 / 12 / 8 / 9,5\end{array}$ & $\begin{array}{l}18 / 19 / 10 / 4 / 24 / \\
12 / 8 / 9,5\end{array}$ & \\
\hline 8 & L10324 & $110-5-138$ & $\begin{array}{l}192103, \\
192101\end{array}$ & $\begin{array}{l}23 / 10 / 4 / 2,3 / 12 / 8 / \\
9,5 / 6\end{array}$ & $\begin{array}{l}10 / 4 / 24 / 12 / 8 / \\
9,5 / 6\end{array}$ & \\
\hline 9 & P13303 & $110-5-138$ & $\begin{array}{l}179164, \\
180161\end{array}$ & $\begin{array}{l}23 / 10 / 4 / 2,3 / 12 / 8 / \\
9,5 / 6 / 3,5 / 1,2\end{array}$ & $\begin{array}{l}10 / 4 / 24 / 12 / 8 / \\
9,5 / 6 / 3,5\end{array}$ & \\
\hline 10 & J18229 & $110-4-122$ & $\begin{array}{l}3414, \\
35111\end{array}$ & $\begin{array}{l}9,5 / 6 / 3,5 / 1,2 / \\
17 / 8,5\end{array}$ & $\begin{array}{l}9,5 / 6 / 3,5 / 7 / 17 / \\
8,5\end{array}$ & \\
\hline 11 & E05168 & $110-3-110$ & $\begin{array}{l}219140 \\
218137\end{array}$ & $\begin{array}{l}9,5 / 6 / 3,5 / 1,2 / \\
17 / 8,5\end{array}$ & $\begin{array}{l}9,5 / 6 / 3,5 / 7 / 17 / \\
8,5\end{array}$ & \\
\hline 12 & K18224 & $110-4-122$ & $\begin{array}{l}15426 \\
15126\end{array}$ & $\begin{array}{l}9,5 / 6 / 3,5 / 1,2 / \\
17 / 8,5\end{array}$ & $\begin{array}{l}9,5 / 6 / 3,5 / 7 / 17 / \\
8,5\end{array}$ & \\
\hline 13 & A22327 & $110-5-138$ & $\begin{array}{l}134238, \\
131239\end{array}$ & $\begin{array}{l}3,5 / 1,2 / 17 / 8,5 / \\
6,8\end{array}$ & $3,5 / 7 / 17 / 8,5 / 6,8$ & \\
\hline
\end{tabular}




\begin{tabular}{|c|c|c|c|c|c|c|}
\hline 14 & J12142 & $110-2-127$ & $\begin{array}{l}6532 \\
6331\end{array}$ & $\begin{array}{l}3,5 / 1,2 / 17 / 8,5 / \\
6,8\end{array}$ & $3,5 / 7 / 17 / 8,5 / 6,8$ & \\
\hline 15 & K03168 & $110-3-110$ & $\begin{array}{l}229110 \\
228107\end{array}$ & $\begin{array}{l}3,5 / 1,2 / 17 / 8,5 / \\
6,8\end{array}$ & $3,5 / 7 / 17 / 8,5 / 6,8$ & \\
\hline 16 & D07219 & $110-4-122$ & $\begin{array}{l}206225, \\
206222\end{array}$ & $\begin{array}{l}3,5 / 1,2 / 17 / 8,5 / \\
6,8\end{array}$ & $3,5 / 7 / 17 / 8,5 / 6,8$ & \\
\hline 17 & L08487 & $110-2-127$ & $\begin{array}{l}15105 \\
12104\end{array}$ & $8,5 / 6,8$ & $8,5 / 6,8$ & \\
\hline 18 & C2431 & $110-1-116$ & $\begin{array}{l}2146 \\
2148\end{array}$ & $\begin{array}{l}9,5 / 6 / 3,5 / 1,2 / \\
17 / 8,5 / 6,8\end{array}$ & $\begin{array}{l}9,5 / 6 / 3,5 / 7 / 17 / \\
8,5 / 6,8\end{array}$ & Pou 5f1 \\
\hline 19 & C2331 & $110-1-116$ & $\begin{array}{l}7146, \\
7148\end{array}$ & $\begin{array}{l}9,5 / 6 / 3,5 / 1,2 / \\
17 / 8,5 / 6,8\end{array}$ & $\begin{array}{l}9,5 / 6 / 3,5 / 7 / 17 / \\
8,5 / 6,8\end{array}$ & Pou 5f1 \\
\hline 20 & A24506 & $110-8-108$ & $\begin{array}{l}12180 \\
12177\end{array}$ & & & $\begin{array}{l}S \\
\text { Cak } \\
\text { Gtf2 }\end{array}$ \\
\hline 21 & K11482 & $110-7-111$ & $\begin{array}{l}18830 \\
18628\end{array}$ & & & $\begin{array}{l}\text { Cak } \\
\text { Gtf2 }\end{array}$ \\
\hline 22 & N0751 & $110-9-155$ & $\begin{array}{l}208175 \\
206173\end{array}$ & & & $\begin{array}{l}\text { Cak } \\
\text { Gtf2 }\end{array}$ \\
\hline 23 & H13218 & $110-4-135$ & $\begin{array}{l}17645 \\
17642\end{array}$ & & & $\begin{array}{l}\text { Cak } \\
\text { Gtf2 }\end{array}$ \\
\hline 24 & D20510 & $110-8-108$ & $\begin{array}{l}141145 \\
141142\end{array}$ & & & $\begin{array}{l}\text { Cak } \\
\text { Gtf2 }\end{array}$ \\
\hline
\end{tabular}




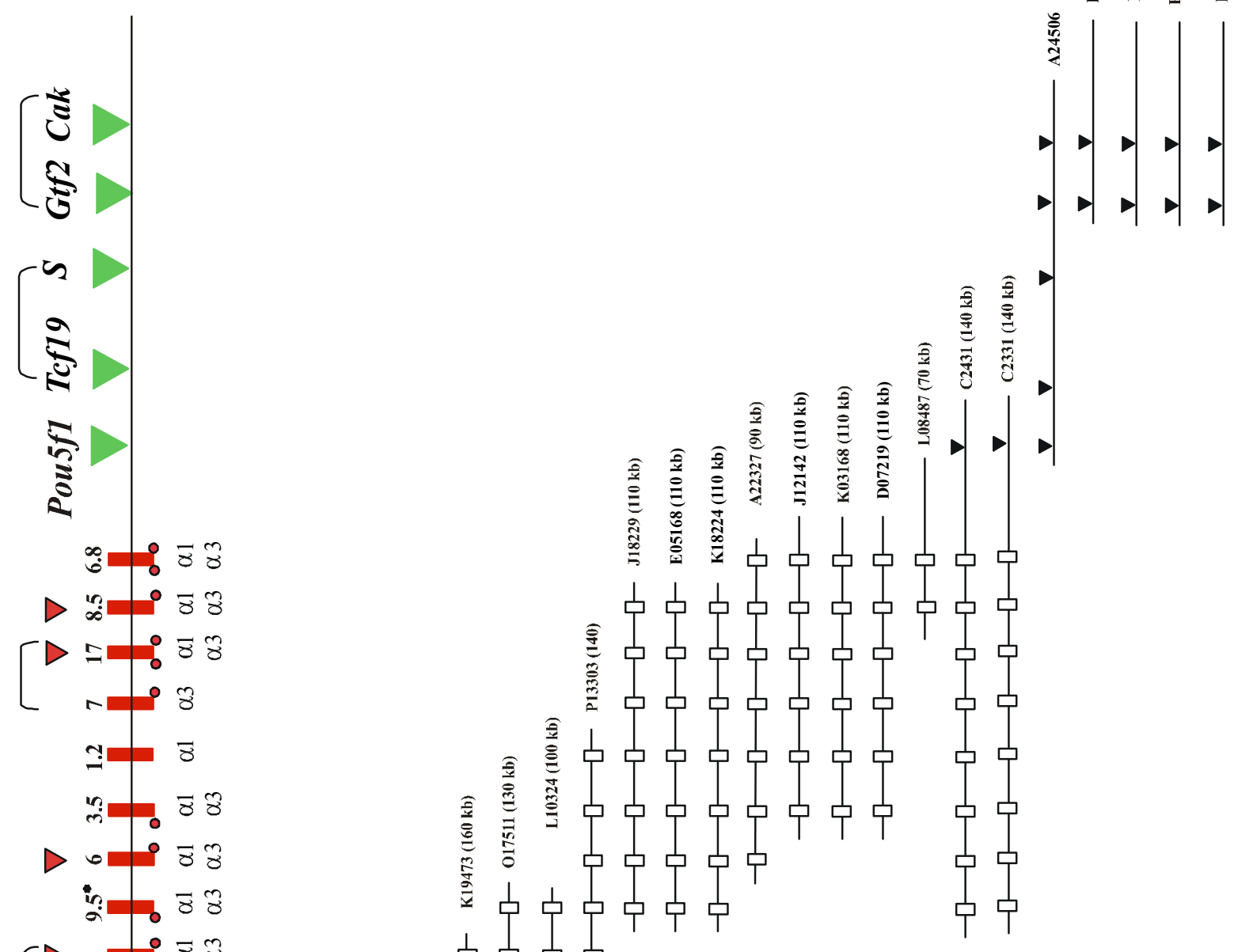

产 离离

政家

을

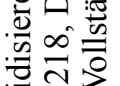

实离

旅

安家

si

表焉

过

西

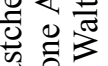

$\ddot{\square}$

氖客

인

을

a

赔声

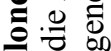

굴

远要

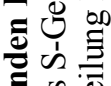

赔要

产

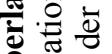

:

흥

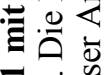

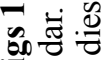

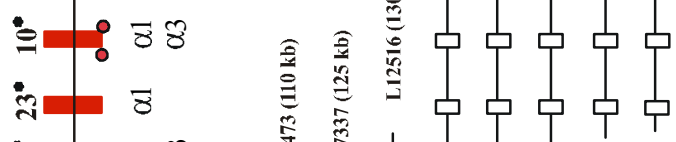

古口宁员

政

过

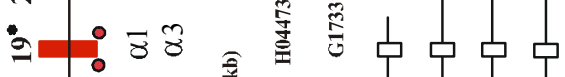

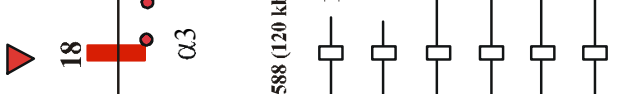

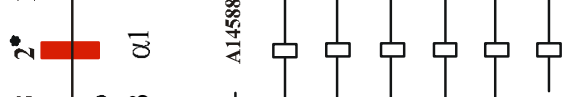

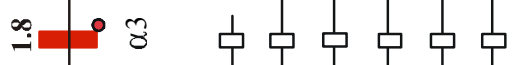

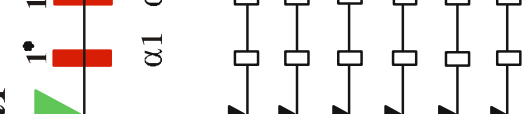

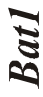

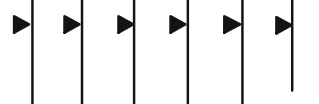

$\frac{\pi}{2}$
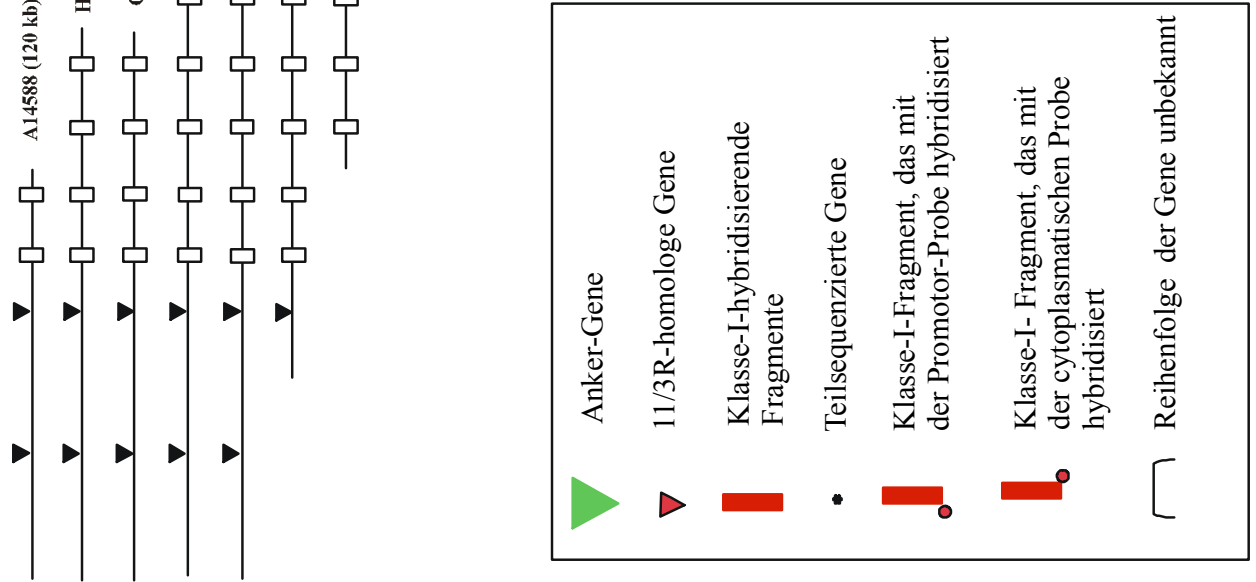

㱐产的

定焉

政

ปัँ

일

要

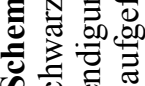

no

$\dot{I} .00$

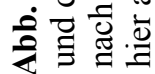




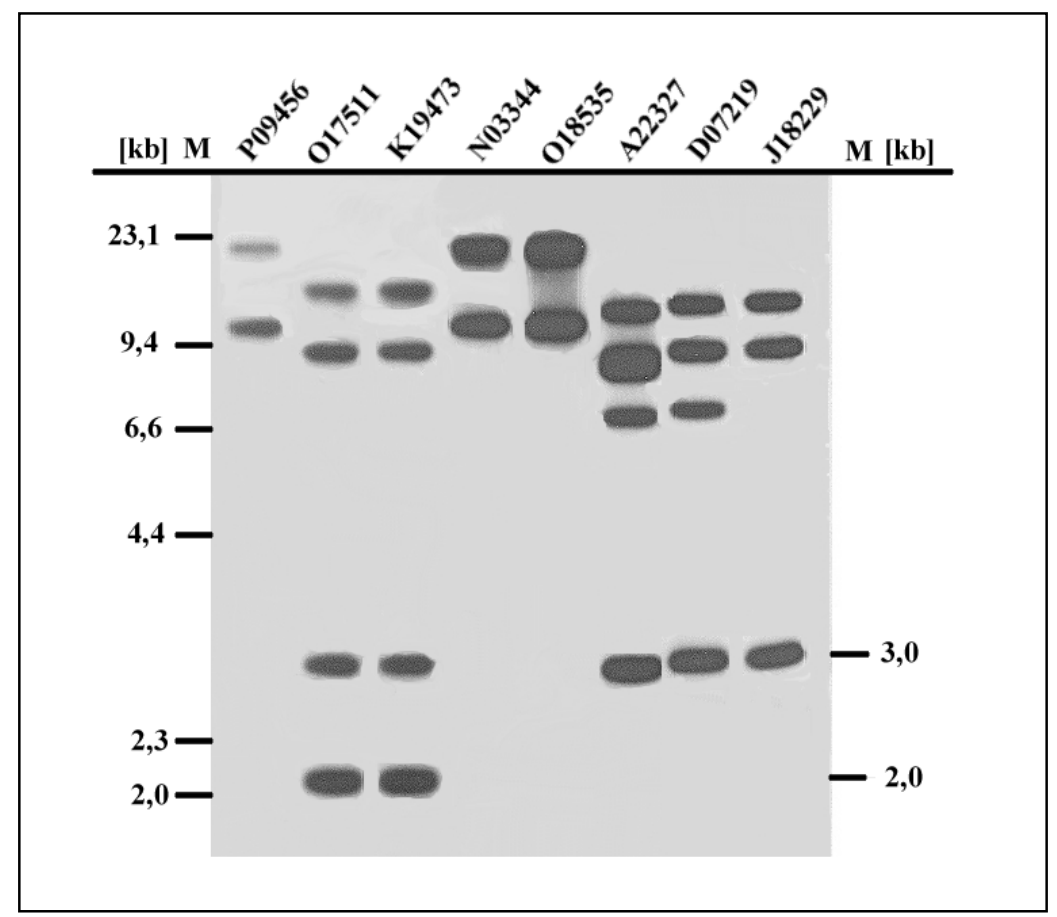

Abb. 15: Hybridisierungs eines Southernblots mit der Promotor-Probe. Es sind überlappende PAC-Klone angegeben, die dem Contig 1 zugeordnet wurden und alle dort detektierten Klasse-I-Gene umfassen. Es ist erkennbar, daß die Promotor-Probe eine weitere Bande der Länge 3,0 kb erkennt, welche weder mit der $\alpha 1$ - noch mit der $\alpha 3$-Probe reagiert. Die drei PAC-Klone P09456, N03344 und O18535 gehören der RT1-A Region an, da sie auch mit Sacm21- bzw. Ring1-Probe hybridisieren (nicht gezeigt). Die Längenstandards sind auf der linken und rechten Seite des Blots angegeben.

Die Überprüfung der PAC-Klone mit der Promotor-Probe ergab, daß nur einige der Klasse-Ipositiven Fragmente des Contig 1 mit dieser Probe hybridisieren sowie die der $R T 1$ - $A$-Region zugeordnete Klone. In der Abb. 15 sind nicht alle Klone des Contigs 1 aufgeführt, sondern ein „minimal-Contig“, das alle Klasse-I-Gene des Contigs repräsentiert. Verglichen mit den Daten aus der $\alpha 1$ - und $\alpha 3$-Hybridisierung reagiert das erste $(1 / 1,8 \mathrm{BamHI})$ und das zweite Gen (2/18 BamHI) nicht mit dieser Promotor-Probe. Dieses könnte bedeuten, daß diese Gene entweder keine Promotoren enthalten oder daß der Promotor keine auszureichende Homologie zu dem der Klasse-Ia-Gene zeigt. Folgende $\alpha 1$-positive BamHI-Fragmente reagieren ebenfalls nicht mit der Promotor-Probe: 23 kb, 4 kb, 12 kb, 8 kb, 6 kb, 1,2 kb, 8,5 $\mathrm{kb}$. 
Die restlichen sieben BamHI-Fragmente die sowohl mit der $\alpha 1$-Probe als auch mit der $\alpha 3-$ Probe hybridisieren und vermutlich vollständige Gene tragen, hybridisieren zusätzlich mit der oben genannten Promotor Probe.

Die Hybridisierung mit einer Sonde aus dem cytoplasmatischen Teil eines klassischen KlasseI-Gens (s. 2.13 und Abb. 5) zeigt, daß fast alle $\alpha 3$-hybridisierenden Fragmente des Contigs 1 mit dieser Probe reagieren. Ausnahmen bilden das $12 \mathrm{~kb}$ - und das 9,5 kb-BamHI-Fragment (Abb. 16).

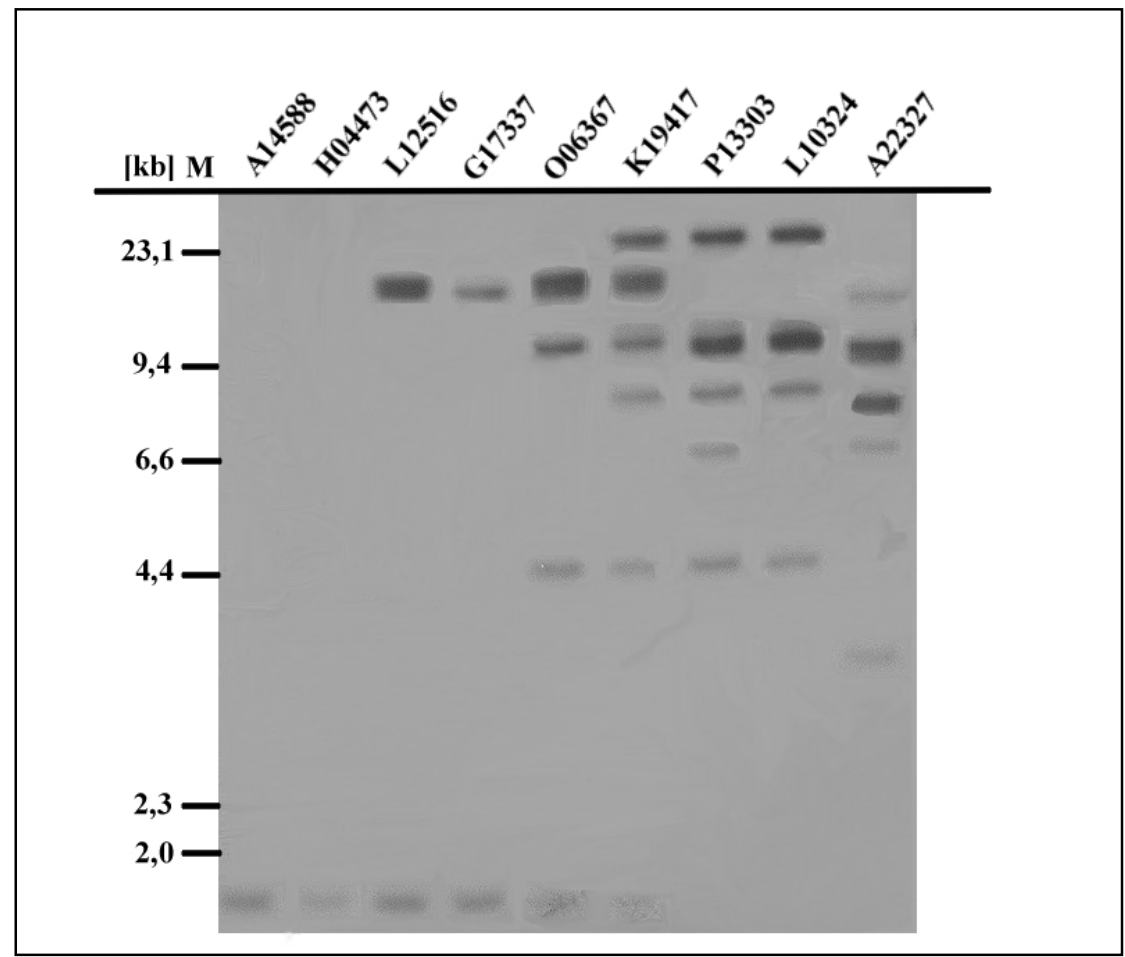

Abb. 16: Hybridisierung eines Southernblots, der Klone aus dem Contig 1 enthält, mit der Sonde aus dem cytoplasmatischen Teil eines klassischen Klasse-I-Gens. Links ist der Längenstandard angegeben.

Ausschließlich die PAC-Klone C2331 und C2341 zeigten eine Hybridisierung mit der Probe für das Gen Pou5f1 (Rosner et al., 1990) auf einer Laufhöhe von 900 bp (Abb. 14).

Die Kartierung des H2-Komplexes (Amadou et al., 1999) sowie die Sequenzierung des humanen MHC (The MHC Sequencing Consortium, 1999) zeigen, daß zwischen dem Pou5f1 und Gna-rs1 (s. Abb. 23) keine Klasse-I-Gene zu finden sind. Diese Region enthält jedoch einige konservierte Gene an orthologer Position bei Maus und Mensch.

Um diese Region auch in der Ratte zu klonieren, wurde ein weiteres Screening der PAC-Bank mit Proben aus dem $C A K$-Gen und dem GTF2H4-Gen (4.2.) des humanen MHC (Forbes und 
Trowsdale 1999) vorgenommen. Fünf positive Klone wurden erhalten: A24506, K11482, N0751, H13318 und D20510. Diese Klone wurden in der Zwischenzeit in der Abteilung Immungenetik weiter untersucht, und es wurde gezeigt, daß der PAC-Klon A24506 die Gene Pou5f1, Tcf19, S, Gtf2 und Cak trägt. Die restlichen vier Klone tragen nur die Gene Gtf2h4 und Cak.

\subsubsection{Sequenzierung der Enden einiger PAC-Klone aus dem Contig 1}

Es wurden Sequenzierungen der Enden aus einigen Klonen des Contigs 1 durchgeführt, um Sequenz-Informationen aus dieser Region zu erhalten und um walking-Proben (STS-Marker) zu erstellen.

Der PAC-Klon A14588 wurde mit dem Vektor-spezifischen Primer pPAC4-3 direkt ansequenziert. Erhalten wurde eine Sequenz von ca. 500 bp. Diese zeigt Homologie zur bekannten Sequenz der $\beta$-Untereinheit der murinen Protein-Kinase CK2 (Boldyreff et al., 1995). Diese Sequenz ist im $3^{6}$-utr des Gens lokalisiert, und die Sequenzidentität auf Nukleotid-Ebene liegt in verschiedenen Bereiche zwischen 87\% und 94\%. Aufgrund der Lokalisation des humanen und des Maus-CK2-Gens in der Klasse-III-Region muß es sich um das centromere Ende des PAC-Klons handeln, das ansequenziert wurde

Mit dem Vektor-spezifischen Primer pPAC4-3 und dem Klasse-Ia-spezifischen Primer RT1.A3“ wurde durch long range PCR am PAC-Klon G17337 ein 6 kb langes Fragment erhalten. Das positive PCR-Ergebnis zeigte zunächst, daß ein Klasse-I-Gen nah am telomeren Ende dieses Klons liegen muß. Sequenzierung mit dem pPAC4-3-Primer ergab eine lesbare Sequenz von 500 bp Länge ohne signifikante Homologie zu den in der Datenbank enthaltenen Sequenzen.

Aus der Endsequenzierung des centromeren Endes des Klons C2331 wurde die Sequenz eines Klasse-I-Gens erhalten, die 90\% Sequenzähnlichkeit zu einem LW2-ähnlichen Klasse I Gen (Yuan et al., 1998) zeigt.

Die Sequenzierungsdaten sind im Anhang gezeigt (8.2) 


\subsubsection{11/3R-homologe Gene im Contig 1}

Das Gen 11/3R (Rothermel et al., 1993) ist ein Klasse-Ib-Gen der Ratte. Die genspezifische Probe 11/3R-5/1 aus dem NC2-Teil des 3'-utr wurde verwendet, um das Contig 1 nach 11/3R-verwandten Genen zu untersuchen. Im Contig 1 wurden sieben Klasse-I-Fragmente identifiziert, die mit dieser Probe hybridisierten die 18 kb-, 24 kb-, 12 kb-, 8 kb-, 6 kb-, 17 kb, und 8,5 kb-BamHI-Fragmente (Abb. 14, 17).

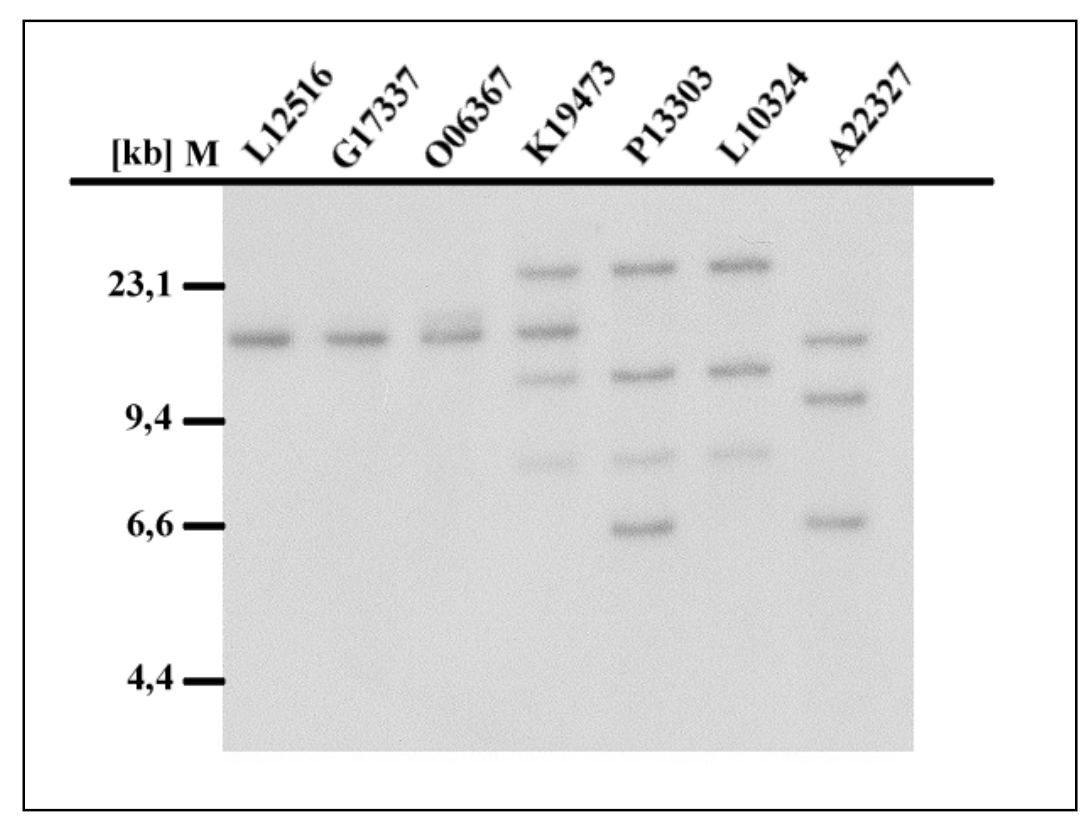

Abb. 17: Southernblot-Hybridisierung mit der 11/3R-5/1-Probe. Einige der $\alpha 3$-hybridisierenden Fragmente reagieren mit dieser Probe. Sieben 11/3R-homologe Gene (Genfragmente) befinden sich im Contig 1. Links ist der Längenstandard angegeben.

\subsubsection{Subklonierung und Teil-Sequenzierung einiger Klasse-I-Gene aus dem Contig 1}

$\mathrm{Zu}$ Beginn der Untersuchungen der RT1-C/M-Region wurden die zuerst erhaltenen Klone A14588, G17337 und O06367 und damit die telomerwärts zu Bat1 gelegenen ersten sechs Klasse-I-Gene eingehender analysiert. Dazu wurden die BamHI-Fragmente des jeweiligen Klons in den pBluescript-Vektor subkloniert und die so erhaltenen Subbanken nach Klasse-IGenen oder Genfragmenten gescreent (s. 3.12). Auf diesem Wege wurden folgende nach der Insertlänge bezeichneten Subklone isoliert: 
$1 \mathbf{k b} \quad \alpha 1$-positives-Fragment des ersten Klasse-I-Gens auf dem Contig 1

$\mathbf{1 , 8} \mathbf{~ k b} \quad \alpha 3$-positives-Fragment des ersten Klasse-I-Gens auf dem Contig 1

2 kb $\quad \alpha 1$-positives-Fragment des zweiten Klasse-I-Gens auf dem Contig 1

$18 \mathbf{~ k b} \quad \alpha 3$ positives-Fragment des zweiten Klasse-I-Gens auf dem Contig 1

19 kb $\quad \alpha 1 / \alpha 3-$ und Promotor/Cyto- positives-Fragment

$23 \mathbf{k b} \quad \alpha 1$-positives Fragment

10 kb $\quad \alpha 1 / \alpha 3-$ und Promotor/Cyto- positives-Fragment

$4 \mathbf{k b} \quad \alpha 1 / \alpha 3$ und Cyto-positives Fragment

Die Reihenfolge dieser Gene auf dem Contig ist durch die dachziegelartige Überlappung der Kloneleicht festzulegen. Das erste Klasse-I-Gen aus dem PAC-Klon A14588 wurde zusätzlich als 3,7 kb EcoRI-Fragment isoliert und subkloniert.

Weiterhin wurden aus den sechs oben erwähnten Genen bzw. Genfragmenten die Sequenzen aus dem Exon 2 des Klasse-I-Gens ermittelt.

In Abbildung 18 wurden diese Sequenzen mit der Sequenz zweier Klasse-I-Gene aus der RT1-A-Region und mit der von zweibereits bekannten Klasse-I-Gene der RT1-C/M-region verglichen. Die variablen Nukleotide wurden jeweils hervorgehoben. 


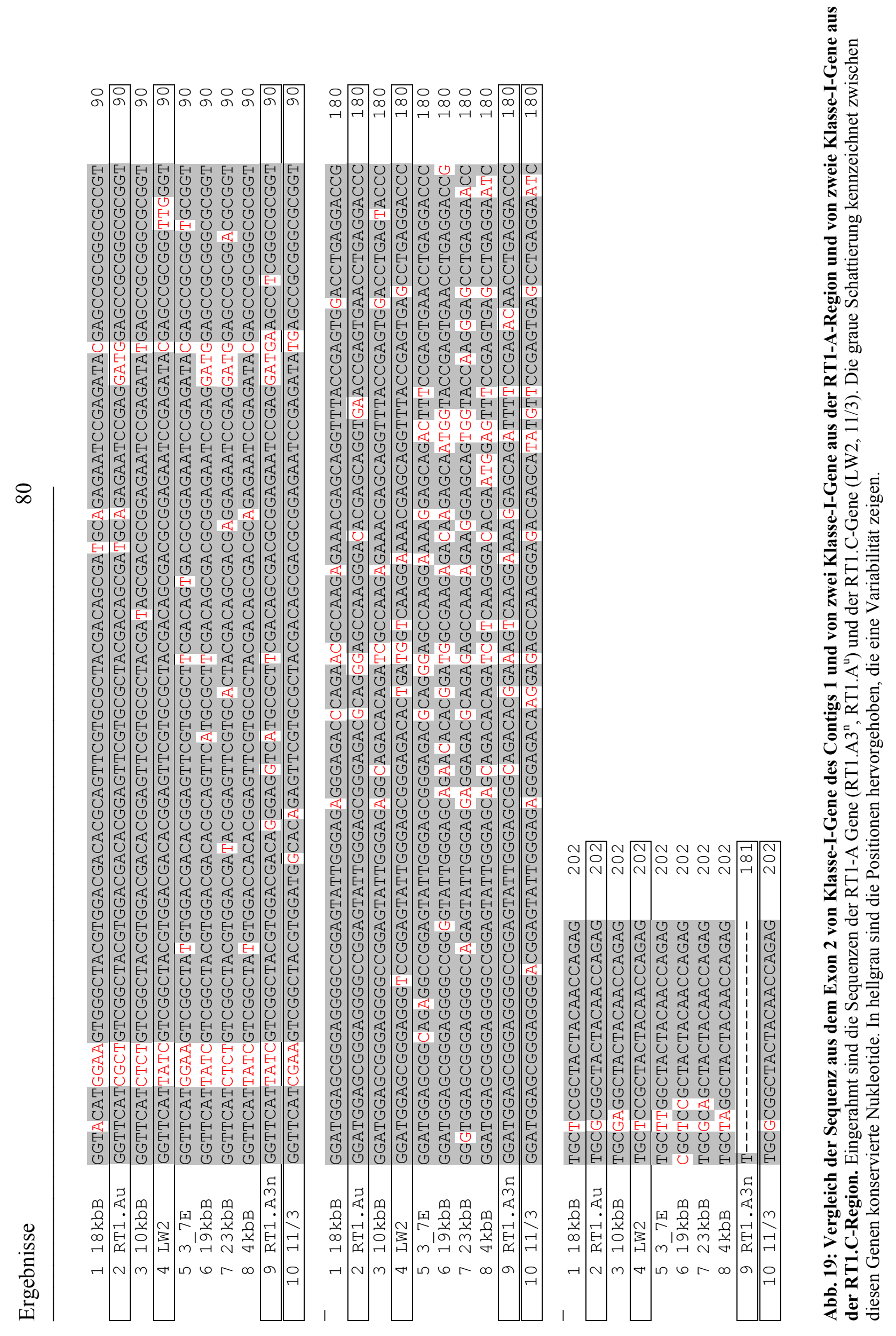


4.3.1.4 Sequenzhomologie der $\alpha$ 1-Domäne von Klasse-I-Gene des Contigs 1 zu anderen Klasse-I-Genen

Durch PCR an den erhaltenen Subklonen unter Verwendung der Exon 2-spezifischen Primer RT1.A3' und RT1.A7 wurden Produkte von 270 bp erhalten und sequenziert. Die Sequenzen wurden mit der Datenbank verglichen. Die ermittelte Sequenzidentität zu anderen Klasse-IGenen wird in Tabelle 4 zusammengefasst.

Tab. 4: Vergleich der Exon-2-Sequenz der sechs centromeren Klasse-I-Gene bzw. Genfragmente des Contigs 1 mit in der Datenbank vorhandenen Klasse-I-Sequenzen. Angegeben sind die jeweils höchste Sequenzidentität, die entsprechende Zugangs-Nummer für die homologe Sequenz in der Datenbank sowie die entsprechende Referenz.

\begin{tabular}{|c|c|c|c|c|}
\hline $\begin{array}{l}\text { Klasse-I-Gen bzw. } \\
\text { Genfragment des } \\
\text { Contigs } 1 \\
\text { (Bezeichnung durch } \\
\text { BamHI- bzw. EcoRI- } \\
\text { Restriktionsfragment }\end{array}$ & $\begin{array}{l}\text { Sequenzidentität } \\
\text { in \% } \\
\text { (Länge der } \\
\text { homologen } \\
\text { Bereiche) }\end{array}$ & $\begin{array}{l}\text { Homologes } \\
\text { Gen }\end{array}$ & $\begin{array}{l}\text { Accession } \\
\text { number }\end{array}$ & Referenz \\
\hline $\begin{array}{l}\text { 1. 1/1,8 BamHI } \\
\text { oder 3,7 EcoRI }\end{array}$ & $99 \%(207 / 209$ bp $)$ & RT1-U ${ }^{\mathrm{c}}$ & AJ005022 & $\begin{array}{l}\text { Leong et al., } \\
1999\end{array}$ \\
\hline 2. 2/18 BamHI & $99 \%(234 / 235$ bp $)$ & $\mathrm{RT} 1-\mathrm{A} 2^{\mathrm{n}}$ & X90376 & $\begin{array}{l}\text { Joly et al., } \\
1998\end{array}$ \\
\hline \multirow{2}{*}{ 3. $19 \mathrm{~kb}$ BamHI } & $90 \%(191 / 211 \mathrm{bp})$ & H2-Q8 (Maus) & U57392 & $\begin{array}{l}\text { Weiss et al., } \\
1984\end{array}$ \\
\hline & $88 \%(216 / 244 b p)$ & $\mathrm{RT} 1-\mathrm{A} 1^{\mathrm{h}}$ & AJ249698 & \\
\hline
\end{tabular}




\begin{tabular}{|c|c|c|c|c|}
\hline 4. $23 \mathrm{~kb} \mathrm{BamHI}$ & $88 \%(177 / 201 b p)$ & RT1-A & X82669 & $\begin{array}{l}\text { Walter et al., } \\
1995\end{array}$ \\
\hline \multirow{2}{*}{$5.10 \mathrm{~kb} \mathrm{BamHI}$} & $95 \%(199 / 209 b p)$ & $\mathrm{RT} 1-\mathrm{A} 1^{\mathrm{k}}$ & AJ 249702 & \\
\hline & $93 \%(196 / 209 b p)$ & RT $1-A 1^{b}$ & AJ2449704 & \\
\hline \multirow{2}{*}{$6.4 \mathrm{~kb} \mathrm{BamHI}$} & $100 \%(202 / 202 b p)$ & RT1.E ${ }^{\mathrm{g}}$ & AJ 243338 & \\
\hline & $100 \%(202 / 202 b p)$ & clone 4 & U50447 & $\begin{array}{l}\text { Wang et al., } \\
1996\end{array}$ \\
\hline
\end{tabular}

Aus den aufgeführten Daten in Tab. 4 ist erkennbar, daß die bisher teilweise sequenzierten Klasse-I-Gene des Contigs 1 eine größere Homologie (zumindest im Exon 2) zu den Klasse-IGenen der RT1-A-Region als zu denen des Contigs 2 (siehe 4.3.2.1) zeigen.

\subsubsection{Beschreibung von Contig 2}

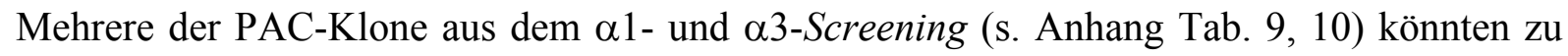
einem zweiten Contig geordnet werden (Contig 2), das eine Länge von ca. $1300 \mathrm{~kb}(1,3 \mathrm{Mb})$ beträgt. Aus Gründen der besseren Übersichtlichkeit wurde das Contig 2 in drei Abschnitte behandelt. In dem ersten Abschnitt wurden die ersten ca. $500 \mathrm{~kb}$ des Contig 2, in dem zweiten Abschnitt die darauffolgenden ca. $400 \mathrm{~kb}$ und in dem dritten Abschnitt die letzten ca. $400 \mathrm{~kb}$ beschrieben. 


\subsubsection{Contig 2, erster Abschnitt}

Im ersten Abschnitt (centromeres Ende) des Contigs 2 konnten 29 überlappende Klasse-IGen-tragende Klone anhand des $\alpha 1 / \alpha 3$-Hybridisierungsmusters angeordnet werden.
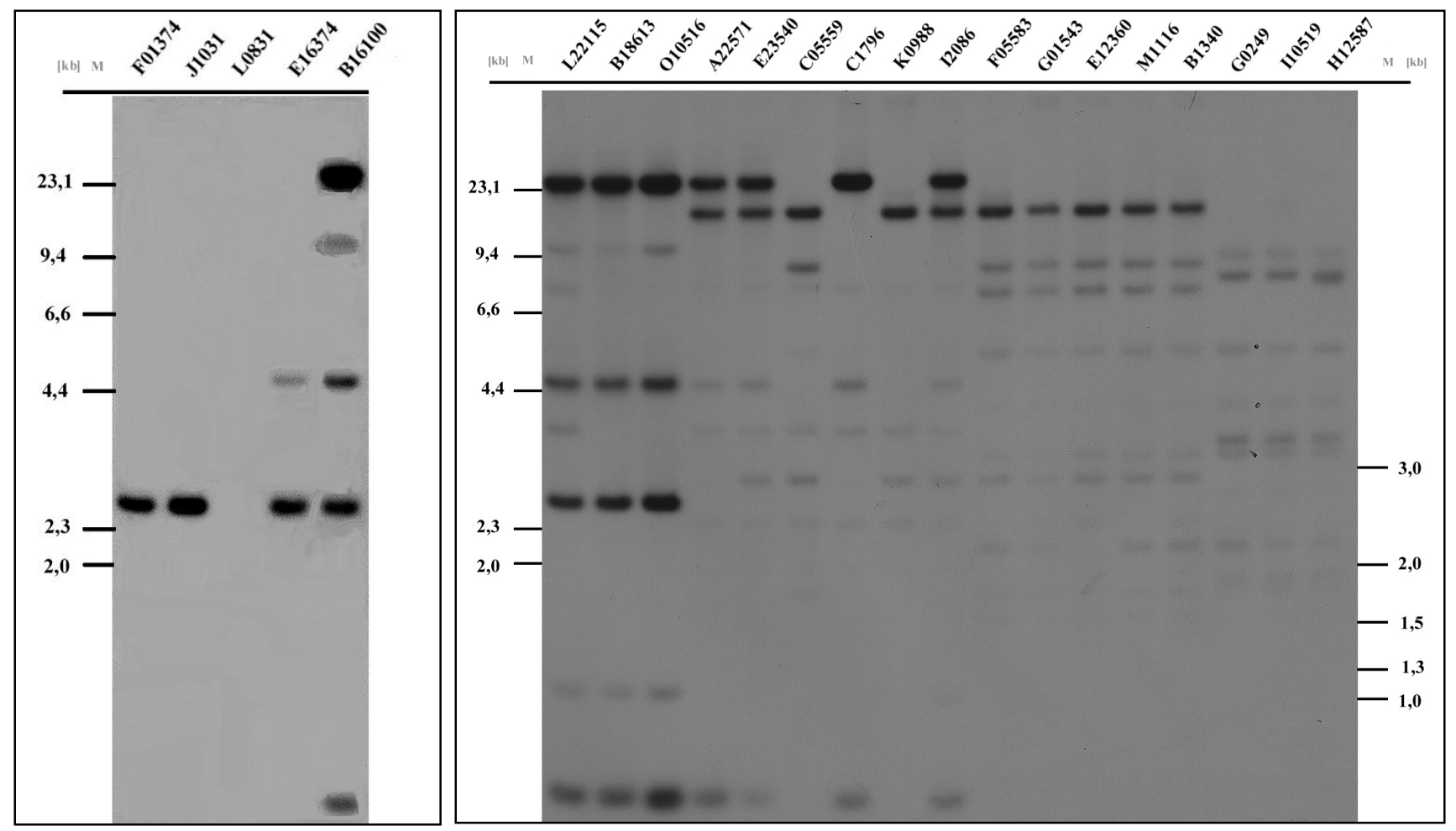

Abb. 19: Southernblot-Hybridisierung mit der $\alpha 1$-Probe. Die telomerwärts liegenden PAC-Klone (s. Abb. 21) zeigen eine große Anzahl mit der $\alpha 1$-Probe schwach hybridisierender Fragmente. Links und rechts sind die Längenstandards angegeben. 


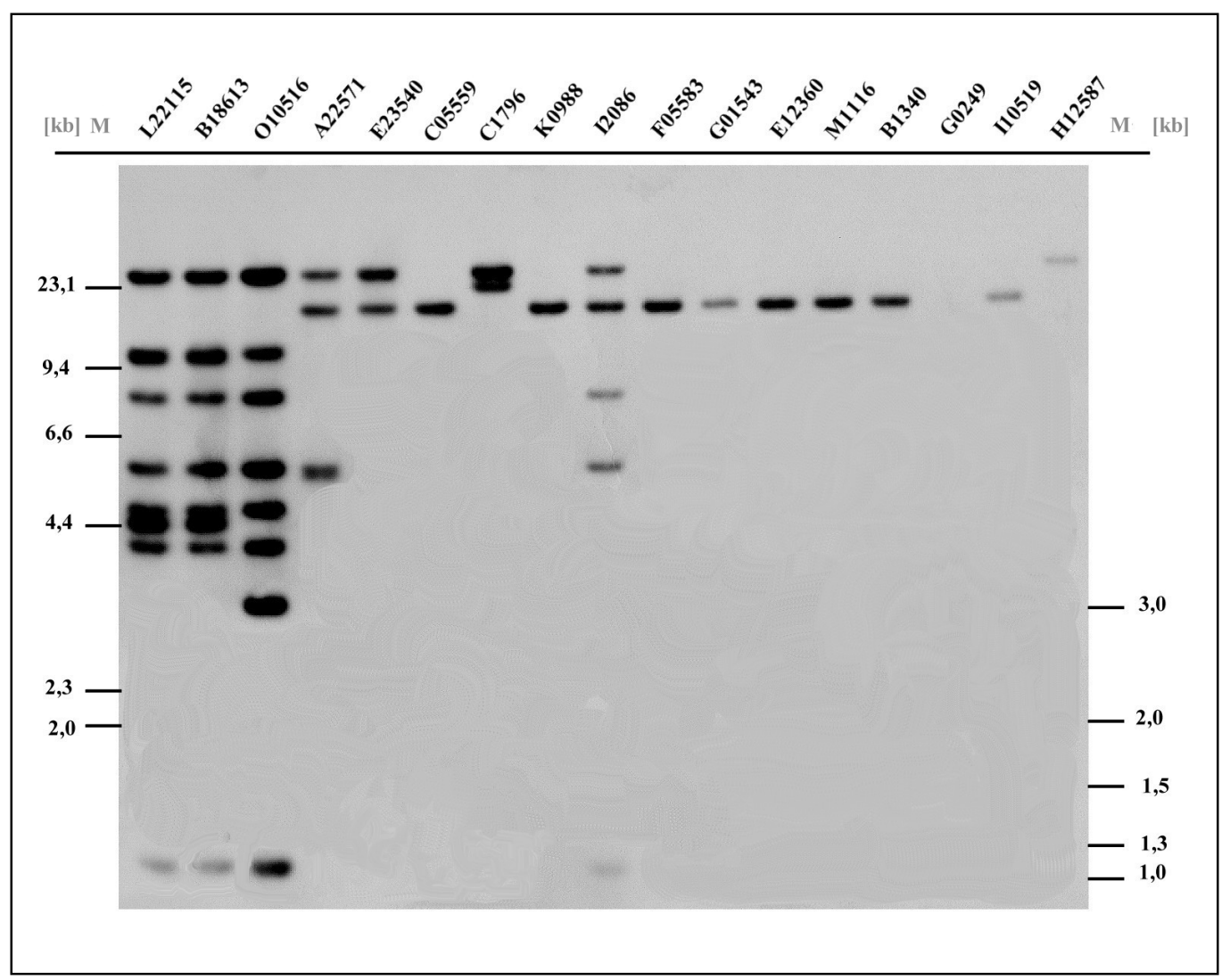

Abb. 20: Southernblot-Hybridisierung mit der $\alpha$ 3-Probe. Auffällig ist, daß die telomerwärts liegenden PAC-Klone (Abb. 21) nur ein $\alpha 3$-hybridisierendes Fragment tragen oder überhaupt keine $\alpha 3$-Hybridisierung zeigen. Links und rechts sind die Längenstandards angegeben.

Die Hybridisierungs-Ergebnisse mit den $\alpha 1$ - bzw. $\alpha 3$-Proben zeigen, daß über eine längere Region am telomeren Ende des ersten Abschnitts von Contigs 2 keine $\alpha 3$-Fragmente zu finden sind, jedoch eine größere Anzahl an $\alpha 1$-hybridisierenden Fragmenten (s. 4.3.2.2).

Tab. 5: PAC-Klone, die den ersten Abschnitt von Contig 2 bilden. Die Koordinaten der Klone aus der genomischen Bank werden angegeben sowie alle überprüften Hybridisierungen mit Klasse-IProben, und Proben von Anker-Genen sowie STS- Markern.

\begin{tabular}{|l|l|l|l|l|l|l|l|}
\hline & PAC & Filter Nr. & Koordinaten & $\begin{array}{l}\text { Länge der mit } \\
\text { der } \alpha 1 \text {-Probe } \\
\text { hybridisieren-den } \\
\text { Fragmente }[\mathrm{kb}]\end{array}$ & $\begin{array}{l}\text { Länge der mit } \\
\text { der } \alpha 3 \text {-Probe } \\
\text { hybridisieren-den } \\
\text { Fragmente }[\mathrm{kb}]\end{array}$ & $\begin{array}{l}\text { Hybridisie- } \\
\text { rung mit } \\
\text { Anker } \\
\text { Proben }\end{array}$ & $\begin{array}{l}\text { MTS- } \\
\text { Marker }\end{array}$ \\
\hline 1 & E06479 & $110-7-107$ & $\begin{array}{l}95220, \\
92219\end{array}$ & - & & Prg1 & \\
\hline
\end{tabular}




\begin{tabular}{|c|c|c|c|c|c|c|c|}
\hline 2 & F05479 & $110-7-107$ & $\begin{array}{l}100215, \\
97214\end{array}$ & & & Prgl & \\
\hline 3 & I16223 & $110-4-122$ & $\begin{array}{l}44116, \\
41116\end{array}$ & & & $\begin{array}{l}\text { Pnuts } \\
\text { Gna-rs1 }\end{array}$ & $\mathrm{I} 162 \mathrm{~T}$ \\
\hline 4 & I19108 & $110-2-127$ & $\begin{array}{l}147118, \\
147116\end{array}$ & & $8 / 10$ & $\begin{array}{l}\text { Pnuts } \\
\text { Gna-rs1 }\end{array}$ & $\mathrm{I} 162 \mathrm{~T}$ \\
\hline 5 & I16274 & $110-4-122$ & $\begin{array}{l}4538 \\
4237\end{array}$ & & $8 / 10 / 4,4$ & $\begin{array}{l}\text { Pnuts } \\
\text { Gna-rs1 }\end{array}$ & $\mathrm{I} 162 \mathrm{~T}$ \\
\hline 6 & F01374 & $110-6-116$ & 23954 & 2,5 & $8 / 10 / 4,4$ & $\begin{array}{l}\text { Pnuts } \\
\text { Gna-rs1 }\end{array}$ & $\mathrm{I} 162 \mathrm{~T}$ \\
\hline 7 & J1031 & $110-1-116$ & $\begin{array}{l}72111, \\
72113\end{array}$ & 2,5 & $8 / 10 / 4,4$ & $\begin{array}{l}\text { Pnuts } \\
\text { Gna-rs1 }\end{array}$ & $\mathrm{I} 162 \mathrm{~T}$ \\
\hline 8 & E16374 & $110-6-116$ & 16459 & $2,5 / 4,6$ & $8 / 10 / 4,4 / 4,6$ & $\begin{array}{l}\text { Pnuts } \\
\text { Gna-rs1 }\end{array}$ & $\mathrm{I} 162 \mathrm{~T}$ \\
\hline 9 & P05384 & $110-9-122$ & $\begin{array}{l}205152, \\
203151\end{array}$ & $4,6 / 12$ & $4,6 / 4 / 12 / 7,5$ & & \\
\hline 10 & B16100 & $110-2-127$ & $\begin{array}{l}4275 \\
4574\end{array}$ & $\begin{array}{c}2,5 / 4,6 / 12 / 0,5 / \\
24\end{array}$ & $\begin{array}{c}10 / 4,4 / 4,6 / 4 / 12 / \\
7,5 / 1 / 5 / 24\end{array}$ & & \\
\hline 11 & B18613 & $110-9-122$ & $\begin{array}{l}34153, \\
31154\end{array}$ & $\begin{array}{c}2,5 / 4,6 / 12 / 0,5 / \\
24\end{array}$ & $\begin{array}{c}4,4 / 4,6 / 4 / 12 / \\
7,5 / 1 / 5 / 24\end{array}$ & & \\
\hline 12 & L22115 & $110-2-127$ & $\begin{array}{l}15105 \\
12104\end{array}$ & $\begin{array}{c}2,5 / 4,6 / 12 / 0,5 / \\
24 / 4,6 / 3,5\end{array}$ & $\begin{array}{c}4,4 / 4,6 / 4 / 12 / \\
7,5 / 1 / 5 / 24\end{array}$ & & \\
\hline
\end{tabular}




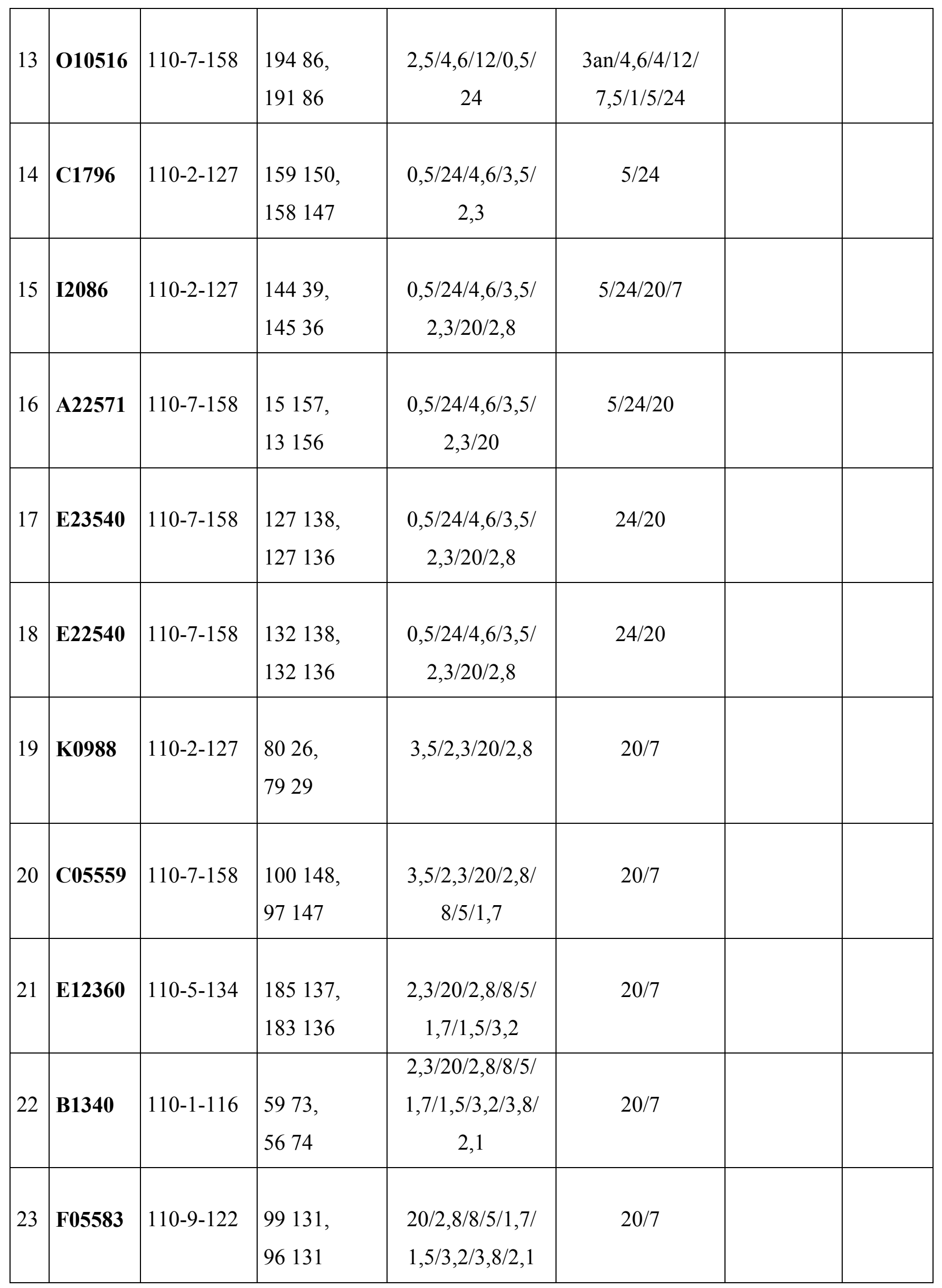




\begin{tabular}{|c|c|c|c|c|c|}
\hline 24 & G01543 & $110-7-158$ & $\begin{array}{l}239208, \\
236209\end{array}$ & $\begin{array}{l}20 / 2,8 / 8 / 5 / 1,7 / \\
1,5 / 3,2 / 3,8 / 2,1\end{array}$ & $20 / 7$ \\
\hline 25 & M11116 & $110-2-127$ & $\begin{array}{l}19020 \\
18719\end{array}$ & $\begin{array}{l}20 / 2,8 / 8 / 5 / 1,7 / \\
1,5 / 3,2 / 3,8 / 2,1\end{array}$ & $20 / 7$ \\
\hline 26 & P05116 & $110-2-127$ & $\begin{array}{l}2205 \\
2174\end{array}$ & $\begin{array}{c}2,3 / 20 / 2,8 / 8 / 5 / \\
1,7 / 1,5 / 3,2 / 3,8\end{array}$ & $20 / 7$ \\
\hline 27 & N12311 & $110-5-143$ & $\begin{array}{l}63172 \\
64175\end{array}$ & $\begin{array}{c}5 / 1,7 / 1,5 / 3,2 / \\
3,8 / 2,1 / 7,5 / 7,6 / 1 \\
9 / 10\end{array}$ & \\
\hline 28 & J02139 & $110-2-127$ & $\begin{array}{l}115112, \\
113111\end{array}$ & $\begin{array}{c}5 / 1,7 / 1,5 / 3,2 / \\
3,8 / 2,1 / 7,5 / 7,6 / \\
1,9 / 10 / 11\end{array}$ & \\
\hline 29 & P04519 & $110-8-104$ & $\begin{array}{l}225161 \\
224164\end{array}$ & $\begin{array}{c}5 / 1,7 / 1,5 / 3,2 / \\
3,8 / 2,1 / 7,5 / 7,6 / \\
1,9 / 10 / 11\end{array}$ & \\
\hline 30 & E14284 & $110-4-131$ & $\begin{array}{l}17557 \\
17356\end{array}$ & $\begin{array}{c}5 / 1,7 / 1,5 / 3,2 / \\
3,8 / 2,1 / 7,5 / 7,6 / \\
1,9 / 10 / 11\end{array}$ & \\
\hline 31 & B08610 & $110-9-138$ & $\begin{array}{l}205152, \\
203151\end{array}$ & $\begin{array}{c}5 / 1,7 / 1,5 / 3,2 / \\
3,8 / 2,1 / 7,5 / 7,6 / \\
1,9 / 10 / 11\end{array}$ & \\
\hline 32 & A02552 & $110-8-104$ & $\begin{array}{l}235160 \\
232159\end{array}$ & $\begin{array}{c}5 / 1,7 / 1,5 / 3,2 / 3,8 / \\
2,1 / 7,5 / 7,6 / 1,9 / 1 \\
0 / 11\end{array}$ & \\
\hline
\end{tabular}




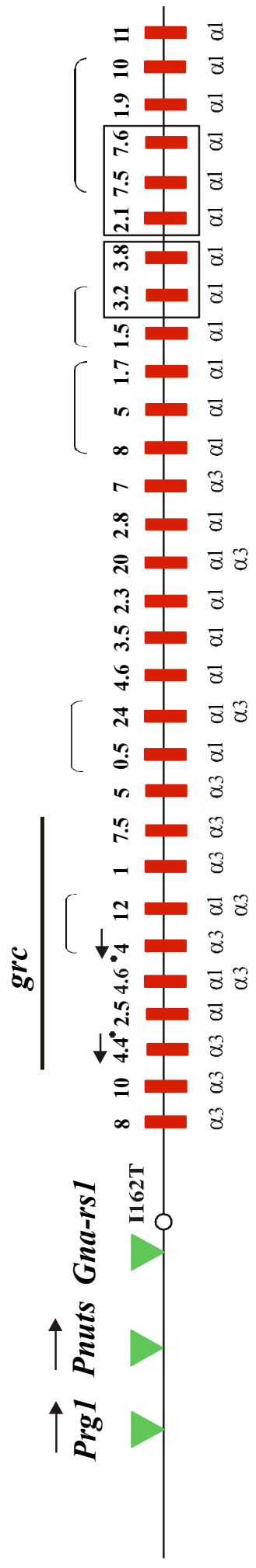

\section{무무}

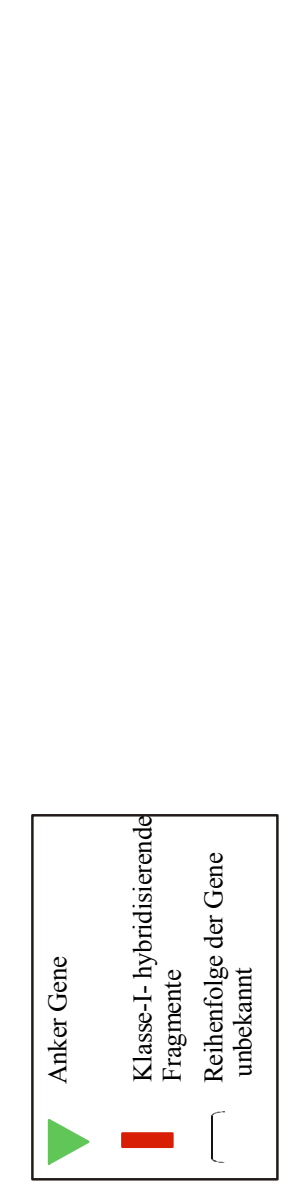

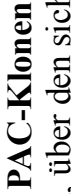

हैं 


\subsection{Die grc-Region}

Alle erhaltenen PAC-Klone aus dem $\alpha 1$-Screening der PAC-Bank wurden auf Southernblots mit der grc-Probe (Salgar et al., 1997) hybridisiert. Die grc-Region des Ratten-MHC enthält rezessive Gene, die Sterilität der männlichen Individuen sowie reduzierte Fertilität der Weibchen verursachen, die Körpergröße reduzieren und die Suszeptibilität für chemisch induzierte Tumoren erhöhen (Gill et al., 1979). Frühere Studien haben gezeigt, daß der grcPhänotyp auftritt, wenn eine bestimmte Deletion von ca. $70 \mathrm{~kb}$ (Cortese Hasset et al., 1989) im MHC vorliegt. Bei grc-positiven Tiere fehlt der oben genannte Phänotyp. Die Gene, die diesen Phänotyp verursachen, sind noch nicht identifiziert.

Einige der Klone, die am centromeren Ende des ersten Abschnitts von Contigs 2 liegen, hybridisieren mit der grc-Probe. Das Muster dieser Hybridisierung ist in Abbildung 22 gezeigt.

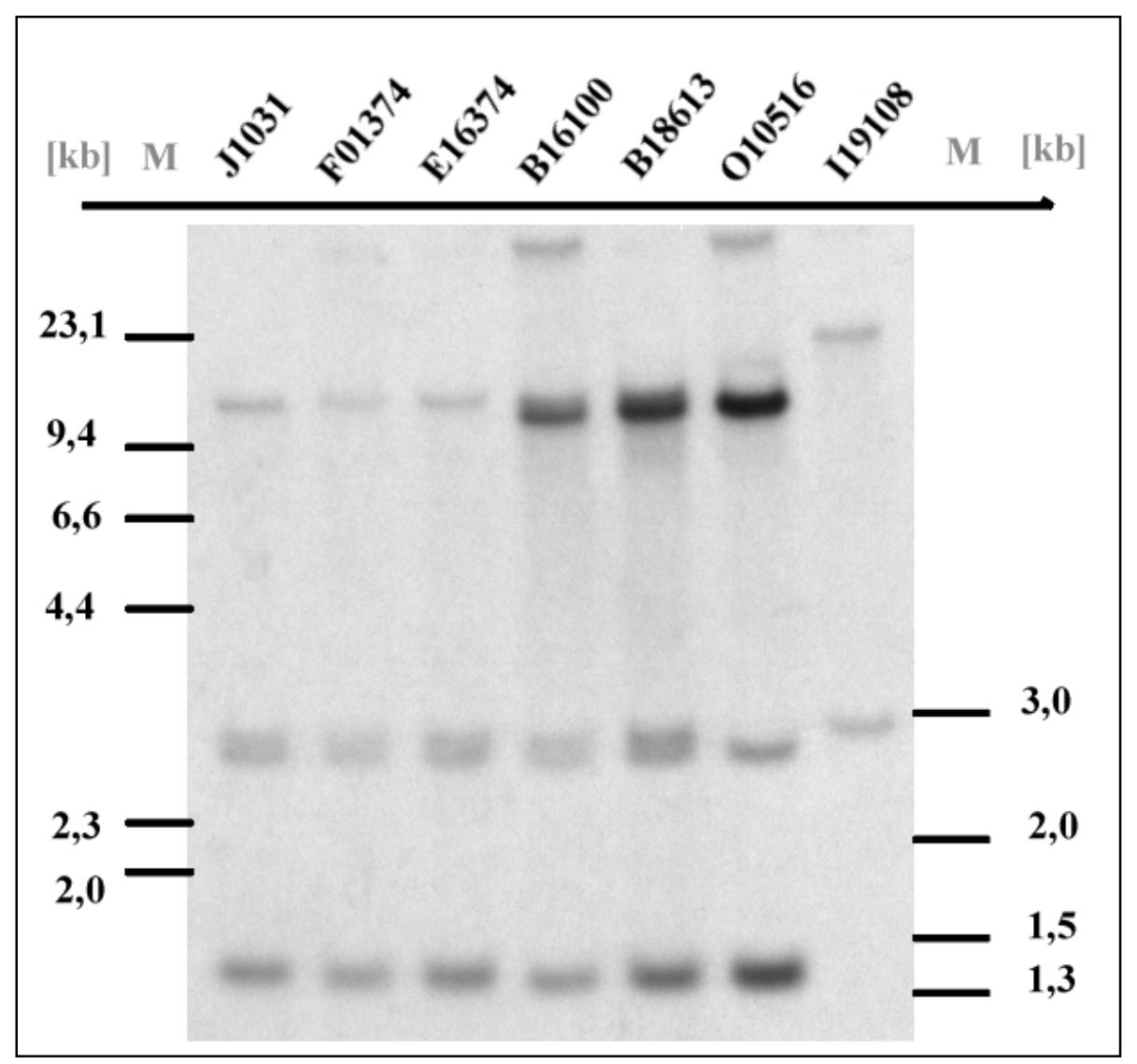

Abb. 24: Southernblot-Hybridisierung mit der grc-Probe. Bei dem Klon I19108 tritt zusätzlich ein Fragment von ca. $24 \mathrm{~kb}$ auf. Dieses ist artfiziell, da es auch mit dem Vektor hybridisiert. Links und rechts sind die Längenstandards angegeben. 
Die Überlappung der grc-positive Fragmente tragenten PAC-Klone ist in Abb. 23 zusammengefasst.

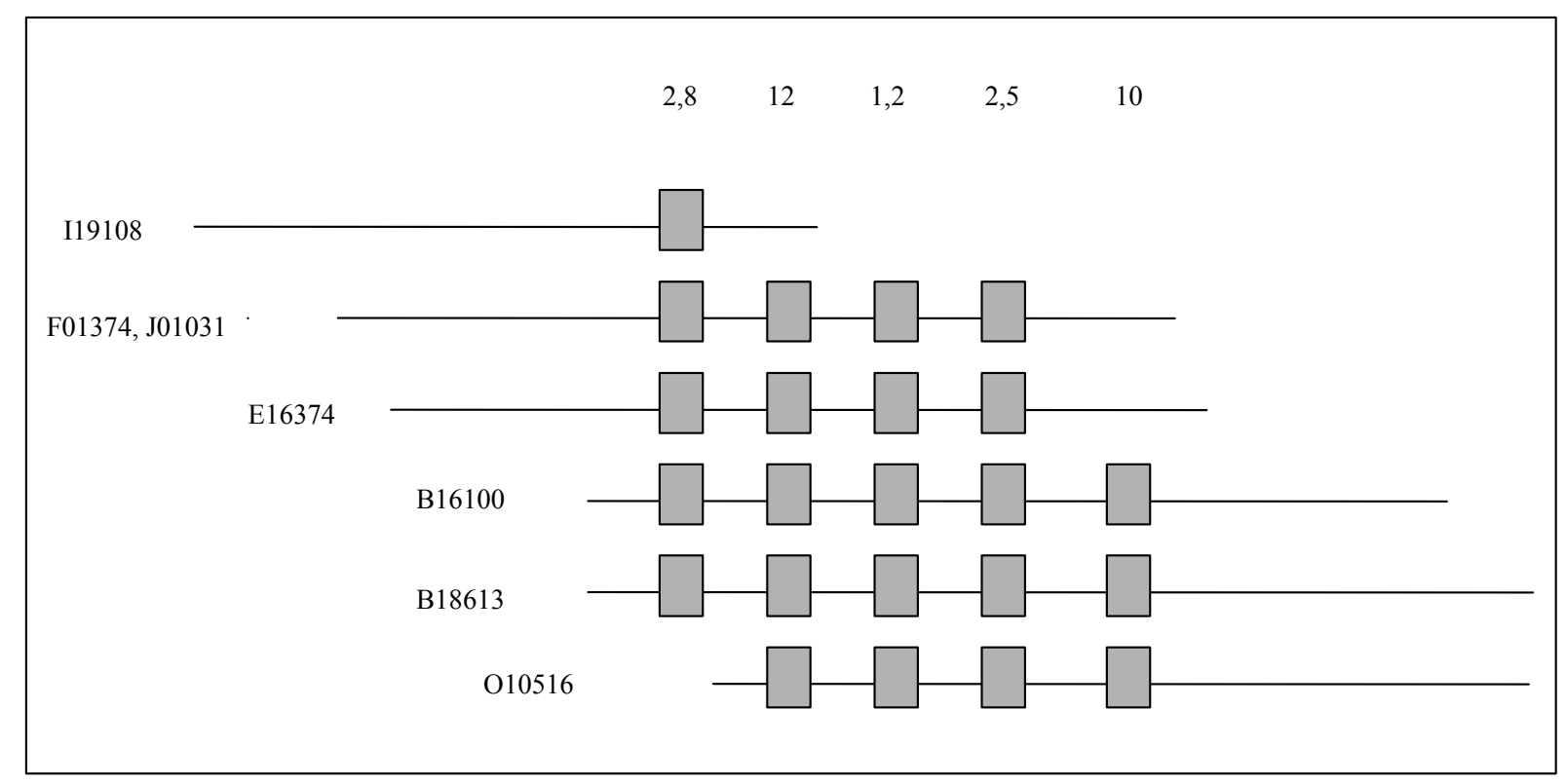

Abb. 23: Schematische Darstellung der grc-positiven PAC-Klone.. Die grauen Kästchen stellen die BamHI-Fragmente dar, die mit der grc-Sonde hybridisieren. Darüber ist deren Länge in kb angegeben.

Anhand dieser Daten ist die grc-Region in der BN-Ratte genau zu kartieren. Aus den hier gezeigten Kartierungs-Daten umfasst die grc-Region einen Bereich von ca. $70 \mathrm{~kb}$, wie von Cortese Hasset et al. (1989) beschrieben. In der Region sind sieben Klasse-I-Gene zu finden, unter diesen RT.BM1 (4,4 BamHI-Fragment), sowie ein H2-T2 ähnliches Gen (4,0 kb BamHI). Die Orientierung beider Gene ist der Abbildung $21 \mathrm{zu}$ entnehmen. Das RT.BM1Gen wurde auch von Salgar et al. (1998) in die Nähe der grc-Region kartiert.

\subsection{RT.BM1-Gene}

Um die RT.BM1-Gene identifizieren zu können, wurde eine Probe aus der nicht codierendenRegion des Gens (Parker et al., 1990) generiert. Die 1 kb lange Probe (s. 4.2.2) wurde zur Überprüfung der PAC-Klone als Sonde eingesetzt. Positive Hybridisierungs-Banden zeigten die Klone F01374, J1031, E16374, B16100, B16100, B18613, und zwar in der Länge 4,4 kb und 2,8 kb (Abb. 24). Der Klon O10516 zeigt eine hybridisierende Bande einer Länge von 3 kb. Das 4,4-kb-Fragment ist hier angeschnitten. Durch die Endsequenzierung dieses Klons wurde an dessen centromerem Ende eine Sequenz erhalten, die der Sequenz in der nicht codierenden Region des RT1-S3-Gens entspricht und einen Mikrosatelliten und der Länge von 
134 bp trägt, der in der nicht codierenden Region des RT1-S3-Gens (Salgar et al., 1998) vorkommt.

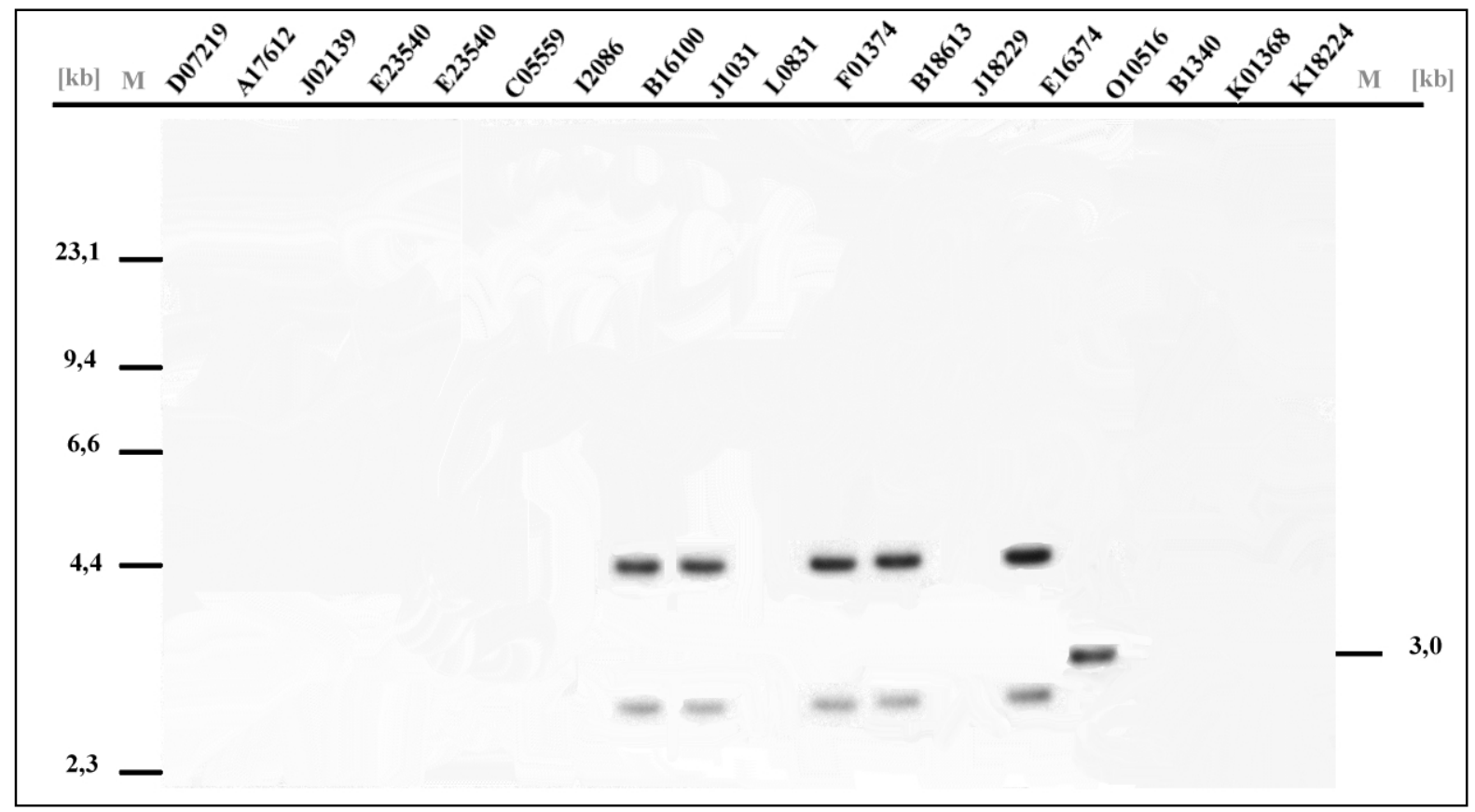

Abb. 24: Southernblot-Hybridisierung der PAC-Klone des ersten Abschnittes von Contigs 2 mit der BM1-Probe. Die zwei hybridisierenden Fragmente deuten auf die Existenz von zwei RT.BM1Genen hin. Beim Klon O10516 tritt ein 3 kb langes Fragment auf. Durch Ansequenzieren dieses Klones wurde gezeigt, daß es sich um ein angeschnittenes RT.BM1-Gen sich handelt. Links uns rechts ist der Längenstandard angegeben.

\subsubsection{3 „Anker-Gene“ des Contigs 2 im ersten Abschnitt}

Durch die Endsequenzierung des Klones E16374 wurde eine Sequenz ermittelt , die identisch mit einem Teil der codierenden Region des Pnuts-Gens (phosphatase I nuclear targeting subunit) (Allen et al., 1998) ist. Durch Analyse der benachbarten Klone mit Pnuts spezifischen Primern, konnte durch PCR festgestellt werden, daß es sich um das centromere Ende des Klones handelt. Somit wurde dieses Gen in der Ratte feinkartiert und konnte außerdem als Marker verwendet werden.

Aus der Endsequenzierung des Klones I16223 wurde an dessen centromerem Ende ein weiteres Gen identifiziert. Es handelt sich hier um das Gen Prgl (Schäfer et al., 1996), dessen Genprodukt homolog zum gly96 Protein der Maus ist und ein durch Wachstumsfaktoren induzierbares kurzlebiges glykolysiertes Protein darstellt. 
Mit einer Probe aus dem Prgl-Gen wurde die PAC-Bank gescreent, und zwei weitere PRG1positive Klone konnten erhalten werden (E06479, F05479). Die Hybridisierung mit der Prg1Probe zeigt zwei hybridisierende Banden auf der Höhe von 4,0 und 4,6 kb. Diese Klone erstrecken sich in vom Contig 2 ca. $140 \mathrm{~kb}$ centromerwärts. Die noch verhandene Lücke zwischen den Cak-positiven Klonen (Ende von Contig 1) und Prgl-positiven Klonen dürfte mit einem Screening der Bank anhand einer walking-Probe zu schließen sein, denn im MHC des Menschen besteht zwischen diesen beiden Genen nur ein Abstand von ca. 150 kb. Der Abstand zwischen dem Pou5f1 und dem HSR1 (Gna-rs1)-Gen beträgt beim Mensch $608 \mathrm{~kb}$ (The MHC Sequencing Consortium, 1999). Bei der Maus ist diese Region zwischen Pou5f1 und Gna-rsl kürzer und beträgt insgesamt ca. $300 \mathrm{~kb}$ (Amadou et al., 1999).

Am telomeren Ende diesen ersten Abschnitts von Contig 2 ist eine Region von ca. $100 \mathrm{~kb} z \mathrm{zu}$ beobachten, die nur $\alpha 1$ - hybridisierende Fragmente aufweist.

\subsubsection{Contig 2, zweiter Abschnitt}

Die oben genannte Region, die nur $\alpha 1$ - hybridisierende Fragmente aufweist, setzt sich über eine Länge von weiteren ca. $150 \mathrm{~kb}$ fort. Insgesamt kommen in diesem Bereich des Contig 2, 25 ausschließlich $\alpha 1$-hybridisierende Fragmente vor in einer gesamten Länge von ca. 250 kb. Bei dem $11 \mathrm{~kb}$ langen Fragment am Ende der Abbildung 21 und am Beginn der Abbildung 30 handelt es sich um dasselbe Fragment. Eine gesamt Übersicht der erstellten Contigs ist im Anhang (?) zu sehen. Um diese Fragmente näher zu charakterisieren, wurde zunächst der PAC-Klon H12587 in den Bluescript KS+-Vektor subkloniert. Aus der erhaltenen Subbank wurden durch Kolonie-Screening (3.12) die Klone isoliert, die mit der a1-Probe hybridisierten. Zwei dieser Subklone mit einer Insert-Länge von 2,1 kb (Klon 24) bzw. 3,4 kb (Klon 14) wurden isoliert und mit vektorspezifischen Primern (M13(-20) und M13N) von beiden Seiten ansequenziert. Bei dem Klon 24 konnte mit dem Primer M13(-20) ein kurzer Abschnitt eines Klasse-I-Gens erhalten werden, welches dem 3'-Ende des Exons 2 ( $\alpha 1$ Domäne) entspricht (Abb. 25). Dieses Fragment der Exon 2-Sequenz ist von anonymer Sequenz flankiert. 
RT1.A

.cgagcaggtgaa

Klon 24 agagcagacctt

ccGAGTGAACCTGAGGTGCGCGG- CTACTAACCCCAACCAGAGCGAGGGCG agGAGTGAACCTGAGGTCCCTGCTGAAGTTACTACAACCAGAGCCAGGGCC

gtgagtgaccccgggtcggaggtcacgaccct aggacctctctgcttcactaggtaagggactgaga

Abb. 25: Vergleich der Teilsequenz aus dem Exon 2 des Klasse-I-Gens RT1.A und der erhaltenen Sequenz aus dem Klon 24 des PAC-Klones H12587. Die Sequenz aus dem Subklon 24 zeigt Homologie zu dem 3'-Ende des Exons. Diese Sequenz ist durch fett gedruckte große Buchstaben markiert.

Zusätzlich wurde 84\% Sequenzidentität zum BAC-Klon citb585c7 (AC005807) aus der H2T-Region der Maus gefunden. Ansequenzieren des Klones 14 mit dem Primer M13r ergab ebenfalls eine homologe Sequenz zu einem Bereich des Maus BAC-Klones citb585c7.

Aus dem Exon 2 des RT1-A ${ }^{\mathrm{u}}$-Gens wurden zwei Proben erstellt, von denen die eine die 5'wärts und die andere die 3'-wärts gelegene Hälfte des Exons 2 enthält (4.2.1). Diese Proben wurden einzeln verwendet um die Exon 2-reichen PAC-Klone zu hybridisieren. Die Hybridisierung zeigte, daß die Probe aus der 5‘-Hälfte des Exons, im Gegensatz zur Probe aus der 3'-Hälfte, nicht mit den -Exon-2-Fragmenten reagiert. Damit wurde gezeigt, daß es sich bei den Exon-2-Fragmenten dieser Region offensichtlich um ganz ähnliche Gen-Fragmente handelt.

Die Abbildung 26 zeigt die Restriktionsanalyse einiger PAC-Klone, die nur $\alpha 1$ Hybridisierung aufweisen. 


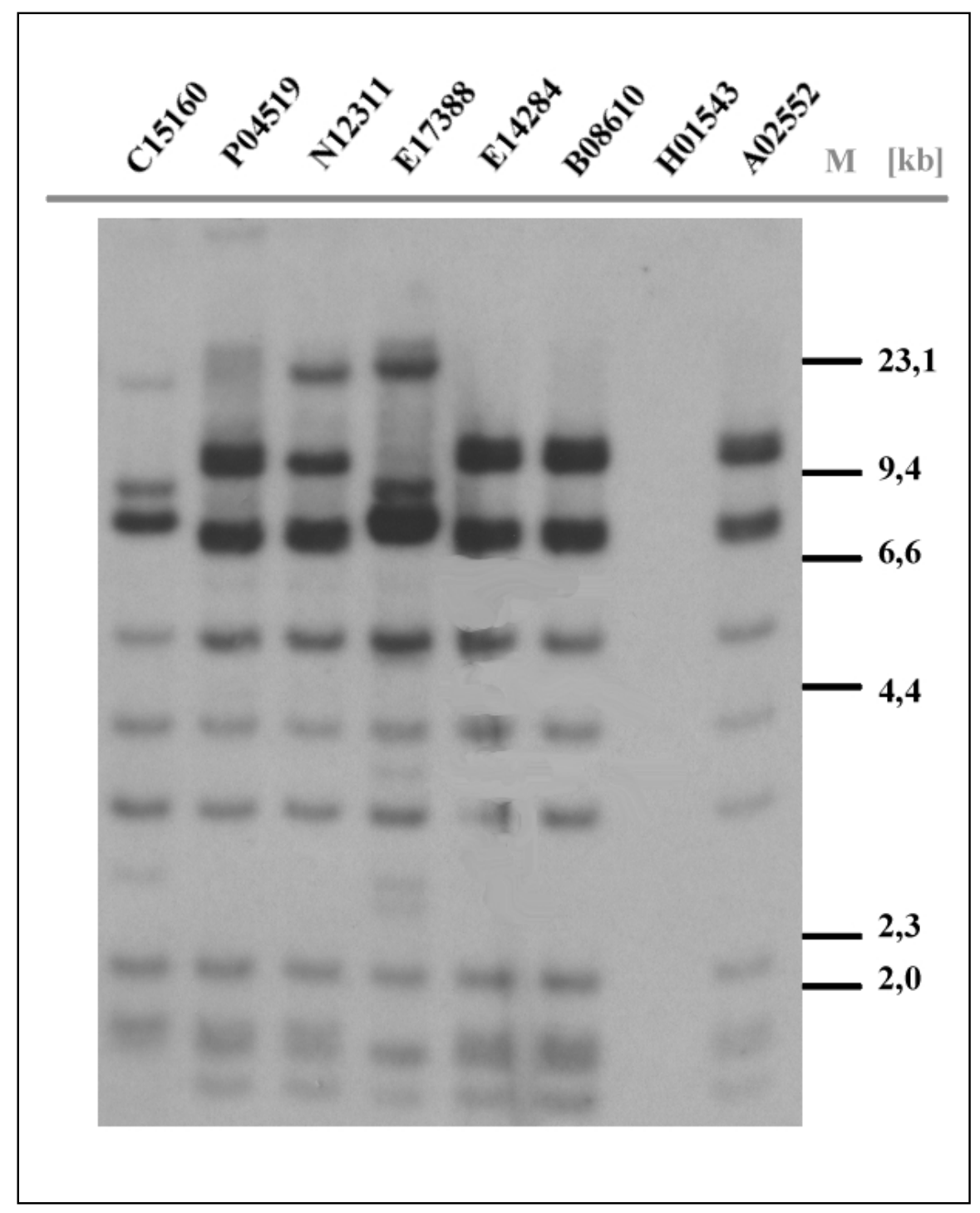

Abb. 26: Southerblotanalyse der der BamHI-gespaltenen PAC-Klone die nur mit der $\alpha$ 1-Probe hybridisieren. Der Klon H01543 ist ein falsch-positiver Klon aus dem ursprünglichen Screening der PAC-Bank. Rechts ist der Längenstandard angegeben.

Der zweite Abschnitt des Contig 2 wurde aus insgesamt 30 PAC-Klonen zusammengestellt. Die größte Anzahl dieser Klone wurde aus dem $\alpha 3$-Screening (Anhang ?) erhalten. In Abb. 27 ist das Hybridisierungsmuster mit der $\alpha 3$-Probe der BamHI-Restriktionsspaltung einer großen Anzahl aus den PAC-Klonen dieser Region des Contig 2 dargestellt. Der Klon I1448 (s.auch Abb.30) enthält keine Klasse-I-hybridisierende-Fragmente und wurde aus einem Sonder Screening der PAC-Bank mit dem STS-Marker der Maus 255D16T erhalten. Die hybridisierungs-Fragmente des Klones G03460 mit der $\alpha 3$-Probe sind auf diesem Blot nicht deutlich zu sehen aufgrund der geringen DNA Menge. Die aufgeführten Klasse-I-Fragmente 
im Bezug auf diesem Klon (s. Abb. 30) basieren auf die Daten eines weiteren Blots (nicht gezeigt). Der Klon I16274 wurde im ersten Abschnitt des Contigs 2 gezeigt, an seinem centromeren Ende (s. Abb. 21). Letztlich der Klon A05218 ist dem telomeren Ende des Contigs 2 zugewiesen (s. Abb. 32) aufgrund seiner Positivität mit der RT1-M3-Probe.
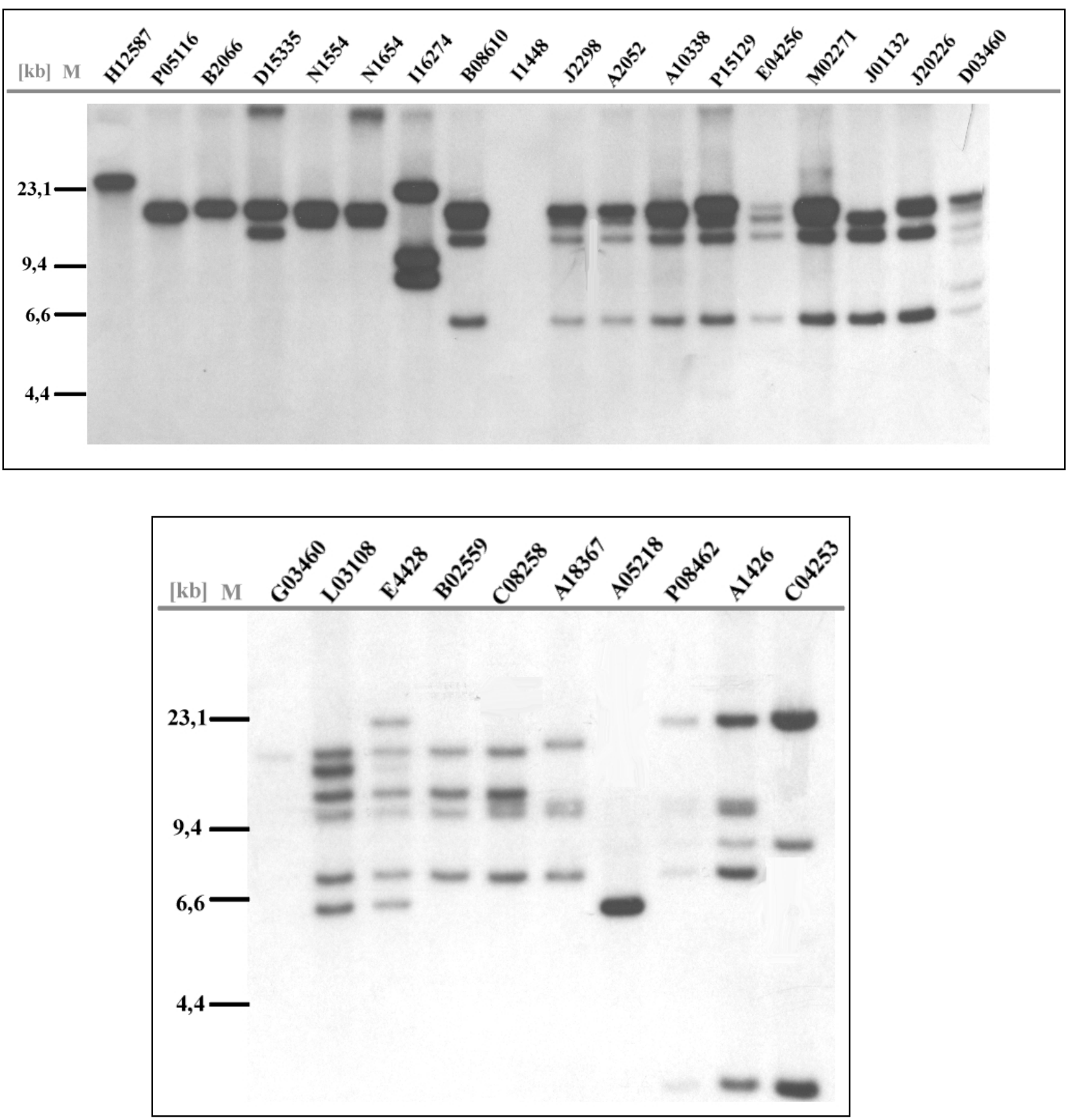

Abb. 27: Southernblot-Hybridisierung der BamHI-gespaltenen PAC-Klone aus dem zweiten Abschnitt des Contigs 2 mit der $\alpha 3$-Probe. Der Klon H12587 enthält eine artifizielle $>23$ kb Bande, auf der zusätzlich zu einem Klasse-I-Gen auch der PAC-Vektor nachgewiesen wurde (nicht gezeigt). Die Klone I16274 und A05218 gehören nicht diesem Contig an (s. Text). Links ist der Längenstandard angegeben. 
Die bereits besprochene Exon-2-reiche Region folgt eine Region mit ausschließlich $\alpha 3-$ hybridisierenden Fragmenten. Diese Region könnte dem Anfang der H2-M-Region der Maus entsprechen (Jones et al., 1999). Im Bereich des Exon 2 zeigen H2-M-Gene geringere Homologie zu anderen Klasse-I-Genen. Dieses kann der Grund für die fehlende Hybridisierung mit der $\alpha 1$-Probe sein. Im Rahmen der vorliegenden Arbeit wurden diese Gene der Ratte nicht näher untersucht.

Eine weiterer Ansatz, die Homologie oder sogar die Orthologie dieser Region des RattenMHC zu der H2-M-Region der Maus zu überprüfen, bestand darin, die Ratten-PAC-Klone mit bestimmten STS-Markern aus der H2-M-Region zu untersuchen. Zu diesem Zweck wurde der STS-Marker 255D16T ausgewählt, welcher am centromeren Ende der H2-M-Region lokalisiert ist. Zwei weitere STS-Marker der Maus, 261A5T und 261A5S, die ca. $200 \mathrm{~kb}$ telomerwärts von 255D16T lokalisiert sind, wurden ebenfalls verwendet.

Die Hybridisierung mit der 255D16T-Probe ergab eine Reihe von positiven Klone. Es zeigte sich eine Hybridisierungs-Bande von ca. $15 \mathrm{~kb}$ bei den PAC-Klonen B08610, J2298, M02271, A2052, A10338, J01131, J20226, E04256, P15129, D03460, G03460, L03108, E4428 und B02559. Aus einem separaten Screening mit der Probe 255D16T wurde zusätzlich der Klon I1448 erhalten, der zwar den Marker, aber kein Klasse-I-Gen trägt. Durch Vergleich der STS-hybridisierenden und nicht hybridisierenden PAC-Klone war es möglich, diesen Marker auf den Ratten-PAC-Contig 2 zwischen den Klasse-I-Gen-BamHI-Fragmenten von 6 und $13 \mathrm{~kb}$ zu identifizieren. In der Abbildung 30 wurde die Lokalisation dieses Markers mit einem schwarz gefüllten Kreis dargestellt. Die Hybridisierung mit den STS-Markern 261A5T und 261A5S ergab ebenfalls positive Klone. Beide Marker kartieren im Bereich zwischen dem 255D16T-Marker und den 7 kb- bzw. 11 kb-Klasse-I-Genen (Abb. 30).

In den Abbildungen 28 und 29 sind jeweils die Hybridisierungs-Banden mit den Markern 261A5T und 261A5S zu sehen. 

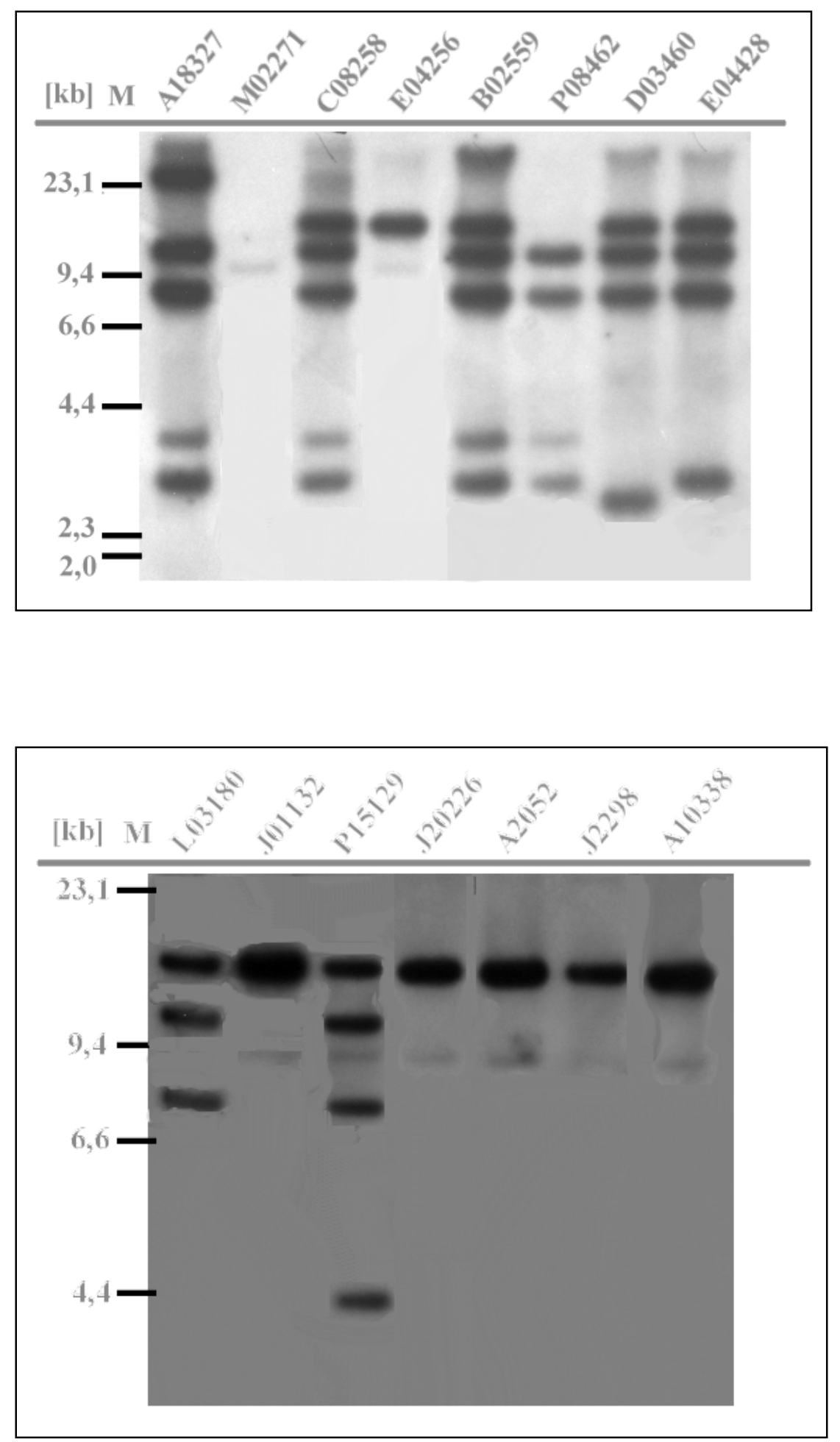

Abb. 28: Southernblot-Hybridisierung BamHI-geschnittener DNA von verschiedenen PACKlonen des Contigs 2 (Abschnitt 2) mit dem STS-Marker 261A5T. Die mehrfach hybridisierenden Banden einiger Klone deutet darauf hin, daß in der Ratte diese Sequenz als mehrfache Kopie vorliegt. Links ist der Längenstandard angegeben. 


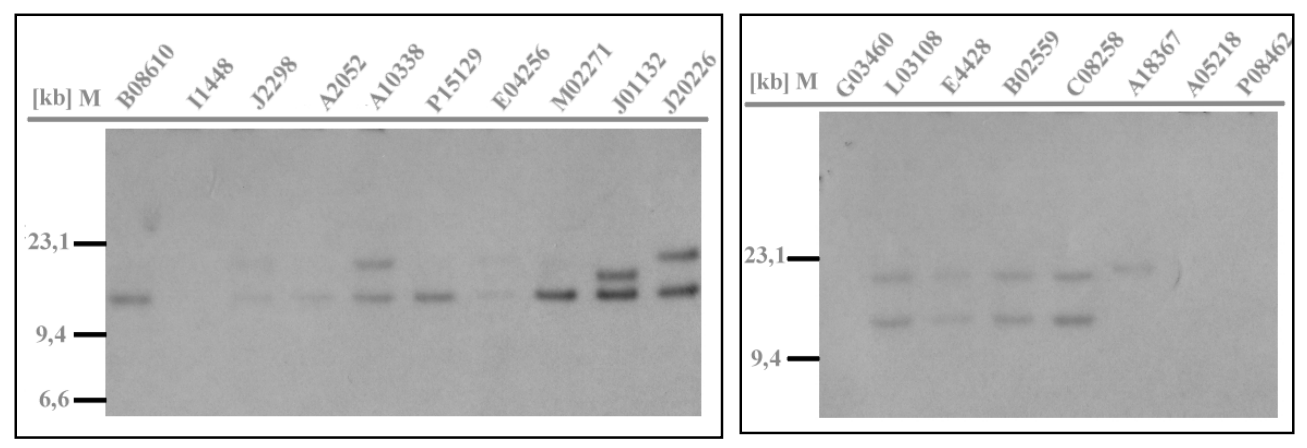

Abb. 29: Southernblot-Hybridisierung BamHI-gespaltener PAC-DNA des Contig 2 (zweiter Abschnitt) mit der 261A5S-Probe. Bei den PAC-Klonen J2298 und E04256 gibt es zwei hybridisierende Banden. Auf dieser Abbildung sind diese aufgrund der schwachen Intensität schwer erkennbar. Links ist der Längenstandard angegeben.

Die Endsequenzierung des Klones J2298 führte zur Identifikation eines Mikrosatelliten (4.2.2), der zur Überprüfung der PAC-Klone verwendet wurde. Weitere Klone, die diesen Mikrosatelliten tragen, sind H12587, G0249, I10519, B2066, D15335, N1554, N1654 und B08610. Die Positivität dieser Klone wurde teilweise durch Hybridisierung und teilweise durch PCR nachgewiesen. Die entsprechenden Primer wurden an der flankierenden Sequenz definiert. Zur Hybridisierung wurde das 100 bp PCR-Produkt verwendet.

Bei einigen der Klone treten Fragmente auf, deren Länge $>20 \mathrm{~kb}$ ist. In diesen Fällen ist die BamHI-Schnittstelle an der Klonierungsstelle nicht mehr vorhanden, so daß nach der Restriktionsspaltung der Klone mit BamHI ein Fragment entsteht, in dem der Vektor pPAC4 enthalten ist. Über die Auftrennung mit einer herkömmlichen Gelelektrophorese kann die genaue Länge solcher Fragmente nicht definiert werden, da oberhalb von 20 kb Länge keine gute Auftrennung möglich ist. Um nachzuweisen, daß die Vektor-Sequenz tatsächlich in diesen Fragmenten vorhanden ist, wurde der reine Vektor präpariert und damit eine Hybridisierung dieser Fragmente durchgeführt. Wie erwartet hybridisierten sie mit der Vektor-Probe. Klone dieses Contigs, die derartige artifizielle Fragmente tragen, sind auf der Abbildung 30 mit einem Stern gekennzeichnet. Es handelt sich um die Klone E17338, H12587, D15335, E4428 und A18367.

Der Klon A18367, welcher die Klasse-I-tragenden Fragmente 7, 11 und 12 beinhaltet, weist ein zusätzliches Fragment der Länge 19 kb auf. In diesem Fall mußte es sich um ein angeschnittenes 23-kb-Klasse-I-Fragment handeln, welches als nächstes in dem Contig auftritt. 
Tab. 6: Zusammenfassung der PAC-Klone, die dem zweiten Abschnitt des Contig 2 bilden.

Aufgeführt sind die entsprechende Filter Nummer der Ratten-Bank die Koordinaten der Klone und die Hybridisierung der Klone mit verschiedenen Proben aus dieser Region.

\begin{tabular}{|c|c|c|c|c|c|c|c|}
\hline & PAC & Filter Nr. & Koordinaten & $\begin{array}{l}\text { Länge der mit } \\
\text { der } \alpha 1 \text {-Probe } \\
\text { hybridisieren- } \\
\text { den Fragm- } \\
\text { ente }[\mathrm{kb}]\end{array}$ & $\begin{array}{l}\text { Länge der mit } \\
\text { der } \alpha 3 \text {-Probe } \\
\text { hybridisieren- } \\
\text { den Fragm- } \\
\text { ente [kb] }\end{array}$ & $\begin{array}{l}\text { Hybridisi- } \\
\text { erung mit } \\
\text { weiteren } \\
\text { Anker Pro- } \\
\text { ben }[\mathrm{kb}]\end{array}$ & $\begin{array}{l}\text { Marker aus } \\
\text { PAC-End- } \\
\text { sequenzie- } \\
\text { rung }\end{array}$ \\
\hline 1 & E17388 & $110-8-104$ & $\begin{array}{l}3758, \\
3756\end{array}$ & $\begin{array}{l}11 / 1,5 / 7,5 / 7,6 / \\
2,1 / 5 / 1,7 / 9 / 3,8 \\
/ 3,2\end{array}$ & & & \\
\hline 2 & C15160 & $110-9-138$ & $\begin{array}{l}4969 \\
5066\end{array}$ & $\begin{array}{l}11 / 1,5 / 7,5 / 7,6 / \\
2,1 / 5 / 1,7 / 9 / 3,8 \\
/ 3,2 / 1,9\end{array}$ & & & \\
\hline 3 & K05363 & $110-6-116$ & $\begin{array}{l}216190, \\
216187\end{array}$ & $\begin{array}{l}11 / 1,5 / 7,5 / 7,6 / \\
2,1 / 5 / 1,7 / 9 / 3,8 \\
/ 3,2\end{array}$ & & & \\
\hline 4 & H12587 & $110-9-122$ & $\begin{array}{l}63125 \\
61123\end{array}$ & $\begin{array}{l}1,5 / 7,5 / 7,6 / 2,1 \\
/ 5 / 1,7 / 9 / 3,8 / \\
3,2 / 3,4 / 5\end{array}$ & & & Mikrosatellit \\
\hline 5 & G0249 & $110-1-116$ & $\begin{array}{l}113130, \\
111128\end{array}$ & $\begin{array}{l}2,1 / 571,7 / 9 / \\
3,8 / 3,2 / 3,4 / 5\end{array}$ & & & Mikrosatellit \\
\hline 6 & I10519 & $110-7-158$ & $\begin{array}{l}194199, \\
195196\end{array}$ & $\begin{array}{l}2,1 / 571,7 / 9 / \\
3,8 / 3,2 / 3,4 / 5\end{array}$ & 18 & & Mikrosatellit \\
\hline 7 & B2066 & $110-1-116$ & $\begin{array}{l}143154, \\
144152\end{array}$ & $3,8 / 3,2 / 3,4 / 5$ & 18 & & Mikrosatellit \\
\hline 8 & D15335 & $110-5-134$ & $\begin{array}{l}143154, \\
144152\end{array}$ & $3,8 / 3,2 / 3,4 / 5$ & 18 & & Mikrosatellit \\
\hline 9 & N1554 & $110-1-116$ & 16895 & $3,4 / 5$ & $18 / 16$ & & Mikrosatellit \\
\hline
\end{tabular}




\begin{tabular}{|c|c|c|c|c|c|c|c|}
\hline & & & 16693 & & & & \\
\hline 10 & N1654 & $110-1-116$ & $\begin{array}{l}16395 \\
16193\end{array}$ & $3,4 / 5$ & $18 / 16$ & & Mikrosatellit \\
\hline 11 & B08610 & $110-9-138$ & $\begin{array}{l}205152 \\
203151\end{array}$ & $3,4 / 5$ & $18 / 16 / 6 / 13$ & $\begin{array}{l}\text { 255D16T } \\
\text { 261A5S }\end{array}$ & Mikrosatellit \\
\hline 12 & J2298 & $110-2-127$ & $\begin{array}{l}13534, \\
13235\end{array}$ & 5 & $18 / 16 / 6 / 13$ & $\begin{array}{l}\text { 255D16T } \\
\text { 261A5T } \\
\text { 261A5S }\end{array}$ & Mikrosatellit \\
\hline 13 & M02271 & $110-4-122$ & $\begin{array}{l}11598, \\
11297\end{array}$ & 5 & $18 / 16 / 6 / 13$ & $\begin{array}{l}\text { 255D16T } \\
261 \mathrm{~A} 5 \mathrm{~S}\end{array}$ & \\
\hline 14 & A2052 & $110-1-116$ & $\begin{array}{l}2380 \\
2178\end{array}$ & & $18 / 16 / 6 / 13$ & $\begin{array}{l}\text { 255D16T } \\
\text { 261A5T } \\
\text { 261A5S }\end{array}$ & \\
\hline 15 & A10338 & $110-5-134$ & $\begin{array}{l}19380 \\
19178\end{array}$ & & $18 / 16 / 6 / 13$ & $\begin{array}{l}\text { 255D16T } \\
\text { 261A5T } \\
\text { 261A5S }\end{array}$ & \\
\hline 16 & J01132 & $110-2-127$ & $\begin{array}{l}240113, \\
237112\end{array}$ & & $16 / 6 / 13$ & $\begin{array}{l}\text { 255D16T } \\
\text { 261A5T } \\
\text { 261A5S }\end{array}$ & \\
\hline 17 & $\mathbf{J} 20226$ & $110-4-122$ & $\begin{array}{l}2431, \\
2131\end{array}$ & & $16 / 6 / 13 / 18$ & $\begin{array}{l}\text { 255D16T } \\
\text { 261A5T } \\
261 \mathrm{~A} 5 \mathrm{~S}\end{array}$ & \\
\hline 18 & E04256 & $110-4-122$ & $\begin{array}{l}10458 \\
10159\end{array}$ & & $18 / 16 / 6 / 13$ & $\begin{array}{l}\text { 255D16T } \\
261 \mathrm{~A} 5 \mathrm{~T} \\
261 \mathrm{~A} 5 \mathrm{~S}\end{array}$ & \\
\hline 19 & P15129 & $110-2-127$ & $\begin{array}{l}170163, \\
167162\end{array}$ & 5 & $18 / 16 / 6 / 13 / 18$ & $\begin{array}{l}\text { 255D16T } \\
\text { 261A5T } \\
261 \mathrm{~A} 5 \mathrm{~S}\end{array}$ & \\
\hline 20 & D03460 & $110-6-161$ & 11064 & & $18 / 16 / 6 / 13 / 18 /$ & $\begin{array}{l}\text { 255D16T } \\
\text { 261A5T }\end{array}$ & \\
\hline
\end{tabular}




\begin{tabular}{|c|c|c|c|c|c|c|}
\hline & & & 10765 & $7 / 11$ & $261 \mathrm{~A} 5 \mathrm{~S}$ & \\
\hline 21 & G03460 & $110-6-161$ & $\begin{array}{l}11049 \\
10750\end{array}$ & $\begin{array}{l}18 / 16 / 6 / 13 / 18 / \\
7 / 11\end{array}$ & $\begin{array}{l}\text { 255D16T } \\
261 \mathrm{~A} 5 \mathrm{~S}\end{array}$ & \\
\hline 22 & L03108 & $110-2-127$ & $\begin{array}{l}227103, \\
227101\end{array}$ & $\begin{array}{l}16 / 6 / 13 / 18 / \\
7 / 11\end{array}$ & $\begin{array}{l}\text { 255D16T } \\
\text { 261A5T } \\
261 \mathrm{~A} 5 \mathrm{~S}\end{array}$ & \\
\hline 23 & E04428 & $110-6-116$ & $\begin{array}{l}22557 \\
22356\end{array}$ & $6 / 13 / 18 / 7 / 11$ & $\begin{array}{l}\text { 255D16T } \\
\text { 261A5T } \\
261 \mathrm{~A} 5 \mathrm{~S}\end{array}$ & \\
\hline 24 & B02559 & $110-7-158$ & $\begin{array}{l}115153, \\
112152\end{array}$ & $13 / 18 / 7 / 11$ & $\begin{array}{l}\text { 255D16T } \\
\text { 261A5T } \\
261 \mathrm{~A} 5 \mathrm{~S}\end{array}$ & \\
\hline 25 & I1448 & $110-10-132$ & $\begin{array}{ll}175 & 120 \\
172 & 119\end{array}$ & & $255 \mathrm{D} 16 \mathrm{~T}$ & \\
\hline 26 & C08258 & $110-4-122$ & $\begin{array}{l}204148, \\
201149\end{array}$ & $13 / 18 / 7 / 11 / 12$ & $\begin{array}{l}261 \mathrm{~A} 5 \mathrm{~T} \\
261 \mathrm{~A} 5 \mathrm{~S}\end{array}$ & \\
\hline 27 & A18367 & $110-6-116$ & $\begin{array}{l}34156 \\
31156\end{array}$ & $7 / 11 / 12$ & $\begin{array}{l}261 \mathrm{~A} 5 \mathrm{~T} \\
261 \mathrm{~A} 5 \mathrm{~S}\end{array}$ & \\
\hline 28 & A1426 & $110-1-116$ & $\begin{array}{l}17579 \\
17280\end{array}$ & $\begin{array}{l}7 / 11 / 12 / 23 / 8 / \\
3,2\end{array}$ & & \\
\hline 29 & P08462 & $110-6-161$ & $\begin{array}{l}20584 \\
20285\end{array}$ & $\begin{array}{l}7 / 11 / 12 / 23 / 8 / \\
3,2\end{array}$ & 261A5T & P0846T \\
\hline 30 & C04253 & $110-4-122$ & $\begin{array}{l}204228, \\
202227\end{array}$ & $23 / 8 / 3,2$ & & \\
\hline
\end{tabular}



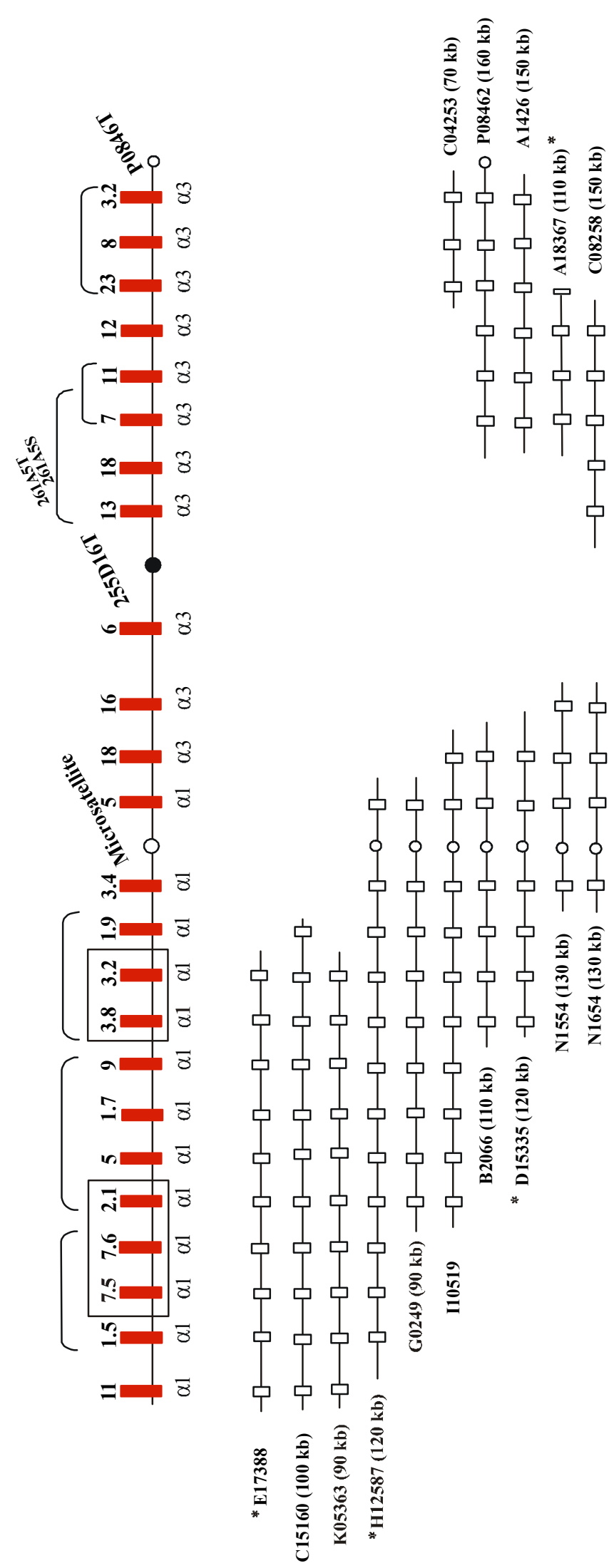


\subsubsection{Contig 2, dritter Abschnitt}

Aus dem $\alpha 3-$ Screening der genomischen Bank wurden unter anderem PAC-Klone erhalten, die a3-positive BamHI-Restriktionsfragmente der Größe 2,3 kb, 4,1 kb und 1,5 kb zeigten. (Abbildung 31). Zwei der Klone mit diesem $\alpha 3$-Muster tragen zusächlich die Gene Tctex5 und Mog.

Aufgrund vorhandener Daten aus der Maus (Wang et al., 1993; Jones et al.,1999) war anzunehmen, daß es sich um die H2-M4, H2-M5 und H2-M6 der Maus homologen Gene handelt, die zwischen den Genen Tctex 5 und Mog in der distalen H2-M-Region Maus lokalisiert sind.

Das RT1-M4 Gen der Ratte wurde bereits beschrieben (Lambracht et al., 1998). In Intron 3 dieses Gens wurde ein imperfektes GT-repeat (TG) $)_{7} \mathrm{CG}(\mathrm{TG})_{2} \mathrm{CG}(\mathrm{TG})_{20}$ identifiziert (Lambracht et al., 1998), das in verschiedenen Rattenstämmen eien Längenpolymorphismus zeigt. Durch das repeat-flankierende Primer war per PCR ein Produkt von 129 bp in der BNRatte erhalten worden (Lambracht et al., 1998). Die PAC-Klone L19417, N20105, K145, A23104, J0567, H11471, K09358 und E21511, welche das Muster der drei a3-Fragmente aufweisen, stellten sich als positiv für den Mikrosatelliten des RT1-M4-Gens heraus. Das von Lambracht et al. (1995) identifizierte BamHI-Restriktionsfragment, welches das RT1-M4-Gen trägt, hat eine Länge von 4,1 kb. Ein Klasse-I-Gen tragendes BamHI-Fragment dieser Länge wurde auch hier ermittelt. Somit wurde im dritten Abschnitt des Contigs 2 das Gen RT1-M4 identifiziert und die Lokalisation bestimmt (Abb.32).

Durch weiteres Screening der genomischen Bank mit den Proben Tctex5, Rfb30, Znf173 (siehe 4.2) wurden Klone erhalten, die sich am centromeren Ende dieses Contigs befinden. Der Klon P20499 trägt alle drei Gene Znf173, Rfb30 und Tctex 5. Zusätzlich trägt er den STSMarker P084T.

Mehrere der Klone hybridisierten zusätzlich mit der Probe aus dem Mog-Gen (4.2 und Abbildung 32). Die Hybridisierung des BamHI-Southern Blots mit der Mog-Probe ergibt eine positive Bande von ca. $500 \mathrm{bp}$.

Die Klone O21242 und H10232 sind positiv mit der Probe Tu42.

Aus der Endsequenzierung des Klones H10232 konnte ein STS-Marker erstellt werden (H102T), der am telomeren Ende des Klones lokalisiert wurde. 
Aufgrund von Daten der Maus-MHC-Kartierung (Amadou et al., 1999) wurde der STSMarker 573K1S, der sich in der Maus zwischen dem Tu42-Gen und dem H2-M3 Gen befindet, für weitere Kartierungen benutzt. Mit diesem Marker wurden alle RT1-M3 und RT1M2 positiven PAC-Klone (4.3.3) untersucht. Zwei dieser Klone, D13419 und J21470, tragen den 573K1S-Marker. Diese Klone weisen außerdem den Ratten-STS-Marker H102T auf, so daß damit die Lücke zu PAC-Klon H10232 überbrückt wird. Die Klone D13419 und J21470, tragen ferner zwei $R T 1-M 3$ positive Banden der Länge 6,2 kb und 2,5 kb.

In der Tabelle 7 werden alle dem dritten Abschnitt des Contigs 2 zugeordneten PAC-Klone zusammengefaßt.

Die Abbildung 31 zeigt eine repräsentative Hybridisierung der BamHI-Restriktionsfragmente einiger Klone aus dem dritten Abschnitt des Contigs 2 mit der $\alpha 3$-Probe (4.2). Die restlichen Klone wurden auf mehreren Southern Blots verteilt überprüft; diese Abbildungen wurden hier nicht eingefügt.

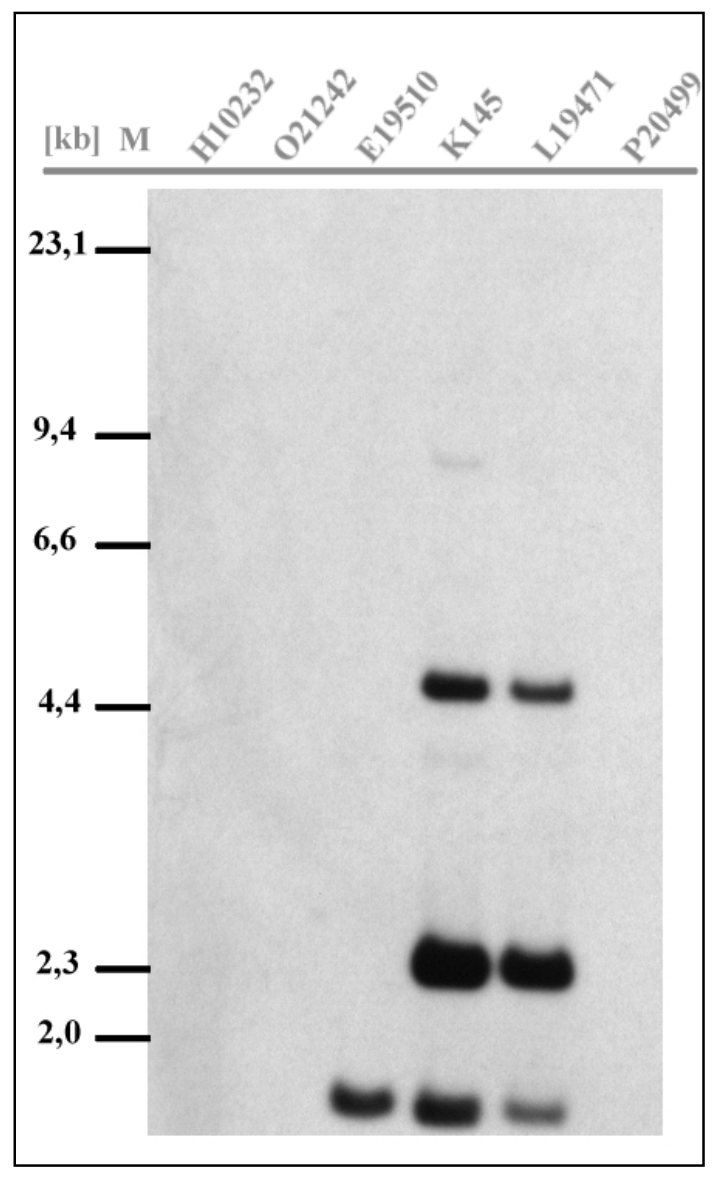

Abb. 33: Southernblot-Hybridisierung einiger Klone aus dem dritten Abschnitt des Contigs 2 mit der $\alpha 3$-Probe. Alle weiteren Klasse-I-tragende Klone dieses Contigs zeigen das gleiche Muster wie die hier abgebildeten Klone. Links ist der Längenstandard angegeben. 
Die Abbildung 34 zeigt eine schematische Darstellung der dem dritten Abschnitt des Contigs 2 zugehörigen Klone. Die Klone D13419, J21470, K15386 und H18232 werden in dem Abschnitt 4.3.3 nochmals aufgeführt.

Tab. 7: Zusammenfassung der PAC-Klone, die dem dritten Abschnitt des Contigs 2 zugeordnet sind. Aufgeführt ist die entsprechende Filter-Nummer der Ratten-Bank, die Koordinaten der Klone und die Hybridisierung der Klone mit verschiedenen Proben aus dieser Region.

\begin{tabular}{|c|c|c|c|c|c|c|c|}
\hline & PAC & Filter $\mathrm{Nr}$. & Koordinaten & $\begin{array}{l}\text { Länge der mit } \\
\text { der } \alpha 1 \text {-Probe } \\
\text { hybridisieren- } \\
\text { den Fragmente } \\
{[\mathrm{kb}]}\end{array}$ & $\begin{array}{l}\text { Länge der mit } \\
\text { der } \alpha 3 \text {-Probe } \\
\text { hybridisieren- } \\
\text { den } \\
\text { Fragmente } \\
{[\mathrm{kb}]}\end{array}$ & $\begin{array}{l}\text { Hybridisie- } \\
\text { rung mit } \\
\text { weiteren } \\
\text { Anker } \\
\text { Proben und } \\
\text { STS- } \\
\text { Markern }\end{array}$ & $\begin{array}{l}\text { Proben } \\
\text { aus PAC- } \\
\text { End- } \\
\text { Sequenzie } \\
\text {-rung }\end{array}$ \\
\hline 1 & P20499 & $110-7-107$ & $\begin{array}{l}2582 \\
2381\end{array}$ & & & $\begin{array}{l}\text { Znf173 } \\
\text { Rfb30 } \\
\text { Tctex5 }\end{array}$ & P0846T \\
\hline 2 & 022140 & $110-2-127$ & $\begin{array}{l}1357 \\
1336\end{array}$ & & & Tctex 5 & \\
\hline 3 & K08519 & $110-7-158$ & $\begin{array}{l}204189 \\
205186\end{array}$ & & & Tctex 5 & \\
\hline 4 & L19417 & $110-6-116$ & $\begin{array}{l}150183, \\
147182\end{array}$ & & $2,3 / 4,1 / 1,5$ & $\begin{array}{l}\text { Tctex5 } \\
\text { Mog } \\
\text { RT1-M4 }\end{array}$ & \\
\hline 5 & N20105 & $110-2-127$ & $\begin{array}{l}142173, \\
142171\end{array}$ & & $2,3 / 4,1 / 1,5$ & $\begin{array}{l}\text { Tctex5 } \\
\text { Mog } \\
\text { RT1-M4 }\end{array}$ & \\
\hline 6 & K145 & $110-1-116$ & $\begin{array}{l}51190, \\
51187\end{array}$ & & $2,3 / 4,1 / 1,5$ & $\begin{array}{l}\text { Mog } \\
\text { RT1-M4 }\end{array}$ & \\
\hline
\end{tabular}




\begin{tabular}{|c|c|c|c|c|c|c|}
\hline 7 & A23104 & $110-2-127$ & $\begin{array}{l}12778, \\
12776\end{array}$ & $2,3 / 4,1 / 1,5$ & $\begin{array}{l}\text { Mog } \\
\text { RT1-M4 }\end{array}$ & \\
\hline 8 & J0567 & $110-9-122$ & $\begin{array}{l}100112, \\
98111\end{array}$ & $2,3 / 4,1 / 1,5$ & $\begin{array}{l}\text { Mog } \\
\text { RT1-M4 }\end{array}$ & \\
\hline 9 & H11471 & $110-6-161$ & $\begin{array}{l}189203, \\
186204\end{array}$ & $2,3 / 4,1 / 1,5$ & $\begin{array}{l}\text { Mog } \\
\text { RT1-M4 }\end{array}$ & \\
\hline 10 & K09358 & $110-5-134$ & $\begin{array}{l}8027, \\
7826\end{array}$ & $2,3 / 4,1 / 1,5$ & $\begin{array}{l}\text { Mog } \\
\text { RT1-M4 }\end{array}$ & \\
\hline 11 & E21511 & $110-7-158$ & $\begin{array}{l}19136 \\
16136\end{array}$ & $2,3 / 4,1 / 1,5$ & $R T 1-M 4$ & \\
\hline 12 & E19510 & $110-7-158$ & $\begin{array}{l}146140, \\
146137\end{array}$ & 1,5 & $\operatorname{Mog}$ & \\
\hline 13 & 021242 & $110-4-122$ & $\begin{array}{l}1409, \\
13710\end{array}$ & & $\begin{array}{l}\text { Mog } \\
\text { Tu42 }\end{array}$ & \\
\hline 14 & H10232 & $110-4-122$ & $\begin{array}{l}7541 \\
7444\end{array}$ & & $T u 42$ & $\mathrm{H} 102 \mathrm{~T}$ \\
\hline 15 & D13419 & $110-6-116$ & $\begin{array}{l}60223, \\
57222\end{array}$ & & $\begin{array}{l}R T 1-M 3 \\
573 \mathrm{~K} 1 \mathrm{~S}\end{array}$ & $\mathrm{H} 102 \mathrm{~T}$ \\
\hline 16 & $\mathbf{J} 21470$ & $110-6-161$ & $\begin{array}{l}13933 \\
13634\end{array}$ & & $\begin{array}{l}R T 1-M 3 \\
573 \mathrm{~K} 1 \mathrm{~S}\end{array}$ & $\mathrm{H} 102 \mathrm{~T}$ \\
\hline 17 & K15386 & $110-6-116$ & $\begin{array}{l}17029, \\
16730\end{array}$ & & $R T 1-M 3$ & \\
\hline 18 & H18232 & $110-4-122$ & $\begin{array}{l}3541, \\
3444\end{array}$ & & $R T 1-M 3$ & \\
\hline
\end{tabular}



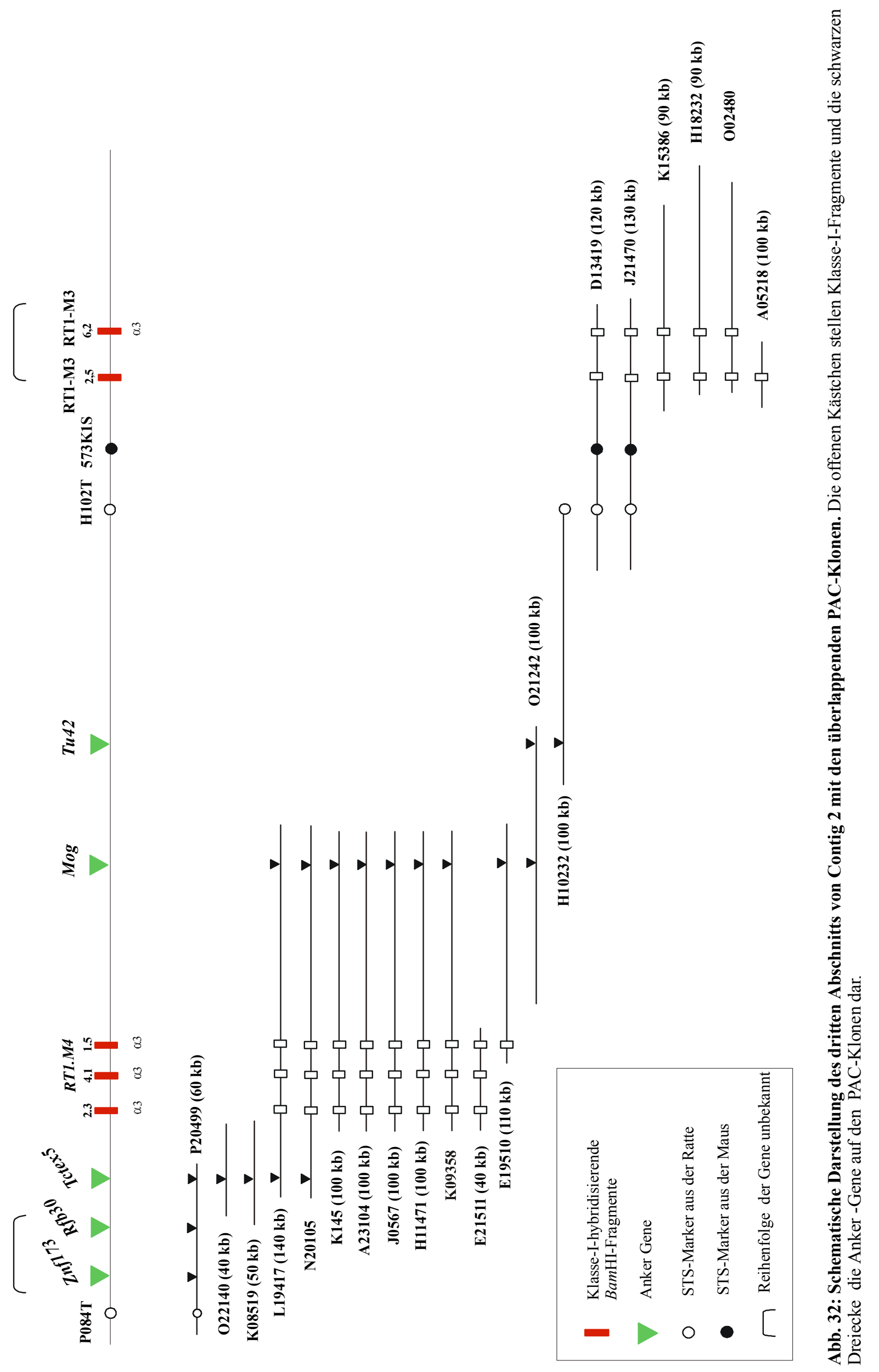


\subsubsection{Endsequenzierung einiger Klone aus dem Contig 2}

Der PAC-Klon I16223 wurde an beiden Enden ansequenziert. Am telomeren Ende wurde eine Sequenz erhalten, die keine Homologie zu bekannten Sequenzen aufweist. Daraus wurden Primer etabliert (STS-Marker I162T), und damit eine PCR auch an den benachbarten PAC-Klonen des Contigs durchgeführt. Die Klone I16223, I19108, I16274, F01374, J1031, L0831, E16374 tragen tatsächlich auch den Marker I162T.

Durch Sequenzierung des centromeren Endes PAC-Klones I16223 wurde eine Teilsequenz des Gens Prg1 (Schäfer et al. 1996) gefunden.

Aus der Sequenzierung eines Endes von Klone E16374 wurde eine Sequenz erhalten, die zum Gen Pnuts (Allen et al. 1998) gehört. Bisher ist in der Ratte die cDNA Sequenz bekannt. Die hier erhaltene Sequenz entspricht einem Teil der codierenden Region und enthält zwei Exons, das dazwischen liegende Intron und jeweils ein Teil der angrenzenden Introns.

Am telomeren Ende des Klones E16374 wurde eine Sequenz aus der nicht codierenden Region eines Klasse-I-Gens ermittelt, welche ausgeprägte Homologie zu einem H2-Tähnlichen-Pseudogen der Maus aufweist.

Der Klon 010516 lieferte am centromeren Ende eine Teilsequenz des RT.BM1-Gens. Die erhaltene Sequenz stammt aus dem $3^{6}$-utr, Exon 7 und 8 sowie angrenzenden Introns.

Eine Endsequenzierung wurde zunächst beim Klon H12587 durchgeführt. An dem centromeren Ende des Klones wurde eine Sequenz identifiziert, die durch Vergleich in der Datenbank teilweise Homologie zu einer nicht näher annotierten Maus-Sequenz aus dem BAC-Klon citb585 (AC005807) von Chromosom 17 zeigt. Ein Banken-Screening mit dieser Probe ergab außer den $\alpha 1$-reichen Klonen, die in der Abbildung 26 zusammengefaßt sind, auch eine Reihe von Klonen, die im schon im ersten Abschnitt des Contigs 2 eingeordnet waren. Aus diesem Befund konnte geschlossen werden, daß diese Sequenz mehrfach im ersten Abschnitt des Contigs 2 und zu Beginn des zweiten Abschnitts von Contig 2 vorkommt und daher als STS-Marker ungeeignet ist.

Die erhaltene Teilsequenz aus dem telomeren Ende dieses Klones war homolog zu einem LINE-Element (Long interspersed repetitive DNA sequence) aus der retroviralen ORF2Region, die für ein der Reversen Transkriptase ähnliches Protein kodiert. 
Beim Ansequenzieren des Klones G0249 wurde ebenfalls eine Sequenz aus LINE-Elementen erhalten.

Die Endsequenz von PAC-Klon $\mathbf{J 2 2 9 8}$ zeigte ausgeprägte Homologie (90\%) zu einem retroviralen gag-Protein. Innerhalb dieser Sequenz ist ein Mikrosatellit von 100 bp enthalten, der aus (GAAA)n(GAAAA)n-Wiederholungen besteht. An der flankierenden Sequenz des repetitiven Elementes wurden Primer definiert und die PCR mit den benachbarten Klonen zeigte, daß sich dieser Mikrosatellit am centromeren Ende des Klones J2298 befindet.

Der Klon A18367 zeigte an einem Ende eine LINE-ähnliche Sequenz. Am anderen Ende wurde eine Sequenz identifiziert, die $82 \%$ und in manchen Bereiche sogar bis $96 \%$ Sequenzidentität zu Sequenzen der BAC-Klone 592j14 (AC005413) und 76k14 (AC005665) aus dem MHC der Maus zeigen.

Bei P08462 konnte das eine Ende erfolgreich ansequenziert werden. Diese Sequenz ist homolog zu einem Bereich im BAC-Klon 20h22 der Maus (AC005960). Aus der erhaltenen Sequenz wurden Primer definiert und mittels PCR gezeigt, daß sich diese Sequenz am telomeren Ende des Klones befindet und als STS-Marker, als P0846T bezeichnet, verwendet werden kann (Abbildung 30).

Die Sequenzierungsdaten sind im Anhang 8.2 aufgeführt.

\subsubsection{Contig 3 und Contig 4 (RT1-M3-, RT1-M2-positive Klone)}

Aus dem a3-Screening wurden außer den PAC-Klonen, die dem zweiten und dritten Abschnitt des Contigs 2 zugeordnet werden konnten, zusätzlich 22 Klone erhalten, die einzelne oder zwei $\alpha 3$-positive BamHI-Restriktionsfragmente aufwiesen. Da das Screening alle Klasse-I-Gen-tragenden Klone umfassen mußte (4.3), wurde vermutet, daß es sich um RT1-M3- und RT1-M2-Gen-tragende Klone handeln könnte. Diese Gene sind am distalen Ende der RT1-M-Region lokalisiert (Amadou et al., 1999; Lambracht et. al., 1999). Die Hybridisierung mit spezifischen Proben des Gens RT1-M3 bzw. des Mausgens H2-M2 bestätigten die Annahme, daß diese PAC-Klone die Gene RT1-M3 und/oder RT1-M2 Gene tragen. Die Abbildungen 33 und 34 zeigen die hybridisierenden Banden mit den spezifischen 
Proben aus RT1-M3 und H2-M2. In der Tabelle 8 werden alle RT1-M3-, RT1-M2-positiven Klone zusammengefasst. Sie bilden neben dem telomeren Teil des dritten Abschnitts von Contig 2 zwei weitere Contigs, Contig 3 und Contig 4, die sich nicht überlappen und bisher nicht an Contig 2 angeschlossen werden konnten.

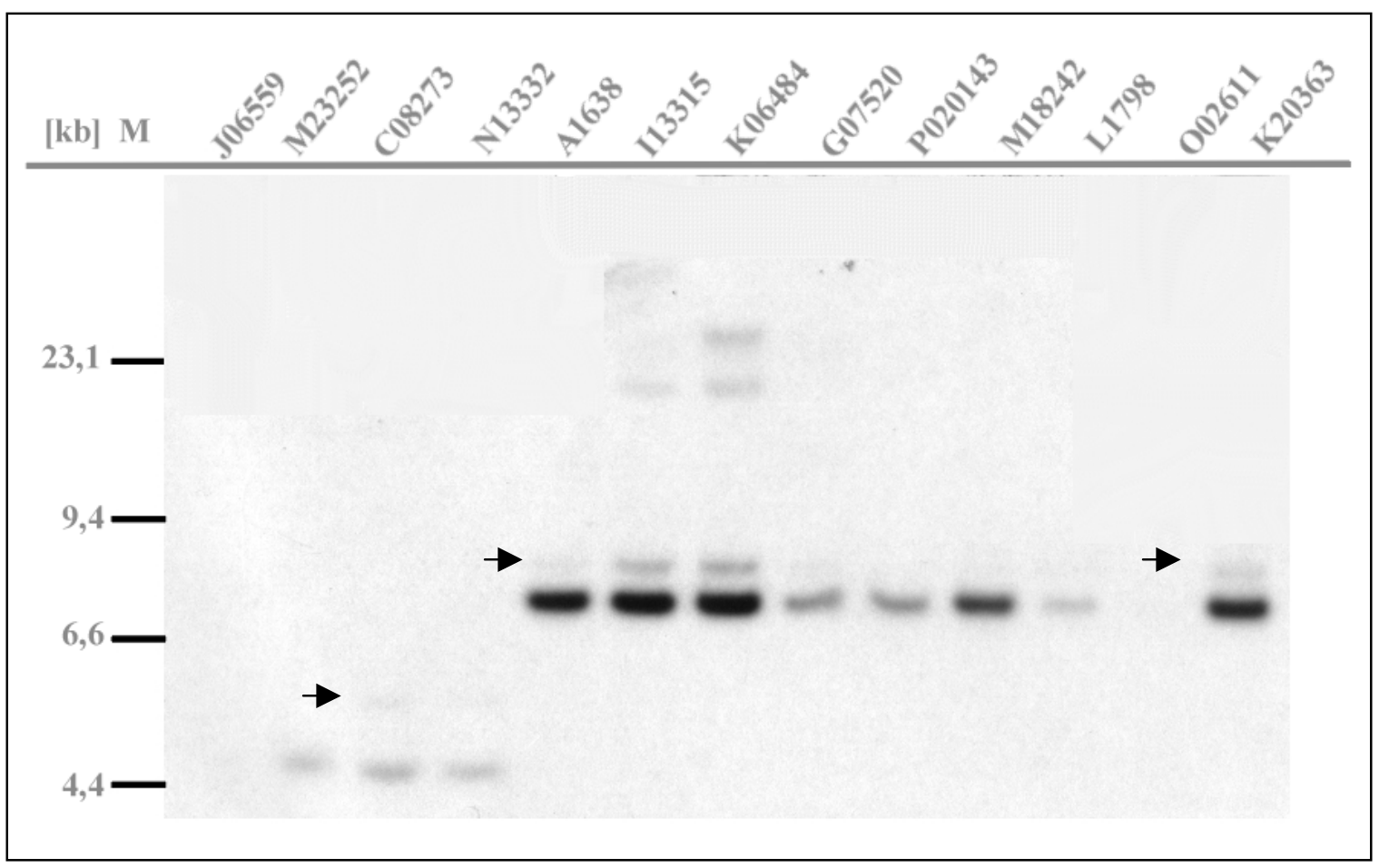

Abb. 33: Southernblot-Hybridisierung mit der H2-M2-Probe. Die mit Pfeilen angedeuteten Banden stellen sehr wahrscheinlich kreuzhybridisierende Banden dar. Links ist der Längenstandard angegeben. 


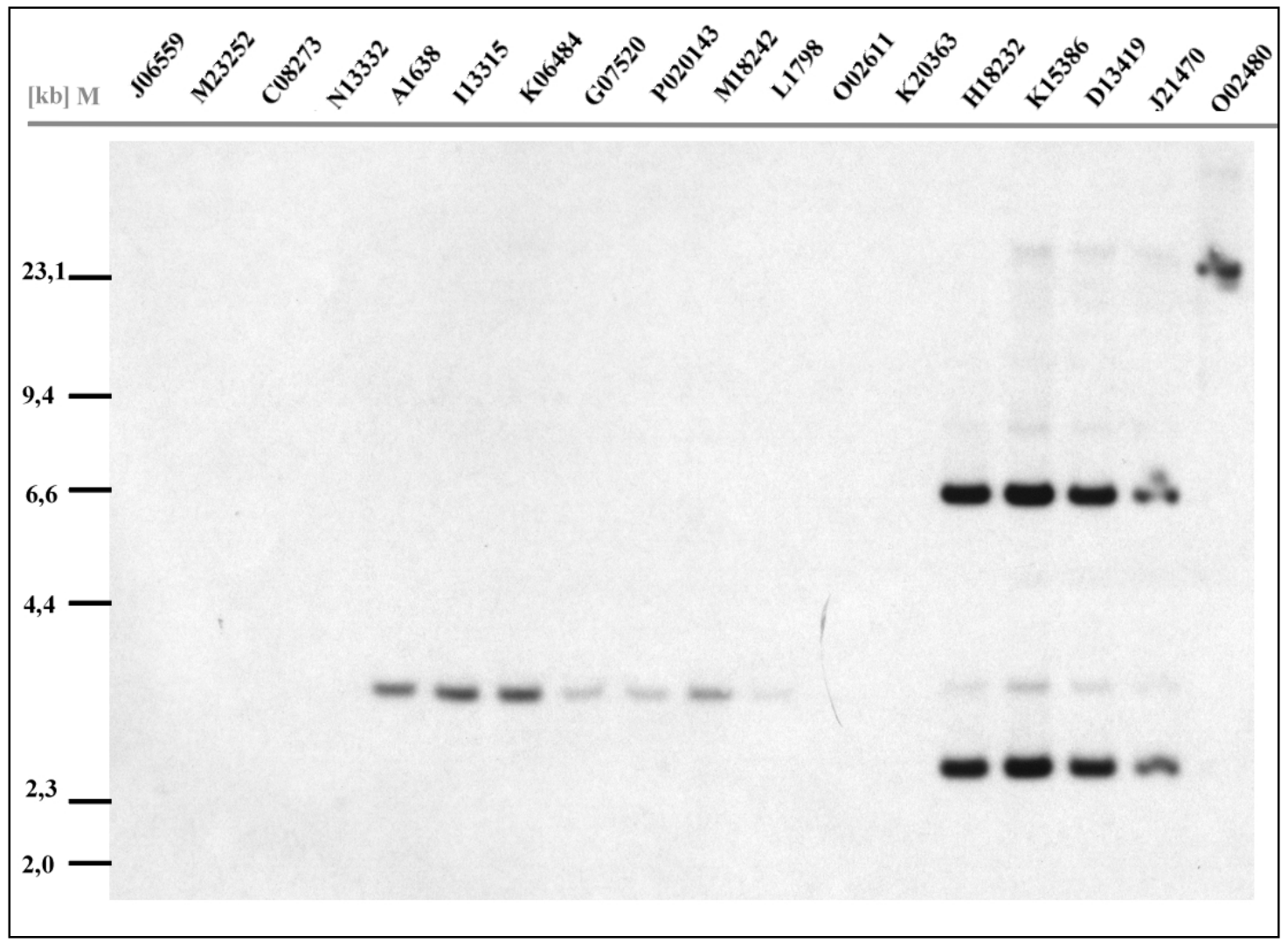

Abb. 34: Southernblot-Hybridisierung BamHI-gespaltener PAC-Klone mit der RT1-M3-Probe.

Es sind nicht alle Klone auf dem Blot repräsentiert. Links ist der Längenstandard angegeben.

In der Tabelle 8 sind alle PAC-Klone zusammengefaßt, die mit RT1-M3- bzw. der H2-M2Probe hybridisieren. Zusätzlich wird die Hybridisierung mit der $\alpha 3$-Probe angegeben.

Tab. 8: Zusammenfassung der PAC-Klone, die das Contig 3 und dem Contig 4 bilden. Aufgeführt sind die entsprechende Filter-Nummer der Ratten-Bank, die Koordinaten der Klone und die Hybridisierung der Klone mit verschiedenen Proben aus dieser Region.

\begin{tabular}{|c|c|l|l|l|l|l|}
\hline \multirow{2}{*}{ PAC } & Filter Nr. & Koordinaten & $\begin{array}{l}\text { Länge der mit } \\
\text { der } R T 1-M 3- \\
\text { Probe hybridi- } \\
\text { sierenden } \\
\text { Fragmente }[\mathrm{kb}]\end{array}$ & $\begin{array}{l}\text { Länge der mit } \\
\text { der H2-M2- } \\
\text { Probe hybridi- } \\
\text { sierenden } \\
\text { Fragmente }[\mathrm{kb}]\end{array}$ & $\begin{array}{l}\text { Länge der mit } \\
\text { der mit der } \alpha 3- \\
\text { Probe hybridi- } \\
\text { sierenden Frag- } \\
\text { mente }[\mathrm{kb}]\end{array}$ \\
\hline 1 & $\mathbf{D 1 3 4 1 9}$ & $110-6-116$ & $\begin{array}{l}6022, \\
57222\end{array}$ & $6,2 / 2,5$ & & 6,2 \\
\hline
\end{tabular}




\begin{tabular}{|c|c|c|c|c|c|c|}
\hline 2 & $\mathbf{J} 21470$ & $110-6-161$ & $\begin{array}{l}13933, \\
13634\end{array}$ & $6,2 / 2,5$ & & 6,2 \\
\hline 3 & H18232 & $110-4-122$ & $\begin{array}{l}3541 \\
3444\end{array}$ & $6,2 / 2,5$ & & 6,2 \\
\hline 4 & K15386 & $110-6-116$ & $\begin{array}{l}17029 \\
16730\end{array}$ & $6,2 / 2,5$ & & 6,2 \\
\hline 5 & O02480 & $110-6-161$ & $\begin{array}{l}23590 \\
23289\end{array}$ & $6,2 / 2,5$ & & 6,2 \\
\hline 6 & A05218 & $110-4-122$ & $\begin{array}{l}21680 \\
21677\end{array}$ & 6,2 & & 6,2 \\
\hline 7 & A1638 & $110-9-122$ & $\begin{array}{l}16478 \\
16179\end{array}$ & 3 & 7 & $3 / 7$ \\
\hline 8 & I13315 & $110-5-134$ & $\begin{array}{l}180199, \\
177200\end{array}$ & 3 & 7 & $3 / 7$ \\
\hline 9 & K06484 & $110-6-161$ & $\begin{array}{l}9330, \\
9128\end{array}$ & 3 & 7 & $3 / 7$ \\
\hline 10 & G07520 & $110-7-158$ & $\begin{array}{l}8949, \\
9046\end{array}$ & 3 & 7 & $3 / 7$ \\
\hline 11 & P020143 & $110-2-127$ & $\begin{array}{l}25162 \\
23161\end{array}$ & 3 & 7 & $3 / 7$ \\
\hline 12 & M18242 & $110-4-122$ & $\begin{array}{l}15519 \\
15220\end{array}$ & 3 & 7 & $3 / 7$ \\
\hline
\end{tabular}




\begin{tabular}{|c|c|c|c|c|c|c|}
\hline 13 & L1748 & $110-10-132$ & $\begin{array}{l}160105 \\
157104\end{array}$ & 3 & 7 & $3 / 7$ \\
\hline 14 & 002611 & $110-9-122$ & $\begin{array}{l}112168, \\
112166\end{array}$ & 3 & 7 & $3 / 7$ \\
\hline 15 & 011597 & $110-9-122$ & $\begin{array}{l}67167, \\
70168\end{array}$ & 3 & 7 & \\
\hline 16 & K20363 & $110-6-116$ & $\begin{array}{l}141190, \\
141187\end{array}$ & 3 & 7 & $3 / 7$ \\
\hline 17 & J06559 & $110-7-158$ & $\begin{array}{l}95113, \\
92112\end{array}$ & & 4,4 & 4,4 \\
\hline 18 & J08559 & $110-7-158$ & $\begin{array}{l}85113, \\
82112\end{array}$ & & 4,4 & 4,4 \\
\hline 19 & M23252 & $110-4-122$ & $\begin{array}{l}12798 \\
12796\end{array}$ & & 4,4 & 4,4 \\
\hline 20 & C08273 & $110-4-122$ & $\begin{array}{l}205228 \\
202227\end{array}$ & & 4,4 & 4,4 \\
\hline 21 & N13332 & $110-5-134$ & $\begin{array}{l}18015 \\
17714\end{array}$ & & 4,4 & 4,4 \\
\hline 22 & I12230 & $110-4-122$ & $\begin{array}{l}18439 \\
18536\end{array}$ & & $\begin{array}{l}>23 \mathrm{~kb} \\
\text { artifizielles } \\
\text { Fragment }\end{array}$ & $>23 \mathrm{~kb}$ \\
\hline
\end{tabular}

Die RT1-M3-positiven PAC-Klone D13419, J21470, K15386, H12232, O02480 und A05218 sind am telomeren Ende des Contigs 2 eingeordnet. Die restlichen RT1-M3- und RT1-M2positiven Klone wurden in der Abbildung 35 schematisch dargestellt. 
Neun der zehn PAC-Klone des Contigs 3 zeigen in der Hybridisierung des BamHISouthernblots mit der Probe RT1-M3 eine $3 \mathrm{~kb}$ lange Bande und eine $7 \mathrm{~kb}$ lange Bande mit der Sonde H2-M2. Zwei der Klone, O02611 und K20363 enthalten nur das 7 kb lange H2M2-hybridisierende Fragment (Abbildung 35).

Im Contig 4 sind Klone zusammengestellt, die eine hybridisierende BamHI Bande einer Länge von 4,4 kb mit der Probe H2-M2 zeigen. Der Klon I12230 zeigt bei der Hybridisierung sowohl mit der $\alpha 3$ - als auch mit der H2-M2-Probe, eine positive Bande auf der Höhe von 23 kb. Dieses ist ein artifizielles BamHI-Fragment. Es wurde durch Ansequenzieren eine Teilsequenz des RT1-M2-Gens der Ratte gefunden.

Diese Daten führen zu der Erkenntnis, daß bei der Ratte eine Duplikation der Gene RT1-M3 und RT1-M2 stattgefunden hat. 


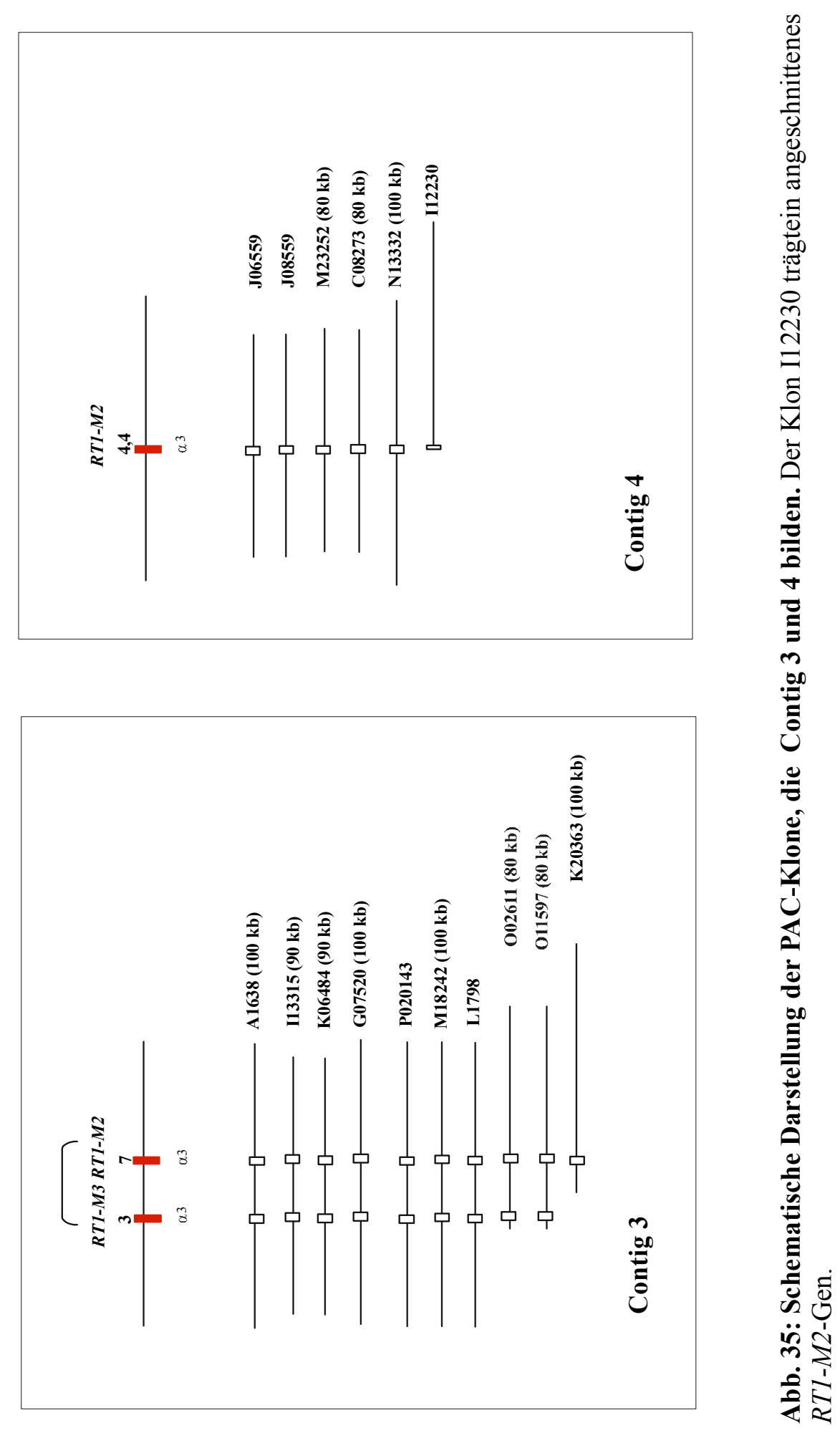




\section{Diskussion}

Im Vergleich zu den Daten, die über den MHC des Menschen und der Maus bekannt sind, ist über das RT1-System nur wenig bekannt. Die Aufklärung der genomischen Organisation des MHC der Ratte, der Anzahl und Anordnung der Klasse-I-Gene, deren Polymorphismus und Funktion, sowie die Entdeckung und Kartierung weiterer, in der Evolution konservierter, Gene dieser Region wäre von großer Bedeutung für das Verständnis dieses Multigen Systems. Die Aufklärung der Struktur des RT1-Komplexes und dessen Vergleich mit bekannten Daten des HLA- und H2-Komplexes könnte sowohl einen Einblick in die Evolution dieses Systems, als auch über die Dynamik dieses Gensystems innerhalb der Spezies gewonnen werden. Da die Ratte als Tiermodell bei der Aufklärung MHC-gekoppelter Krankheiten und experimenteller Transplantation dient, wäre die weitere Analyse des RT1-Systems von außerordentlicher Wichtigkeit.

Maus und Ratte besitzen als einzige der bisher untersuchten Spezies Klasse-I-Gene auf beiden Seiten der Klasse-II-, Klasse-III-Genregion. Bei den meisten Antworten cytotoxischer TLymphozyten läßt sich die Restriktion in der RT1.A-Region kartieren (Günther und Wurst, 1984). Durch Southernblot-Analyse ist aber gezeigt worden, daß die meisten Klasse-I-Gene auf der anderen Seite der Klasse-II-, Klasse-III-Region lokalisiert sind (Günther et al., 1985, Cortese Hassett et al., 1986). Die Untersuchungen von Jameson et al., 1992 zeigten, daß mindestens 61 Klasse-I-Gene in dieser Region zu finden sind.

Durch diese Arbeit wurde gerade diese Region, die die Hälfte des RT1-Komplexes ausmacht, strukturell analysiert, und somit ein großer Fortschritt zur Entschlüsselung des Ratten MHC erreicht

Nun wurde im Rahmen dieser Arbeit möglich eine Region von ca. 2,3 Mb des Ratten-MHC (RT1-Komplex) in 4 Contigs aus überlappenden PAC-Klonen zu klonieren und kartieren. Die Länge der Contigs wurde durch zusammenstellen der Länge von PAC-Klonen, welche das minimal Contig bilden, berechnet. Es handelt sich um die RT1-C/M-Region, welche die telomere Hälfte des RT1-Komplexes auf dem Chromosom 20 darstellt. Diese Analyse wurde an dem RT1 ${ }^{\mathrm{n}}$-Haplotyp durchgeführt, ein Rattenstamm der weite Anwendung in der Immunologie findet.

Das erste Contig mit einer Länge von ca. $630 \mathrm{~kb}$ ist in der Klasse-III-Region mit den Genen Cak, Tnfa und Batl verankert. Zwischen dem ersten und dem zweiten Contig besteht zur Zeit noch eine Lücke, die allerdings nicht größer als $200 \mathrm{~kb}$ sein dürfte. Diese Angabe basiert auf einem Vergleich mit der homologen Region des MHC des Menschen (HLA-Komplex). 
Das zweite Contig umfaßt einen Bereich von ca. $1500 \mathrm{~kb}$, und es folgen zwei weitere kurze Contigs von jeweils ca. $150 \mathrm{~kb}$, die wahrscheinlich das telomere Ende des Ratten-MHC darstellen. Diese Annahme beruht auf der Identfizierung der Gene RT1-M3 und RT1-M2 im Contig 3 und einem weiteren RT1-M2-Gen im Contig 4. Die erforderliche Nachprüfung der Kontinuität dieser Contigs wird momentan mittels spezifischer Marker in der Abteilung Immungenetik durchgeführt.

Die Klone zur Konstruktion der physikalischen Karte dieses Teiles des Ratten-MHC wurden aus mehrfachen Screenings einer genomischen PAC-Bank (Woon et al., 1998) des RattenGenoms erhalten. Die Bank hatte einen Umfang von 10 Genom-Äquivalenten und die durchschnittliche Länge der PAC-Inserts beträgt $147 \mathrm{~kb}$. Das Screening mit der $\alpha 1$ - und der a3-Probe sollte alle Klasse-I-tragenden Klone liefern, da es sich ganz offensichtlich um eine vollständige genomische Bank handelt. Durch Screenings mit weiteren Proben konnten Klasse-I-Gen-tragende Klone mit Klasse-I-negativen PAC-Klonen verbunden und $\mathrm{zu}$ größeren Contigs angeordnet werden. Insgesamt werden die 4 konstruierten Contigs der RT1$C / M$-Region von 122 PAC-Klonen gebildet.

\subsection{Contig 1}

Wie bereits oben erwähnt, ist das Contig 1 in der Klasse-III-Region verankert. Dieses wurde durch Anwesentheit der Gene Tnfa und Batl gezeigt.

In der im Rahmen dieser Arbeit konstruierten physikalischen Karte der RT1-C/M-Region existiert zwischen dem Contig 1 und dem Contig 2 noch eine Lücke.

Der physikalischen Karte des H2-Komplexes des Maus-Stammes C57BL/6 (H2 ${ }^{\mathrm{b}}$ ) (Amadou et al., 1999) kann entnommen werden, daß der Abstand zwischen dem Pou5f1- (Oct4) und dem Gna-rs 1-Gen maximal 300 kb beträgt. Die physikalische Länge der genomischen PAC-Klone, auf welchen diese Gene in der Ratte kartiert wurden, übersteigt jedoch schon die Länge von $450 \mathrm{~kb}$. Es ist offensichtlich, daß diese Region einen Längen-Unterschied zwischen Ratte und Maus aufweist. Im Menschen-MHC beträgt die Distanz zwischen den beiden Genen nach den neuesten Daten aus der kompletten Sequenzierung des HLA-Komplexes (The MHC Sequencing Consortium, 1999) 624 kb. Sollte der Abstand zwischen dem Pou5f1- und dem Gna-rs1-Gen bei der Ratte auch eine ähnliche Länge wie beim Menschen haben, dann wäre die vorhandene Lücke mit zwei PAC-Längen $(2$ x $150 \mathrm{~kb})$ zu schließen.

Am centromeren Ende des Contigs 1, welches in der Klasse-III-Region verankert ist, wurden in einem Bereich von $90 \mathrm{~kb}$ drei konservierte Gene identifiziert (CK2, Tnfa und Bat1). Am 
telomeren Ende des Contigs 1 wurden fünf konservierte Gene, nähmlich Pou5f1, Tcf19, S, Gtf2 und Cak in einem Bereich von $200 \mathrm{~kb}$ identifiziert. Zwischen diesen zwei Bereichen von in der Evolution konservierten Genen befindet sich eine Region, die in über ca. $350 \mathrm{~kb}$ mit Klasse-I-Genen besetzt ist. Orthologe Regionen sind sowohl im HLA- als auch im H2Komplex zu finden. Beim Menschen ist zwischen dem BAT1- und dem POU5F1-Gen ebenfalls eine Klasse-I-Gen enthaltende Region von ähnlicher Größe zu finden. In dieser Region sind die MICA- und MICB-Gene (Bahram et al., 1994) sowie die HLA-B- und HLAC-Gene lokalisiert. Die MICA- und MICB-Gene werden in intestinalen Epithelien exprimiert und das von ihnen kodierte Klasse-I-ähnliche Protein bindet kein $\beta$-Mikroglobulin und keine Peptide. Die Expression des MICA-Gens wird durch Streß, wie z.B. Hitzeschock, induziert (Groh et al., 1996). MICA ist ein Ligand für das NKG2D-Molekül (Bauer et al., 1999), einem auf NK-Zellen vorkommenden Rezeptor. Die im Rahmen dieser Arbeit konstruierten Contigs wurden mit MIC-spezifischen Proben sowie mit HCG-spezifischen Proben -die Gene der HCG Familien befinden sich in unmittelbarer Nähe zu den MIC Genen- überprüft und es konnten keine derartigen Gene bei der Ratte gefunden werden. Auch im Mausgenom finden sich keine MIC-Gene (Bahram et al., 1994).

Eine gleichartige Organisation ist in dieser Region auch bei der Maus zu beobachten. Zwischen den zwei Bereichen konservierter Gene befinden sich die Klasse-I-Gene der H2D/L und H2-Q-Subfamilien. Die Anzahl dieser Gene ist bei der Maus Haplotyp-abhängig variabel.

Im Contig 1 befinden sich zwischen Bat1 und Pouf51 elf BamHI-Fragmente, die mit den $\alpha 1$ und $\alpha 3$-Proben hybridisieren, vier Fragmente, die nur mit der $\alpha 1$-Probe und drei Fragmente, die nur mit der $\alpha 3$-Probe reagieren. Es ist schwierig, Aussagen über die genaue Anzahl der Klasse-I-Gene zu machen. Wenn angenommen wird, daß die elf BamHI-Fragmente, welche mit beiden Proben hybridisieren, ein vollständiges Gen darstellen und die benachbarten $\alpha 1-$ und $\alpha 3$-Fragmente zu demselben Klasse-I-Gen gehören, dann sind in der Region zwischen Bat1 und Pou5f1 16 Klasse-I-Gene anzunehmen. Fünf der 16 Gene enthalten wahrscheinlich eine interne BamHI-Schnittstelle. Eine Antwort auf diese Frage, wird die Sequenzierung der gesamten Region liefern.

In der RT1-C-Region war unter anderem das Gen 11/3R lokalisiert worden, welches zu einer Genfamilie von ca. 10 Mitgliedern gehört (Rothermel et al., 1993). Dieses Gen weist gegenüber anderen Klasse-I-Genen der Ratte Besonderheiten auf, so z.B. eine kürzere transmembranöse Region als bei den meisten bekannten Klasse-I-Moleküle der Ratte, und der eher der transmembranen Region der H2-K-, -D, -L und -Q-Moleküle der Maus ähnelt. 
Weiter fehlt das Exon 7 in der cDNA und das Stopcodon in Exon 8 ist mutiert, so daß eine Verlängerung des cytoplasmatischen Teiles um acht Aminosäuren entsteht. Darüberhinaus ist 3'-utr ungewöhnlich lang. Mit einer 11/3R-genspezifischen Probe wurden alle PAC-Klone durch Hybridisierung überprüft und sieben Gene als positiv identifiziert, die in der RT1-CRegion lokalisiert sind und somit zu der 11/3R-Familie gehören. Ein Gen aus der RT1- $A$ Region hybridisiert ebenfalls mit der 11/3R-spezifischen Probe. Die Gesamtzahl der in dieser Arbeit identifizierten 11/3R-homologen Gene stimmt in etwa mit den auf SouthernblotAnalyse basierenden Daten überein (Rothermel et al., 1993). Erstmals konnten diese Gene nun genau kartiert werden.

Aus den ersten sechs Genen im Contig 1 wurden Sequenzen des Exons 2, welches für die $\alpha 1$ Domäne der Klasse-I-Gene kodiert, erstellt. Das Sequenzalignment mit bekannten Sequenzen der Datenbank zeigte, daß diese Gene in Exon 2 höhere Homologie zu RT1-A-Klasse-I-Genen als zu RT1-C-Klasse-I-Genen aufweisen. Dies ist ein weiteres Indiz dafür, daß die Klasse-IGene der am centromeren Ende des Ratten-MHC gelegenen RT1- $A$-Region durch eine Translokation von Klasse-I-Genen aus der RTl-C-Region entstanden sind. Durch die Verwendung einer spezifischen Probe aus dem Promotor eines $R T 1$ - $A$-gekoppelten Klasse-IaGens wurde gezeigt, daß die meisten der Klasse-I-Gene, die sich zwischen Bat1 und Pou5f1 befinden, ähnliche Promotoren enthalten. Alle weiteren Klasse-I-Gene/Genfragmente in den darauf folgenden Contigs reagieren nicht mit dieser Probe. Bei der Verwendung einer spezifischen Probe aus dem cytoplasmatischen Teil eines RT1-A-gekoppelten Klasse-Ia-Gens konnte ein ähnliches Reaktionsmuster beobachtet werden.

Der Bereich der Klasse-I-Gene zwischen den Bat1- und Pou5f1-Genen entspricht der H2D/L- und H2-Q-Region des Maus MHC die ebenfalls von Bat1 bzw. Pou5f1 begrenzt werden.

Die Sequenz aus der $\alpha 1$-Domäne des auf dem 4 kb BamHI-Fragment identifizierten Klasse-IGens ist identisch mit dem von Wang et al. (1996) beschriebenen cDNA Klon 4, welcher ebenfalls aus dem RT $1^{\mathrm{n}}$-Haplotyp stammt und einem funktionellen Gen entspricht

\subsection{Contig 2}

Am centromeren Ende des Contigs 2 wurden die konservierten Gene Prg1, Pnuts und Gnars 1 lokalisiert, denen eine lange, mit Klasse-I-Genen besetzte Region folgt, deren Länge ca. $800 \mathrm{~kb}$ beträgt.

Im ersten Drittel dieser Klasse-I-Region sind vier BamHI-Fragmente identifiziert worden, die sowohl mit der $\alpha 1$ - als auch mit der $\alpha 3$-Probe hybridisieren und offensichtlich vollständige 
Klasse-I-Gene tragen. Sechs BamHI Fragmente reagieren dagegen nur mit der $\alpha 1$-Probe und acht weitere nur mit der $\alpha 3$-Probe. Aufgrund der durch die dichte Überlappung der PACKlone festgelegten Lokalisation der einzelnen entweder mit der $\alpha 1$ - oder mit der $\alpha 3$-Probe hybridisierenden Fragmente ist davon auszugehen, daß auf jeden Fall für vier der $\alpha 3-$

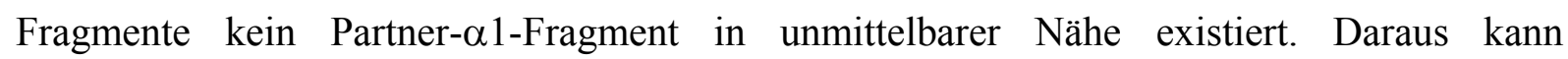
geschlossen werden, daß das Exon 2 dieser Gene entweder viel variabler als in RT1-Agekoppelten Klasse-I-Genen ist und deshalb keine Reaktion mit der verwendeten $\alpha 1$-Probe stattfinden kann oder daß es sich um Klasse-I-Genfragmente handelt, denen das Exon 2 fehlt. Bei drei weiteren $\alpha 3$-hybridisierenden Fragmente existieren in unmittelbarer Nachbarschaft $\alpha 1$-hybridisierende Fragmente. In diesen Fällen ist die Annahme erlaubt, daß diese Fragmente zusammen gehören und jeweils ein Klasse-I-Gen darstellen, welches eine interne BamHIStelle beinhaltet. Weiterhin sind drei $\alpha 1$-hybridisierende Fragmente vorhanden, die mit großer Wahrscheinlichkeit singuläre Genfragmente darstellen.

Generell ist es zur Zeit noch nicht möglich, eine genauere Aussage über die Anzahl der in dieser Region enthaltenen Klasse-I-Gene/Genfragmente zu machen. Der Versuch, durch Restriktionsspaltung mit anderen Enzymen, wie z.B. HindIII und EcoRI ein eventuell weniger kompliziertes Bild der hybridisierenden Fragmente $\mathrm{zu}$ erhalten, brachte keine neuen Erkenntnisse, da die erhaltenen Bilder ebenso komplex waren. Definitive Information kann ausschließlich das Durchsequenzieren der Region anhand überlappender Klone der Contigs liefern.

Eine eingehendere Untersuchung war bei zwei Klasse-I-Genen aus diesem Bereich des Contigs 2 möglich. Durch die Endsequenzierung zweier PAC-Klone wurde Sequenzinformation aus Bereichen von Klasse-I-Genen erhalten. Zum einen wurde so das schon beschriebene RT.BMI-Gen (Parker et al., 1990) identifiziert. Aus der Richtung der erhaltenen Sequenz und der Lage der angewendeten Primer war es möglich, die Orientierung des Gens festzustellen. Das identifizierte Gen befindet sich auf dem 4,4 kb umfassenden $\alpha 3$ positiven BamHI-Fragment zu Beginn des Contigs 2. Das RT.BM1 scheint ortholog zum H2T23-Gen der Maus zu sein, dessen Genprodukt Peptide von Leadersequenzen aus Klasse-IMolekülen präsentiert und über diesen Weg zur Hemmung von NK-Zellen beiträgt (Salgar et al., 1998). Zum anderen wurde die Teilsequenz eines weiteren Klasse-I-Gens wurde auf dem $4 \mathrm{~kb}$ langen BamHI-Fragment erhalten. Dieses zeigt die gleiche Orientierung wie das RT.BM1-Gen und weist Homologie zu einem H2-T2-Pseudogen auf.

Die beiden ansequenzierten Gene befinden sich innerhalb der grc-Region. Die grc-Region (growth and reproduction complex) konnte ebenfalls im Rahmen dieser Arbeit feinkartiert 
werden (s. Abb. 21) und umfaßt einen Bereich von ca. 70 kb. Deletionsmutanten bei Ratten, denen die grc-Region fehlt, zeigen abnormale Wachstums- und ReproduktionsCharakteristika sowie erhöhte Suszeptibilität gegenüber karzinogenen Substanzen (Cortese Hassett et al., 1989; Gill et al., 1995). Durch genaue Analyse der PAC-Klone, der grc-Region wird es möglich sein die Gene, welche für den grc-Phänotyp verantwortlich sind, zu identifizieren.

Dem ersten Drittel der Klasse-I-Gen-haltigen Region des Contigs 2 folgt ein ca. 250 kb langer Abschnitt, in dem ausschließlich $\alpha 1$-hybridisierende BamHI-Fragmente gefunden wurden. Die Anzahl dieser Fragmente beträgt 25. Zwei dieser Fragmente wurde subkloniert und die Sequenzierung ergab, daß es sich um die 5'-Hälfte von Exon 2 eines Klasse-I-Gens handelt, das von anonymen Sequenzen flankiert wird. Durch Hybridisierung mit den jeweiligen Hälften eines Exons 2 konnte festgestellt werden, daß es sich bei allen 25 Fragmenten um sehr ähnliche Fragmente der 5'-Hälfte von Exon 2 handelt. Innerhalb dieser $\alpha 1$-Genfragmentreichen Region sind Blöcke von zwei oder drei $\alpha 1$-Fragmenten als duplizierte Einheiten erkennbar (s. Abb 21 und 30). Offenbar fanden zum Teil Block-Duplikationen und Inversionen statt. Eine homologe Region ist in der der Maus nicht zu finden. Gen-Fragmente ähnlicher Art, wenn auch nicht in dieser Anzahl und Anordnung wurden allerdings im HLAKomplex beschrieben, z.B. HLA-Z1 in der Klasse-II Region, welches 87 bp aus dem Exon 4 beinhaltet (Beck et al., 1996).

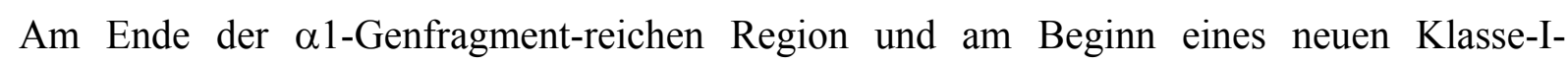
Genabschnittes ist ein Mikrosatellit der Zusammensetzung (GAAA)n(GAAAA)n von 100 bp Länge identifiziert worden. Er zeigte keinen Polymophismus beim Vergleich verschiedener Rattenstämme.

Diesem Bereich schließt sich eine ca. $300 \mathrm{~kb}$ lange Region an, in welcher 11 Klasse-IGene/Genfragmente identifiziert wurden. Diese hybridisieren alle mit der $\alpha 3$-Probe (Exon 4), jedoch nicht mit der verwendeten $\alpha 1$-Probe (Exon 2). Es muß sich um Klasse-I-Gene handeln, die gegenüber einem klassischen Klasse-I-Gen ein weniger konserviertes Exon 2 aufweisen. Aufgrund dieser Tatsache und der Lokalisation ließ sich vermuten, daß hier der Beginn der RT1-M-Region vorliegt. Drei STS-Marker (255D16T, 261A5T und 261A5S) aus der homologen Region der Maus wurden verwendet, um diesen RT1-Bereich zu überprüfen. Es konnte gezeigt werden, daß alle drei Marker in ähnlicher Anordnung in der Ratte vorkommen, mit dem Unterschied, daß die Anzahl der zwischen den Markern befindlichen 
Klasse-I-Gene in der Ratte geringer ist als bei der Maus und der Marker 261 A5T in der BNRatte offensichtlich mehrfach dupliziert vorliegt.

Am telomeren Ende Klasse-I-Region dieses Contigs wurde ein neuer STS-Marker etabliert (P0846T), der den Übergang zur nächsten Gruppe überlappender PAC-Klone vermittelt. Am centromeren Ende dieser anschließenden Region sind die konservierten Gene Znf173, Rfb30 und Tctex5 lokalisiert. Telomerwärts dieser Gene wurden in einem Abstand von ca. $100 \mathrm{~kb}$ zwei ebenfalls konservierte Gene lokalisiert, Mog und das Tu42. In dem dazwischen liegenden Bereich von ca. $100 \mathrm{~kb}$ wurden drei Klasse-I-Gene identifiziert. Eins dieser drei Gene konnte durch PCR anhand eines bekannten Mikrosatelliten als das RT1-M4-Gen identifiziert werden.

Wird der Bereich der RT1-M-Region der Ratte mit der orthologen H2-M-Region der Maus verglichen, so ist zu erkennen, daß diese unterschiedlich lang sind und zum anderen Unterschiede in der Anzahl von Klasse-I-Genen bestehen.

Im 700 kb umfassenden Segment zwischen H2-T1 (am telomeren Ende der H2-T Region gelegen) und Znf173 befinden sich in der Maus insgesamt 16 Klasse-I Gene, die die M1- und M10-Familie bilden. In der Ratte wurde zwar noch keine Genanalyse durchgeführt, die zeigt, daß es sich um H2-M1- und H2-M10-homologe Gene handelt, es läßt sich aber aus den bereits erwähnten Daten postulieren, daß die aus elf Klasse-I-Genen bestehende Region in der Ratte den centromeren Teil der RT1-M-Region darstellt. Die Anzahl dieser Gene scheint in der Ratte geringer und in einem kürzeren Bereich lokalisiert zu sein als bei der Maus.

Zwischen Znf173 und Mog befinden sich in der Maus innerhalb von 180 kb drei Klasse-IGene (M6, M4 und M5). Das entsprechende Segment der Ratte hat eine ähnliche Länge und trägt die gleiche Anzahl von Klasse-I-Genen. Eins dieser Gene wurde genauer untersucht und als das RT1-M4-Gen identifiziert. Dieses Gen trägt einen polymorphen Marker dessen Länge in der BN Ratte 129 bp (Lambracht et al., 1998) beträgt. Bei den anderen beiden Klasse-IGenen handelt es sich wahrscheinlich um H2-M5- und H2-M6-homologe Gene der Ratte, so daß dieser Abschnitt des MHC bei Ratte und Maus sehr konserviert erscheint und die entsprechenden Klasse-I-Gene sehr wahrscheinlich auch ortholog sind.

Im telomeren Bereich des Contigs 2 wurden zwei STS Marker kartiert, der in dieser Arbeit etablierte H102T-Marker und der Marker 573K1S aus der orthologen Region der Maus (Amadou et al., 1999). Im Anschluß befinden sich zwei Klasse-I-Gen/Genfragmente, die mit der RT1-M3-spezifischen Probe reagieren. 


\subsection{Contigs 3 und 4}

Zwei weitere Contigs überlappender PAC-Klone, die jeweils ca. $150 \mathrm{~kb}$ groß sind wurden erstellt. Im Contig 3 konnte ein weiteres RT1-M3- und ein RT1-M2-Gen/Genfragment identifiziert werden und auf dem Contig 4 ein weiteres RT1-M2-Gen. Diese zwei Contigs schließen sich eventuell dem Contig 2 an, was jedoch im Rahmen dieser Arbeit nicht mehr überprüft wurde. Interessante sind im Vergleich zur Maus die Gene RT1-M3 und RT1-M2 in der Ratte dupliziert.

Die homologen Maus Gene H2-M3 (Wang et al., 1991) und H2-M2 (Bronson et al., 1989) sind nicht klassische Klasse-I-Gene und zeigen nur im Bereich des Exon 4 hohe Homologie $\mathrm{zu}$ anderen Klasse-I-Gene. Es wurde gezeigt, daß von H2-M3-Gen kodiertes Klasse-IbMolekül N-formylierte Peptide mitochondrialen oder bakteriellen Ursprungs zytotoxischen TLymphozyten präsentieren kann und ist an der Immunantwort nach Infektion mit Listeria monocytogenes beteiligt (Pamer et al., 1992).

Das bereits untersuchte RT1.M3-Gen (Wang et al., 1991) zeigt ebenfalls nur im Bereich des Exon 2 eine 92\%ige Homologie zu anderen Klasse-I-Gene der Ratte.

Die H2-M3- und H2-M2-Gene sind in dieser Anordnung am distalsten Ende des MHC kartiert (Jones et al., 1999), umgeben von olfaktorischen-Rezeptor-Gene. Ein entsprechender Abschnitt mit olfaktorischen-Rezeptor-Gene existiert auch am telomeren Ende des Menschen MHC, jedoch fehlen homologe Gene zum H2-M3 und H2-M2.

Die Übersicht der physikalischen Karte der RT1.C/M Region des Ratten MHC ist in Abb. 36 zu sehen. Beim Contig 1 ist erkennbar, das zwischen zwei Regionen konservierter Gene, eine $350 \mathrm{~kb}$ lange Region von Klasse-I-Genen sich erstreckt. In die centromere Region konservierter Gene gehören das Tnf und Bat1 Gen, mit denen das Contig in der Klasse-IIIregion verankert ist. In der telomerwärts liegende Region konservierter Gene, wurden die Gene Pou5f1, Tcf19, S, Gtf2 und Cak kartiert. Zwischen dem Contig 1 und dem Contig 2 besteht noch eine zu schließende Lücke. Im Contig 2 ist auch ebenfalls deutlich zu sehen, daß zwischen Blöcken aus konservierten Gene, sich unterschiedlich lange Klasse-I-Gen-Regionen ausdehnen. Die Länge dieses Contigs beträgt ca. 1500 kb. Es folgen zwei Contigs, die jeweils eine Länge von $150 \mathrm{~kb}$ betragen. Das Contig 3 trägt jeweils ein RT1-M3 und ein RT1-M2Gen/Genfragment. Auf dem Contig 4 befindet sich ein RT1-M2 Gen/Genfragment.

Eine detailierte Gesamtüberschicht der erstellten physikalischen Karte befindet sich im Anhang 3, deren ausführliche beschreibung ist dem Kapitel 4.3 zu entnehmen.. 


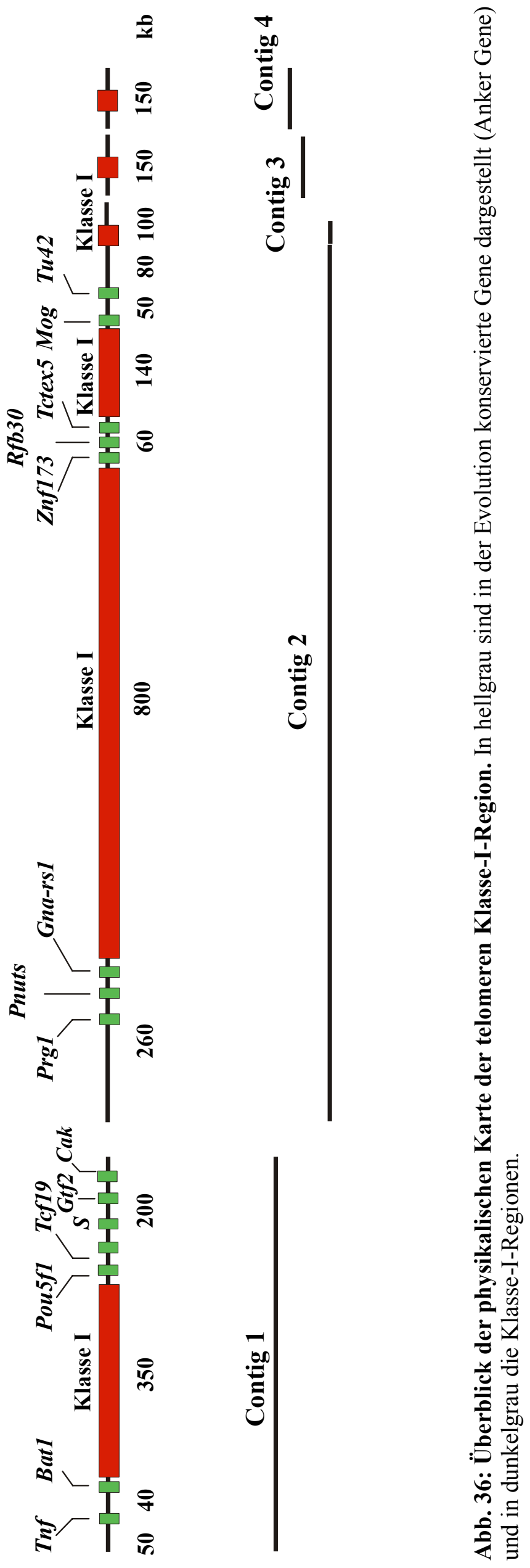


5.4 Vergleich zwischen RT1-, H2- und HLA-Komplex in den Klasse-I-Regionen

Es wurde bereits erwähnt, daß bei Maus und Ratte centromerwärts der Klasse-II-Region zusätzlich eine Klasse-I-Region existiert. Diese Bereiche, genannt H2-K und RT1-A, liegen bei diesen beiden Spezies an orthologer Position (Walter und Günther, 2000). Diese Regionen werden hier allerdings nicht detailliert behandelt, da sie nicht Inhalt der Untersuchungen der vorliegenden Arbeit sind. Es sollte jedoch erwähnt werden, daß diese Klasse-I-Bereiche innerhalb von Blöcken aus konservierten und orthologen Genen lokalisiert sind.

Nach einer Hypothese, die sich auf die Evolution der Klasse-I-Region des MHC bezieht, wird das framework durch konservierte Gene mit essentieller Funktion gebildet (Amadou et al., 1995; Amadou, 1999). Innerhalb dieser ursprünglichen Struktur gibt es permissive Regionen, in denen Duplikationen oder Deletionen von Klasse-I-Genen erlaubt sind. Die Diskrepanzen in der Länge der Klasse-I-Regionen werden als Expansionen oder Kontraktionen im Bezug zum ursprünglichen framework und nicht zwischen den Spezies angesehen.

Die Abbildung 37 ist eine Darstellung der framework Genregionen und der variablen KlasseI-Regionen in Länge und Anzahl an Klasse-I Gene/Genfragmente. Die identifizierten framework Gene kommen an orthologen Positionen auch bei Mensch und Maus vor. Zwischen den Blöcken orthologer konservierter Gene befinden sich Regionen von Klasse-IGene ebenfalls an orthologen Stellen. Dies bedeutet allerdings nicht, daß die Klasse-I-Gene an sich ortholog sind. Die RT1.C-Region zeigt Orthologie zu entsprechenden H2-D/L, H2-Q Region des MHC der Maus. Auch Orthologie scheint zu existieren zu Genen der H2-TRegion. Als Beispiel kann das RT1. BM1-Gen genannt werden, welches zu Beginn des Contig 2 kartiert wurde und Ortholog dem H-2T23 der Maus ist (Parker et al., 1991).

Hochkonserviert scheinen die Klasse-I-gene der RT1.M-Region zu sein. Bei der Ratte wie in Maus wurden in dieser Region ebenfalls drei Gene kartiert, wobei das RT1-M4 genau identifiziert werden konnte. Auch RT1.M2-, RT1-M3-Gene konnten an orthologer Region zu den Maus H2-M2- und H2-M3-Gene identifiziert werden. Allerdings scheinen in der Ratte diese Gene dupliziert zu sein im Gegensatz zur Maus (Abb. 37). Beim Menschen existieren solche Gene nicht. Hervorzuheben ist, daß die im Rahmen der vorliegenden Arbeit erhobenen Daten in dem framwork Modell passen. Die Regionen hochkonservierter Gene („AnkerGene") sowie die Klasse-I-Regionen in dem hier untersuchten Bereich befinden sich an orthologen Positionen bei Mensch, Ratte und Maus. Variationen sind in der Anzahl der Klasse-I-Gene und der Länge der Klasse-I-Regionen zu beobachten. 


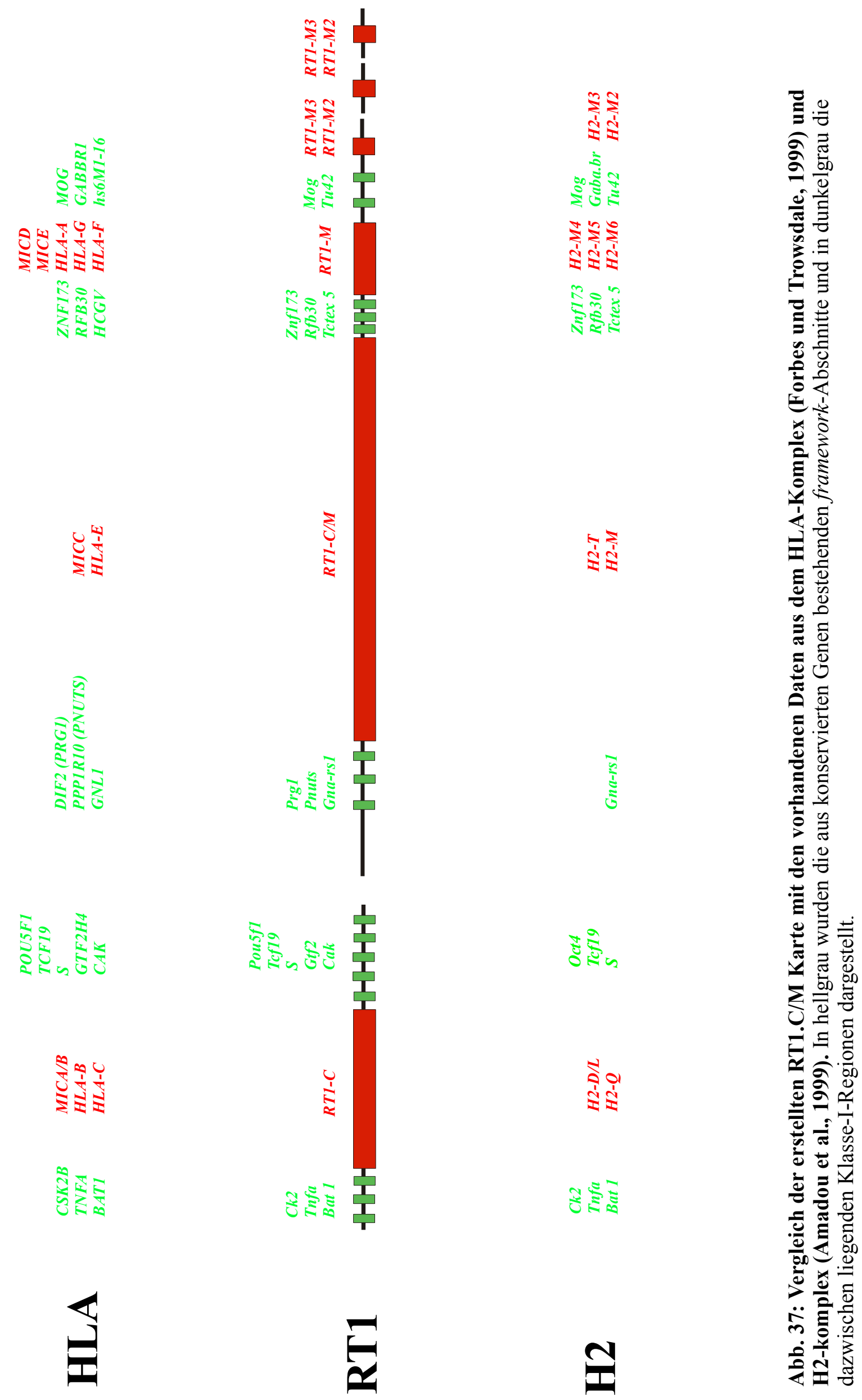




\subsection{Ausblick}

Durch die vorgelegten Ergebnissen, wurde fast im ganzen die strukturelle Organisation der telomeren Klasse-I-Genregion, des Ratten MHC in einem Umfang von über $2 \mathrm{Mb}$ aufgeklärt. Die Informationen aus den erstellten kontinuierlichen genomischen Contigs und die Identifizierung der gesamten auf diesen befindenden Klasse-I-Gene/Genfragmente sowie die Identifizierung und Feinkartierung einer hohen Anzahl von nicht Klasse-I-Genen, die in der Evolution konserviert geblieben sind, gewähren nun einen klaren Einblick in die Anordnung dieser besonders interessanten genomischen Region.

Der Vollständigkeithaber sollte in einem nächsten Schritt die noch bestehende Lücke zwischen dem Contig 1 und Contig 2 geschlossen werden. Die Zugehörigkeit der Contigs 3 und 4, welche eventuell das distalste Ende des Ratten MHC darstellen, sollte ebenfalls festgestellt werden.

Die vorgestellte Arbeit bildet den Meilenstein für das Starten systematischer Untersuchungen, welche nun zur Beantwortung langwierig gestellter Fragen auf einen schnelleren Weg weiterführen können. Z.B Fragen der Evolution des Haupthistokompatibilitätssystems, nachdem auch ausführliche Informationen aus der Analyse des MHC weiterer Spezies wie Mensch, Maus, usw. vorhanden sind. Aber auch genetische Vorgänge, die innerhalb der Spezies stattgefunden haben, könnten besser verstanden werden.

Die Verfeinerung unserer Kenntnisse über die Struktur des Ratten MHC hat präzisere Voraussetzungen verschafft zur Analyse von MHC-assoziierten Krankheitbildern. Dazu könnte die transiente Transfektion von Zellinien evt. mit ganzen PACs, die nun bekannte Gene tragen, behilflich sein. Ein zusätzliches weiterführendes Experiment wäre die Expressionanalyse, der identifizierten in der Evolution konservierten Gene.

Ganz präzise Informationen über die genaue Reihenfolge und Anzahl der Klasse-I-Gene wird natürlich die bevorstehende Sequenzierung dieser Region, anhand eines minimal Contigs liefern. Klasse-I-Gene können auf ihrer Restriktionsfunktion überprüft werden, um die Klasse-Ia bzw. Klasse-Ib-Gene bestimmen zu können.

Eine Reihe der beschriebenen weiterführenden Experimenten werden momentan in der Abteilung Immungenetik durchgeführt. 


\section{Zusammenfassung}

In der vorliegenden Arbeit wurde eine genomische BAC-Bank aus der LEW.1W/Gun-Ratte erstellt, die aus 128.760 Klonen besteht. 50\% dieser Klone haben kurze Inserts ( $\varnothing 6 \mathrm{~kb}$ ), die restlichen 50\% haben Inserts einer Durchschnittslänge von $50 \mathrm{~kb}$. Zusätzlich wurden 33.600 Klone einer Durchschnittslänge von $30 \mathrm{~kb}$ etabliert. Insgesamt wurden 1,4 Genomäquivalente kloniert.

Nachdem eine PAC-Bank der BN-Ratte mit 10 Genomäquivalenten verfügbar war, wurde diese Bank genutzt, um die eigentliche Fragestellung, die Klonierung der RT1-C/M-Region des Ratten-MHC (major histocompatibility complex) zu beobachten. Insgesamt wurden 122 PAC-Klone der RT1-C/M-Region isoliert und in 4 Contigs angeordnet, die insgesamt ca. 2,3 Mb umfassen.

Das Contig 1 hat eine Größe von ca. $630 \mathrm{~kb}$ und ist in der Klasse-III-Region des MHC verankert. Es enthält einen ca. 350 kb langen, Klasse-I-Gene-tragenden Bereich, den sich eine weitere Region von in der Evolution konservierten Genen anschließt, wie z.B. Pou5f1, Tcf19, $S$, Cak und Gtf2. Diese Region entspricht der Lage nach der H2-D/L und H2-Q-Region des Maus-MHC.

Zwischen dem Contig 1 und dem folgenden Contig 2 besteht z.Z noch eine Lücke, deren Größe auf ca. 200 kb geschätzt wird.

Das Contig 2 hat eine Größe von ca. 1500 kb, dessen erster Abschnitt ebenfalls aus einer Reihe konservierter Gene besteht, wie z.B Prgl, Pnuts und Gna-rs1. In der darauffolgende Region von ca. $800 \mathrm{~kb}$ finden sich Klasse-I-Gene. Auffällig ist in diesem Bereich ein Abschnitt von ca. $250 \mathrm{~kb}$, welcher nur Klasse-I-Genfragmente enthält, die aus dem 3‘-Ende eines Exon 2 bestehen. Am Beginn des Klasse-I-Abschnittes konnte die grc-Region (growth und reproduction complex) kartiert werden und benachbart das schon bekannte Gen RT.BMI. Durch weitere Sequenz-Informationen konnte die Orthologie zu der H2-T-Region des MausMHC abgeleitet werden. Das telomere Ende dieser Klasse-I-Region stellt offensichtlich den Beginn einer zur H2-M homologen Region dar, denn STS-Marker aus dem entsprechenden Bereich des Maus-MHC konnten hier kartiert werden. Im Anschluß wurden die konservierten Gene Znf173, Rfb30 und Tctex5 innerhalb von $60 \mathrm{~kb}$ kartiert. Es folgt eine kürzere Klasse-IRegion, bestehend aus drei Klasse-I-Genen in einem Abstand von ca. $140 \mathrm{~kb}$ unter denen das RT1-M4 identifiziert wurde. Telomerwärts dieser zweiten Klasse-I-Region befinden sich zwei 
weitere konservierte Gene, Mog und Tu42, und am äußersten Ende des Contigs 2 zwei RT1M3-Gene.

Die folgenden Contigs 3 und 4 haben eine Länge von jeweils ca. $150 \mathrm{~kb}$, wobei im Contig 3 ein RT1-M3- und ein RT1-M2-Gen und im Contig 4 ein weiteres RT1-M2-Gen identifiziert wurden. Im Gegensatz zur Maus sind entsprechend die RT1-M2- und RT1-M3-Gene bei der Ratte dupliziert.

Auch in der Ratte, wie beim Menschen und dem Maus-MHC, sind die Klasse-I-Regionen zwischen Blöcken konservierter Gene an orthologen Positionen gelegen. Durch diese Erkenntnisse über die Organisation der RT1.C/M Region des Ratten-MHC wird eindeutig, daß auch diese in dem von Amadou 1999 postulierten framework Modell paßt. 


\section{Literaturverzeichnis}

Amadou C. (1999): Evolution of the Mhc class I region: the framework hypothesis. Immunogenetics 49:362-367

Amadou C., Kumanovics A., Lambracht-Washington D., Yoshino M., Fischer Lindahl K. (1999): The mouse major histocompatibility complex: some assembly required. Immunol $\operatorname{Rev~167:211-221~}$

Amadou C., Ribouchon M.T., Mattei M.G., Jenkins N.A., Gilbert D.J., Copeland N.G., Avoustin P., Pontarotti P. (1995): Localization of new genes and markers to the distal part of the human major histocompatibility complex (MHC) region and comparison with the mouse: new insights into the evolution of mammalian genomes. Genomics 26:9-20

Bauer S., Groh V., Wu J., Steinle A., Phillips J., Lanier L.L., Spies T. (1999): Activation of NK cells and T cells by NKG2D, a receptor for stress-inducible MICA. Science 285:727729

Beck S., Abdulla S., Alderton RP., Glynne RJ., Gut IG., Hosking L.K., Jackson A., Kelly A., Newell WR., Sanseau P., Radley E., Thorpe K.L., Trowsdale J. (1996): Evolutionary dynamics of non-coding sequences within the class II region of the human MHC. J Mol Biol 255:1-13

Bjørkman P.J., Saper M.A., Samraoui B., Benett W.S., Strominger J.L., Wiley D.C. (1987): The foreign antigen binding site and $\mathrm{T}$ cell recognition regions of class $\mathrm{I}$ histocompatibility antigens. Nature 329:512-518

Bihoreau M.T., Gauguier D., Kato N., Hyne G., Lindpaintner K., Rapp J.P., James M.R., Lathrop G.M. (1997): A linkage map of the rat genome derived from three F2 crosses. Genome Res 7:434-440

Birren B., Lai E. (1994): Rapid pulsed field separation of DNA molecules up to $250 \mathrm{~kb}$. Nucleic Acids Res 22:5366-5370 
Boldyreff B., Issinger O.G. (1995): Structure of the gene encoding the murine protein kinase CK2 beta subunit. Genomics 29:253-256

Brorson K.A., Richards S., Hunt S.W., Cheroutre H., Fischer Lindahl K., Hood L. (1989): Analysis of a new class I gene mapping to the Hmt region of the mouse. Immunogenetics 30:273-283

Butcher G.W., Howard J.C. (1979): A recombinant in the major histocompatibility complex of the rat. Nature 266:362-364

Cai L., Taylor J.F., Wing R.A., Gallagher D.S., Woo S.-S., Davis S.K. (1995): Construction and characterization of a bovine bacterial artificial chromosome library. Genomics 29:413-425

Charles C., Yoon J.K., Simske J. S., Lau L. (1993): Genomic structure, cDNA sequence, and expression of gly96, a growth factor-inducible immediate-early gene encoding a shortlived glycosylated protein. Oncogene 8:797-801

Chu T.W., Capossela A., Coleman R., Goei V.L., Nallur G., Gruen J.R. (1995): Cloning of a new „Finger“ protein gene (ZNF173) within the class I region of the human MHC. Genomics 29:229-239

Colle E., Guttmann R.D., Fuks A. (1986): Insulin-dependent diabetes mellitus is associated with genes that map to the right of the class I RT1.A locus of the major histocompatibility complex of the rat. Diabetes 35:454-458

Cortese Hassett A.L.C., Locker J., Rupp G., Kunz H.W., Gill T. J. III (1989): Molecular analysis of the rat MHC II. Isolation of genes that map to the RT1.E-grc region. J Immunol 142:2089-2096

Devlin J.J., Weiss E.H., Paulson M., Flavell R.A. (1985): Duplicated gene pairs and alleles of the class I genes in the Qa2 region of the murine major histocompatibility complex: a comparison. EMBO J 4:3203-3207 
Diamond A. G., Hood L.E., Howard J.C., Windle M., Winoto A. (1989): The class II genes of the rat MHC. J Immunol 142:3268-3274

Dominov J., Miller J.B. (1996): POU homeodomain genes and myogenesis. Dev Genet 19:108-118

Dower W., Miller J.F., Ragsdale C.W. (1988): High efficiency transformation of E.coli by high voltage electroporation. Nucleic Acids Res 16:6127-6145

Drivas G.T., Shih A., Coutavas E.E., Rush M.G., D'Eustachio P. (1990): Characterisation of four novel ras-like genes expressed in a human teratocarcinoma cell line. Mol Cell Biol 10:1793-1798

Duffy A.J., Coltman D.W., Wright J.M. (1996): Microsatellites at a common site in the second ORF of L1 elements in mammalian genomes. Mamm Genome 7:386-387

Duran L.W., Zeller J.C., Lundy J.K., Chang-Miller A., Krco C.J., David C.S., Pease L.R. (1987): Genetic analysis of the H-2D region using a new intra-D-region recombinant mouse stain. J Immunol 139:2818-2824

Fisher S.E., Vargja-Khadem F., Watkins K.E., Monaco A.P., Pembury M.E. (1998): Localisation of a gene implicated in a severe speech and language disorder. Nature Genet 18: $168-170$

Forbes S.A., Trowsdale J. (1999): The MHC quarterly report. Immunogenetics 50:152-159

Frohman M.A. (1993): Rapid amplification of cDNA for generation of full-length cDNA ends: Thermal RACE. Methods Enzymol 218:340-356

Frohman M. A., Martin G.R. (1988): Rapid amplification of cDNA ends using nested primers. Technique 1:165 
Gill T.J. III, Salgar S.K., Yuan X.-J., Kunz H.W. (1997): Current status of the genetic and physical maps of the major histocompatibility complex in the rat. Transplant Proc 29:16571659

Gorer P.A. (1936): The detection of antigenic differences in mouse erythrocytes by the employment of immune sera. Br J Exp Path 17:42-50

Grant S.G.N., Jessee J., Bloom F.R., Hanahan D. (1990): Differential plasmid rescue from transgenic mouse DNAs into Escherichia coli methylation-restriction mutants. Proc Natl Acad Sci USA 87:4645-4649

Groh V., Bahram S., Bauer S., Herman A., Beauchamp M., Spies T. (1996): Cell stressregulated human major histocompatibility complex class I gene expressed in gastrointestinal epithelium. Proc Natl Acad Sci USA 93:12445-12450

Gruen J.R., Weissman S.M. (1997): Evolving views of the MHC. Blood 90:4252-4265

Guerrin M., Simon M., Montezin M., Haftek M., Vincent C., Serre G. (1998): Expression cloning of human corneodesmosin proves its identity with the product of the S gene and allows improved characterisation of its processing during keratinocyte differentiation. $J$ Biol Chem 274:22640-22647

Guillaudeux T., Janer M., Wong G. K-S., Spies T., Geraghty D.E. (1998): The complete genomic sequence of 424,015 bp at the centromeric end of the HLA class I region: Gene content and polymorphism. Proc. Natl Acad Sci USA 95:9494-9499

Günther E. (1985): Immunogenetic aspects of organ transplantation in the rat. In: Thiede A., Deltz E., Engemann R, und Hamelmann H. (Hrsg) Microsurgical Models in Rats for Transplantation Research, Berlin, Springer pp. 83-94

Günther E. (1990): Immunological markers. In: Hedrich H.J. (Hrsg) Genetic Monitoring of Inbred Strains of Rats, Stuttgart New York, Fischer pp. 23-35 
Günther E. (1996): Current status of the molecular genetic analysis of the rat major histocompatibility complex. Folia Biol (Praha) 42:129-145

Günther E., Kiesel U., Kolb H., Krawczak M., Rothermel E., Wurst W. (1991): Genetic analysis of sucseptibility to diabetes meletus in F2-hybrids between diabetes-prone BB and various MHC-recombinant congenic rat strains. J Autoimmun 4:543-551

Günther E., Wurst W. (1984): Cytotoxic T lymphocytes of the rat are predominantly restricted by RT1.A and not RT1.C-determined major histocompatibility complex class I antigens. Immunogenetics 20:1-12

Günther E., Wurst W., Wonigeit K., Epplen J. T. (1985): Analysis of the rat major histocompatibility complex by Southern blot hybridization. J Immunol 134:1257-1261

Günther E., Butcher G., Gill T.J. III, Kunz H.W., Natori T. (1997): Report on rat chromosome 20. Rat Genome 3:97-107

Hänze J., Fischer L., Koenen M., Worgall S., Rascher W. (1998): Electroporation of nucleic acids into prokaryotic and eukaryotic cells by square wave pulses. Biotechnology Techniques 12:159-163

Helou K., Walter L., Günther E., Levan G. (1998): Cytogenetic orientation of the rat major histocompatibility complex (MHC) on chromosome 20. Immunogenetics 47:166-169

Henry J., Ribouchon M.T., Depetris D., Mattei M.G., Offer C., Tazi-Ahnini R., Pontarotti P. (1997): Cloning, structural analysis, and mapping of the B30 and B7 multigenic families to the major histocompatibility complex (MHC) and other chromosomal regions. Immunogenetics 46:383-395

Hosida F., Nishimura S., Uchida H., Ohki M. (1990): An F factor based cloning system for large DNA fragments. Nucleic Acids Res 18:3863-3869

Hunt III S. W., Cook M. E., Ecklund S.R. (1993): Fine map of the region homologous to the rat grc complex in the TL region of the mouse. Immunogenetics 37:386-389 
Jameson S. C., Tope W.D., Tregett E. M., Windle J.M., Diamond A. G., Howard J.C. (1992): Cloning and expression of class I major histocompatibility complex genes of the rat. $J$ Exp Med 175:1749-1757

Janer M., Geraghty D.E. (1998): The human major histocompatibility complex: 42,221 bp of genomic sequence, high-density sequence-tagged site map, evolution, and polymorphism for HLA class I. Genomics 51:35-44

Jensen (1903): zitiert nach Klein J. (1986)

Joly E., Clarkson C., Howard J.C., Butcher G.W. (1995): Isolation of a functional cDNA encoding the RT1.A ${ }^{\mathrm{u}}$ MHC class I heavy chain by a novel PCR-based method. Immunogenetics 41:326-328

Jones E.P., Kumanovics A., Yoshino M., Fischer Lindahl K. (1999): Mhc class I and nonclass I gene organization in the proximal H2-M region of mouse. Immunogenetics 49:183-195

Jones E.P., Xiao H., Schultz R.A., Flaherty L., Trachtulec Z., Vincek V., Larin Z., Lehrach H., Fischer Lindahl K. (1995): MHC class I gene organization in >1.5 Mb YAC contigs from the H2-M region. Genomics 27:40-51

Kim U-J., Birren B.W., Slepak T., Mancino V., Boysen C., Kang H.-L., Simon M.I., Shizuya H. (1996): Construction and characterization of a human bacterial artificial chromosome library. Genomics 34:213-218

Klein J. (1986): Natural History of the Major Histocompatibility Complex. Wiley, New York

Klein J., Figueroa F. (1986): Evolution of the major histocompatibility complex. CRC Crit Rev Immunol 6:295-387

Klein J., Sato A., O'hUigin C. (1998): Evolution by gene duplication in the major histocompatibility complex. Cytogenet Cell Genet 80:123-127 
Kirisits M.J., Vardimon D., Kunz H.W., Gill T.J. III (1994): Mapping of the TNFA locus in the rat. Immunogenetics 39:59-60

Kobayashi T., Hirayama Y., Kobayashi E., Kubo Y., Hino O. (1995): A germline insertion in the tuberous sclerosis ( $\mathrm{Tsc} 2)$ gene gives rise to the Eker rat model of dominantly inherited cancer. Nature Genet 9:70-74

Krishnan B.R., Jamry I., Chaplin D.D. (1995): Feature mapping of the HLA class I region: localization of the POU5F1 and TCF19 genes. Genomics 30:53-58

Kunz H.W., Gill T.J. III, Dixon B.D., Taylor F.H., Greiner D.L. (1980): Growth and reproduction complex in the rat: genes linked to the major histocompatibility complex that affect development. $J$ Exp Med. 152:1506-1518

Kwon J., Chung I.Y., Benveniste E.N. (1993): Cloning and sequence analysis of the rat tumor necrosis factor-encoding genes. Gene 132:227-236

Lambracht D., Hänisch L., Wurst W., Günther E., Wonigeit K. (1990): Restriction fragment-length polymorphism analysis of a second laboratory-derived mutant RT1 haplotype. Transplant Proc 22:2512-2513

Lambracht D., Prokop C., Hedrich H.J., Fischer Lindahl K., Wonigeit K. (1995): Mapping of the H2-M homolog and MOG genes in the rat MHC. Immunogenetics 42:418-421

Lambracht-Washington D., Shisa H., Butcher G.W., Fischer Lindahl K. (1998): A polymorphic microsatellite marker in the rat major histocompatibility complex class I gene, RT1.M4, and a new recombinant RT1 haplotype, r39. Immunogenetics 48:420-421

Lambracht D., Wonigeit K., Howard J.C., Fischer Lindahl K. (1997): Markers for interspecies relationship in the RT1 complex. Transplant Proc 29:1665-1667

Laval S., Butler R., Shelling a.N., Handy A.M., Poulsom R., Ganesan T.S. (1994): Isolation and characterization of an epithelial-specific receptor tyrosine kinase from an ovarian cancer cell line. Cell Growth Diff. 5:1173-1183 
Leong L.Y., Le Rolle A.F., Deverson E.V., Powis S.J., Larkins A.P., Vaage J.T., Stokland A., Lambracht-Washington D., Rolstad B., Joly E., Butcher G.W. (1999): RT1-U: identification of a novel, active, class Ib alloantigen of the rat MHC. J Immunol 162:743-52

Marinoni J.C., Roy R., Vermeulen W., Miniou P., Lutz Y., Weeda G., Seroz T., Gomez D.M., Hoeijmakers J.H., Egly J.M. (1997): Cloning and characterization of p52, the fifth subunit of the core of the transcription/DNA repair factor TFIIH. EMBO J 16:1093-1102

Matsuura A., Takayama S., Kinebuchi M., Hashimoto Y., Kasai K., Kozutsumi D., Ichimiya S., Honda R., Natori T., Kikuchi K. (1997): RT1.P, rat class Ib genes related to mouse TL: evidence that CD1 molecules but not authentic TL antigens are expressed by rat thymus. Immunogenetics 46:293-306

Miller J.F., Dower W.J., Tompkins L.S. (1988): High-voltage electroporation of bacteria: genetic transformation of Campylobacter jejuni with DNA. Proc Natl Acad Sci USA 85:856860

Monaco A.P., Larin Z. (1994): YACs, BACs, PACs and MACs: artificial chromosomes as research tools. TIBTECH 12:280-286

Müller U., Jongeneel C.V., Nedospasov S.A., Fischer Lindahl K., Steinmetz M. (1987): Tumor necrosis factor and lymphotoxin genes map close to $\mathrm{H}-2 \mathrm{D}$ in the mouse major histocompatibility complex. Nature 325:265-267

Nair S., Dey R., Sanford J.P., Doyle D. (1992): Molecular cloning and analysis of an eIF4A-related rat liver nuclear protein. $J$ Biol Chem 267:12928-12935

Osoegawa K., Woon P.Y., Zhao B., Frengen E., Tateno M., Catanese J.J., de Jong P.J. (1998): An improved approach for construction of bacterial artificial chromosome libraries. Genomics 52:1-8

Pamer E.G., Wang C.R, Flaherty L., Fischer Lindahl K. und Bevan M.J. (1992): H-2M3 presents a listeria monocytogenes peptide to $\mathrm{CD} 8^{+}$cytotoxic T lymphocytes. Cell 70:215-223 
Parker K., Carter C.A., Fabre J.W. (1990): A rat class I cDNA clone with an Alu-like sequence and mapping to two genes in RT1.C/E. Immunogenetics 31:211-214

Parker K.E., Carter C.A. Murphy G., Fabre J.W. (1991): The rat RT.BM1 MHC class I cDNA shows a high level of sequence similarity to the mouse H-2T23d gene. Immunogenetics 34:211-3

Pham-Dinh D., Jones E.P., Pitiot G., Della Gaspera B., Daubas P., Mallet J., Le Paslier D., Fischer Lindahl K., Dautigny A. (1995): Physical mapping of the human and mouse MOG gene at the distal end of the MHC class Ib region. Immunogenetics 42:386-391

Pham-Dinh D., Mattei M-G., Nussbaum J.L., Roussel G., Pontarotti P., Roeckel N., Mather I.H., Artzt K., Fischer Lindahl K., Dautigny A. (1993): Myelin/oligodendrocyte glycoprotein is a member of subset of the immunglobulin superfamily encoded within the major histocompatibility complex. Proc Natl Acad Sci USA 90:7990-7994

Pierce J.C., Sternberg N., Sauer B. (1992): A mouse genomic library in the bacteriophage P1 cloning system: organization and characterisation. Mamm Genome 3:550-558

Pietzsch A., Büchler C., Schmitz G. (1998): Genomic organization, promoter cloning, and chromosomal localization of the Dif-2 gene. Biochem Biophys Res Commun 245:651-657

Rolstad B., Vaage J.T., Naper C., Lambracht D., Wonigeit K., Joly E., Butcher G.W. (1997): Positive and negative recognition by rat NK cells. Immunol Rev 155:91-104

Rosner M.H., Vigaro M.A., Ozato K., Timmons P.M., Poirier F., Rigny P.W.J., Staudt L.M. (1990): A POU-domain transcription factor in early stem cells and germ cells of the mammalian embryo. Nature 345:686-692

Rothermel E., Heine L., Wurst W., Günther E. (1993): Characterization of a class Ib gene of the rat major histocompatibility complex. Immunogenetics 38:82-91 
Rubocki R.J., Lee D.R., Lie W.-R. Myers N.B. Hansen T.H. (1990): Molecular evidence that the H-2D and H-2L genes arose by duplication. Differences between the evolution of the class I genes in mice and humans. J Exp Med 171:2043-2061

Salgar S.K., Kunz H.W., Gill T. J. III (1995): Nucleotide sequence and structural analysis of the rat RT1.Eu and RT1.Aw3 genes, and of genes related to RT1.O and RT1.C. Immunogenetics 42:244-53

Salgar S.K., Kunz H.W., Gill T.J. III (1998): Structural organization, sequence analysis, and physical mapping of the Grc-linked class Ib gene RT1.S3 in the rat. Immunogenetics 48:76-81

Salgar S., Yuan X., Kunz H.W., Gill T.J. III (1997): Physical mapping and structural analysis of new gene families RT1.S and Rps2r in the grc region of the rat major histocompatibility complex. Immunogenetics 45:353-364

Schäfer H., Trauzold A., Siegel E.G., Fölsch U.R., Schmidt W.E. (1996): PRG1: a novel early-response gene transcriptionaly induced by pituitary adenylate cyclase activating polypeptide in a pancreatic carcinoma cell line. Cancer Res 56:2641-2648

Schöler H.R., Dressler G.R., Balling R., Rohdewohld H., Gruss P. (1990): Oct-4: a germline-specific transcription factor mapping to the mouse t-complex. EMBO $J$ 9:21852195

Schöler H.R., Ruppert S., Suzuki N., Chowdhury K., Gruss P. (1990): New type of POU domain in germ line-specific protein Oct-4. Nature 344:435-439

Sheng Y., Mancino V., Birren B. (1995): Transformation of Escherichia coli with large DNA molecules by electroporation. Nucleic Acids Res 23:1990-1996

Shiina T., Kikkawa E., Saito W., Tamiya G., Oka A., Watanabe K., Yamazaki M., Tashiro H., Okumura K., Ando A., Kimura M., Soeda E., Pontarotti P., Inoko H. (1998): Physical mapping between the S and HLA-E genes in the human MHC class I region: construction of a BAC, PAC, and cosmid contig. Immunogenetics 48:402-407 
Shiina T., Tamiya G., Oka A., Takishima N., Inoko H. (1999): Genome sequencing analysis of the 1.8 Mb entire human MHC class I region. Immunol Rev 167:193-199

Shiina T., Tamiya G., Oka A., Yamagata T., Yamagata N., Kikkawa E., Goto K., Mizuki N., Watanabe K., Fukuzumi Y., Taguchi S., Sugawara C., Ono A., Chen L., Yamazaki M., Tashiro H., Ando A., Ikemura T., Kimura M., Inoko H. (1998): Nucleotide sequencing analysis of the 146-kilobase segment around the IkBL and MICA genes at the centromeric end of the HLA class I region. Genomics 47:372-382

Shizuya H., Birren B., Kim U.J., Marcino V., Slepak T., Tachiiri Y., Simon M. (1992): Cloning and stable maintenance of 300-kilobase-pair fragments of human DNA in Escherichia coli using an F-factor-based vector. Proc Natl Acad Sci USA 89:8794-8797

Snell G.D. (1948): Methods for the study of histocompatibility genes. J Genetics 49:87-108

Stark O., Günther E., Kohoutova M., Vojcik L. (1977): Genetic recombination in the major histocompatibility complex (H-1, AgB) of the rat. Immunogenetics 5:183-187

Steinmetz M., Stephan D., Fischer Lindahl K. (1986): Gene organization and recombinational hotspots in the murine major histocompatibility complex. Cell 44:895-904

Steinmetz M., Winoto A., Minard K., Hood L. (1982): Clusters of genes encoding mouse transplantation antigens. Cell 28:125-134

Stephan D., Fischer Lindahl K., Meyer E., Hämmerling G., Hood L., Steinmetz M. (1986). Organization and evolution of D region class I genes in the mouse major histocompatibility complex. J Exp Med 163:1227-1244

Sternberg N. (1990): Bacteriophage P1 cloning system for the isolation, amplification, and recovery of DNA fragments as large as 100 kilobase pairs. Proc Natl Acad Sci USA 87:103107 
The MHC sequencing consortium (1999): Complete sequence and gene map of a human major histocompatibility complex. Nature 401:921-923

Thomson G. (1995) HLA disease associations: models for the study of complex genetic disorders. Crit Rev Clin Lab Sci 32:183-195

Totaro A., Grifa A., Carella M., Rommens J.M., Valentino M.A., Roetto A., Zelante L., Gasparini P. (1998): Cloning of a new gene (FB19) within HLA class I region. Chem Biophys Res Commun 250:555-557

Trowsdale J. (1995): ,Both man \& bird \& beast' ${ }^{6}$ comparative organization of MHC genes. Immunogenetics 41:1-17

Uehara H. (1991): Mouse Oct-3 maps between the tcl12 embryonic lethal gene and the Qa gene in the H-2 complex. Immunogenetics 34:266-269

Vardimon D., Locker J., Kunz H.W., Gill T. J. III (1992): Physical mapping of the MHC and grc by pulsed field electrophoresis. Immunogenetics 35:166-175

Vernet C., Ribouchon M-T., Chimini G., Pontarotti P. (1994): Structure and evolution of a member of a new subfamily of GTP-binding proteins mapping to the human MHC class I region. Mamm Genome 5:100-105

Wai L. T., King-C. Chow (1995): A modified medium for efficient electrotransformation of E.coli. Trends Genet 1:128-129

Walter L., Günther E. (1995): Cosmid cloning of the RT1.A encompassing region of the rat major histocompatibility complex. Transplant Proc 27:1501

Walter L., Günther E. (1997): Clonal contigs of the class I regions of the rat major histocompatibility complex. Transplant Proc 29:1660

Walter L., Günther E. (1998): Identification of a novel highly conserved gene in the centromeric part of the major histocompatibility complex. Genomics 52:298-304 
Walter L., Günther E. (2000): Physical mapping and evolution of the centromeric class I gene-containing region in the rat MHC. Immunogenetics, im Druck.

Walter L., Fischer K., Günther E. (1996): Physical mapping of the Ring1, Ring2, Ke6, Rxrb, Col11a2, and RT1.Hb genes in the rat major histocompatibility complex. Immunogenetics 44:218-221

Walter L., Heine L., Günther E. (1994a): Sequence, expression, and mapping of a rat Mhc class Ib gene. Immunogenetics 39:351-354

Walter L., Rauh F., Günther E. (1994b): Comparative analysis of the three major histocompatibility complex-linked heat shock protein 70 (Hsp70) genes of the rat. Immunogenetics 40:325-330

Walter L., Tiemann C., Heine L., Günther E. (1995): Genomic organization and sequence of the rat major histocompatibility complex class Ia gene RT1.Au. Immunogenetics 41:332

Wang C.R., Fischer Lindahl K. (1993): Organization and structure of the H-2M4-M8 class I genes in the mouse major histocompatibility complex. Immunogenetics 38:258-271

Wang C.R., Loveland B.E., Fischer Lindahl K. (1991): H-2M3 encodes the MHC class I molecule presenting the maternally transmitted antigen of the mouse. Cell 66:335-345

Wang C.R., Lambracht D., Wonigeit K., Howard J.C., Fischer Lindahl K. (1995): Rat RT1 orthologs of the mouse H2-M class Ib genes. Immunogenetics 42:63-67

Wang G.L., Holsten T.E., Song W-Y., Wang H-P., Ronald P.C. (1995): Construction of a rice bacterial artificial chromosome library and identification of clones linked to the Xa-21 disease resistence locus. Plant J 7:525-533

Wang M., Chen X-N., Shouse S., Manson J., Wu Q., Li R., Wrestler J., Noya D., Sun Z.G., Korenberg J., Lai E. (1994): Construction and characterization of a human chromosome 2-specific BAC library. Genomics 24:527-534 
Wang M., Stepkowski S.M., Tian L., Langowski J.L., Hebert J.S., Kloc M., Yu J., Kahan B.D. (1996): Nucleotide sequences of the distinct cDNA clones coding for the rat class I heavy chain $\mathrm{RT} 1^{\mathrm{n}}$ antigen. Immunogenetics 45:73-75

Watts S., Davis A.C., Goodenow R.S. (1989): Sequence analysis of the C3H H-2K1k gene: relationship to the H-2 loci. Immunogenetics 29:355-357

Weiss E.H., Golden L., Fahrner K., Mellor A.L., Devlin J.J., Bullman H., Tiddens H., Bud H., Flavell R.A. (1984): Organization and evolution of the class I gene family in the major histocompatibility complex of the C57BL/10 mouse. Nature 310:650-655

Widmark E., Ronne H., Hämmerling U., Servenius B., Larhammar D., Gustafsson K., Böhme J., Peterson P., Rask L. (1988): Family relationships of murine major histocompatibility complex class I genes sequence of the T2A pseudogene, a member of the gene family 3. J Biol Chem 263:7055-7059

Woo S.S., Jiang J., Gill B.S., Paterson A. H., Wing R.A. (1994): Construction and characterization of a bacterial artificial chromosome library of Sorgum bicolor. Nucleic Acids Res 22:22-49

Woodcock M., Crowther P.J., Doherty J., Jefferson S., DeCruz E., Noyer-Weidner M., Smith S.S., Michael M., Graham M.W. (1989): Quantitativ evaluation of Escherichia coli host strains for tolerance to cytosine methylation in plasmid and phage recombinants. Nucleic Acids Res 17:3469-3478

Woon P.Y., Osoegawa K., Kaisaki P.J., Zhao B., Catanese J.J., Gauguier D., Cox R., Levy E.R., Lathrop G.M., Monaco A.P., de Jong P.J. (1998): Construction and characterization of a 10-fold genome equivalent rat P1-derived artificial chromosome library. Genomics 50:306-316

Wroblewski J.M., Kaminsky S.G., Milisauskas V.K., Pittman A.M., Chaplin D.D., Spies T., Nakamura I. ( 1990): The B144-H-2D ${ }^{\mathrm{b}}$ interval and the location of the mouse homologue of the human D6S81E locus. Immunogenetics 32:200-204 
Wroblewski J. M., Kaminsky S. G., Nakamura I. (1994): Bat-1 genes and the origin of multiple class I loci in the H-2D region. Immunogenetics 39:276-280

Young I.Y., Abe K., Bennett D., Artzt K. (1992): Testis-/embryo-expressed genes are clustered in the mouse H-2K region. Proc Natl Acad Sci USA 89:773-777

Yuan X.J., Salgar S., Cortese Hassett A.L., McHugh K.P., Kunz H.W., Gill T.J. III (1996): Physical mapping of the E/C and grc regions of the rat major histocompatibility complex. Immunogenetics 44:9-18

Yuan X.-J., Kunz H.W., Gill T.J. III (1999): Physical mapping and sequencing of class I genes in a 150-kb contig in the EC region. Transplant Proc 31:1507-1512

Zhou Y., Chaplin D.D. (1993): Identification in the HLA class I region of a gene expressed late in keratinocyte differentiation. Proc Natl Acad Sci USA 90:9470-9474

Zimmer R., Verrinder Gibbins A.M. (1997): Construction and characterization of a largefragment chicken bacterial artificial chromosome library. Genomics 42:217-226 
8. Anhang 1

8.1 Zusammenstellung der insgesamt erhaltenen PAC-Klone aus mehreren Screenings der Ratten-Bank

Tab. 9: PAC-Klone aus dem $\alpha 1-$ Screening

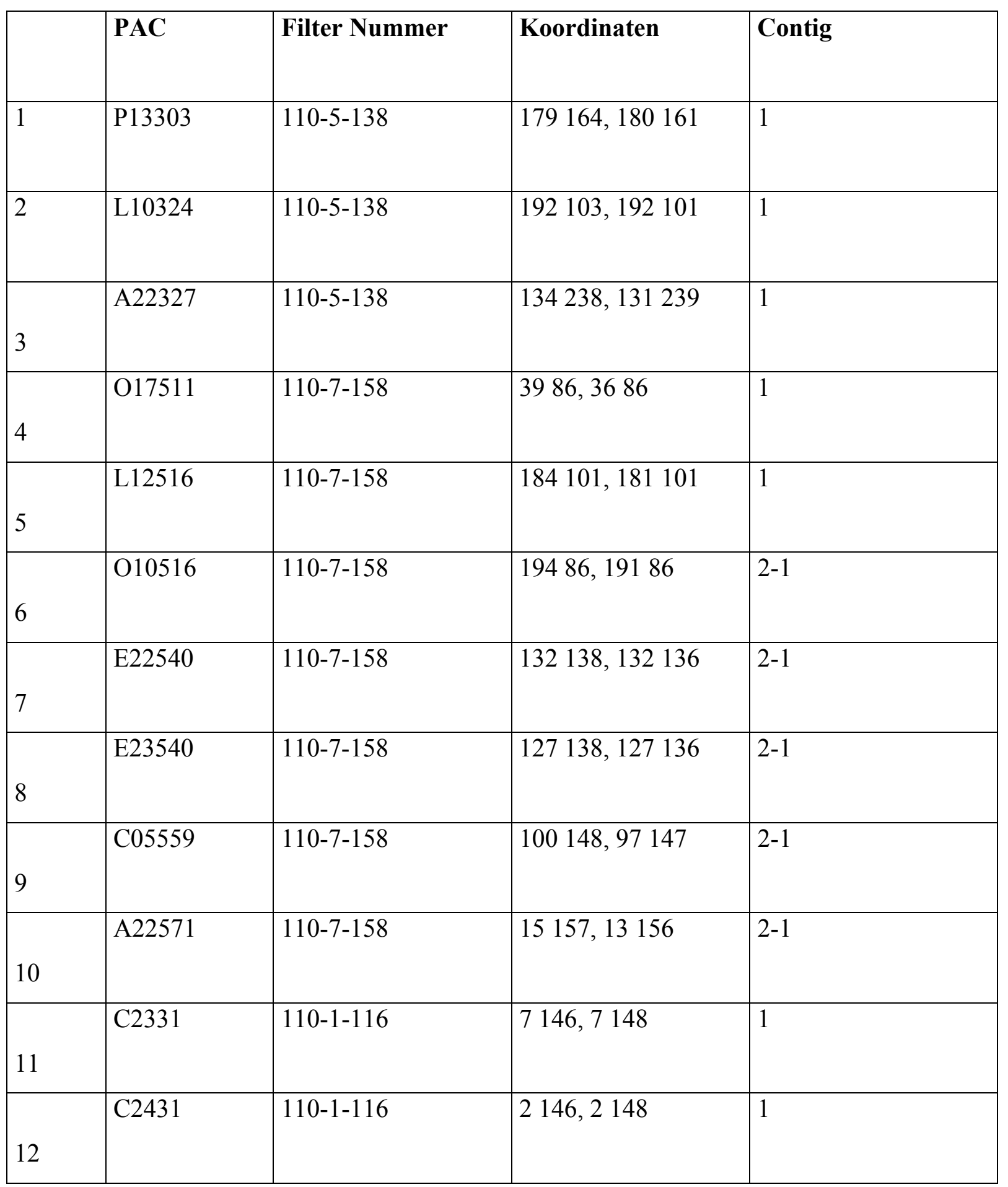




\begin{tabular}{|c|c|c|c|c|}
\hline 13 & $\mathrm{~J} 1031$ & $110-1-116$ & 72111,72113 & $2-1$ \\
\hline 14 & B1340 & $110-1-116$ & 5973,5674 & $2-1$ \\
\hline 15 & G0249 & $110-1116$ & 113130,111128 & $2-2$ \\
\hline 16 & I2086 & $110-2-127$ & 14439,14536 & $2-1$ \\
\hline 17 & B16100 & $110-2-127$ & 4275,4574 & $2-1$ \\
\hline 18 & $\mathrm{~L} 22115$ & $110-2-127$ & 15105,12104 & $2-1$ \\
\hline 19 & M11116 & $110-2-127$ & 19020,18719 & $2-1$ \\
\hline 20 & J02139 & $110-2-127$ & 115112,113111 & $2-1$ \\
\hline 21 & J12142 & $110-2-127$ & 6532,6331 & 1 \\
\hline 22 & E05168 & $110-3-110$ & 219140,218137 & 1 \\
\hline 23 & K03168 & $110-3-110$ & 229110,228107 & 1 \\
\hline 24 & D07219 & $110-4-122$ & 206225,206222 & 1 \\
\hline 25 & K18224 & $110-4-122$ & 15426,15126 & 1 \\
\hline 26 & J18229 & $110-4-122$ & 34114,35111 & 1 \\
\hline 27 & K05363 & $110-6-116$ & 216190,216187 & $2-2$ \\
\hline 28 & E16374 & $110-6-116$ & 16459 & $2-1$ \\
\hline 29 & F01374 & $110-6-116$ & 23954 & $2-1$ \\
\hline
\end{tabular}




\begin{tabular}{|c|c|c|c|c|}
\hline 30 & H04473 & $110-6-161$ & 104 203, 101204 & 1 \\
\hline 31 & K19473 & $110-6-161$ & 29188,26189 & 1 \\
\hline 32 & L08487 & $110-6-161$ & 85103,82102 & 1 \\
\hline 33 & F05583 & $110-9-122$ & 99131,96131 & $2-1$ \\
\hline 34 & H12587 & $110-9-122$ & 64201,61201 & $2-2$ \\
\hline 35 & B18613 & $110-9-122$ & 34153,31154 & $2-1$ \\
\hline 36 & C1796 & $110-2-127$ & 159150,158147 & $2-1$ \\
\hline 37 & N01508 & $110-7-158$ & 11615,11612 & RT1-A (Ring1+) \\
\hline 38 & $\mathrm{~J} 23517$ & $110-7-158$ & 9114,10111 & RT1-A (Ring1+) \\
\hline 39 & O18535 & $110-7-158$ & 3288,3286 & RT1-A \\
\hline 40 & G11561 & $110-7-158$ & 190 208, 187207 & RT1-A (Ring1+) \\
\hline 41 & O02564 & $110-7-158$ & 23588,23287 & RT1-A (Ring1+) \\
\hline 42 & N03344 & $110-5-138$ & 23013,22712 & RT1-A \\
\hline 43 & Р09456 & 110-6-161 & 19985,19882 & RT1-A \\
\hline 44 & D07348* & $110-5-138$ & 210143,207142 & Falsch positiv \\
\hline 45 & C15354* & $110-5-138$ & 169147,168149 & Falsch positiv \\
\hline 46 & A17269 & $110-4-122$ & 38240,36238 & Falsch positiv \\
\hline
\end{tabular}




\begin{tabular}{|c|c|c|c|c|}
\hline 47 & M04281 & $110-4-122$ & 103179,104177 & Falsch positiv \\
\hline 48 & N04397 & 110-6-116 & 10493,10194 & Falsch positiv \\
\hline 49 & I09407 & 110-6-116 & 80200,77199 & Falsch positiv \\
\hline 50 & L19588* & $110-9-122$ & 149101,146101 & Falsch positiv \\
\hline 51 & M19588* & $110-9-122$ & 14996,14696 & Falsch positiv \\
\hline 52 & E01596 & $110-9-122$ & 12058,11757 & Falsch positiv \\
\hline 53 & G16598 & $110-9-122$ & 165128,162127 & Falsch positiv \\
\hline 54 & F24606 & $110-9-122$ & 12552,12351 & Falsch positiv \\
\hline 55 & A17612 & $110-9-122$ & 157158,157156 & Falsch positiv \\
\hline 56 & J04363 & 110-6-116 & 221195,221192 & Falsch positiv \\
\hline 57 & L0831 & & & $\begin{array}{l}\text { Dieser Klon muß } \\
\text { überprüft werden }\end{array}$ \\
\hline
\end{tabular}

Kommentar zu Tab. 9:

Die mit Sternchen kennzeichneten falsch-positiven Klone zeigten mittelstarke Signale in dem Filter-screening. Die übrigen falsch positive Klone waren im Filter-Screening nur sehr schwach positiv.

Von den 12 falsch-positiven Klonen, zeigten 8 sehr schwache Signale auf dem Hybridisierungs-Filter. Diese könnten bei der prozentualen Berechnung der falsch-positiven Klone vernachlässigt werden. Vier der falsch-positiven Klone sind mit Sternchen gekennzeichnet und zeigen auf dem Hybridisierungs-Filter mittelstarke Signale.

Klon L0831 muß erneut überprüft werden, ob er als positiv oder falsch-positiv eingeordnet werden muß.

Aus dem $\alpha 1$-Screening wurden 44 positive Klone erhalten. Siebenunddreißig wurden der $R T 1-C$-Region zugeordnet und sind in den konstruierten Contigs wiederzufinden. Sieben gehören der $R T 1-A$-Region an. 
Tab. 10: PAC-Klone aus dem $\alpha 3-$ Screening

\begin{tabular}{|c|c|c|c|c|}
\hline & PAC & Filter Nummer & Koordinaten & Contig \\
\hline 1 & K145 & $110-1-116$ & 51190,51187 & $2-3$ \\
\hline 2 & A1426 & $110-1-116$ & 17579,17280 & $2-2$ \\
\hline 3 & A1638 & $110-1-116$ & 16478,16179 & 3 \\
\hline 4 & A2052 & $110-1-116$ & 2380,2178 & $2-2$ \\
\hline 5 & N1554 & $110-1-116$ & 16895,16693 & $2-2$ \\
\hline 6 & N1654 & $110-1-116$ & 16395,16193 & $2-2$ \\
\hline 7 & B2066 & $110-1-116$ & 143154,144152 & $2-2$ \\
\hline 8 & J0567 & $110-1-116$ & 100112,98111 & $2-3$ \\
\hline 9 & J2298 & $110-2-127$ & 13534,13235 & $2-2$ \\
\hline 10 & A23104 & $110-2-127$ & 12778,12776 & $2-3$ \\
\hline 11 & N20105 & $110-2-127$ & 142173,142171 & $2-3$ \\
\hline 12 & I19108 & $110-2-127$ & 147118,147116 & $2-1$ \\
\hline 13 & L03108 & $110-2-127$ & 227103,227101 & $2-2$ \\
\hline 14 & P05116 & $110-2-127$ & 2205,2174 & $2-1$ \\
\hline 15 & P15129 & $110-2-127$ & 170163,167162 & $2-2$ \\
\hline
\end{tabular}




\begin{tabular}{|c|c|c|c|c|}
\hline 16 & J01132 & $110-2-127$ & 240113,237112 & $2-2$ \\
\hline 17 & P20143 & $110-2-127$ & 25162,23161 & 3 \\
\hline 18 & A05218 & $110-4-122$ & 21680,21677 & $2-3$ \\
\hline 19 & J20226 & $110-4-122$ & 2431,2131 & $2-2$ \\
\hline 20 & I12230 & 110-4-122 & 18439,18536 & 4 \\
\hline 21 & H18232 & 110-4-122 & 3541,3444 & $2-3$ \\
\hline 22 & M18242 & $110-4-122$ & 15519,15220 & 3 \\
\hline 23 & M23252 & $110-4-122$ & 12798,12796 & 4 \\
\hline 24 & C04253 & $110-4-122$ & 204 228, 202227 & $2-2$ \\
\hline 25 & E04256 & $110-4-122$ & 10458,10259 & $2-2$ \\
\hline 26 & C08258 & $110-4-122$ & 204 148, 201149 & $2-2$ \\
\hline 27 & M02271 & $110-4-122$ & 11598,11297 & $2-2$ \\
\hline 28 & C08273 & $110-4-122$ & 205 228, 202227 & 4 \\
\hline 29 & I13315 & $110-5-134$ & 180199,177200 & 3 \\
\hline 30 & N13332 & $110-5-134$ & 18015,17714 & 4 \\
\hline 31 & D15335 & $110-5-134$ & 50225,47224 & $2-2$ \\
\hline 32 & A10338 & $110-5-134$ & 19380,19178 & $2-2$ \\
\hline
\end{tabular}




\begin{tabular}{|c|c|c|c|c|}
\hline 33 & K09358 & $110-5-134$ & 8027,7826 & $2-3$ \\
\hline 34 & E12360 & $110-5-134$ & 185 137, 183136 & $2-1$ \\
\hline 35 & K20363 & $110-6-116$ & 141190,141187 & 3 \\
\hline 36 & A18367 & $110-6-116$ & 34156,31156 & $2-2$ \\
\hline 37 & K15386 & $110-6-116$ & 17029,16730 & $2-3$ \\
\hline 38 & L19417 & $110-6-116$ & 150183,147182 & $2-3$ \\
\hline 39 & D13419 & $110-6-116$ & 60223,57222 & $2-3$ \\
\hline 40 & E04428 & $110-6-116$ & 22557,22356 & $2-2$ \\
\hline 41 & D03460 & 110-6-161 & 11064,10765 & $2-2$ \\
\hline 42 & P08462 & $110-6-161$ & 20584,20285 & $2-2$ \\
\hline 43 & $\mathrm{~J} 21470$ & $110-6-161$ & 13933,13634 & $2-3$ \\
\hline 44 & H11471 & 110-6-161 & 189 203, 186204 & $2-3$ \\
\hline 45 & O02480 & 110-6-161 & 23590,23289 & $2-3$ \\
\hline 46 & K06484 & 110-6-161 & 9330,9128 & 3 \\
\hline 47 & E19510 & $110-7-158$ & 146140,146137 & $2-3$ \\
\hline 48 & E21511 & $110-7-158$ & 19136,16136 & $2-3$ \\
\hline 49 & I10519 & $110-7-158$ & 194 199, 195196 & $2-2$ \\
\hline
\end{tabular}




\begin{tabular}{|c|c|c|c|c|}
\hline 50 & G07520 & $110-7-158$ & 8949,9046 & 3 \\
\hline 51 & G01543 & $110-7-158$ & 239208,236209 & $2-1$ \\
\hline 52 & B02559 & $110-7-158$ & 115153,112152 & $2-2$ \\
\hline 53 & J06559 & $110-7-158$ & 95113,92112 & 4 \\
\hline 54 & P05384 & $110-9-122$ & 205152,203151 & $2-1$ \\
\hline 55 & K0988 & $110-2-127$ & 8026,7929 & $2-1$ \\
\hline 56 & I16274 & $110-4-122$ & 4538,4237 & $2-1$ \\
\hline 57 & B08610 & $110-9-138$ & 205152,203151 & $2-2$ \\
\hline 58 & J08559 & $110-7-158$ & 85113,82112 & 4 \\
\hline 59 & O02611 & $110-9-122$ & 112 168, 112166 & 3 \\
\hline 60 & O11597 & $110-9-122$ & 189 170, 188167 & 3 \\
\hline 61 & G03460 & $110-6-161$ & 11049,10750 & $2-2$ \\
\hline 62 & G03251* & $110-4-122$ & 107 208, 107206 & Starkes Signal \\
\hline 63 & P20279* & $110-4-122$ & & Starkes Signal \\
\hline 64 & H24281 & 110-4-122 & & $\begin{array}{l}\text { Sehr schwaches } \\
\text { Signal }\end{array}$ \\
\hline 65 & M13574 & $110-7-158$ & 6017,5816 & $\begin{array}{l}\text { Sehr schwaches } \\
\text { Signal }\end{array}$ \\
\hline 66 & A08445 & 110-6-161 & 85 156, 84159 & $\begin{array}{l}\text { Sehr schwaches } \\
\text { Signal }\end{array}$ \\
\hline
\end{tabular}


Kommentar zu Tab. 10:

Von den 66 positiven Reaktionen waren bei der Überprüfung der Klone selbst 5 negativ, wobei drei davon beim Filter-Screening sehr schwache Signale ergeben haben. Die Klone G03251 und P20279 zeigten im ursprünglichen Filter-Screening starke Signale, waren jedoch im Southernblot negativ.

Tab. 11: Erhaltene PAC-Klone aus dem Screening mit der Bat1-Probe

\begin{tabular}{|l|l|l|l|}
\hline & PAC & Koordinaten & Contig \\
\hline 1 & A14588 & 17178,17380 & 1 \\
\hline 2 & G17337 & 36128,38130 & 1 \\
\hline 3 & O06367 & 9186,9486 & 1 \\
\hline
\end{tabular}

Tab. 12: PAC-Klone aus dem gleichzeitigen Screening mit den Proben TCF19, Gna-rs1, RFB30, Tctex 5 und Tu42.

\begin{tabular}{|l|l|l|l|l|l|}
\hline & PAC & $\begin{array}{l}\text { Filter } \\
\text { Nummer }\end{array}$ & Koordinaten & Contig & $\begin{array}{l}\text { Hybridisierung } \\
\text { mit der Probe }\end{array}$ \\
\hline 1 & I16223 & $110-4-122$ & 44116,41116 & $2-1$ & Gna-rs1 \\
\hline 2 & O22140 & $110-2-127$ & 1357,1336 & $2-3$ & Tctex5 \\
\hline 3 & K08519 & $110-7-158$ & 204189,205186 & $2-3$ & Tctex5 \\
\hline 4 & O21242 & $110-4-122$ & 1409,13710 & $2-3$ & Tu42 \\
\hline 5 & H10232 & $110-4-122$ & 7541,7444 & $2-3$ & Tu42 \\
\hline
\end{tabular}

Tab. 13: Klone aus dem Screening mit RFb30.

\begin{tabular}{|l|l|l|l|l|}
\hline & PAC & $\begin{array}{l}\text { Filter } \\
\text { Nummer }\end{array}$ & Koordinaten & Contig \\
\hline 1 & P20499 & $110-7-107$ & 2582,2381 & $2-3$ \\
\hline
\end{tabular}

Tab. 14: Klone aus dem gleichzeitigen Screening mit 255D16 und H2-M2.

\begin{tabular}{|l|l|l|l|l|l|}
\hline & PAC & $\begin{array}{l}\text { Filter } \\
\text { Nummer }\end{array}$ & Koordinaten & Contig & $\begin{array}{l}\text { Hybridisierung } \\
\text { mit der Probe }\end{array}$ \\
\hline 1 & I1448 & $110-10-132$ & 175120,172119 & $2-2$ & $255 \mathrm{D} 16$ \\
\hline 2 & L1748 & $110-10-132$ & 160105,157104 & 3 & H2-M2 \\
\hline
\end{tabular}


Tab. 15: Positive Klone aus dem Prg1-Screening

\begin{tabular}{|l|l|l|l|l|}
\hline & PAC & $\begin{array}{l}\text { Filter } \\
\text { Nummer }\end{array}$ & Koordinaten & Contig \\
\hline 1 & E06479 & $110-7-107$ & 95220,92219 & $2-1$ \\
\hline 2 & F05479 & $110-7-107$ & 100215,97214 & $2-1$ \\
\hline
\end{tabular}

Tab. 16: Positive Klone aus dem H125T Screening

\begin{tabular}{|l|l|l|l|l|}
\hline & PAC & $\begin{array}{l}\text { Filter } \\
\text { Nummer }\end{array}$ & Koordinaten & Contig \\
\hline 1 & C15160 & $110-3-119$ & 4969,5066 & $2-2$ \\
\hline 2 & P04519 & $110-8-104$ & 225161,224164 & $2-1$ \\
\hline 3 & N12311 & $110-5-143$ & 64175,63172 & $2-1$ \\
\hline 4 & E17538 & $110-8-104$ & 3758,3756 & $2-2$ \\
\hline 5 & E14284 & $110-4-131$ & 17557,17356 & $2-1$ \\
\hline 6 & B08610 & $110-9-138$ & 205152,203151 & $2-1$ \\
\hline 7 & A02552 & $110-8-104$ & 235160,232159 & $2-1$ \\
\hline
\end{tabular}

Tab. 17: Positive Klone aus dem CAK und GTF Screening*

\begin{tabular}{|l|l|l|l|l|}
\hline & PAC & $\begin{array}{l}\text { Filter } \\
\text { Nummer }\end{array}$ & Koordinaten & Contig \\
\hline 1 & A24506 & $110-8-108$ & 12180,12177 & 1 \\
\hline 2 & K11482 & $110-7-111$ & 18830,18628 & 1 \\
\hline 3 & N0751 & $110-9-155$ & 208175,206173 & 1 \\
\hline 4 & H13218 & $110-4-135$ & 17645,17642 & 1 \\
\hline 5 & D20510 & $110-8-108$ & 141145,141142 & 1 \\
\hline
\end{tabular}

*Die Hybridisierung des Southernblots mit den entsprechenden Proben wurde nach Fertigstellung der experimentellen Arbeiten in der Abteilung Immungenetik durchgeführt.

In der Abbildung 38 wurde übersichtlich die Anzahl der aus den verschiedenen Screenings erhaltenen PAC-Klone. 


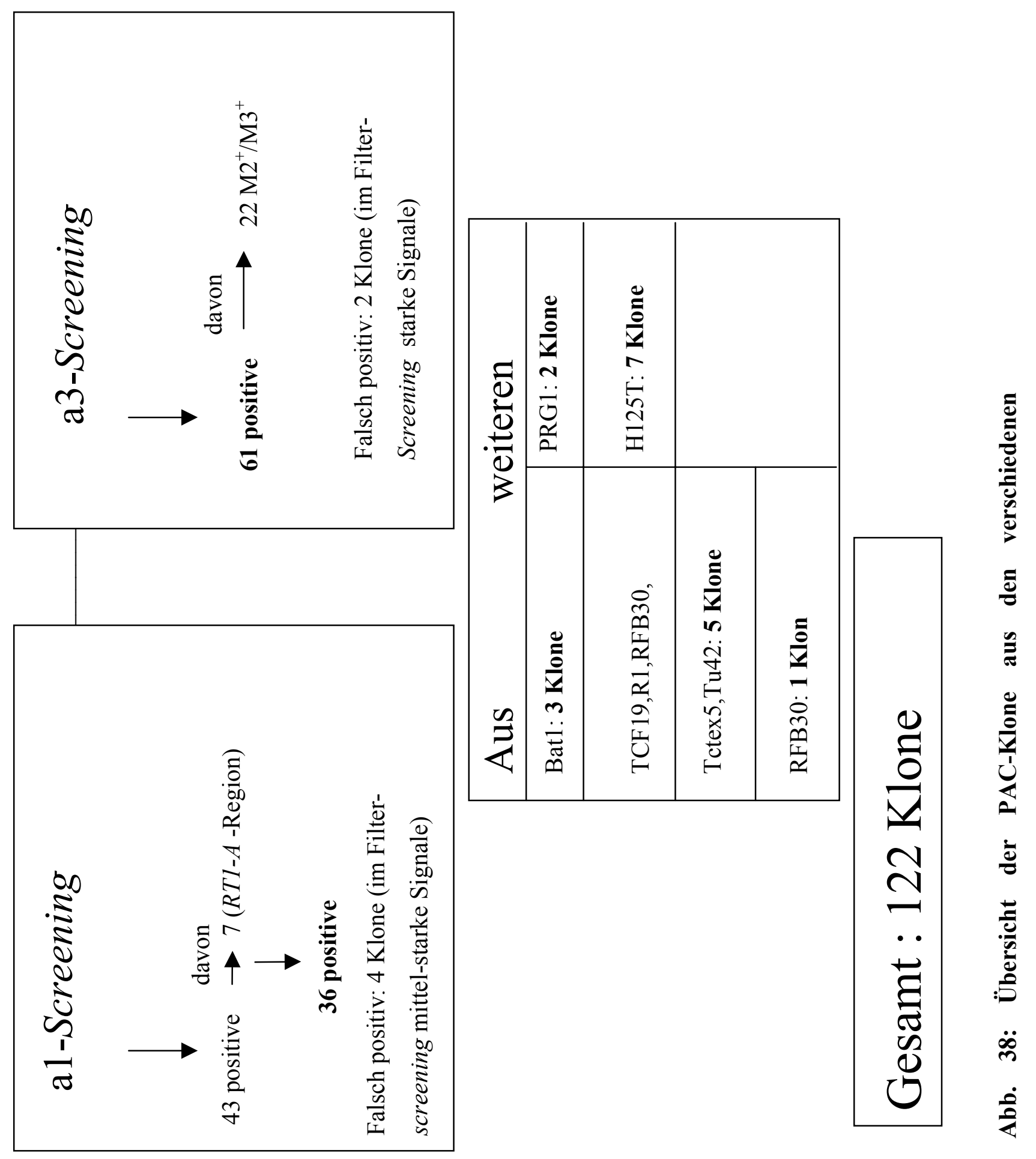




\subsection{Sequenzdaten aus PAC-Endsequenzierung}

$>\mathrm{A} 14588$ (CK2)

TGGGCGACCCCATTTAGGTGACACTATAGAAGGATCACAcTTTTTTGANCTTCAGA GGNACCCATGGGTTAGACAGGCAGTCTGAGCAGAAACTGCTGTGGGTGCAGAGG TGCACTCCTGTCTGAGGCAGGGTCCTGACCAGAGGAGGAAGTTATCTATTGGCAG GAAGAATGGCCCGTCCTCACCCACACTGTCTGGTTTCCATGTGGGCCACAGCCGA GTACCAGCTGGCTTTATCAGGTGTCTTTATNCCAGACACTGCCTTGAAAGGCCCA TGCCCCACCTCAGGGACCACCGCTTAGTCTGTCTCTGGCACTGCCTGCTGTCACCT ACACAGCAGGNTTGGTCCCCATTATTCGGGGAGAGGTTGGCcAGAGACAAAGCCT CCCAACCTTTCCAGATGTGTCTCTGNGTCTCGGTCTCCAAGAAGGGGGCACACAG ACCACTGAGCAACTGGGACTNTTGCCTCCTTACAGCTNATTNCTGANGGGAGAGC CTTACAGACAGCTAAGGANTTNCATGAACCCCAGAGAAAGCAA

$>\mathrm{G} 17337$

GGTGACACTATAGAAGGATCTTAGGAGGGAGAATTGAGGCCCTGTGGAAAACGA CCCAAATGCCTCAGGTCCCAGGCTCTATGGCCAGCAGGGGGCAGCATGTACCTGC CCATGGCACCTGGGTCCCACATCCTCCACTTAGCTACCTTAAGGAGAAGGCCTCT CTCAAGAGTTCACTTGGTGGCCAGATGGCCTGGTGAGGCTTCCAGGTAGTGTGGG GAGTAGTTTGGGAGGGACGTAGCATGGAAACGCTCCAAGCCAGCCTTCTTAACA ATGAGTTATTGGTTCTTCAACAGAGTCATGAGTCACTGCATGGGAAGCAACTGCA CAGTTACAGAACAGAGCTCCACACAGACACAAGGAGGGGGAAAATGCGTAACTT TAAAAGATGGGGTTGGTGGGAGGGTGGAGAGATAGCTANCAGTTAAGACACTGC TGTCTTCAGAGGTCTGAGT

$>$ I16223 (STS-Marker)

AAGCCCAGCTCTGACTTTTACGACTGCACTTCTGGCAGGAGGAGCGACTCAAGCC TTCGCGAAAGAAAATAACCAAAAAGCATACAAAGAAACGTACGGCGTCTCTCAT ATTACACGCCATGATATGCTGCAGTACAGGAGACAACTGTGACGCCAGGTCTAAG ACCCTTCCTTACCTTGTGTACAAGAGGTGAGAAGAGACCTTAGTAATTAGGATCT TAGATATTTGTGGGCTTCTATTTTGTTTTAGATTCTTTTCTGTGTGTTTTCCCTGCA TGTATGTATGTCTCTGGTTCCTGCCGAGGACAGAGAGAGCAGTAGATCCCCTGAA GTTGGGGTTGTGGACTGTTGCAAGCCACTGTGGGTCCTGGGAACAGACTTGGNGG TCCTGCAAGGCCTGAGACTTCTCTTAACCCCGAGTCACCCTTTTGCTCTGCAGTTT 
GATCTTAGTGGAATGACAGGACCTGGTTTATTAGAAGTCTGTCTTATGAGTGAAG TAGGTGGTGG

$>$ I16223 (PRG1)

GCATCCTCCGCCGCCAGGGCCTGCGACACACCTTCTTCAGCCATCAAAATCTAGG CAGAAGATGATGGCNTGCAGGAGAAAGAGGATCCTCTTGGCAATGTTG

$>$ E16374 (PNUTS)

CTTGCATGCCTGCAGGCGGGGCAGCATCGCCTGGAGCAGCTGNGGCACTGCAAA GGAAAGGCAGTCAAAAATCTCCCAACTCCCACTTCTCTCCAAAGGCCCAGGCTCC TTGGAAACCTACACCAGTGCCCATACCTNTGCCGCTTGAGGGGGATGGGCTTNAG GTTGTACTTGTCTGACACAACCACAGNGCTGGAGTTCTTCTTCACAGGCACCAAA NATGGGGTGTCCAGCTCCAGTCCTGAGGANAAACATGTTGAC

$>\mathrm{E} 16374$ (H2-T)

GTGGCAGGCCTGGCGGCCGCTGGCCGTCGACATTTAGGTGACACTATAGAAGGAT CCAACACTTCCTCACTTTGCTCCCTTTCCTTCCTTTTGAAACACAATTGTACCCCCT GGGCCATGTGTGGTAGAAGCATGGGACCTGTACCTTCATTTTCTCTCTAGAAAGG TTGCAATTAGGACATTGTCCTGAGTCTCAGAAGAGACTATGAATTCTGAACTTTT AAGGTGTTGGAGACTGACAGATTATGGGGACTTTGGAAGCTGGATTGAATGTTTG ACATTATGATAGGGCTACAAACTGTTGGACCAGGTATGTTAATTTGAATGAAAAT GGCCCCCATTGGCCTATAGACTTGAAGGCGTGGTCATTAGGGAGGGGTCCTATTA AAGGGATTAGGAGGTGTGTCACTGGGGGTGGCTTAGAAGTTCCAAANCAGAGCC AGTCCAGAGGNTTTTTTCTGCTGCCTAGGACCA

$>010516$ (RT.BM1)

CTCCTGAGCGTTTGGATTAAAGGCTTGTGCCCCACCACCACCCATGAAGCAGCAA ACACTCTTAACCACTGAGCTATCTCTCCAGTCACCATCCACCCCAGTCCTTTTAAT GACCTTGTGTGGACTCTAAAGACACTGGATGTCTAGAGATAAACAGACAGCAGA GTTGACCATGGTGTGCCCTATTCATTTAAAAAATATTTTTTAGATTTATTTATCAT ATATAGCTGTGTTCAGACACATCAGAAGAGAGCATCANGATCTCATTACATATGG TTGTGAGCCACCATGTGGTTGCTGGGATTTGAACCAGGACCTCTGTAAGAGAAGT CAGTGCTCTTAACACTGAGCCATCTCTCCAGCATTTGNTTTGTTTAAAACAATGAC CATAAGAGGAATGGTGGACTTCTAGCTTGTTCTGGCTCAGNAA 
$>010516$ (RT.BM1) 102

CCTTCAACCCAGTCAGCTCCTTCCGGTGGGCGCGGGGCATGACTATTGGCGCGCC AAAGCTTGCATGCCTGCAGGCAGCAAGGCTTTCCAGATCTCTGACTGGCCTCAGA AGGCATGAAAAGGTATGAAAACCCATGGGGGCCTGGGATCGGACCTGAGGCAAT AGGGAAGAACAGGGCC

$>\mathrm{H} 12587$ (ORF) 107

AGTAGGCTTTTCCCAGGCATGCAGGGATGGTTTAATATATGGAAAACCATCAATG TGATCCATTATATAAACAAACTGAAAGAACAAAACCACATGATCATTTCATTAGA CGCTCNNNAAGCATTTAAGAAATTCAACACCCCTTCATGATAAAGGTCCTGGAAA GAACAGGNATTCAAGGCCCATACCTAAACACAGCAAATGCC

$>\mathrm{H} 12587$ (ORF) 108

GCCCTTGNTTNCCTTCAACCCAGTCAGCTCCTTCCGGTGGGCGCGGGGCATNACT ATTGGCGCGCCAAAGCTTGCATGCCTGCANTCTAACTTCTTGAGTTCTTTCTATAT TTTTGATATAAGCCCTCTATCAGTTGTAGGATTGCTAAAGATCTTTTCCCAATCTG TTGGTTGTNGTTTTGCCTAACCACAATGTCCTTT

$>\mathrm{H} 12587$ (ano) 109

CCTGGCGGCCGCCTGGCCGTCGACATTTAGGTGACACTATAGAAGGATCATTGTG GCCTCCACTGTCCCTCTGACAAAGCAGACGCCTGCTCCTTCCTTCCTTCCCTGGAC TCTGCCTTGTCTTTAAGAACTTCCTTCTCTATGAAGCAAGGGATGCTTTCCTAACT CTTGATTTTTTTTTCTGCCCTTAGGATATTTCTCCCTTCAGGCTGAGACTTCTTTGG TCTTTTTCCAGTCGTAGACCTTGGGAGACTGCAGCATATCATGGCGTGTAATATG AGAGACGCCGTACGTTTCTTTGTATGCTTTTTGGTTATTTTCTTTCGCGAAGGCTT GAGCCGCTCCTCCTGCCAGAAGTGCAGTCGTAAAAGTCAGAACTGTGGCTTGNTT TACAATTTTTTTGATGTCATGTCATGCTCT

$>$ H12587 Subklon 24

GATTCGAGCTCGGTACCCGGGGATCCTGACATTCTTAGAATCAGATCTGATGATA GGAATGAATAGTTAGGGTGCTATAAGTGGGGCCATTGTATGCACACTGCAGGTAC CCGGGTAGGAGACTCCTTTTGGGCCCCAAGTCACAGTCAGATTTCCACTGTGTGG GAGTCCCCAGGAGCCCGAGGACATGCCTGCCAGCCATCCTTCCCTAGAAATCCTC 
TCAACTGAATGTGAAAGAGGGTCCCAGGCCCAGAGTCCCCCCAGGTCCTTAAAG GTGGGGAAGAACCTCAGACATGGGTCATGAGGCCTCTCAGTCCCTTACCTAGTGA AGCAGAGAGGTCCTGGCCCTGGCTCTGGTTGTAGTAACTTAAGCAGGGACCTCAG GTTCACTCCTAAGGTCTGCTCTTACCTTTTCCACTCTGTGTCTCTTGCTCCAAAACT CTGGACCCTTGTGCTCACCAGCAGCGCGAAGGCTCATCCTNGACTTCTGATC

$>$ J2298 (Mikrosatellit D20Gun1)

GAATAGTCCCNGCTTGTTTAGAGGATAAGCGATGTGAGGAAGTCGTTAGAACAG GTCAGAGAATCCTTGCAGAGCATCAAGAAAGTATGTCAGAGGGAGAAAAGGTCC CAAAGAAAGAAAGGAAAAGAAAAGGAGACANAAGGAACAGAGAGAAGGCAGA GANTAAAAAAGGAGATAATCAGGACCAGGAAATAGATAAGATATATCCCTCCTT AAAAGCCTTGACTTTAGAAATGTCAGATGAGTCATGAGCTTANTGAGGATGGTGA GGCTTGACCTTGAAGANGAGGCTGCTCANNTTGAGGGGGAGAGATGTGATCCGG ACTGTCCACACGCTAACACCACGTGCA

>A18367 LINE 172

TGGCCGCGACATTTAGGTGACACCATAGAAGGATCGCTTTTGGTAAAATGGCCAT TTTTACTATATTAATCCTGCCATTCCATGAGCATGGGAGATCTTTCCATCTTCTAN GGTCTTCTTCAATTTCTTTCTTCAGTGTCTTGAAGTTCTTATTGACAGATCTTTACT TGCTTGGTTAAAGNCACACCGGGGGACTTTATATTATTTGGG

>A18367 LINE 173

TACGACTGCACTTCTGGCAGGAGGAGCGACTTAAGCCTTCGCGAAAGAAAATAA CCAAAAAGCATACAAAGAAACGTACGGCGTCTCTCAAATTACACGCCATGATAT GCTGCAGAAAGAAACAGNAAGAGCATATGCCAGCAGCTTGCAGCACACCTAAAA GCTCTNGGAGNNAAAAGAAGCAAATACACCCAGGAGGAGTAGAAGGCAGGAAA TAATCAAACTCAGAGCTGAAATCAACCAAGTAGAAACAAAAAGGGACCATAGAA AGAATCAACAGAACCAAAAGTTGGTTCTTTCTGAAATTCAACANGATAAACCCTT AGCCAGACTAATGAGAGGGACCCCAGAGAGGTGGTGTCCAAATTTAACCAAATC AGAAATTGAAAA

$>\mathrm{A} 18367$ (592j14, 76k14) 170

CCTGTGATCCCAGCTTTGATATTAGGGAAAAAGAGAGGTCTTTGAGGAACTACTT GTCTCTGAAAATGACAAGGATAAAAATTTACAAACAGCGCAAATCCCCATTAATT 
GGAACAAGTGTCTTCAGATCCACAAGACTTATTTTGACCCAGGTTGAAATTATTTT ATATTATTTTCATTTCATAAGGGTCTCAAAATGAGTTCCCAACATAGTATGAAAG AATATATTACACATANGAAAATTTACCTTGGAGAAACAT

$>$ A18367 171

CTCATGAACGTTCACCTACCACTTGCATCCCAGGAATGAATACCGGCCCTTCCTA CTCTTTGAGTAGTGTTTTNTCACCTTGTACCACAGAACTGATAATACCCAATGCTG ATTTGCAATCTGAGCCAGTTTGTAGCTCTTTGATCATTTCTACATGGTAACATTTC CAATTTTAATACAATAGACCTCAAGAAATAAGAGTTAAATTTAGTGGTCAATTCA GAGCCCAGTTCCACAGTTGGAGACAGGGAGAGTCCAGTTGAGTTAAAATAGAAA TGTAGTTTTCCAGGTTATGCACCTTAGGCAGTCTGAACACTGGCCACTGTATGAG GTTCTTTCCСTCCTGAACTCTGGACTCATGCATATGATTCTGTGTCAAGGAAAGGA TCAGAGGGTTAAGGGGTGGAGAGGCCCAANTTTACTTCAGCACCTTCAAATTACT ATCCTGGAGCATGGCTGGGGAAAGTTNTTTACCTGATCATGCTNCTGG

$>\mathrm{P} 08462(20 \mathrm{~h} 22)$

GGTAGGCCTGGCGGCCGCTGGCCGTCGATTGAGTTGTCGCCGACCTTTTGATAAA ACATGTAGATTGTTGTGTCATCAGCGTCTTCCGGGCTTCCCGCAAGAGCAAACAC AACGTGATAGCCGTTGTATTCAGCTACTGTTCCGTCAGCGTTTTGCAGCGGCCAG CTGTCCCACACATCAAGTCCTTTTGCAGACCTAATATTTTTAANCGGTTGATTGAT CCGAATTGAGGCACTTGGTATTTTTCGTTTTGCTGCTGTTTAGGGATCTGCAGCAT ATCATGGCGTGTAATATGAGAGACGCCGTACGTTCTTTGTATGCTTTTTGGGTATT TTCTTTCGCGAAAGGCTTGAGTCGGT

>P0846T (STS-Marker)

ACTTAACTCACACTCAGCATCCCCCTGCCTCCGTTTTCCAACATTAGGATCAAGGA CTAAGTACCACCAGAGCTGGCCTCGAGTCTTATGACTCCTGCTTCGTTCCCCAGA GATGGTGACCAGGGTTTCCCCCATTCTCATGTATCATCAAAGGTCAGGACTTTGC CTCCCTCTTTGAGCCCCCTTTTTTCAGGTTAAATTACTACTTTCTTCTGCATCACCT ACGGTCTGAGCTCCACGTGTTCCTGAGTGAAAATGAAATTCTCTCACCCAGAGGG GAAAAAATG

$>\mathrm{H} 10232(217)$ 
GTCAAGAACCAAATNTCAGTAAGAAGTCAAGAAGCTGGTCTGACAATAACCCAG GACAATAGGAACATGATGAGAAAGACCTGATTCTATTCTATCTTCTAATGGAGAG TATATTACAGGATTCTNTCTAAAGTAATTTATTATTGCTGTTATCGTGTGTATGTTT ATAAAATTACTTATGACATTTCATTTTGTGGGAAATCANCNCGCAGTTCCACCAT AAAATTTGCATGCTCAAACCAATATACACAATAGGGATTTAGCCCTTCCAATGGT CATACTGCA

$>$ I12230 (RT1.M2)

CTTTTAAGATTGAAATATTTGTGGTTATGACATTCTGAATTGTGCCTTTGGGAATA ACAGGCCATATCCCTTCCCAACAAGGAGGCAGAGAAGACTTATCTGGAGATTGG AGTTCCTCAGTTGGAAAGAAATCTCAGGCTACCCCTTCCACCACCTGAGCTCTTCT TNCAAATGACAAGTGTAACCACAGAAGCTCCCAGGAGAACCAGGCCAACAGCAA CCACTATTGTGGGAATGAACGACTGAGGAGGTCTACCTGGAAAGAAATGAAAAT ATGTAGGACCCTGACCCCAGATCTCAAGCCTTGACCCTGCTCAAGGTCTCCAGAA GGGCTTCTGCTTTCTCTAACCCAGAATATGTGCCCACTTCCTACTTACTCCATCTC AGGGTGAGGGGTCAGGCAGCCCCTCATGTTCTACATAGCATGTATAATTCTGCTC TTCCCCGAAGGCACCACCACAGCTGCCCACTTCTGGANGGTTCCATCCCTGAGCA TATCATGGCG 
|

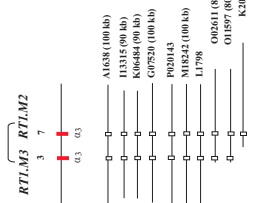

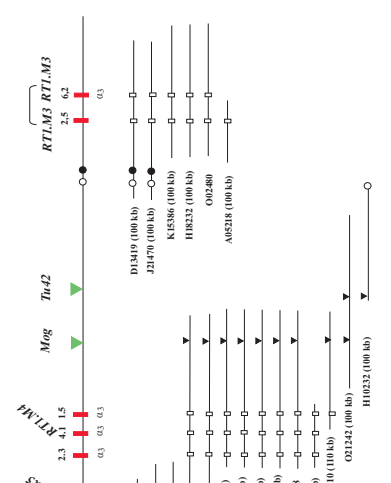

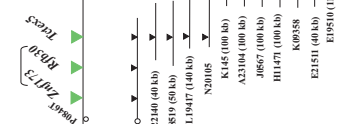

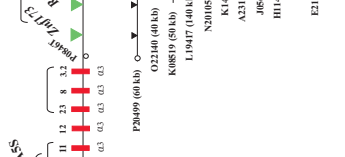

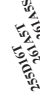

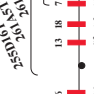

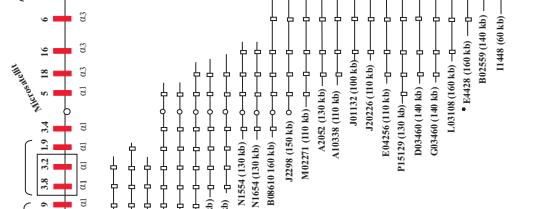

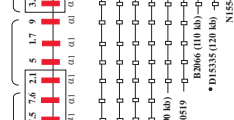

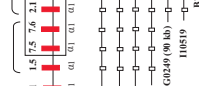

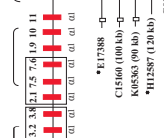

$\left(\begin{array}{ll}2 \\ 0\end{array}\right.$

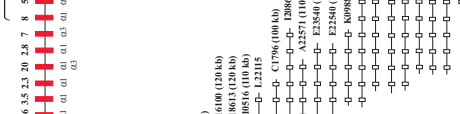

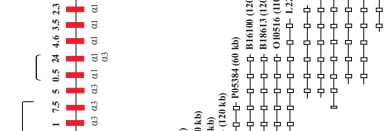

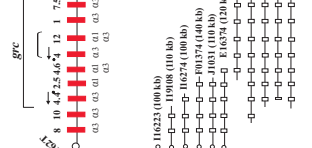

है

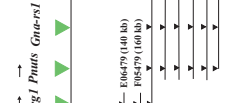

(15)

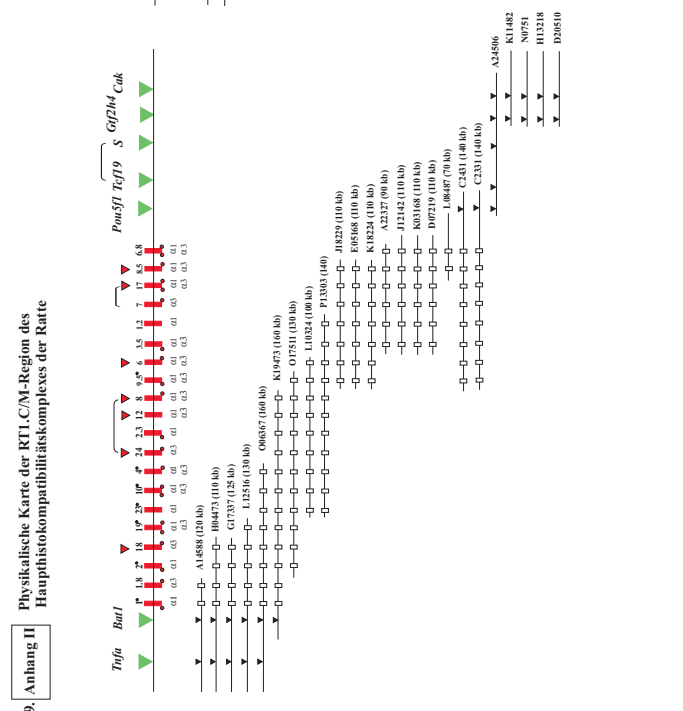




\section{Danksagung}

Herrn Prof. Dr. Eberhard Günther möchte ich für die Überlassung des interessanten Themas, für seine stetige Diskussionsbereitschaft und die vielfältigen Anregungen danken.

Herrn Prof. Dr. Hans-Joachim Fritz danke ich für seine Bereitschaft, die Betreuung dieser Arbeit zu übernehmen.

Herrn Dr. Lutz Walter danke ich für zahlreiche fruchtbare Diskussionen und Anregungen.

Frau Diana Otto danke ich für fleissige technische Assistenz insbesondere für das fast unermüdliche Präparieren von Plasmid-DNA.

Allen Mitarbeitern der Abteilung Immungenetik danke ich für die Kollegialität und die Hilfsbereitschaft.

Meine „Kollegin“ Frau Dr. Heike Olbrich möchte ich für „wahre Freundschaft, die die Schreibfehler des anderen korrigiert" danken.

Mein Dank gilt ebenfalls dem Ressourcen-Zentrum im Deutschen Human Genom-Projekt in Berlin für die Zurverfügungstellung der Bank-Filter und der Klone.

Der Europäischen Union danke ich für die Finanzierung dieser Arbeit. 


\section{Lebenslauf}

Name: $\quad$ Sofia Ioannidu

Staatsangehörigkeit: griechisch

Geburtsdatum: $\quad$ 08.05.1961

Geburtsort: $\quad$ Vergina/Griechenland

Familienstand: $\quad$ verheiratet, zwei Kinder (9 und 12 Jahre)

Schulbesuch: $\quad$ 1967-1973 Grundschule Vergina/Griechenland

1973-1976 Gymnasium Veria/Griechenland

1976-1979 Lyzeum Veria/Griechenland

1979 Abitur Veria/Griechenland

1980-1981 Inligua Sprachschule Hannover

1982-1983 Niedersächisches Studienkolleg Hannover

1983 Feststellung der Hochschulreife Hannover

Studium: 1983-1988 Chemiestudium an der Universität Göttingen

1988-1996 Studium der Biologie an der Universität Göttingen

28.04.1995 mündliche Diplomprüfung

1995-1996 Anfertigung der Diplomarbeit unter Anleitung von Herrn

Prof. Dr. H.-J. Fritz

Tätigkeit:

06.08.1996-31.01.1997 Tätigkeit als wiss. Mitarbeiterin im Institut für Molekulare Genetik

01.02.1997-31.12.1999 Tätigkeit als wiss. Angestellte in der Abteilung Immungenetik am Zentrum für Hygiene und Humangenetik der Universität Göttingen

Promotion: $\quad$ 1997-2000 Anfertigung der Dissertation zum Thema „Physikalische Kartierung der RT1-C/M-Region des Haupthistokompatibilitätskomplexes der Ratte“ 